\title{
EVALUATION OF CARBON DIOXIDE EMISSION CONTROL STRATEGIES IN NEW YORK STATE
}

Final Report of 1990-91 Work

S. C. Morris, J. Lee, G. Goldstein, and D. Hill

January 1992

Biomedical and Environmental

Assessment Group

Analytical Sciences Division 


\section{EVALUATION OF CARBON DIOXIDE EMISSION CONTROL STRATEGIES IN NEW YORK STATE FINAL REPORT OF 1990-91 WORK}

S.C. Morris, J. Lee, G. Goldstein, and D. Hill January 1992

Biomedical and Environmental Assessment Group

Analytical Sciences Division

Department of Applied Science

Brookhaven National Laboratory

Associated Universities University, Inc.

Research Supported Jointly by Empire State Electric Energy Research Corporation, New York State Energy Research and Development Authority, and the U.S.

Environmental Protection Agency

This research was performed under the auspices of the United States Department of Energy under Contract No. DE-AC02-76CH00016 
This report was prepared as an account of work sponsored by an agency of the United States Government. Neither the United States Government nor any agency thereof, nor any of their employees, not any of their contractors, sub- contractors, or their employees, makes any warranty, express or implied, or assumes any legal liability or responsibility for the accuracy, completeness, or usefulness of any information, apparatus, product, or process disclosed, or represents that its use would not infringe privately owned rights. Reference herein to any specific commercial product, process, or service by trade narne, trademark, manufacturer, or otherwise, does not necessarily constitute or imply its endorsement, recomniendation, or favoring by the United States Government or any agency, contractor, or subcontractor thereof. The views and opinions of authors expressed herein do not necessarily state or reflect those of the United States Government or any agency, contractor or subcontractor thereof. 


\begin{abstract}
A MARKAL model was developed for the State of New York. It represents the state's energy system as a set of typical technologies for generating, converting, and using energy as it evolves over a 45-year period. NYMARKAL was applied here in demonstration analyses to explore strategies to reduce $\mathrm{CO}_{2}$ emissions. NYMARKAL was installed at the State Energy Office and in the Offices of the New York Power Pool. Staff members from both organizations and other state agencies were trained in its use. Example scenarios showed that It is more difficult and more expensive to reduce carbon emissions in New York State than in the United States as a whole. Were a common carbon tax instituted, it would have less effect in New York and most carbon emissions reduction would take place elsewhere in the country where it is more cost-effective. Alternatively, were all states required to reduce $\mathrm{CO}_{2}$ emission an equal percentage (say by $20 \%$ ), the cost per unit emissions reduction to New York would be much greater than in the rest of the country.
\end{abstract}




\section{ACKNOWLEDGMENTS}

Several people are due thanks for getting this project started. These include $S$. Baron and F. Salzano at Brookhaven; P. Torpey of ESEERCO, P. Coffey of the New York Power Pool who as the ESEERCO project officer got the project off the ground and kept it moving; D. Najewicz who, as the initial NYSERDA project officer shepherded the proposal through several rounds of approval at that agency, and B. Solomon of EPA who supported the initial phases of the study. Fred Strmisa and Janet Joseph of NYSERDA took over from D. Najewicz when he left government service. John Lydick, a student intern with our group, made valuable contributions to the initial stages of the study. M. Garrell of Adelphi University contributed to the database on municipal solid waste, landfill gas, solar and wind energy.

The progress and applicability of the work were greatly enhanced by the regular participation of representatives of numerous other state and federal people including $J$. E. Snuth and A. Sanghi of the State Energy Office, A.J. Domaracki of the Public Service Commission, R. Twaddell of the Department of Environmental Conservation, and J. Scheraga of the US Environmental Protection Agency.

We especially thank the New York State Energy Office staff for their interest, cooperation, and assistance throughout the study. In addition to J.E. Smith and A. Sanghi mentioned above, we wish to name the following SEO staff in our thanks: $M$. Schultz, M. Bowman, H. Sheevers, P. Smith, J. Parmelee, and J. Wang.

We also thank E. Williams of the US Department of Energy Office of Policy, Planning and Analysis who provided approval and DOE oversight for our participation in this study and who funded parallel work on the US MARKAL model that helped to maintain a critical mass of effort at Brookhaven directed toward work on energy systems modeling.

Others whom we thank for their assistance in providing data and/or many helpful discussions include K. Anderson, A. Desell, R. A. Hiney, T. Larson, T. E. Link, J. Ralston, P. Schwengels, R. Stewart, F. Vitale, G. Walmet, and C-O. Wene. 


\section{EXECUTIVE SUMMARY}

NYMARKAL is a model of the New York State energy system. It represents the State's energy' system as a set of typical technologies for generating, converting, and using energy as it evolves over a 45 -year period. In a variety of scenarios, the model chooses from a menu of several hundred candidate technologies and energy resources to select the set that meets projected demands for energy services, environmental restrictions, and other constraints at least cost. Among numerous options available are fuel switching, improved efficiency of supply-side and demand-side technologies, enduse conservation, increased use of renewable energy, reforestation, and pollution taxes such as a carbon tax. NYMARKAL was applied here in demonstration analyses to explore strategies to reduce $\mathrm{CO}_{2}$ emissions. The analyses begin with the same economic forecast used in the State Energy Plan. The energy plan forecasts of fuel and technology irends, however, are based on projections of current trends, modified by environmental regulations and behavioral factors. MARKAL takes a different approach. Its results are based more rigidly on least-cost decision-making. By avoiding some assumptions about behavior and current societal trends, MARKAL is freed to seek potentially better futures. This is especially appropriate when looking 20 to 40 years ahead, an imporiant time-frame for considerations of greenhouse gas emissions. MARKAL can be made to match projections of current trends, but doing that would decrease its real power. Some of the important lessons from a MARKAL analysis can be gained by comparing MARKAL scenarios with trend projections.

MARKAL, an acronym for MARket ALlocation, is a sophisticated linear program optimization model that captures the complex inter-relationships of energy systems across the spectrum from primary energy supply to energy servica demands. It treats demand-side and supply-side investments equally. MARKAL is an inherently flexible model able to address a wide range of energy and environmental issues. It has been adapted for use in many countries to model national, provincial, and local energy systems. Coupled with the MARKAL Users Support System on a microcomputer, MARKAL is a responsive, "user-friendly" modeling system for energy-environmental analysis, planning, and policy use.

Development work consisted of configuring the New York State energy system in MARKAL, developing a database of energy resources and technologies and environmental emission coefficients for Niew York State, testing the configured model, and developing and analyzing example s':enarios. This report describes and documents the development of NYMARKAL and the associated data, and reports the results of example analyses. The actual data and full results of the scenarios analyzed were provided separately in electronic media form.

The objective was to provide a tool for contiruing analysis and planning, however, not a one-time report. Analyses reported here serve only as a starting point. NYMARKAL is installed and running at the State Energy Office and in the Offices of the New York Power Pool. Staff members from the Power Pool, New York State Energy Research and Development Authority, the State Energy Office, Department of Environmental Conservation, and Public Service Commission received hands-on training as part of the project. 
Several scenarios were analyzed. They were designed to address important issues and to illustrate different ways to use MARKAL. Scenarios examined are listed and described in Table S-1. Each scenario was run without $\mathrm{CO}_{2}$ constraint and against four different levels of $\mathrm{CO}_{2}$ constraint: stable at 1990 levels and 10\%, 20\%, and 30\% reduction from 1990 levels in 2008 and thereafter. Not all scenarios had feasible results for all $\mathrm{CO}_{2}$ reduction levels. The ability to demonstrate the point of technical infeasibility is a useful MARKAL feature. A scenario- $\mathrm{CO}_{2}$ constraint combination is called a case.

We call the unconstrained case of the Conventional Technology Scenario the "Reference Case" since it is the case most of the alternative scenarios are built upon (by adding technologies or tightening or relaxing constraints on technologies). The reference case is not meant to be a business-as-usual simulation, but it needs to be sufficiently realistic that the results are meaningful lessons to guide future policy. MARKAL produces a least-cost solution under conditions of perfect foresight and perfect economic "rationality." We do not have perfect foresight, but we can use alternative scenarios to test the robustness of decisions under different future conditions. As a society, we base our decisions on a broad range of factors, many of which cannot be easily included in a computer model. We gladly give up some economic rationality or efficiency to address other goals, such as equity or environmental protection.

Table S-1. Scenarios examined and their description.

\begin{tabular}{|l|l|l|}
\hline File Name & \multicolumn{1}{|c|}{ Scenario } & \multicolumn{1}{c|}{ Description } \\
\hline BNYS & Conventional Technology & $\begin{array}{l}\text { Allows substantial increases in nuclear } \\
\text { and 1.8 GW imports of hydropower. }\end{array}$ \\
\hline TREE & Reforestation & $\begin{array}{l}\text { Adds ability to sequester carbon by } \\
\text { planting trees. }\end{array}$ \\
\hline QUEB & $\begin{array}{l}\text { More Hydroelectric } \\
\text { Imports }\end{array}$ & $\begin{array}{l}\text { Imports from Quebec allowed to grow } \\
\text { from 1000 MWe in 1993 to 10,000 MWe } \\
\text { in 2028. Additional Nuclear also } \\
\text { allowed. }\end{array}$ \\
\hline TAXC & Carbon Tax & $\begin{array}{l}\text { Same as Reference Case with the addition } \\
\text { of a \$15/ton carbon tax in 1993, } \\
\text { escalating 10\%/year. This scenario is an } \\
\text { alternative approach to the usual method } \\
\text { of fixed emission constraints. }\end{array}$ \\
\hline CONS & $\begin{array}{l}\text { Increased End-use } \\
\text { Conservation }\end{array}$ & $\begin{array}{l}\text { Double end-use conservation } \\
\text { opportunities at higher cost added to } \\
\text { Reference Case. }\end{array}$ \\
\hline NNQB & $\begin{array}{l}\text { More Hydroelectric; no } \\
\text { new nuclear }\end{array}$ & $\begin{array}{l}\text { Imports from Quebec allowed to grow to } \\
\text { 15,000 MWe in 2028. No new nuclear } \\
\text { power. }\end{array}$ \\
\hline
\end{tabular}


MARKAL points the direction of increased "rationality" and shows how far the system can go in that direction, thus helping to identify the most attractive alternatives to gain specified objectives. In an alternative scenario, we can force a solution that MARKAI, from its narrow view, considers less than optimal (for example, no new nuclear power); this allows us to determine how much we are giving up from the rigid economic efficiency viewpoint. Experimentation with the model may help us find other solutions that achieve the same goals at lesser cost.

Climate change is a global issue. It is being addressed in international, national, and state forums. New York may, on its own, decide to take action to reduce $\mathrm{CO}_{2}$ emissions. New York may also be required to take action based on national legislation or international agreements entered into by the United States. It is important to understand the costs and other implications for the State and how New York compares with the rest of the U.S. We draw upon our MARKAL analysis of the U.S. as a comparison. It is more difficult and more expensive to reduce carbon emissions in New York State than in the United States as a whole. This can be illustrated by three different comparisons between the two studies:

- Greater emission reductions were feasible in the US than in New York.

- The average cost of achieving stated emissions reduction largets was lower in the U.S. than in New York.

- $\mathrm{CO}_{2}$ reductions resulting from the same level carbon tax were greater in the U.S. than in New York.

The implication is that, were a common carbon tax instituted, it would have less effect in New York and most carbon emissions reduction would take place elsewhere in the country where it is more cost-effective. Alternatively, were all states required to reduce $\mathrm{CO}_{2}$ emission an equal percentage (say by $20 \%$ ), the cost per unit emissions reduction to New York would be much greater than in the rest of the country. If as a nation we wish to reduce carbon emissions, the most cost-effective approach would be to aim at greater emissions reduction outside of New York.

What makes reducing $\mathrm{CO}_{2}$ emissions in New York more difficult and more expensive? Studies around the world have generally found that reducing $\mathrm{CO}_{2}$ emissions invariably translates into reducing coal use. Coal provides a substantial fraction of primary energy in the United States and therefore the country as a whole has the capability of significant reductions in $\mathrm{CO}_{2}$ emissions with the impact largely confined to this single sector. The US also has a bigger and more diverse arsenal of alternative technologies and resources than does New York. For example, geothermal and solar energy are more abundant in other parts of the country.

What do the MARKAL results so far say about how $\mathrm{CO}_{2}$ emissions can be reduced in New York State? What must go, what new technologies or resources should come to the fore? We examined end-use conservation, increased efficiency in use of fossil fuels, fuel switching among fossil fuels (e.g., oil or coal to natural gas), nuclear power, hydroelectric power, other non-carbon energy sources, and sequestering carbon in trees. These are each discussed below.

Advocates of conservation and renewables often argue that these are "no regret" options, that is, even if $\mathrm{CO}_{2}$ reductions were to prove unnecessary, investment in conservation and renewables will have been money well spent. MARKAL analyses 
examine this issue in the following way: technologies that are indeed "no regret" will be selected in the cases with no $\mathrm{CO}_{2}$ constraints. Our MARKAL analysis eliminates the institutional barriers that impede introduction of these technologies in the real world. Our findings are that conservation indeed enters the energy system rapidly even in the absence of $\mathrm{CO}_{2}$ constraints. The additional conservation technologies available in the Enhanced Conservation Scenario are sufficient to allow MARKAL to achieve the $20 \% \mathrm{CO}_{2}$ reduction target.

Without $\mathrm{CO}_{2}$ constraints, renewable energy use increases at a slower rate in New York than in the U.S., but renewables are added faster than in the US as $\mathrm{CO}_{2}$ constraints are imposed.

Nuclear and Quebec hydropower were the two primary non-carbon fuels that could fill the gap left by reductions in coal and oil to meet $\mathrm{CO}_{2}$ emissions constraints as demands for energy services continue to increase. Reductions in $\mathrm{CO}_{2}$ emissions of $10 \%$ or more could not be sustained in the model without using one of these sources of energy. If the State wants or needs to do more than stabilize $\mathrm{CO}_{2}$ emissions, and wants to avoid adding new nuclear capacity, importing hydroelectric power from Quebec or both, other options must be explored. Although solar, biomass, wind and municipal solid wastes are included in the model, opportunities to use these resources in New York are limited. Although MARKAL does not deal directly with behavioral and cultural changes that might decrease energy demands, it can analyze the technological and cost implications of scenarios that depict such changes.

Simply keeping track of emissions of other pollutants in NYMARKAL provides the opportunity to assess the effect of $\mathrm{CO}_{2}$ constraints on sulfur dioxide, nitrogen oxides, and particulate pollution emissions. Reductions that occur as a result of the systems response to $\mathrm{CO}_{2}$ constraints are dramatic, especially in $\mathrm{SO}_{2}$ and particles. A $10 \%$ reduction in the level of $\mathrm{CO}_{2}$ emissions can result in a reduction of other pollutants beyond what has been possible through existing clean air legislation. There are two sides to this result. First, $\mathrm{CO}_{2}$ constraints can yield substantial collateral benefits in reducing emissions of other pollutants. As with energy conservation, $\mathrm{CO}_{2}$ constrairits tend to push in the direction of more general environmental quality improvement. On the other side, however, it must be remembered that greater air quality improvements have not been made to date largely because of the large costs involved. The fact that they occur automatically as the result of meeting $\mathrm{CO}_{2}$ emission reduction targets cloes not make these costs any less burdensome to society.

How much of a reduction in New York State $\mathrm{CO}_{2}$ emissions is technologically feasible? The demand for energy services in New York State is projected to grow. Without an unlimited supply of energy, at some point this increasing demand must exceed supply, resulting in a technically infeasible situation. When $\mathrm{CO}_{2}$ emissions restrictions are added, the system becomes further constrained and the point of infeasibility comes closer in time to the present. The question of technological feasibility then is not if a reduction is infeasible, but at what point in the future will a given level of $\mathrm{CO}_{2}$ emissions reduction become infeasible? The State Energy Office's usual planning horizon is about 20 years. That puts the point at which carbon emission controls are imposed in this study near the edge of the planning horizon, yet it appears that maintaining $\mathrm{CO}_{2}$ emission goals beyond initial target dates may be harder than meeting initial targets. Therefore, this study looked two decades further into the future, to 2028. Beyond the third or fourth decade of the next century, social and 
technological changes bcyond our vision can be expected to intervene. New technologies or resources may emerge, technologies may advance beyond expectation, or population shifts, lifestyles of technological changes may result in lower demands for energy services. Global clirnate change is a problem that requires us to consider consequences much further into future, at least to 2100 , but we cannot expect to make detailed projections that far ahead. We can and do need to consider detailed technological options over a 40.50 year future, however, and that is the task on which NYMARKAL focuses.

NYMARKAL helps to provide insight. Sometimes this confirms conventional wisdom but other times it poin s out overlooked possibilities and fills knowledge gaps. One can gain insight by reading about the results of model runs, but the model can be used to greater advantage. Energy system planning involves an interaction among complex technological, econonic, environmental, social, and political considerations. It is through interaction among people from those areas that real advances can be made. NYMARKAL can proyide a ciommon framework of discussion for such interaction. 


\section{TABLE OF CONTENTS}

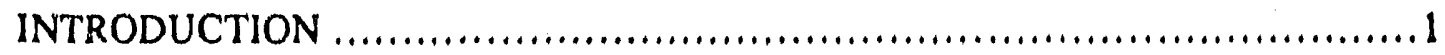

DESIGN AND CONFIGURATION OF NY MARKAL $\ldots \ldots \ldots \ldots \ldots \ldots \ldots \ldots \ldots \ldots .2$

Units.................................................................2

Demand Structure ..................................................... 3

Energy Resources and Carriers............................................3

End-use Conservation ................................................4

Electric Power Plants ....................................................5

Process Technologies ................................................5

Energy Storage Technologies...........................................6 6

Environmental Emissions..............................................6 6

Emissions Embodied in Energy Imports ............................7

Emissions During Construction and Embodied in Nonenergy Imports .......................................................8

NYMARKAL ENERGY RESOURCE AND TECHNOLOGY DATABASE........9

APPROACH AND SCENARIOS EXAMINED ...............................9

INTERPRETING THE RESULTS ............................................11

CONVENTIONAL TECHNOLOGY SCENARIO............................... 12

Primary Energy Use .................................................13

Single Family Residential Energy Use ..................................18

Multi-Family Residential ...............................................21

Cornmercial ...........................................................22

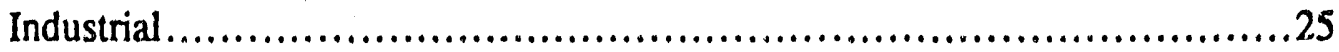

Transportation.........................................................28

Electricity Generation.................................................. 32

Emissions .................................................... 37

Comparison of Reference Case with State Energy Plan................40

REFORESTATION SCENARIO ...........................................41

INCREASED HYDROELECTRIC IMPORTS SCENARIO ......................46

ADDITIONAL HYDRO BUT NO NEW NUCLEAR SCENARIO .................49

ENHANCED BUILDING CONSERVATION SCENARIO $\ldots \ldots \ldots \ldots \ldots \ldots \ldots \ldots \ldots . \ldots . \ldots \ldots$

CARBON TAX SCENARIO .................................................53

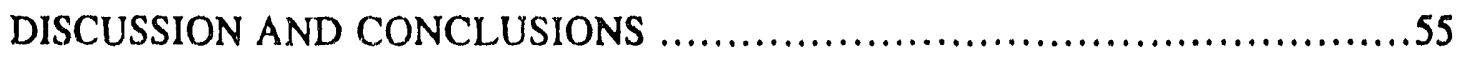

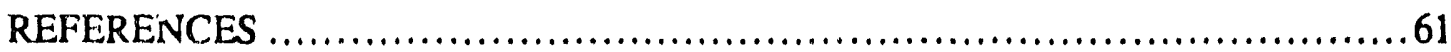




\section{AITPENDICES}

1. LISTING AND DESCRIPTION OF NYMARKAL OUTPUT FILES.............63

11. EMISSIONS OF OTHER GREENHOUSE GASES $\ldots \ldots \ldots \ldots \ldots \ldots \ldots \ldots \ldots \ldots . \ldots . \ldots \ldots$

Reference ........................................................65

III. DOCUMENTATION OF NYMARKAL DEMAND CATEGORIES AND

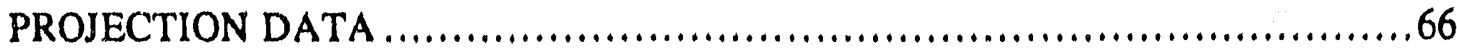

Demand Categories......................................................66

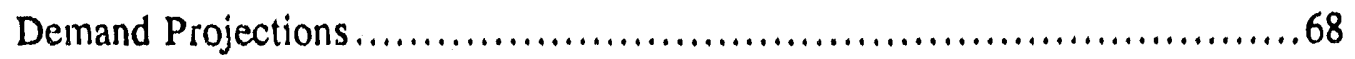

IV. ENVIRONMENTAL EMISSIONS COEFFICIENTS .......................71

References ...................................................... 71

V. DOCUMENTATION OF TECHNOLOGY DATABASE $\ldots \ldots \ldots \ldots \ldots \ldots \ldots . . . . . . .81$

Data Structure And Sources..............................................81

Energy Resource....................................................82

Conversion Technologies..............................................82

Process Technologies ................................................83

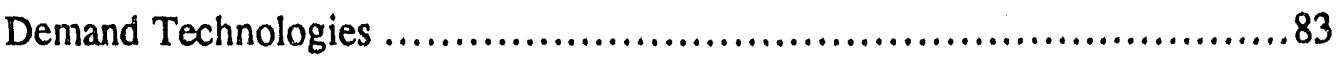

Energy Conservation Data from EASI ....................................84

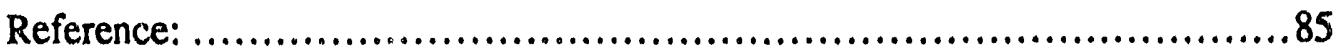




\section{INTRODUCTION}

New York MARKAL (NY MARKAL) uses the common MARKAL described by Fishbone and Abilock (1981) implemented on a microcomputer with the MARKAL Users Support System (MUSS) described by Goldstein (1991). MARKAL, an acronym for MARket Allocation, is a large scale linear program optimization model that captures the complex inter-relationships of energy systems across the spectrum from primary energy supply to energy service demands. MARKAL is an inherently flexible model able to address a wide range of energy and environmental issues. It has been adapted for use in many countries to model national, provincial, and local energy systems. Coupled with MUSS on a microcomputer, MARKAL $i_{i}$ a responsive, "user-friendly" modeling system for energy-environmental analysis, planning, and policy use.

NY MARKAL implements MARKAL for the New Yorl: State Energy System. Development work consisted of configuring the New York. State energy system in MARKAL, developing a database of energy resources and technologies and environmental emission coefficients for New York State, testing the configured model, and developing and analyzing example scenarios. This report describes and documents the development of NY MARKAL and the associated data and the example analyses. The actual data and full results of the scenarios analyzed are provided separately in electronic media formiat from which they can be reviewed and manipulated much easier by using MUSS. A listing and description of these files are given in Appendix I. The objective was to provide a tool for continuing analysis and planning, however, not a one-time report. Staff members from the New York Power Pool, New York State Energy Research and Development Authority (NYSERDA), the State Energy Office (SEO), Department of Environmental Conservation (DEC), and Public Service Commission (PSC) received hands-on training as part of the project. This report uses examples to provide guidance for further analyses. Detailed users' manuals were provided separately (Goldstein, 1991; Giesen et al., 1989; Fishbone et al., 1983).

The impetus for this work was to evaluate carbon dioxide $\left(\mathrm{CO}_{2}\right)$ emission control measures for New York State. The analyses explore least-cost strategies to reduce $\mathrm{CO}_{2}$ emissions and evaluate the cost of $\mathrm{CO}_{2}$ reduction under different conditions. Since the energy system is the principal source of $\mathrm{CO}_{2}$ emissions, an energy systems model is the appropriate context in which to examine reduction strategies. Approaches available to the model to reduce $\mathrm{CO}_{2}$ emissions include: fuel switching, improvements in technological efficiency, increased use of non-carbon energy sources, incentives for accelerating implementation of new technologies, and technological based energy conservation measures. Reforestation, a potential offset policy for $\mathrm{CO}_{2}$ was incorporated directly in the model. Besides $\mathrm{CO}_{2}$ emissions, emissions of sulfur dioxide $\left(\mathrm{SO}_{3}\right)$, nitrogen oxides $\left(\mathrm{NO}_{\mathbf{x}}\right)$, and particles were calculated for each scenario. Although the model, at this point, only addresses $\mathrm{CO}_{2}$ as a greenhouse gas, separate estimates were included of emissions in New York State of other greenhouse gases to provide prospective on the role of $\mathrm{CO}_{2}$ emissions from the energy system (Appendix II). 


\section{DESIGN AND CONFIGURATION OF NY MARKAL}

The configuration of MARKAL is defined by the demand structure and by the resource and technology characterization. The latter refers to the way technologies are defined as opposed to the values in the database, which are covered in the next section. The user has great flexibility in structuring MARKAL, from an aggregate structure with few demand categories and few technologies, each representing a group of technologies, to a highly detailed real-world structure that can get down to the individual plant level. The trade-off is that as the model gets more detailed it is more complex, more difficult to modify, longer to run, and more difficult to analyze the results. If the model is too simple, important distinctions and interdependencies will not be captured, leaving the model inadequate to do the job it was meant to do. NY MARKAL is not simple; it includes 37 demand categories and contains several hundred technologies. The results are still a broadbrush view of the state energy system. This level is suitable to provide a clear overall picture with enough technological detail for most purposes. The beauty of the mc teling system is that the analysi can easily increase the level of detail in any specific area for a special study that requires a spyglass be put over a narrow sector, while maintaining the backdrop of the rest of the energy system at the more standard level. Decisions on the level of detail are often a function of the availability of data. For New York State, we matched the way the State gathers and reports data so that the model would fit into the data framework already in use.

NYMARKAL was designed with nine 5-year time periods, the first centered on 1988 and the last on 2028. The dates corresponded to those used in the 1989 State Energy Plan. The time horizon was longer than that of the State Energy Plan because the nature of the $\mathrm{CO}_{2}$ emissions problem required it. Within limits, MARKAL gives the user control over selecting the number of time periods and their duration, but long usage has proven nine 5-year time periods to be an effective design for MARKAL models. A 45-year time horizon is reasonable for a technologically based model. Development and market penetration lead-times are such that one can confidently expect that, 45 years from now, the energy system will be composed primarily of technologies that are either now available or are well understood and can be characterized. As one goes beyond 50 years, it is more likely that larger and larger shares of the energy system will be based on technologies with characteristics we could not now predict.

\section{Units}

To maintain consistency with SEO data formats, energy units in the NYMARKAL database were entered in billion $\left(10^{9}\right)$ British thermal units (BBtu), electrical capacity units in megawatts (MW), and monetary units in thousands of 1988 US dollars. Pollution emission coefficients are entered in kilograms per $\mathrm{BBtu}$, except for $\mathrm{CO}_{2}$ emissions that, because of their larger size, are entered in metric tons per BBtu. Because the database deals with unit costs of individual technologies, while the results of the model generally provide aggregate numbers, units in the reports are scaled by a factor of 1000: energy is in trillion (1012) Btu (TBtu), capacity ir. gigawatt (GW), monetary units in millions of 1988 US dollars, pollution emissions in metric tons except for $\mathrm{CO}_{2}$ emissions that are in thousands of metric tons. The scaling factors for the reports are under user control and can be changed in the MARKAL file "Units.NYS." That file is self-documented. 


\section{Demand Structure}

Demands for energy services are what drives MARKAL. The basic demand structure includes two residential sectors (single and multiple family), three commercial sectors (office buildings, service buildings, other buildings), an industrial sector and a transportation sector (automobile, light and heavy trucks, bus, subway and urban rail, air, and water vessels). The residential, commercial, and industrial sectors are each further broken down into demand categories (e.g., space heat, water heat, process heat). There are 37 demand categories in all; these are detailed in Appendix III, along with the documentation of the demand projection data. These demands provide the basic drivers for NY MARKAL.

The demand structure is easily modified to suit special needs. For example, if one wished to do a special study of commercial lighting, the existing demand category

"Lighting and Appliances" in each of the commercial sectors could be split into "lighting" and "other appliances." Lighting technologies in the data base would be re-labeled, and presumably a broader range of lighting technologies defined. Given the needed information was in hand, making this modification to the existing database would take an experienced analyst only a few minutes. The additional detail could be used either for a special study or could be maintained as a permanent part of the database.

\section{Energy Resources and Carriers}

In MARKAL, the term "energy carrier" is used instead of fuel because of its

Table 1. Energy Carriers in NYMARKAL.

\begin{tabular}{|l|l|}
\hline Electricity & Wood biomass \\
Coal & Residential Firewood \\
Coke & Herbaceous Crops \\
Coal-Water Mixture & Microalgae Diesel Equiv. \\
Carbon & Municipal Solid Waste \\
Crude Oil & Solar \\
Kerosene & Wind \\
Jet Fuel & Wave \\
Diesel Fuel & Hydroelectric \\
Light Distillate & LWR Fabricated Fuel \\
Heavy Distillate & High Temperature Heat \\
Residual Oil & Low Temperature Heat \\
Gasoline & Conservation \\
Liquid Petroleum Gas & Biogas \\
Natural Gas & Liquid Hydrogen \\
Pipeline Quality Gas & Hydrogen Gas \\
Medium Btu Synthetic Gas & Ethanol \\
Compressed Natural Gas & Methanol \\
Propane & \\
\hline
\end{tabular}
broader connotations. Energy carriers include wind, solar and hydroelectric; high and low temperature heat used in industrial and district heating systems; and fuels wch as coal and oil. End-use conservation is also treated as an energy carrier as discussed in the next section. Energy carriers included in NY MARKAL are listed in Table 1. In the case of renewable energy carriers, such as solar, wind, and hydro, a fossil equivalent energy is defined for accounting purposes, e.g., to calculate values such as total primary energy. Several nuclear energy carriers are defined, but only LWR fuel is currently included in the imports. 
Several energy carriers are given distinct names in NYMARKAL for different enduses for purposes of pollution emissions accounting as discussed below. Also, special energy carriers called "steam turbine fuels" and "combustion turbine fuels" were defined to handle dual-fueled and multi-fueled power plants (Figure 1). The latter processes allow the model to determine the fuel mix.

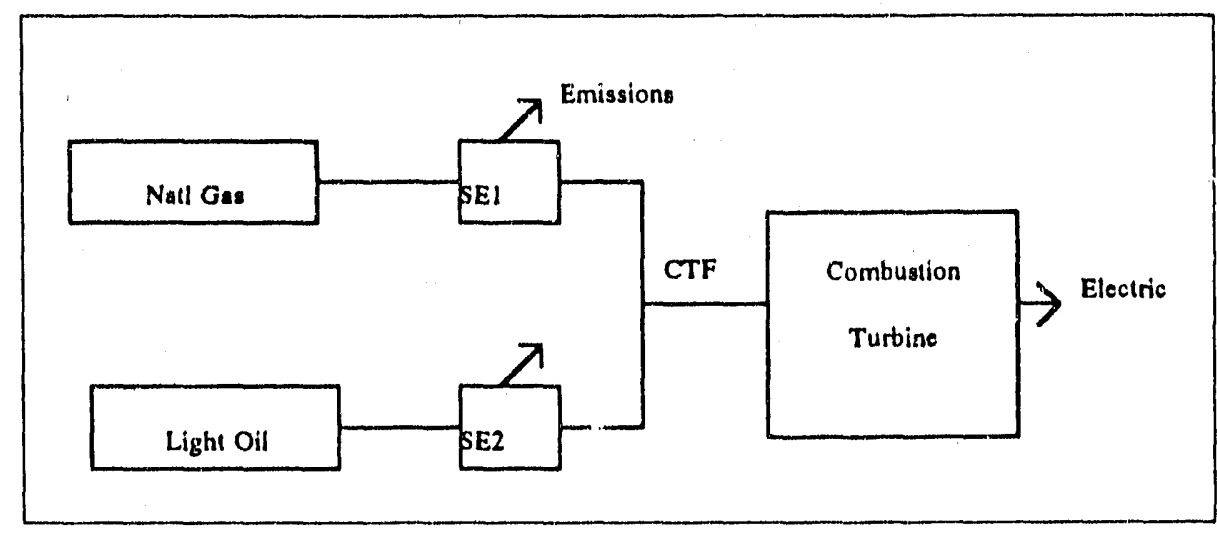

Figure 1 Schematic view of use of dummy processes (SE1 and SE2) and dummy fuel (CTF) for environmental emissions and optimization of fuel mix for dual-fuel device.

Energy resources are the limited resources from which fuels are obtained, e.g., oil fields and coal seams. New York State is not rich in energy resources. In the data base it was assumed that all fossil and nuclear fuels would be imported. NYMARKAL contains no oil or gas wells, no coal or uranium mines. Further, it includes no refineries or other fuel processing facilities. These assumptions are not strictly true. There is some oil refining in New York as well as some coal and gas production, but the amounts are insignificant when examining the state energy system as a whole. There may be cases in which one might want to consider opportunities for increased natural gas production in the state. These were not examined, but could easily be added.

While the sun, wind, and waves are potential energy resources, they are not generally included as such in MARKAL; constraints on use of these renewable resources are placed on the technologies that convert them to heat or elestricity rather than limiting the resource itself. Domestic resources included in NYMARKAL are wood, herbaceous crops, and municipal solid waste.

\section{End-use Conservation}

Efficiency of end-use devices can be explicitly specified in the MARKAL database. Many technological approaches to end-use conservation, however, are not well characterized by changes in efficiency. The best examples are building shell conservation measures such as adding wall and ceiling insulation. These decrease the demand for energy services, in this case for space heat. Demands are exogenously specified in MARKAL, however, so to allow MARKAL control over building conservation, a dummy fuel called "conservation" was invented. Building shell conservation technologies, fueled by

"conservation," are then characterized in the database in the same way as are other 
technologies. MARKAL can choose to buy building conservation as a means of meeting space heat demands. Increased efficiciency in motor vehicles are treated in the same way. Limits are placed on the amount of the total demand that can be met by conservation. Energy conservation is an energy savings from the norm. We assume building conservation in the base year (1988), for example, to be zero. This is not because 1988 buildings have no insulation, but because we take them as the standard; there is no absolute point for zero conservation. In the industrial sector, many of the conservation measures included are from SEO's database developed from the Energy Advisory Service to Industry (EASI). These are mostly retrofit measures. We assume that these retrofit conservation measures would be inappropriate for industrial facilities built after 1998, and so this conservation option dies as existing industrial facilities end their useful life.

\section{Electric Power Plants}

Existing electric power plants were characterized in NY MARKAL in more detail than in typical MARKAL applications. Existing plants are defined by vintage (10 year intervals) and type. This allows use of these plants to be tracked or characterized separately and facilitates analysis of questions of early or extended retirement and retrofitting of pollution control devices. Fifty-one types of electric generation plants are described. Twenty-seven of these are existing plants, of which 23 are described by vintage. Twentyfour plant types are new technologies, of which five are non-central facilities (local wind, local photovoltaic, and three types of fuel cells). MARKAL feeds electricity from noncentral facilities directly into the distribution grid, avoiding transmission losses.

\section{Process Technologies}

Process technologies serve two purposes in MARKAL. The first is to characterize intermediate processes such as oil refineries and nuclear fuel fabrication. Since New York primarily imports finished fuels, few of these processes are included in the database. Ones that are included are hydrogen liquefaction, electrolytic hydrogen production, landfill gas production, production of biogas from herbaceous crops, and production of ethanol or methanol from wood and herbaceous crops and wood. Carbon sequestration is included as a process. Processes are also used to define district heating grids. Only one district heating grid is currently defined in NYMARKAL, but the number is not limited. Although MARKAL includes electric and district heating grids inherently, defining them separately provides greater user control over expansion of the grid. The same technique could be used to investigate expansion of the electrical or gas pipeline grid (transmission or distribution or both).

The second use of processes is as dummy technologies for modeling convenience, for example to provide a convenient place in the fuel cycle to designate environmental emissions or to allow the model flexibility in selecting the fuel mix for multi-fuel power plants. NYMARKAL contains 40 such dummy processes. Although we refer to them as "dummy" processes since they perform no work and incur no losses, most are not included in the MARKAL class "Dummy." If these processes are included in the Dummy Class, no capacicy vectors are generated, thus making the problem smaller and faster to run. Their outputs, then, are not accessible by MUSS. By keeping them out of the Dummy Class, we sacrifice some run time to have them in the results tables where they can be accessed and 
used in customized tables, for example to display fuel use for groups of electric power plants. Processes with environmental emissions will appear in the emissions tables of the results without regard to whether they are in the Dummy Class or not.

\section{Energy Storage Technologies}

Three types of storage technologies are included in NY MARKAL: hydroelectric pumped storage, electrolytic hydrogen production, and electric automobile batteries. The latter are included on the assumption that electric automobiles will be charged at night.

\section{Environmental Emissions}

Environmental emissions are included in NYMARKAL at the technology level and act on the activity of the technology. Emissions coefficients are included for carbon dioxide $\left(\mathrm{CO}_{2}\right)$, sulfur dioxide $\left(\mathrm{SO}_{2}\right)$, total suspended particles (TSP), and nitrogen oxides $\left(\mathrm{NO}_{\mathrm{x}}\right)$. Activity for conversion technologies in MARKAL is expressed as electricity out, while emissions coefficients are more commonly expressed as fuel in. Modifying emissions coefficients to an output basis would require a change in the emission coefficient if the conversion process efficiency were to be changed. It is better to maintain the environmental coefficients in terms of fuel inputs. To do this, dummy processes were established in front of each conversion technology. These had a fuel input (e.g., residual oil) that was the same as the conversion technology, which was passed through at $100 \%$ efficiency to an output fuel that was exactly the same but was given a different name for identification purposes. The emission coefficients for the conversion technologies were then assigned to these associated processes (Figure 1). For demand technologies, activity is defined in terms of fuel in, so emissions coefficients could be assigned directly.

While this is the most common approach to emissions, MARKAL allows other methods. For example, were one interested in including land use as an environmental factor, MARKAL allows emissions to be associated with initial investment so that the land use would be counted only once for each facility.

$\mathrm{CO}_{2}$ emissions coefficients were based on those used by the New York State Energy Office (NYSEO, 1991b). Each fossil fuel was given a single $\mathrm{CO}_{2}$ emissions coefficient, although the coefficients were applied by technology. Negative coefficients were used for carbon sequestering or when fuels were used for industrial feed stock. Emissions coefficients for $\mathrm{SO}_{2}, \mathrm{NO}_{\mathrm{x}}$ and total particles were taken primarily from the U.S. Environmental Protection Agency's Source Classification Codes and Emission Factor Listing (AFSEF), based on the recommendation of the Department of Environmental Conservation. AFSEF was provided by EPA on a diskette. In some cases the AFSEF coefficients were too specific and were aggregated to the level of the technology defined in the MARKAL database. In other cases, the AFSEF did not include technologies in the MARKAL database, and coefficients were obtained elsewhere, including DOE technology characterization handbooks (DOE, 1980a; 1980b; 1981; 1983; 1988), Butcher and Ellenbeker (1982), DeLuchi et al. (1987), University of Oklahoma (1975), Moskowitz and Hamilton (1988), Beller (1975). Even within AFSEF, different coefficients are stated in different units, generally mass of pollutant per unit weight or volume of fuel. These ware all transformed to units of kilograms per million $B t u(\mathrm{Kg} / \mathrm{mmBtu})$. 
The existing automobile fleet posed a special problem. Cars were not specifically "vintaged" in the model, but it was assumed that as the existing fleet aged, the older cars would drop out and the fleet average miles per gallon and emissions per mile would improve. A spread-sheet model was developed to step through this process, and emissions per unit energy from the existing fleet were calculated for each period. The rate of loss was calculated by a statistical regression of the age of cars of different model years in the 1987 US fleet. New cars are essentially "vintaged" within the model and a separate outside calculation was not necessary.

A complete listing of the emissions coefficients used, keyed to sources, and the spread-sheet for the existing automobile fleet, is provided in Appendix IV.

\section{Emissions Embodied in Energy Imports}

A key concern for New York State in considering approaches to $\mathrm{CO}_{2}$ emissions reduction is to assure that policies are not adopted that simply move the emissions out of state. For example, New York imports some electricity from coal fired power plants in Pennsylvania; it would be silly to reduce in-state coal-fired power plant operations and increase these imports. Emissions coefficients are thus associated with imports. Imports of Pennsylvania electricity are given the same emissions coefficient as domestic coal-fired power plants (adjusted for the fact that the power plant emissions are imposed on the fuel inputs while the electricity import emissions are imposed on the electricity output of the plants).

Nuclear power involves the use of oil and coal-fired electricity in mining, milling conversion, enrichment, fuel fabrication, waste storage and processing and transportation. In the U.S. MARKAL model, these requirements are explicitly characterized as part of these processes so that most such emissions are captured endogenously. For New York, however, it is assumed that only the nuclear power plants are in the state, all other parts of the nuclear fuel cycle existing elsewhere in the United States. $\mathrm{A} \mathrm{CO}_{2}$ emissions coefficient was associated with nuclear fuel imports to include these fuel-cycle emissions. The emission factor used was based on data reported by Perry et al. (1977) detailing electricity and oil use in mining, milling, conversion, enrichment, fabrication, transportation, and waste disposal. Oil and electric requirements in mining and milling are highly dependent on the grade of the uranium ore; poorer ores require more fuel. It has been suggested that expanding nuclear power would require exploitation of lower grade ores, leading to higher fuel use and increased $\mathrm{CO}_{2}$ emissions (Mortimer, 1991). Oil and coal consumption for two cases reported by Perry et al. were multiplied by our coefficients for $\mathrm{CO}_{2}$ emissions for oil and coal. The coefficients used depend on assumptions of how the electricity is produced (Table 2); we assumed that all electric power is provided by coal. For our analysis we chose to use a value between high-grade and low-grade ore, but closer to the low grade: $0.001 \mathrm{Kton} / \mathrm{BBtu}$.

Essentially all electric power for the nuclear fuel cycle is today provided by coal, but this could change in the future. It is probably reasonable to assume that were $\mathrm{CO}_{2}$ emission constraints imposed in New York and if this led to an increased use of nuclear power, the same would hold true for the U.S. as a whole. Our analysis of the U.S. energy system suggests that, under these circumstances, the percentage contribution of nuclear to the nation's electric supply would increase substantially relative to coal. Electricity supply 
for the nuclear fuel cycle would tend to be more from nuclear than coal. This would result in a decrease in the $\mathrm{CO}_{2}$ emissions coefficient for nuclear fuel imports to New York. We have not assumed any such decrease, however, probably resulting in an excessive penalty for nuclear under high $\mathrm{CO}_{2}$ emissions constraint.

Table 2. $\mathrm{CO}_{2}$ emissions coefficient for nuclear fuel. Emissions in Ktons carbon per BBtu fuel.

\begin{tabular}{|l|l|l|}
\hline Ore Quality & $0.18 \%$ & $0.0006 \%$ \\
\hline Emissions & 0.000227 & 0.001317 \\
\hline
\end{tabular}

next section.
Besides direct fuel and electricity use, Perry et al. (1977) also provide estimates on $\mathrm{CO}_{2}$ produced in construction of facilities and embodied in the materials used. To be consistent with the use of other technologies, these viere not included. The implications of these indirect emissions are discussed in the

For practical purposes, no $\mathrm{CO}_{2}$ is emitted in the production of hydroelectric power. Reservoirs at hydroelectric projects may, however, lead to enhanced natural emissions of methane as a result of decay of vegetative matter covered when flooding the reservoir. $\mathrm{CO}_{2}$ equivalent emissions of 55 pounds/Mwh were used in the analysis based on a study of the proposed Quebec Hydro reservoir sites (Thérien, 1990).

Oil, gas, and coal imports also involve out-of-state emissions in the extraction and processing stages, but these "re such a small fraction of the in-state einissions associated with the combustion of these fuels that it is ignored.

\section{Emissions During Construction and Embodied in Nonenergy Imports}

Energy and pollution emissions are embodied in products and materials imported inio the state. For example, automobiles purchased in New York State embody energy use and pollution emissions associated with their manufacture and with the manufacture of the steel, plastic, and other materials of which they are made. These are not direct effects of energy policy and are beyond the scope of the current work. An important factor in national and international considerations of $\mathrm{CO}_{2}$ emissions reduction is that policy constraints on emissions in one cuuntry would tend to drive energy-intensive industry to places with less stringent emissions policies, or might otherwise put local industries at a disadvantage. This is an issue worthy of consideration in New York State, but does not loom as large as it does at the national level because heavy industry is not as important a part of the New York economy as it is for the U.S. as a whole.

New York State is a large consumer of the products of heavy industry, however, and a focus on energy and associated environmental emissions embodied in consumer products, while not an energy policy issue, could prove to be a useful approach to reducing greenhouse gas emissions.

Emissions during construction of energy facilities are, in general, small compared to emissions during operations. This issue of construction or manufacturing phase emissions is often raised when comparing fossil-fuel facilities with renewables. A photovoltaic cell produces no environmental emissions during its operation, but there are emissions during its manufacture. MARKAL can incorporate these effects but this kind of analysis is beyond the scope of the present work. 


\section{NYMARKAL ENERGY RESOURCE AND TECHNOLOGY DATABASE}

The NYMARKAL resource and technology database draws on extensive experience with the U.S. MARKAL database and those from other countries, especially Sweden, but it reflects the characteristics of resources and technologies available in New York. Hundreds of energy technologies are characterized in the NYMARKAL database. Documentation of the database is provided in Appendix $V$. Technology characterization data are, in many cases, time specific. That is, when a new technology is expected to become available and how fast improvements in cost and performance are expected are explicitly specified in the database. These specifications are made in terms of the nine 5-year time periods (19882028) upon which NYMARKAL was designed. Alternative scenarios generally involve changes to the database, either adding a new technology not in the base scenario, e.g., another level of end-use conservation, or modifying the characterization of a technology, e.g., examining the effect of an accelerated R\&D program by allowing the technology to enter the market sooner or at lower cost.

\section{APPROACH AND SCENARIOS EXAMINED}

Our general approach to MARKAL analysis is to fix the base year (1988 in this case) and then allow the model freedom to make decisions after that. When reviewing the results, the analyst must decide if unexpected resul's are valid signals of how the energy system could run better or are due to the model's lirnited understanding of reality. If the latter is the case, it is then appropriate to improve the model's understanding, for example by adding bounds on growth rates, investment, or other parameters that force the model into a more realistic solution. There are no exact rules on how rigorously this should be done. Our preference is to severely limit our interference with the model initially, then to impose more realistic bounds in sensitivity runs.

Several scenarios were analyzed. Scenarios examined are listed and described in Table 3. These are discussed in more detail in the individual sections below along with their analysis. Each scenario was run without $\mathrm{CO}_{2}$ constraint and against four different levels of $\mathrm{CO}_{2}$ constraint: stable at 1990 levels and $10 \%, 20 \%$, and $30 \%$ reduction from 1990 levels in 2008 and thereafter (not all scenarios had feasible results for all $\mathrm{CO}_{2}$ reduction levels). A scenario- $\mathrm{CO}_{2}$ constraint combination is a case. We use a consistent approach for file names of each case: a four-letter mnemonic to represent the scenario (e.g., TREE), supplemented with a number to represent the $\mathrm{CO}_{2}$ constraint level. Following the TREE example, the $\mathrm{CO}_{2}$ unbounded case is TREE1; $\mathrm{CO}_{2}$ stability is TREE10, 10\% reduction is TREE1 10; $20 \%$ reduction is TREE120. Scenarios were selected in part because they address important energy issues for New York State, but also to serve as examples of how NYMARKAL can be used to analyze specific issues.

Other scenarios involve either more restrictive conditions (e.g., not allowing any further investment in nuclear power), addition of alternatives that were not appropriate to the base case because we did not want them associated with every scenario (e.g., greatly increased hydroelectric imports), or a different approach to $\mathrm{CO}_{2}$ emissions reduction (e.g., carbon tax). 
We call the unconstrained case of the Conventional Technology Scenario the "Reference Case" since it is the case most of the alternative scenarios are built upon (by adding technologies or tightening or relaxing constraints on technologies). The reference case is not meant to be a business-as-usual simulation, but it needs to be sufficiently realistic that the results are meaningful lessons to guide future policy. MARKAL produces a least-cost solution under conditions of perfect foresight and perfect economic "rationality," We do not have perfect foresight, but we can use alternative scenarios to test the robustness of decisions under different future conditions. As a society, we base our decisions on a broad range of factors, many of which cannot be easily included in a computer model. We gladly give up some economic rationality or efficiency to address other goals, such as equity or environmental protection. MARKAL points the direction of increased "rationality" and shows how far the system can go in that direction, thus helping to identify the most attractive alternatives to gain specified objectives. In an alternative scenario, we can force a solution that MARKAL, from its narrow view, considers less than optimal (for example, no new nuclear power); this allows us to determine how much we are giving up from the rigid economic efficiency viewpoint. Experimentation with the model may help us find other solutions that achieve the same goals at lesser cost.

Table 3. Scenarios examined and their description.

\begin{tabular}{|c|c|c|}
\hline File Name & Scenario & Description \\
\hline BNYS & Conventional Technology & $\begin{array}{l}\text { Allows substantial increases in nuclear } \\
\text { and } 1.8 \mathrm{GW} \text { imports of hydropower. }\end{array}$ \\
\hline TREE & Reforestation & $\begin{array}{l}\text { Adds ability to sequester carbon by } \\
\text { planting trees. }\end{array}$ \\
\hline QUEB & $\begin{array}{l}\text { More Hydroelectric } \\
\text { Imports }\end{array}$ & $\begin{array}{l}\text { Imports from Quebec allowed to grow } \\
\text { from } 1000 \mathrm{MWe} \text { in } 1993 \text { to } 10,000 \mathrm{MWe} \\
\text { in } 2028 \text {. Additional Nuclear also } \\
\text { allowed. }\end{array}$ \\
\hline TAXC & Carbon Tax & $\begin{array}{l}\text { Same as Reference Case with the addition } \\
\text { of a } \$ 15 / \text { ton carbon tax escalating } \\
10 \% / \text { year. This scenario is an alternative } \\
\text { approach to the usual method of fixed } \\
\text { emission constraints. }\end{array}$ \\
\hline CONS & $\begin{array}{l}\text { Increased End-use } \\
\text { Conservation }\end{array}$ & $\begin{array}{l}\text { Double end-use conservation } \\
\text { opportunities at higher cost added to } \\
\text { Reference Case. }\end{array}$ \\
\hline NNQB & $\begin{array}{l}\text { More Hydroelectric; no } \\
\text { new nuclear }\end{array}$ & $\begin{array}{l}\text { Imports from Quebec allowed to grow to } \\
15,000 \mathrm{MWe} \text { in } 2028 \text {. No new nuclear } \\
\text { power. }\end{array}$ \\
\hline
\end{tabular}


Table 4. Inclusion of nuclear and increased Quebec hydropower in scenarios.

\begin{tabular}{|c|c|c|}
\hline Scenario & $\begin{array}{c}\text { Increased } \\
\text { Nuclear }\end{array}$ & $\begin{array}{c}\text { Increased } \\
\text { Hydro }\end{array}$ \\
\hline BNYS & $\mathrm{X}$ & \\
\hline CONS & $\mathrm{X}$ & \\
\hline TREE & $\mathrm{X}$ & \\
\hline QUEB & $\mathrm{X}$ & $10 \mathrm{GW}$ \\
\hline NNUC & & \\
\hline NNQB & & $15 \mathrm{GW}$ \\
\hline
\end{tabular}

government policies.
Analysis of alternative scenarios has three purposes. The first is to examine how the energy system would respond to possible alternative futures. This might include future conditions driven by government policy, changes in the availability of technologies (either constraints on the use of existing technologies or introduction of new technologies) or changes in fuel cost assumptions. The second purpose is to help rank various alternatives identified by MARKAL. The third purpose is to determine the sensitivity of results to various assumptions and to investigate the effectiveness of potential

Several custom tables were designed to facilitate understanding of the results. Custom tables are a strong feature of MUSS and it is hoped that these tables will guide and encourage New York State MARKAL users to design additional custom tables in NYMARKAL to meet their own needs for special kinds of information or analysis. The custom tables included with the NYMARKAL package and used in the following section are documented in Appendix VI.

The most controversial issues included are nuclear power and increased imports of Quebec hydroelectric power. All scenarios assume the additional $1 \mathrm{GW}$ of hydropower currently being reconsidered will be available in 1993. This issue is a candidate for MARKAL analysis, but was not addressed here. The hydropower issue addressed is the much longer term issue of substantial (e.g., $10 \mathrm{MW}$ ) reliance on Quebec Hydro over the next 40 years. Table 4 shows which scenarios include each of these two energy sources. The design aims to show the implications of each independently and in competition with each other.

\section{INTERPRETING THE RESULTS}

A MARKAL run produces a massive amount of information (a typical output file from NYMARKAL is $750 \mathrm{~KB}$ and the linear program ,olution file is over $1 \mathrm{MB}$ ). A listing of output tables is given in Appendix I. Explanation of the MARKAL output tables can be found in the MARKAL Report Writer documentation (Giesen et al., 1989). Fortunately, MUSS provides the ability to quickly access key subsets of results and examine this information graphically. Graphs comparing results from several cases can be produced with a single keystroke.

Results are examined in stages: 
First, summary statistics: use of primary fuels overall and by sector; environmental emissions; total costs and summary costs for fuels, supply-side technology and demand-side technology.

Second, a detailed examination of the activity of individual technologies. A strength of MARKAL is the ability to provide guidance on the value and role of individual technologies. Whether a specific technology is selected at all, whether it increases or decreases in use, and its relative increase or decrease under different scenarios are key indicators of the technology's value.

Third, a deeper look at the reduced costs of technologies. For technologies that were not selected, these indicate by how much they missed. This provides clues to sensitivity, e.g., how big a difference in cost estimates would have led to selection? It also provides clues to possible policy questions, e.g., how big a reduction in cost would have to be achieved through R\&D to make this technology competitive? Among attractive technologies that the model brings into the system to their limit, reduced costs provide clues to how strongly the technology is wanted, e.g., how much the total system cost will be reduced if one additional unit of capacity could be added to the system.

Finally, other details in the results, some of which may be suggested by the preceding examination. This includes, for example, examining environmental emissions results to determine the specifics of how reductions in $\mathrm{CO}_{2}$ are achieved.

NYMARKAL was run for nine 5-year time periods, from 1988 to 2028 . Any model that "builds" capital item" having a lifetime of more than one time step must address the question of how to end the model properly. For example, a model would be disinclined to build an expensive plant with a 40-year life near the end of the study period if it assumed that was also the end of the world. MARKAL addresses this problem by essentially selling the entire energy system at the end of the study period, thus getting credit for any residual capacity remaining. This is a well recognized and accepted approach that generally works well, but artifacts may still creep in. It is wise to ireat any abrupt changes in the last period with caution. This is especially true in NYMARKAL because much of the front-end of the fuel cycles (e.g., mines, refineries) is missing so the system has less inertia than it otherwise might. On the other hand, one should not ignore possible information to be gained from the last period.

\section{CONVENTIONAL TECHNOLOGY SCENARIO}

The Conventional Technology scenario is designated BNYS1. It does not represent the recommended, preferred, or most realistic future. It simply consists of the basic set of technologies, resources, and emissions factors that the other scenarios build upon. For the most part, the model was allowed free rein in the reference case, choosing technologies with its least-cost blinders on. It allows substantial nuclear growth. MARKAL allows imports of electricity, but does not allow capacity to be associated with imports. Since the system must have adequate capacity to meet peaking and reserve requirements, electricity withu st associated capacity is not as valuable. Existing contractual imports from Quebec (equivalent to $800 \mathrm{MW}_{\mathrm{e}}$ ) are configured in the model as imports and constrained to enter 
the system. The additional planned $1000 \mathrm{MW}$ is configured as a domestic hydropower plant (EQB), thus allowing it to contribute to the state's electrical capacity. Its costs, however, are all included as annual costs; the capacity charge included as a fixed annual cost. The $20 \% \mathrm{CO}_{2}$ reduction case was not feasible, although the infeasibility occurred only in the ninth period (2028). This indicates that a $20 \%$ reduction in $\mathrm{CO}_{2}$ could be achieved in 2008, but it could not be sustained through 2028 without introduction of measures not included in the scenario.

Early runs indicated mucil greater use of coal and a parallel increase in pollutant emissions in future years than was predicted by the New York State Energy Office. A constraint was introduced to prevent $\mathrm{SO}_{2}$ emissions from rising above current levels. This constraint is less stringent than state plans, but was sufficient to bring the model within the bounds of a more likely future. Implementing more detailed constraints on $\mathrm{SO}_{2}, \mathrm{NO}_{\mathrm{x}}$ and TSP would improve the reality of the model. This would require some adjustments to the model configuration, for example to fully implement the use of coals and oils of different sulfur content. Nonetheless, the single constraint on $\mathrm{SO}_{2}$ is sufficient for the current purpose.

To summarize the results of the reference case, coal becomes the primary fuel for producing electricity, although renewables increase also. Natural gas, oil and nuclear decline as electrical power fuels. The system builds no new nuclear plants, a decision made solely on grounds of cost. End-use conservation increases. When $\mathrm{CO}_{2}$ constraints are imposed, coal declines as an electric fuel, to be replaced primarily by nuclear. Electricity takes on a large role in the State's energy system, especially in the residential sector. More detail is given below.

\section{Primary Energy Use}

Primary energy use in the three cases of the Conventional Technology Scenario is summarized in Figure 2 and shown individually for each fuel in Figures 3-6. Growth rates, which are tabulated in Table 5, are calculated by the formula:

$$
A_{1}=A_{0} e^{r t}
$$

Where: $\quad A_{0}=$ energy use in 1988

$A_{1}=$ energy use in 2028

$t=$ interval (40 years)

$r=$ annual rate of increase

Solving for annual rate in percentage terms gives

$$
r=100\left[\frac{\ln A_{1}-\ln A_{2}}{t}\right]
$$




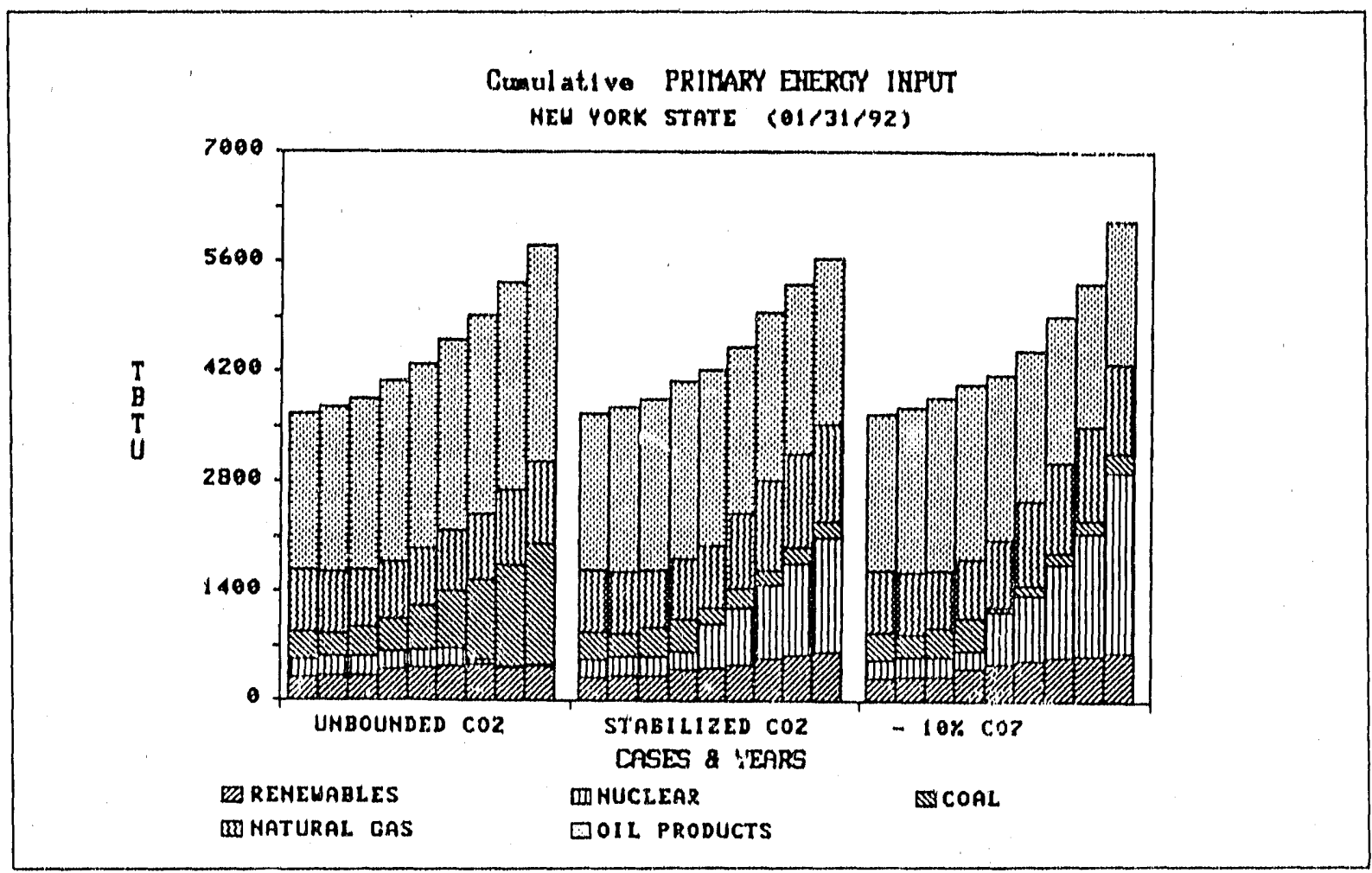

Figure 2. Primary energy use in Conventional Technology Scenario.

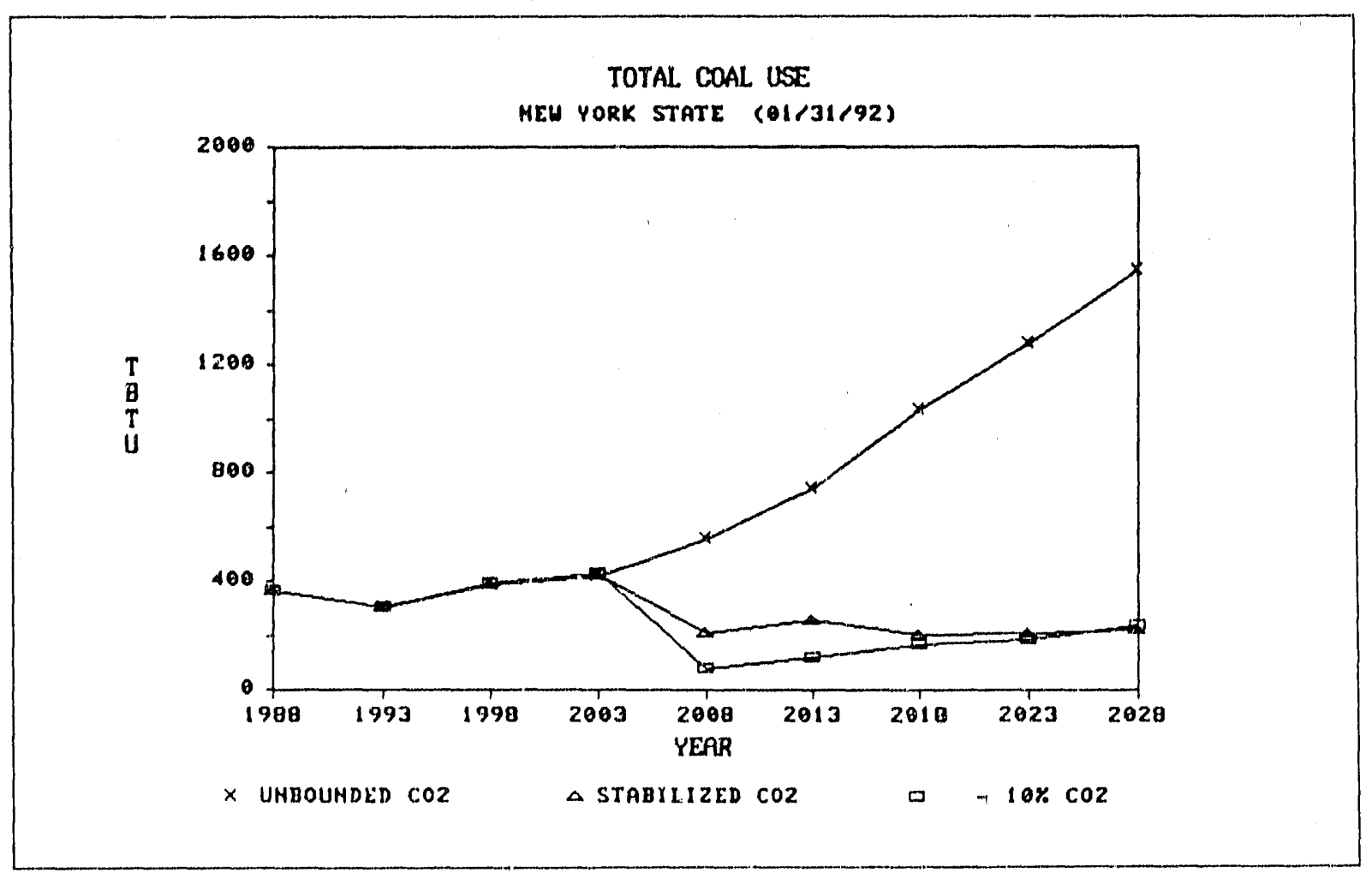

Figure 3. Primary ccal use in Conventional Technology Scenario. 


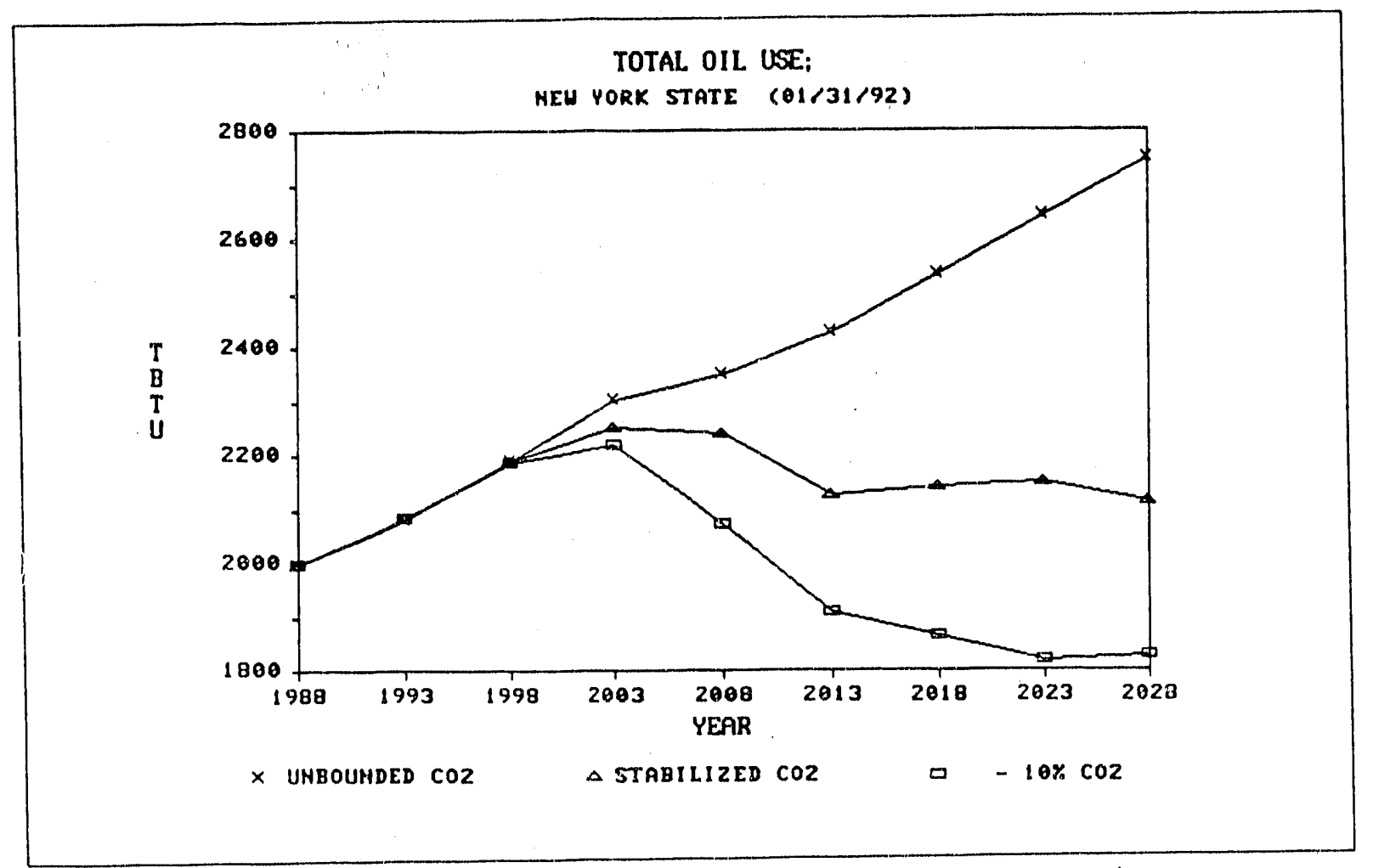

Figure 4. Primary oil use in Conventional Technology Scenario.

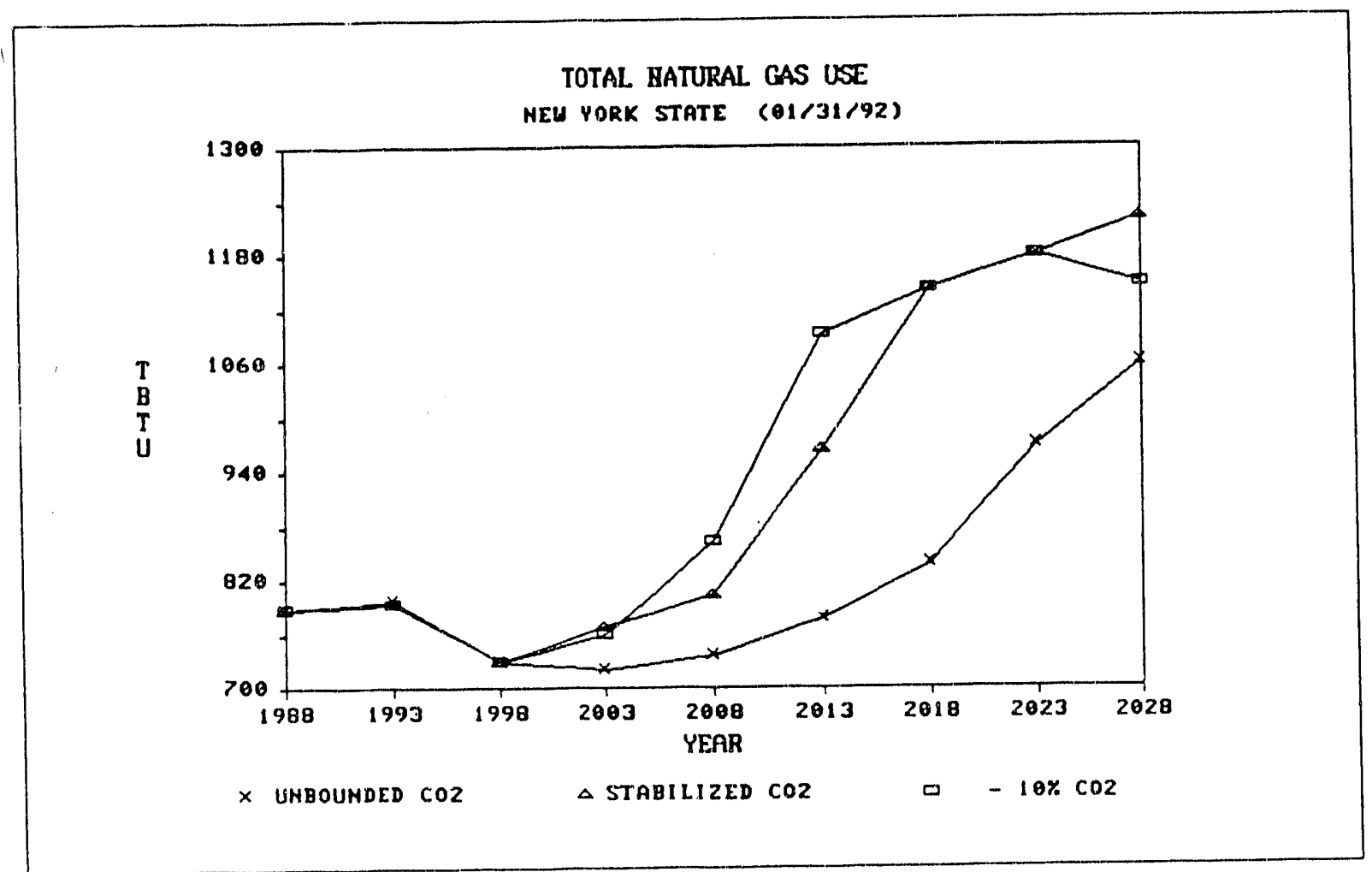

Figure 5. Primary natural gas use in Conventional Technology Scenario. 
TOTAL RUCLEAR FUEI, USE

MEU YORK STATE (01/31/92)

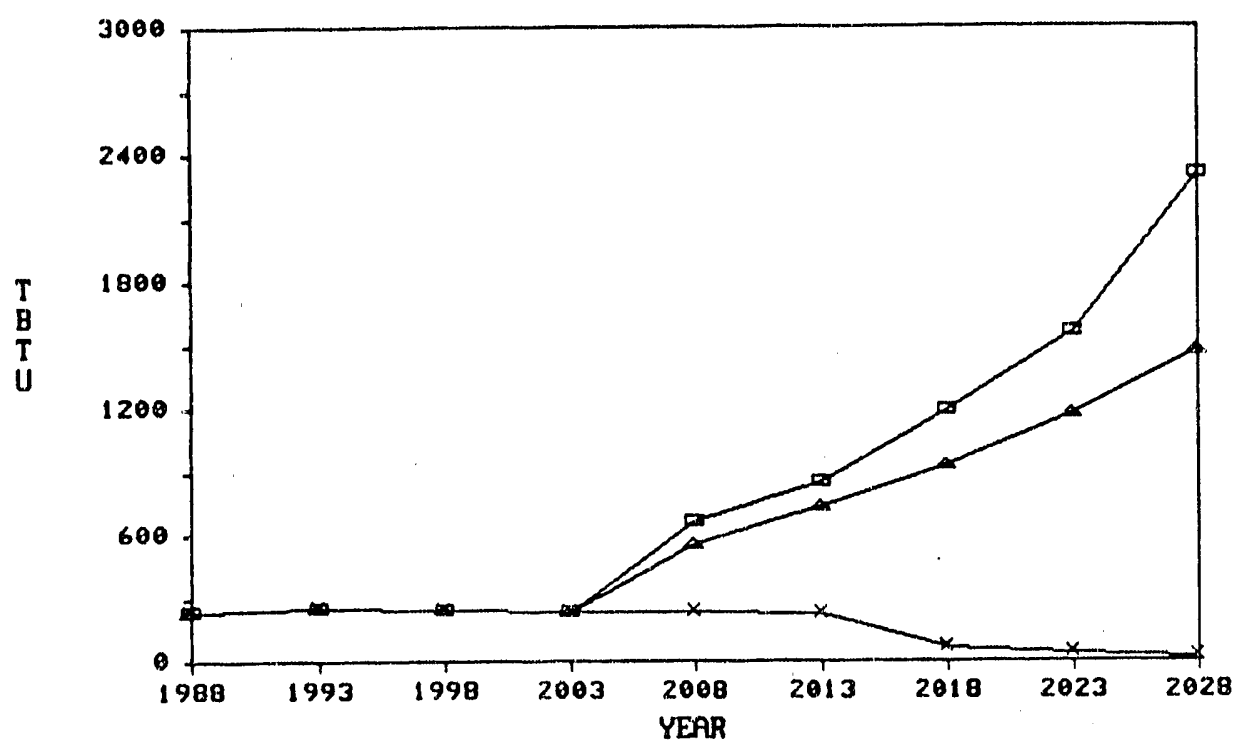

$\times$ UMBQUNDED COZ $\triangle$ STABILIZED COZ $\square \quad-10 \% \mathrm{COZ}$

Figure 6. Primary nuclear fuel use in Conventional Technology Scenario.

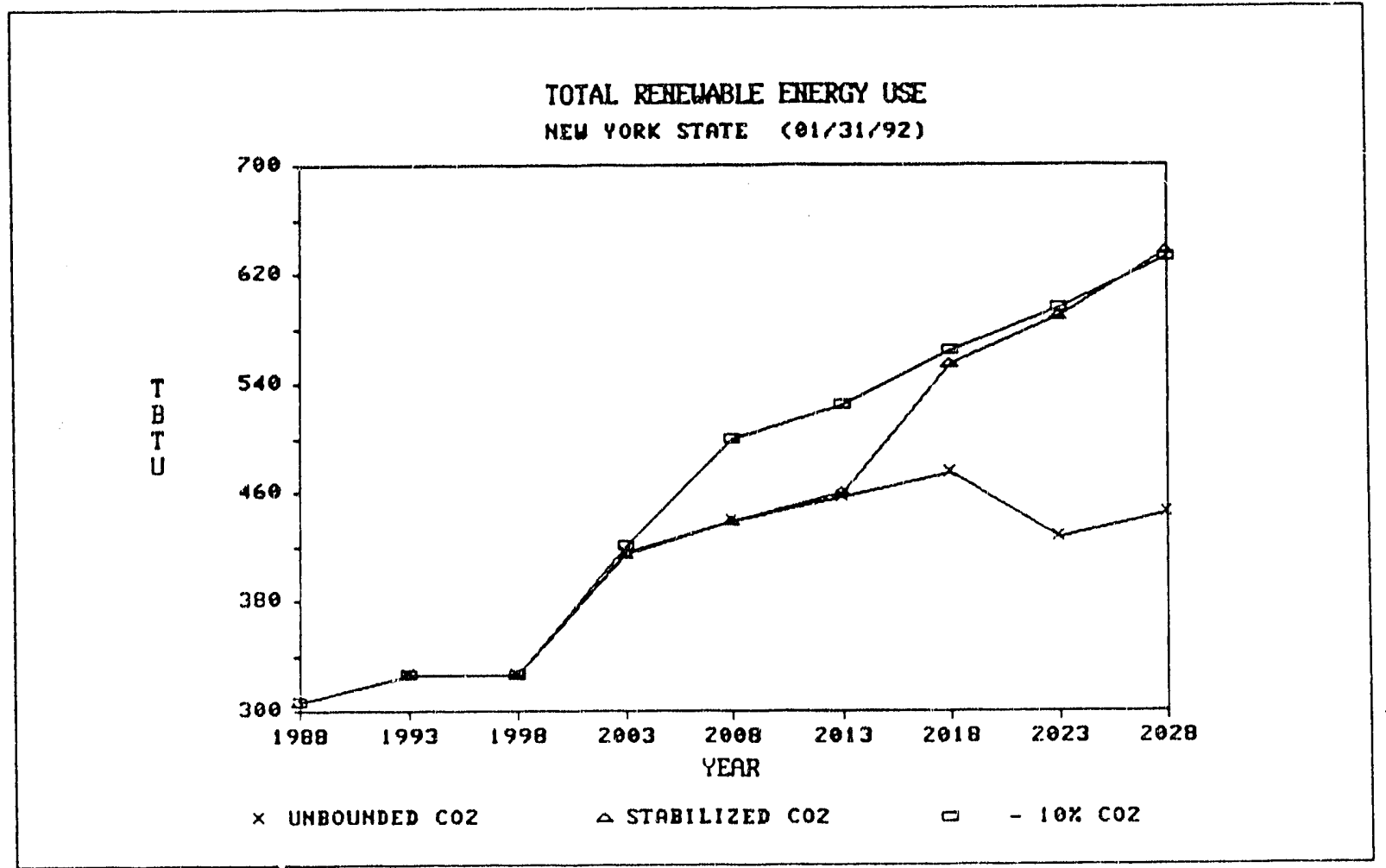

Figure 7. Primary renewable use (fossil equivalent) in Conventional Technology Scenario. 
In the unconstrained case, oil remains, by far, the dominant energy source in the state, although its use grows at a slower rate than useful energy demand (1.3\%/year). Coal averages 3.6\%/year, quadrupling its 1988 level. Natural gas declines in use from 1988 to a low in 2003 , but then increases. Its growth rate over the entire study period was $0.7 \% /$ year. Renewable technologies increase steadily at an average of $0.8 \% /$ year. Nuclear declines as existing plants reach the end of their useful life. The system makes no new investments in nuclear capacity. End-use conservation is the fastest growing "energy source, " increasing its contribution at a rate of $4.9 \%$ /year.

As $\mathrm{CO}_{2}$ constraints are imposed, the increase in coal use turns around and becomes a decrease. A similar effect happens with oil, although more slowly. Nuclear also reverses its downward trend and enters the system strongly (the implications of no new nuclear are explored in an alternative scenario). Natural gas, renewables, and conservation come into the energy system at an increased rate. The apparent growth in total primary energy reflects the use of fossil-fuel equivalents for primary fuel use of renewables since there is no satisfactory way to compare coal with solar on a "primary energy" basis.

Table 5. Primary energy growth rates $1988-2028$, Conventional Technology Scenario.

\begin{tabular}{|c|c|c|c|}
\hline \multirow{2}{*}{$\begin{array}{c}\text { Energy Type } \\
\text { Case: }\end{array}$} & REFERENCE & STABLE & $-10 \%$ \\
\hline Conservation* & 4.9 & 6.1 & 6.2 \\
\hline Coal & 3.6 & -0.8 & -0.8 \\
\hline Natural Gas & 0.7 & 1.1 & 1.0 \\
\hline Nuclear & -5.9 & 4.5 & 5.4 \\
\hline Oil & 0.8 & 0.1 & -0.2 \\
\hline Renewables & 0.8 & 1.5 & 1.4 \\
\hline Total Primary** & 1.1 & 1.0 & 1.2 \\
\hline *Rate over 35 years (1992-2018) \\
**Excludes conservation.
\end{tabular}

Another way to look at changes in primary use is by changes in the fractional use of each fuel. Figure 8 shows the change in the share of primary energy between the unconstrained and the $10 \%$ reduction case. 

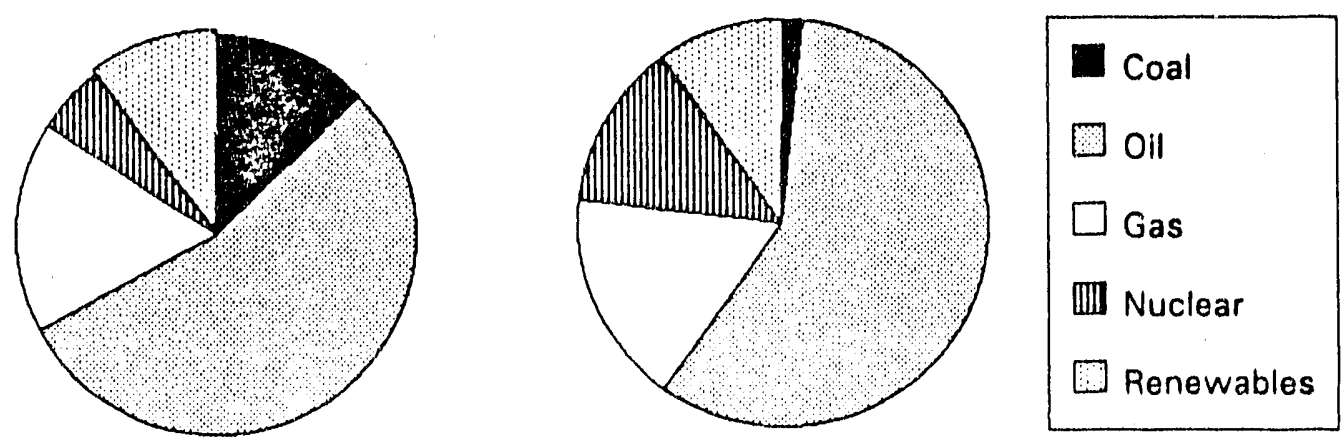

Figure 8. Primary energy use in 2008 for unconstrained (left) and $10 \%$ reduction case (right) in Conventional Technology Scenario.

\section{Single Family Residential Energy Use}

Figure 9 shows the energy mix in terms of useful energy supplied for single family residential. In the unconstrained case, gas increases at $1.2 \% /$ year and electric by $0.3 \% /$ year while oil remains essentially constant. Conservation (building shell improvements and more efficient space heating and air conditioning equipment) increases to satisfy $8.1 \%$ of total residential demand by 2028 . Minor fuels (coal, propane, wood) disappear. The latter is an artifact of the model not recognizing the special niches these fuels fill; it has no significant effect on the overall result and could be fixed if one wished to examine the role of these fuels specifically. As $\mathrm{CO}_{2}$ constraints are imposed, the most striking result is that oil decreases and the disappears in the $10 \%$ reduction case. Gas increases after $\mathrm{CO}_{2}$ constraints, but then decreases in favor of electricity over time, as noncarbon based sources, primarily nuclear in this scenario, increasingly dominate electricity production. Electricity use grows at $0.8 \%$ /year in the $\mathrm{CO}_{2}$ stability case (more than double its growth rate in the reference case). In the $10 \%$ reduction case, electricity grows at the $0.8 \%$ /year rate through 2023 , but then increases dramatically in the last period resulting in an overall growth rate of $2.4 \% /$ year. This last period increase in electric is made primarily at the expense of gas. 


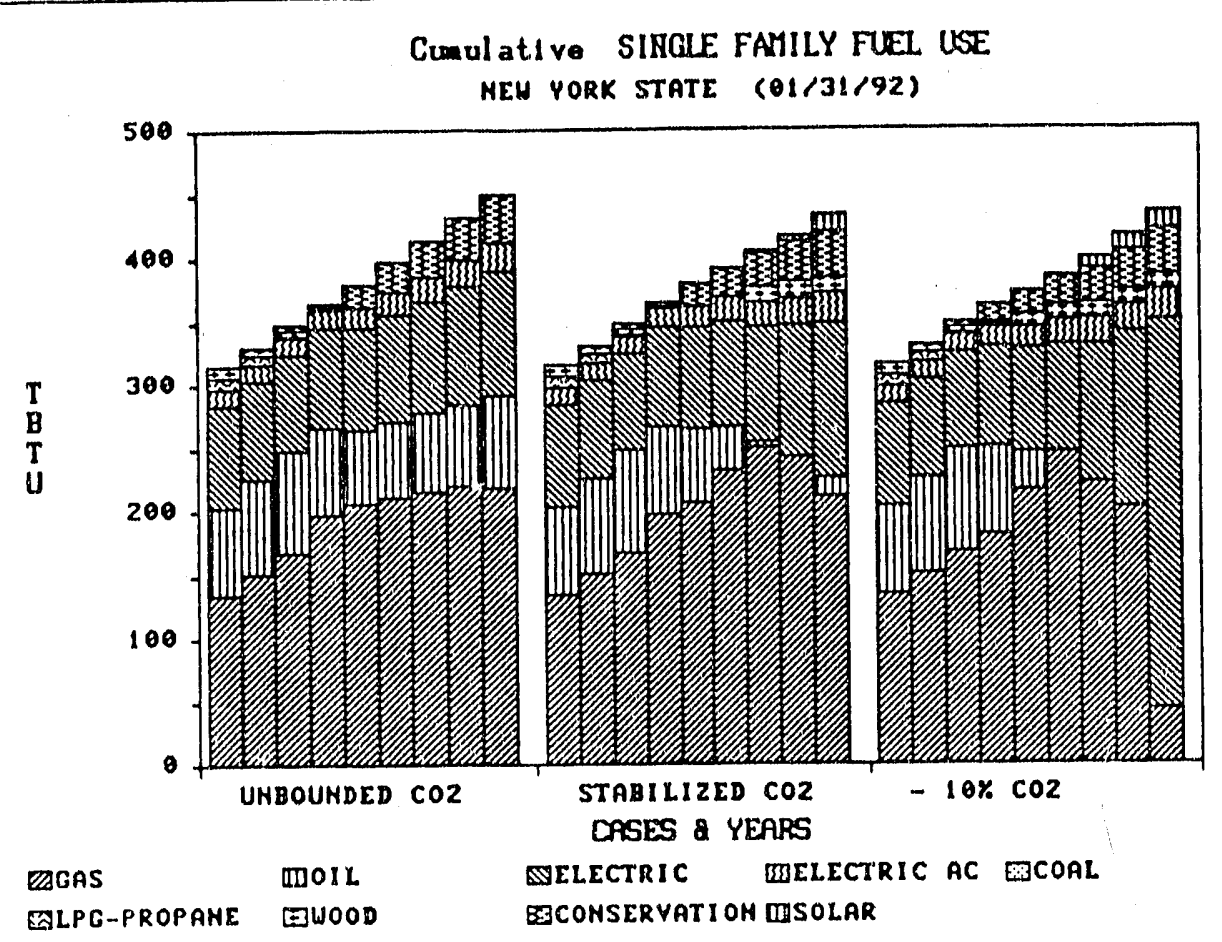

Figure 9. Useful energy supplied by energy source, single family residential, Conventional Technology Scenario.

Looking at the more detailed energy demand categories within single family residential, space heat is dominated by natural gas in the reference case. $\mathrm{As} \mathrm{CO}_{2}$ constraints are imposed, electric heat increases and, in the $10 \% \mathrm{CO}_{2}$ reduction case, essentially replaces gas (Figure 10). There is a significant difference among cases in the way gas and electric are used for space heating, however. Advanced gas burners did not enter the reference case. They enter after 2013 in the $\mathrm{CO}_{2}$ stability case and after 2003 in the $10 \%$ reduction case. Gas heat pumps enter the $\mathrm{CO}_{2}$ stability case in 2023 , but in the $10 \%$ reduction case, as gas declines slowly as a space heating fuel and is replaced by electric heat. In the last two periods this process increases and electric heat pumps take over completely; gas heat pumps do not enter. Looking at electric heat, in the reference case existing electric heat declines, disappearing in 2008. This probably ignores some niches where electric heat is best. As $\mathrm{CO}_{2}$ constraints are imposed, the more efficient electric devices (heat pumps and advanced heat pumps) begin to enter the system again. In the $10 \% \mathrm{CO}_{2}$ reduction case, however, there is a massive shift in the last period, with electric resistance heating taking over from gas. This results from the system trying to meet the growing energy demand without increasing $\mathrm{CO}_{2}$ emissions. As shown below, MARKAL does this by shifting gas from the residential sector to the industrial sector where there are more limited opportunities to use electric. The size of the shift is clearly too big to occur in a single 5-year period in the real world, but it shows the extent to which the system must struggle to meet the $\mathrm{CO}_{2}$ constraint. With $\mathrm{CO}_{2}$ constraints, solar and wood appear as growth fuels, serving $4.3 \%$ and $6.0 \%$ of single family space heating demands in 2028 in the stability and $10 \% \mathrm{CO}_{2}$ reduction cases. 


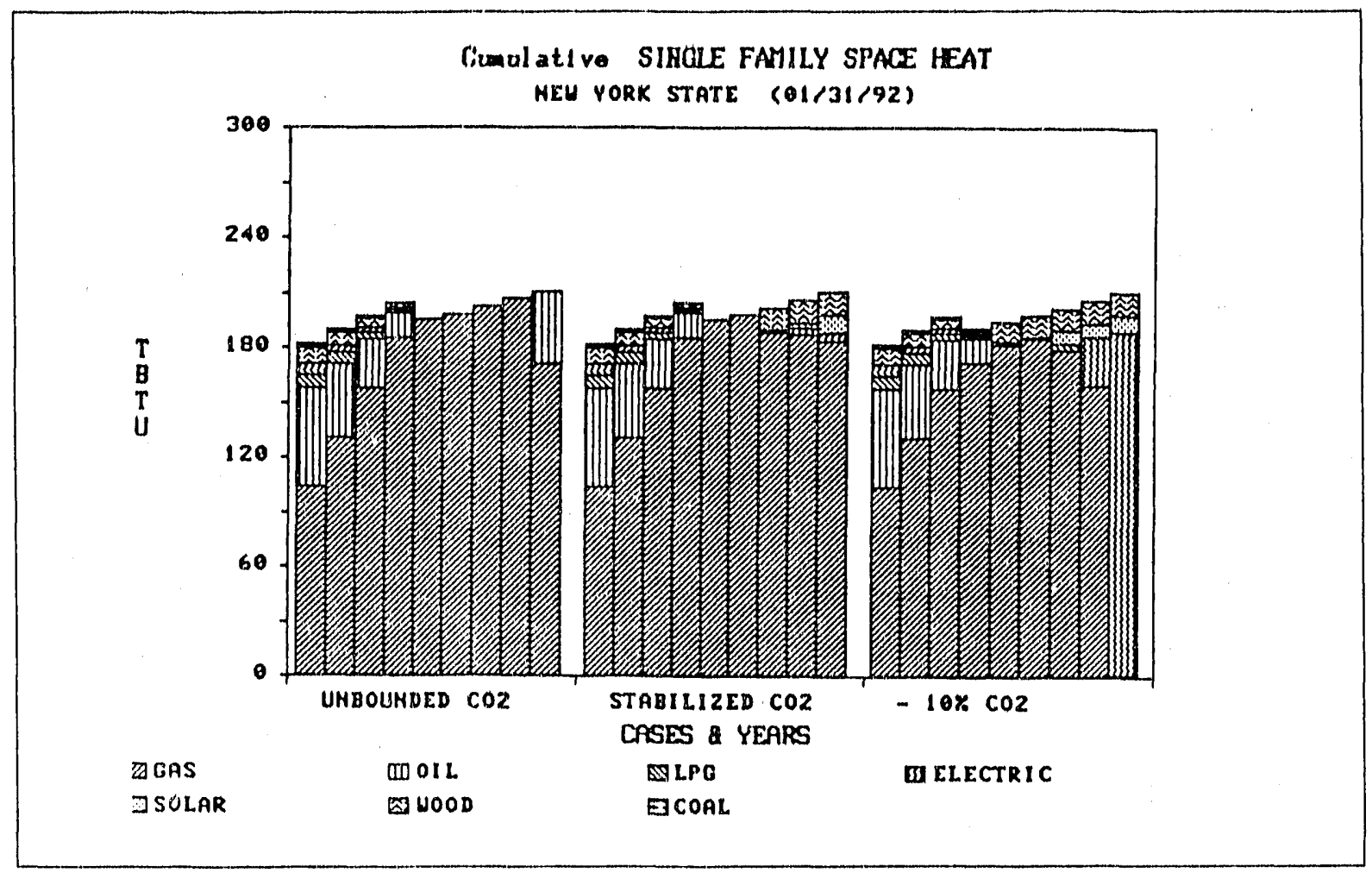

Figure 10. Space heating fuels, single family residential in Conventional Technology Scenario.

Although oil space heat essentially disappears by 2008 , oil water heat increases its market share in the reference case until it is replaced by gas in the last period and only gradually disappears in the $\mathrm{CO}_{2}$ constrained cases. Water and space heating are not linked in the model and this anomalous result makes it clear that they should be. Average efficiency of single family air conditioning increases for 20 years, levels off, then increases dramatically in the last per od as the system switches to higher efficiency air conditioners. As with the gas-electric shift in heating, this last period shift is too abrupt to be realistic, but shows the direction the system is under pressure to move. Over the entire study period, air conditioner efficiency increased at a rate of $0.7 \% /$ year, reflecting a shift to higher efficiency air conditioning inits. Gas takes over $100 \%$ of the market for cooking in 2003 and thereafter in the reference case. This shift reflects only economics and not other consumer preferences. Perhaps more important, the model does not at this point include the cost of extending the gas distribution system to serve this larger share of the market. This result should thus be interpreted as a reflection of the greater value of gas to achieving the objective function; a more complete accounting of all costs would undoubtedly decrease the tendency for gas to gain such a large market share. After $\mathrm{CO}_{2}$ constraints are imposed, however, electric cooking increases in use and eventually drives out gas cooking stoves. Lighting and miscellaneous appliances also shift nearly 100\% to improved types in 2003 and thereafter in both the reference and constrained cases. An alternative scenario could, of course, be constructed to reflect different policies or preferences for cooking or lighting technology. 


\section{Multi-Family Residential}

Multi-family residential shares the same general pattern as single-family (Figure11). There are some differences. Gas decreases, then increases rapidly in the reference case (overall growth rate $1.9 \%$ /year). A similar pattern is seen in the $\mathrm{CO}_{2}$ constrained cases, but gas use declines after its increase, to be replaced with electricity. As in single family homes, gas use shifts initially to more efficient burners, then (only under $\mathrm{CO}_{2}$ constraint) to gas heat pumps. Oil increases before it fades. In the reference case, oil does not disappear from the multi-family residential sector until 2028 but as $\mathrm{CO}_{2}$ constraints increase, it leaves the scene sooner. In the $10 \% \mathrm{CO}_{2}$ reduction case, oil is gone by 2013 . Although electricity grows more rapidly under $\mathrm{CO}_{2}$ constraints, it never takes on as large a share as in single family homes. Electricity has a $1 \% /$ year growth in the reference case and a $2 \% /$ year growth in the $10 \%$ reduction case, in which it fills $55 . \%$ of the multi-family energy demand. Energy conservation never achieves as large a share (maximum $1.6 \%$ of total multi-family energy demand). Solar does not enter the reference case. It grows to $4.0 \%$ of demand in the stability case but only $2.6 \%$ in the $10 \%$ reduction case where it is partially displaced by electricity.

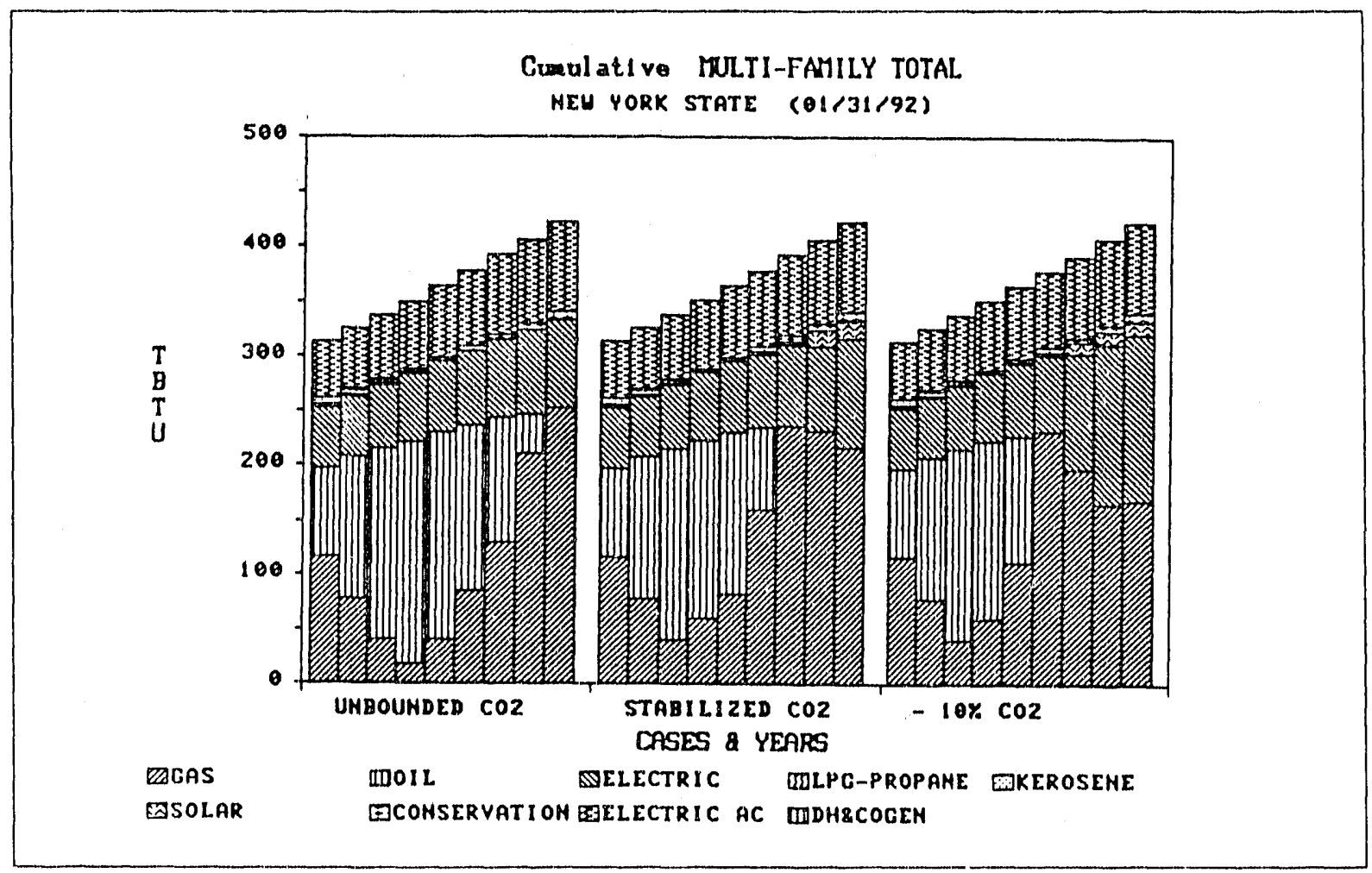

Figure 11. Useful energy supplied by energy source, multi-family residential in Conventional Technology Scenario

In the reference case, similar to the pattern in single family homes, gas water heating decreases, disappears, then reappears at the end of the study period. Its reappearance is earlier and stronger in the $\mathrm{CO}_{2}$ stability case then in the reference case, but in the $10 \%$ reduction case gas water heat again exits the system in the last two periods, to be replaced primarily with electric and, to a much lesser extent, solar water heating. Solar heat eventually fills about $6 \%$ of the multi-family hot water demand. Oil water heat, 
conversely, increases until 2018, then decreases and disappears in the last period in the reference case. Under $\mathrm{CO}_{2}$ constraint it disappears earlier. Electric water heat disappears rapidly.

As in single family homes, air conditioning technology mix is similar in all cases. Efficiency in air conditioning technology increases for 20 years, then levels off, then increases in the last period for an overall growth rate of $0.9 \% /$ year.

Cooking in multi-family housing is dominated by electricity in both the reference and $\mathrm{CO}_{2}$ constrained cases. Moreover, unlike single family, there is no shift to more efficient lighting and appliances in multi-family housing. This finding needs a more detailed analysis.

\section{Commercial}

Energy demand categories in the commercial sector include space heat, water heat, air conditioning and ventilation, and lighting and miscellaneous appliances. Technologies and fuels to supply energy service demands in these categories are estimated for three building types independently (office, service, and miscellaneous buildings) but results are combined here for the entire cummercial sector.

Figure 12 shows the pattern of how commercial space heating is met by fuel. Conservation increases steadily at $4.6 \% /$ year in all cases. In the referencc case, heavy oil becomes the dominant fuel over time. Other fuels are eliminated from the picture completely after 2008. Parts of the commercial sector may not be suitable for such a shift. This is a potential place for improvement in future updates of the model. $\mathrm{As} \mathrm{CO}_{2}$ constraints are imposed, heavy oil fuels decrease to be replaced primarily by gas and secondarily by electric. This shift takes place after 2008 , with a tendency for the latter fuels to decline and then increase after 2008 when constraints are imposed. The shift to gas rather than electric is the opposite of what happens at the same time in single family residential.

For commercial water heating, conservation enters at a rate of $3.9 \% /$ year in all cases. Natural gas becomes the predominant fuel in the reference case (Figure 13). This decoupling of space and water heating fuels is similar to the result in single-family residential and should be corrected in later versions. Under $\mathrm{CO}_{2}$ constraint, gas continues to be important, but electric water heating gradually dominates.

Electricity dominates commercial air conditioning and ventilation in all cases (Figure 14), growing at $1.3 \%$ /year in the reference and stability cases and slightly higher in the $10 \%$ reduction case. Conservation enters at $4.3 \% /$ year in all cases. Gas air conditioning grows at $1.7 \%$ year in the reference case and the stability case, but declines in the last three periods in the $10 \%$ reduction case.

Commercial lighting and miscellaneous changes little among cases. Electric dominants the demand category; gas supplies about $10 \%$ of total energy service demand. The $10 \% \mathrm{CO}_{2}$ reduction case shows a slightly higher electrical growth and a correspondingly lower gas growth. Conservation grows through 2008 in all cases, then declines. The system does not invest in improved lighting systems in the commercial 
sector, although after $\mathrm{CO}_{2}$ constraints come in, reduced costs are low, indicating the decision was close. Even moreso than in multifamily housing, this finding is counter intuitive, seemingly in opposition to other evidence of the cost-effectiveness of more efficient lighting. A more detailed analysis is necessary.

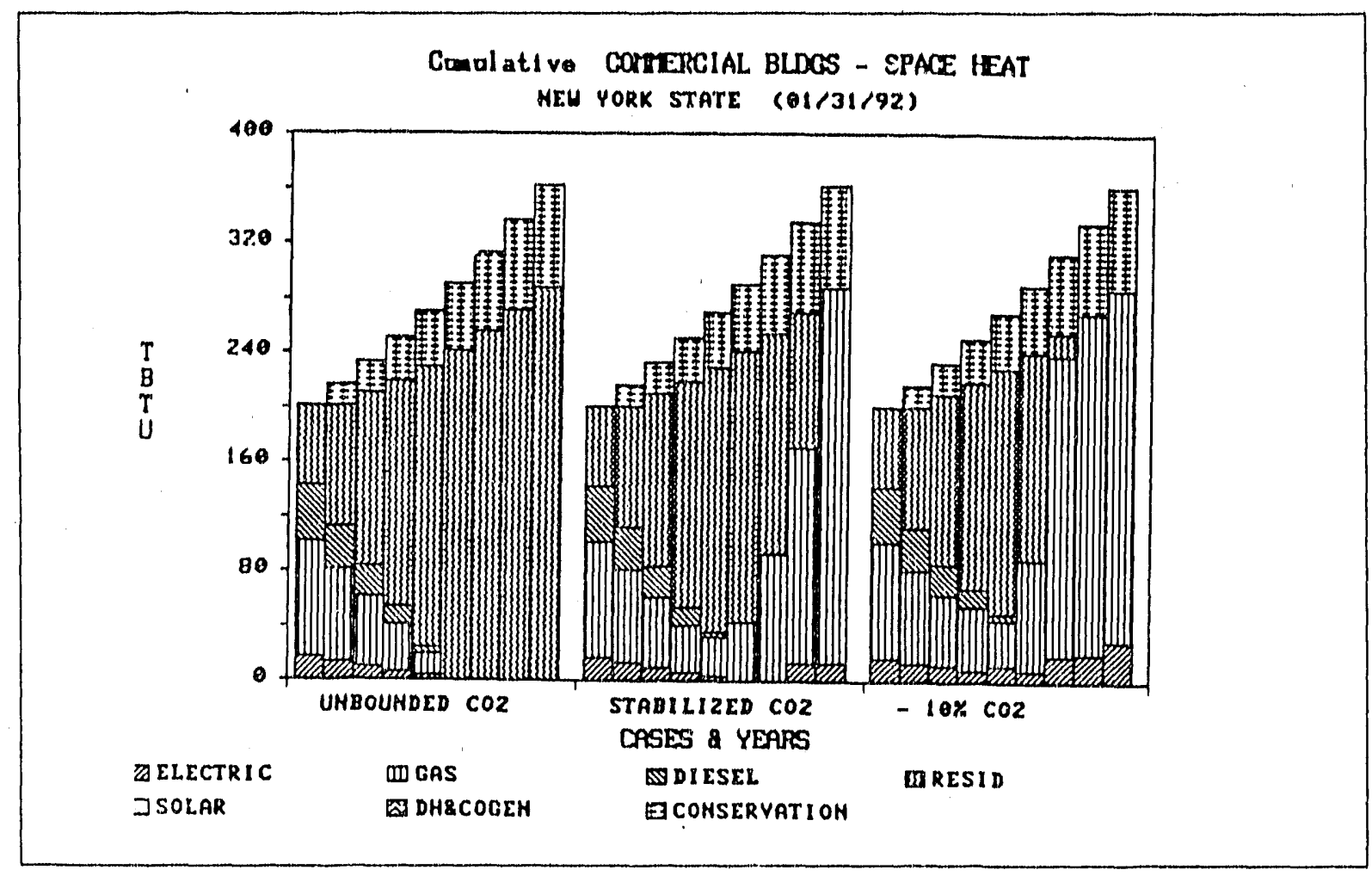

Figure 12. Space heating fuels, commercial buildings in Conventional Technology Scenario. 


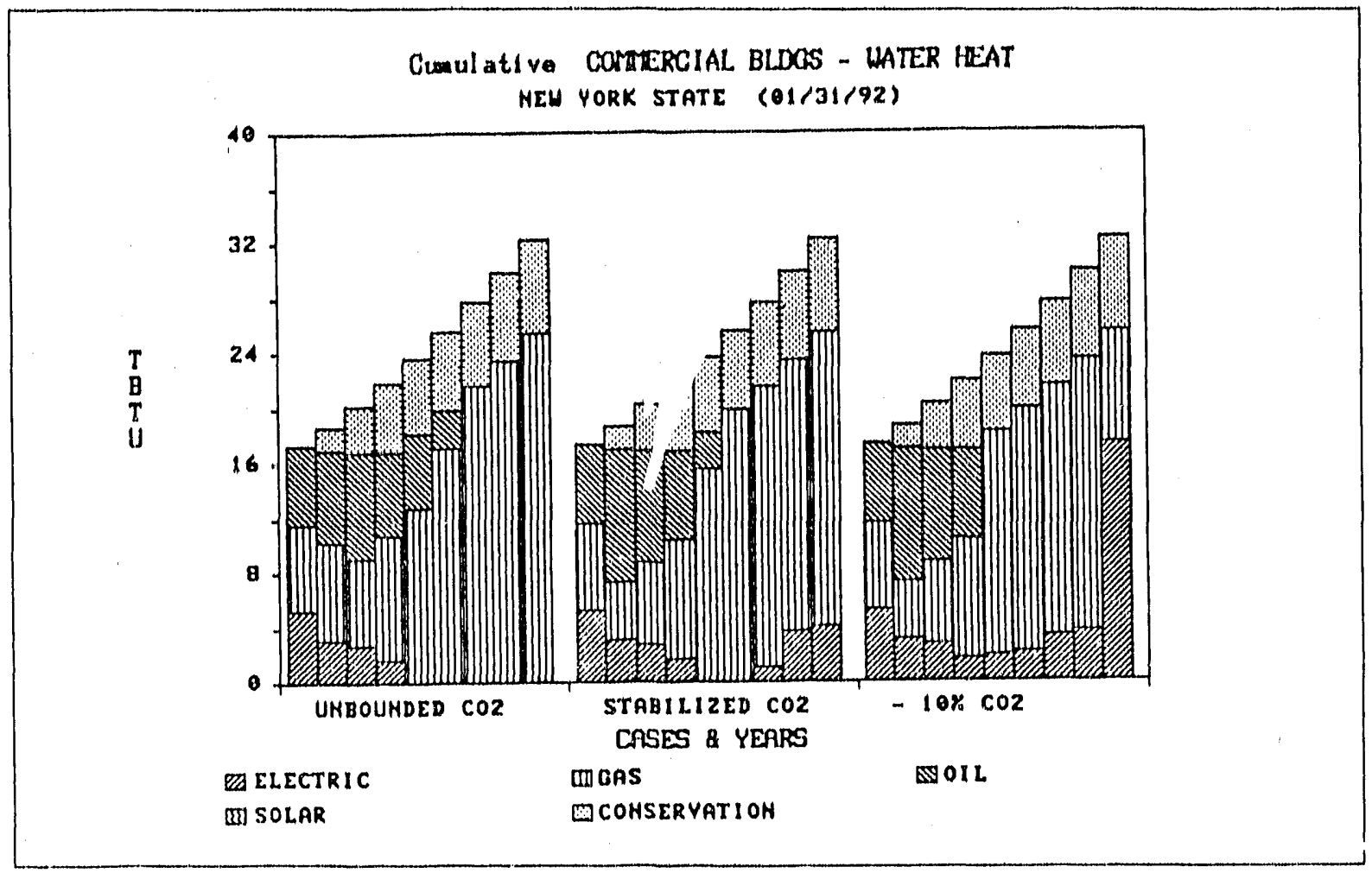

Figure 13. Water heating fuels, commercial buildings in Conventional Technology Scenario.

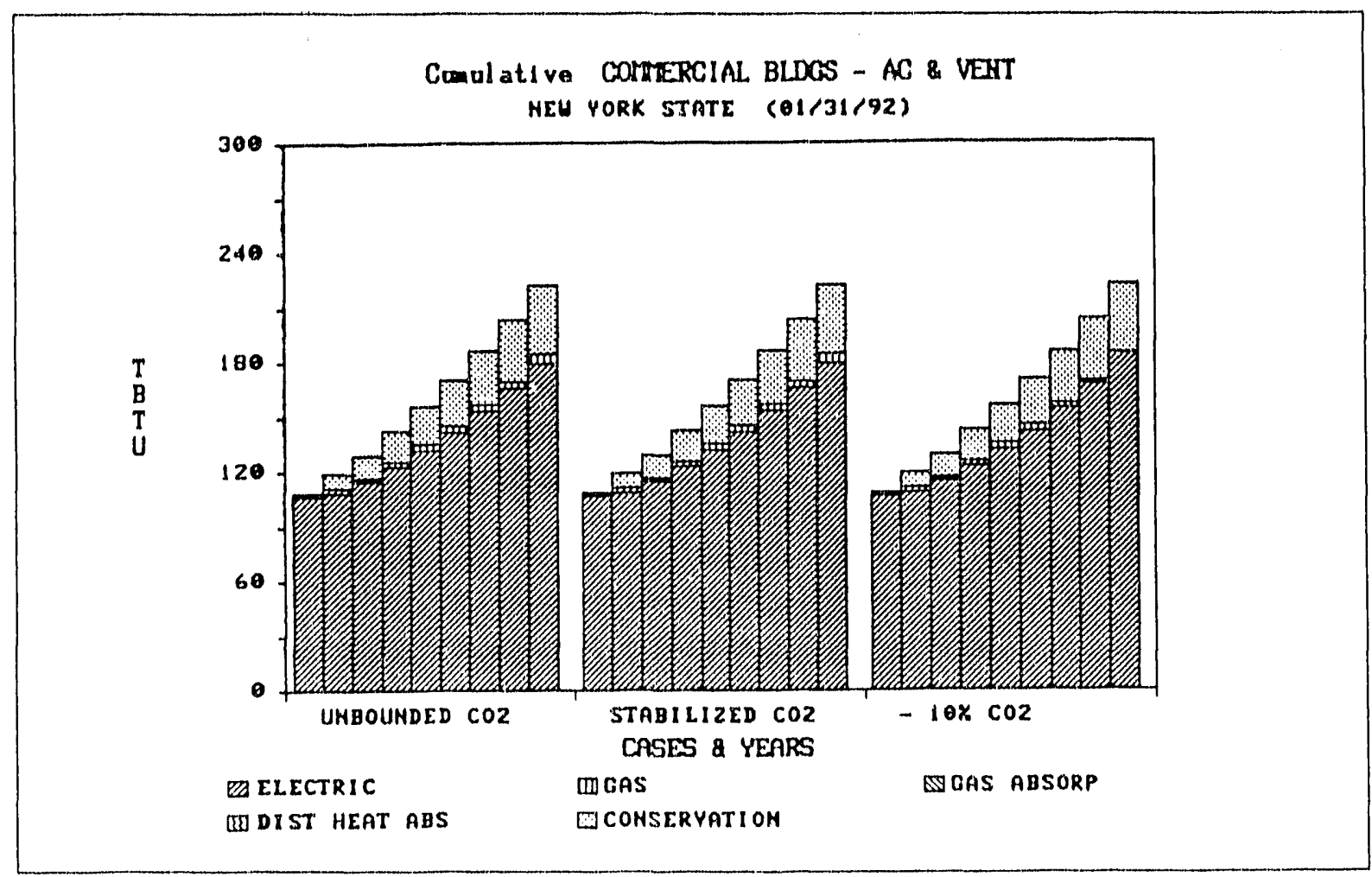

Figure 14. Air conditioning and ventilation use by fuel, commercial buildings in Conventional Technology Scenario. 


\section{Industrial}

The industrial energy mix is shown in Figure 15. Industrial use of electricity more than doubles between 1988 and 2028 in all cases (average $2.2 \%$ year growth rate). Oil increases at $4.4 \%$ year through 2008 in all cases. It continues to go up in the reference case, although not steadily, averaging $3 \%$ year for the total study period. In the $\mathrm{CO}_{2}$ stability case, it goes up faster, although leveling off in the last period, averaging $4.1 \%$ year growth. This increase offsets the decrease in coal use. In the $10 \%$ reduction case, however, oil has too high a carbon content to be used to offset coal and, although it fluctuates, it finally declines (Figure 16). Coal use remains constant in the reference case until the last period, when there is a jump associated with introduction of improved coal burners that partly replace oil. Coal use drops rapidly after 2013 in the $\mathrm{CO}_{2}$ stability case, and after 2003 in the $10 \%$ reduction case (Figure 17). Natural gas declines to zero in 2018 in the reference case. In the $\mathrm{CO}_{2}$ constrained cases it grows again after 2018, capturing $46 \%$ of the industrial demand in 2028 in the $10 \%$ reduction case (Figure 18), Renewables enter only in the last period in the reference case, begin in 2018 in the stability case and in 2008 in the $10 \%$ reduction case. In the latter, their use increases at $6.5 \%$ year over those last 20 years, ultimately capturing $4.8 \%$ of the market in 2028 (Ficure 19).

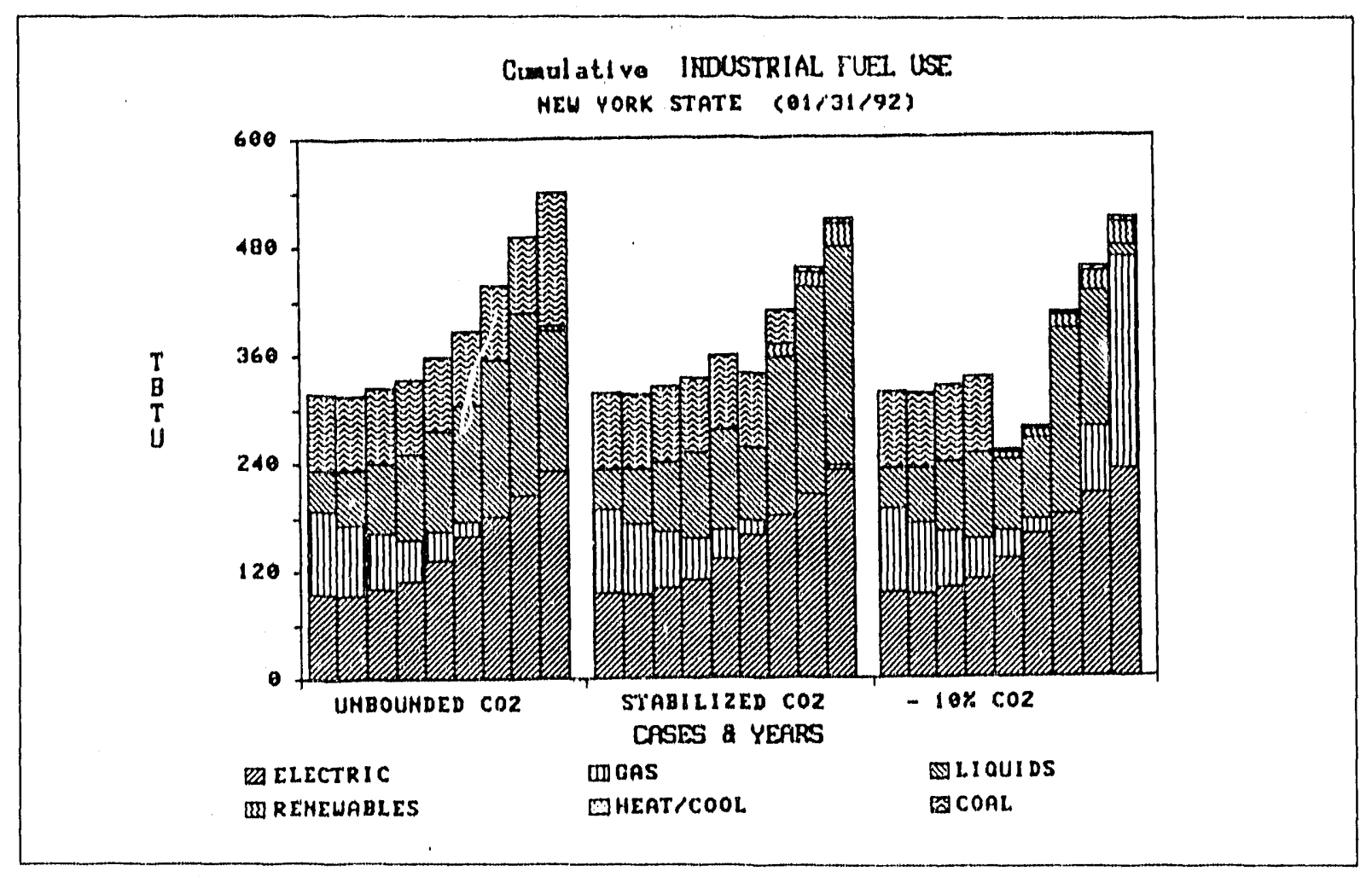

Figure 15. Industial energy mix in Conventional Technology Scenario. 


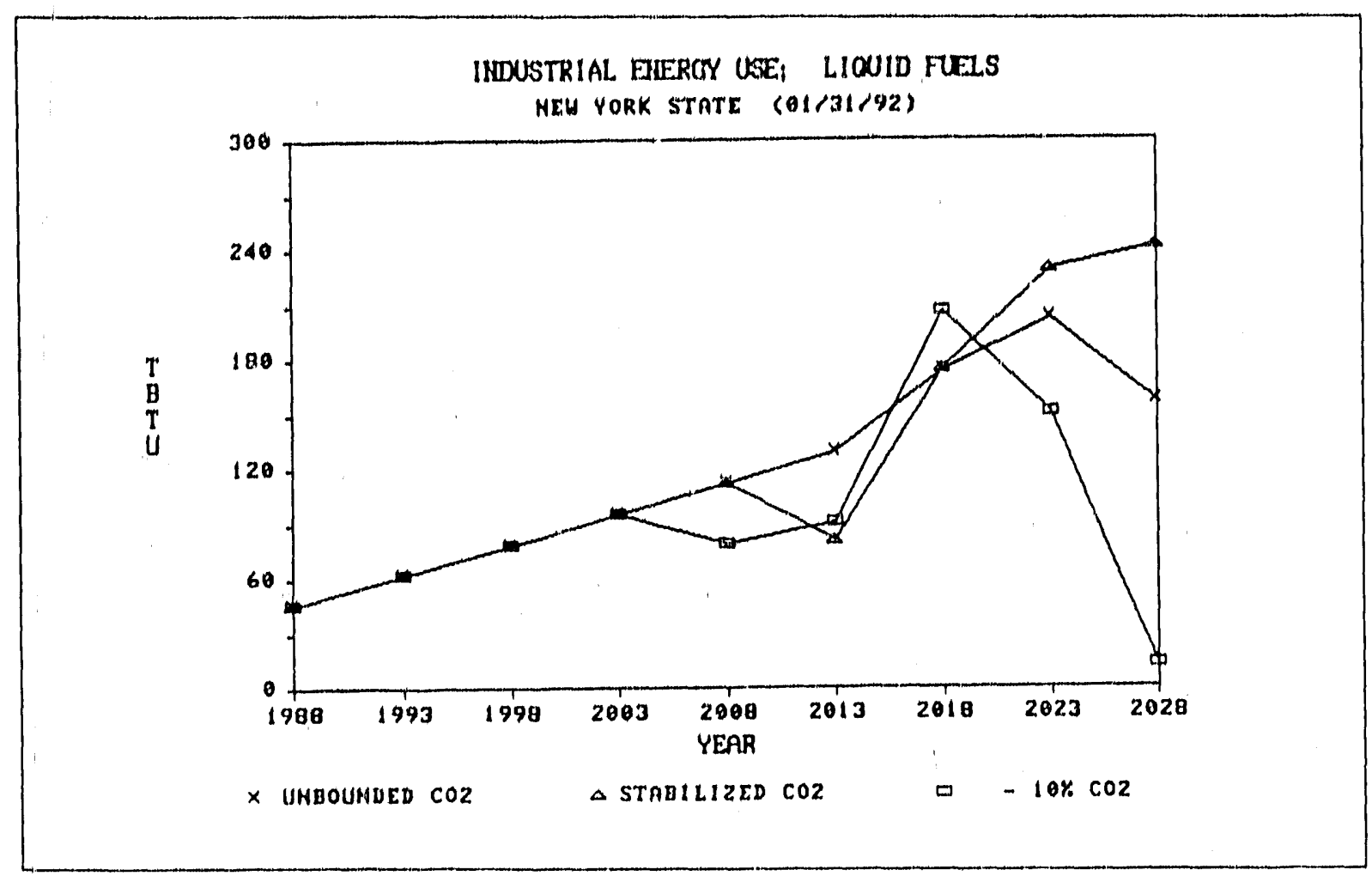

Figure 16. Industrial oil use in Conventional Technology Scenario.

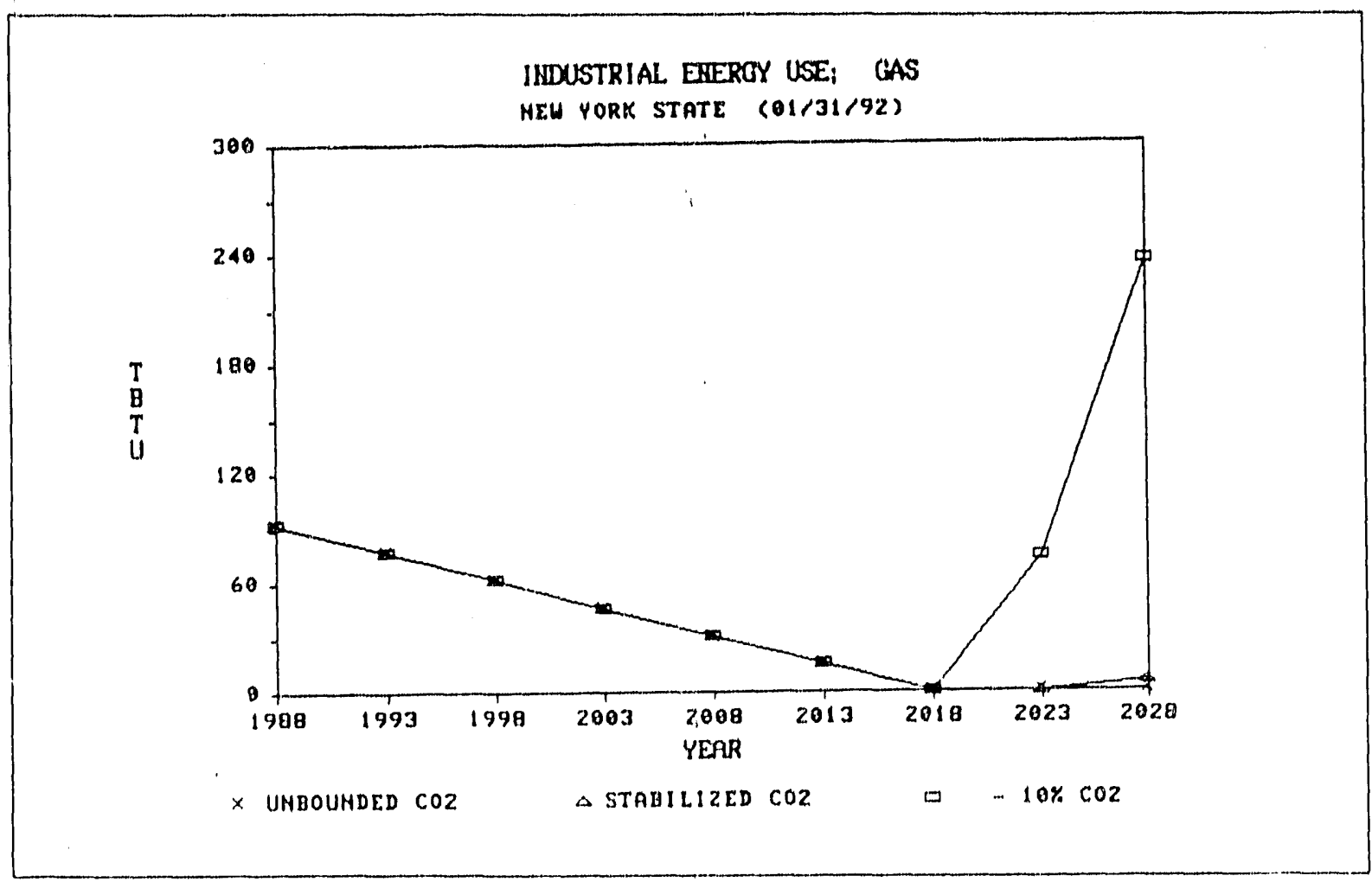

Figure 17. Industrial coal and coke use in Conventional Technology Scenario. 


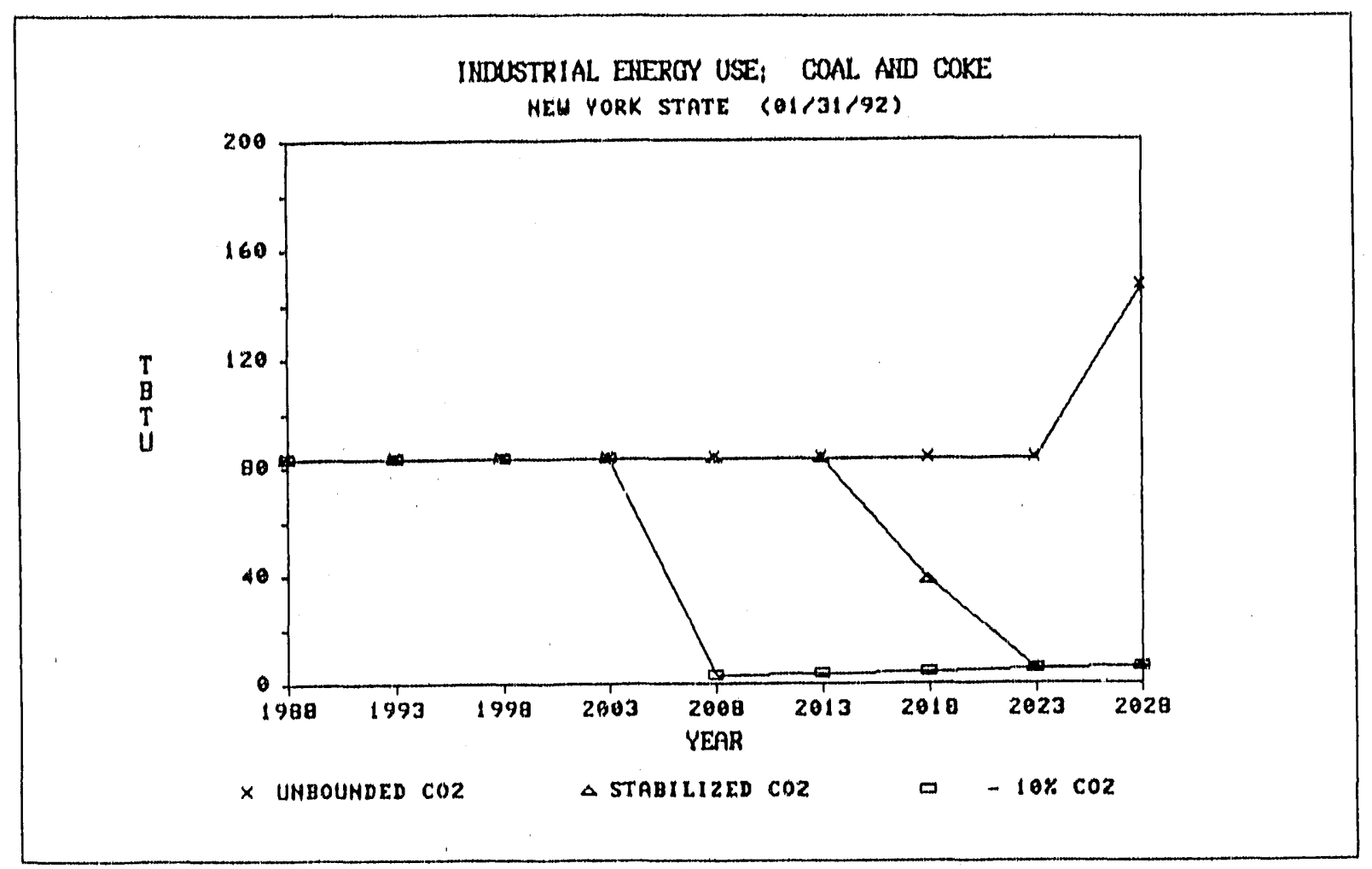

Figure 18, Industrial gas use in Conventional Technology Scenario.

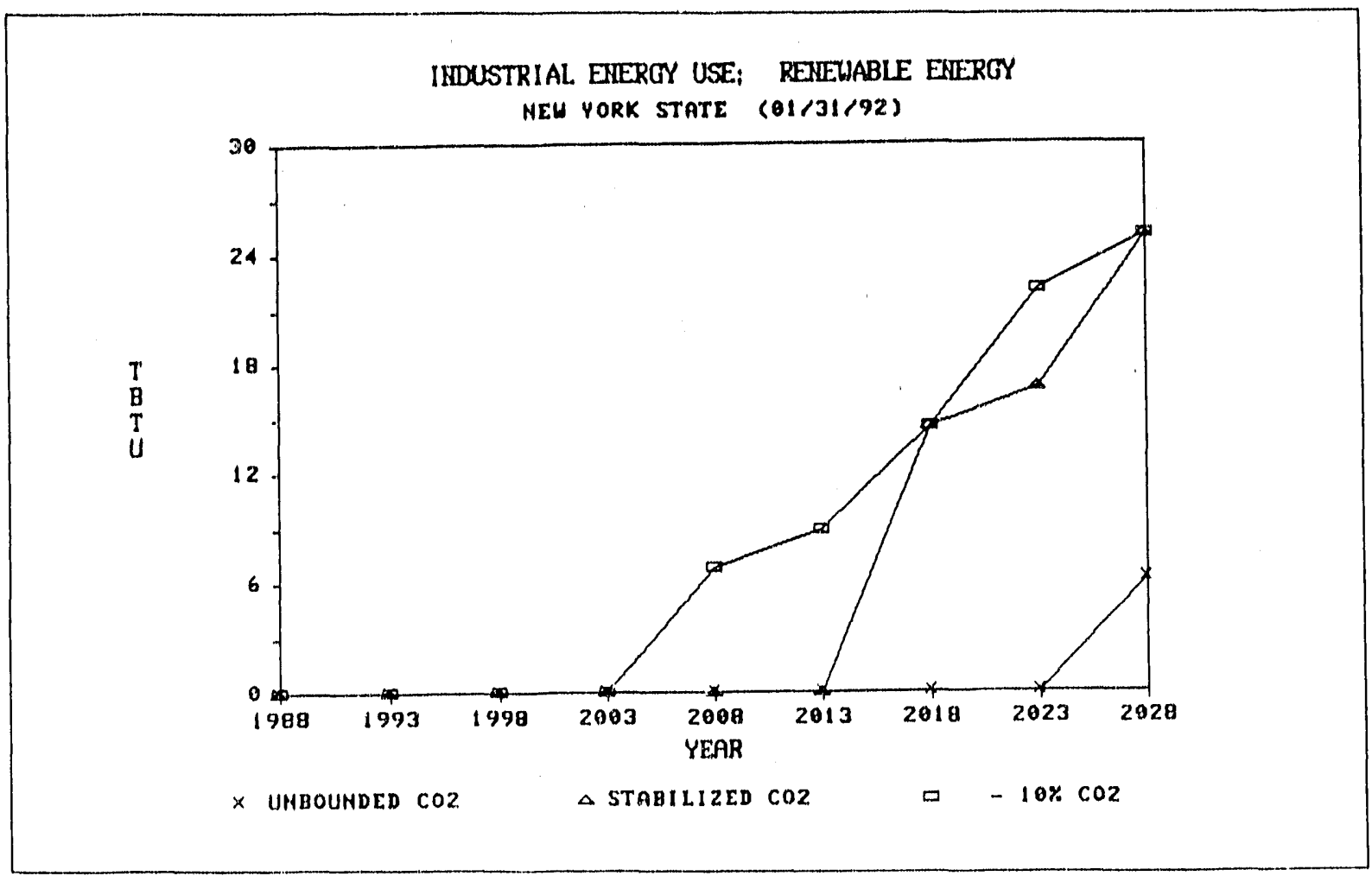

Figure 19. Industrial use of renewable energy sources in Conventional Technology Scenario. 


\section{Transportation}

The transportation sector continues to be dominated by petroleum products. While other fuels increase over time in all cases, they contribute less than $5 \%$ in 2028.

Autornobiles. Gasoline continues to be the dominant fuel. Diesels contribute less than $10 \%$, and less than that in the $10 \%$ reduction case. Electric cars grow steadily in all cases at $8.6 \%$ /year, approaching $10 \%$ of the market in 2028 . Compressed natural gas cars also grow steadily at $6.6 \%$ year in all cases, but reach a market share of under $4 \%$ in 2028 . Methanol cars begin to enter the market in 2008, but in no case gain a significant market share. Hydrogen cars do not enter the market. Going behind the fuel categories, there is a clear shift to greater efficiency. The automobile sector overall exhibits a $1.3 \% /$ year increase in efficiency in the $10 \% \mathrm{CO}_{2}$ reduction case. Figures 20 and 21 illustrate this in the shift in gasoline fueled cars. In the reference case, the existing fleet is replaced by $10 \%$ more efficient cars, which are in turn replaced by $20 \%$ efficient cars. In the $10 \% \mathrm{CO}_{2}$ reduction case, the turnover is faster and after 2018 the $20 \%$ more efficient cars are replaced by $40 \%$ more efficient cars.

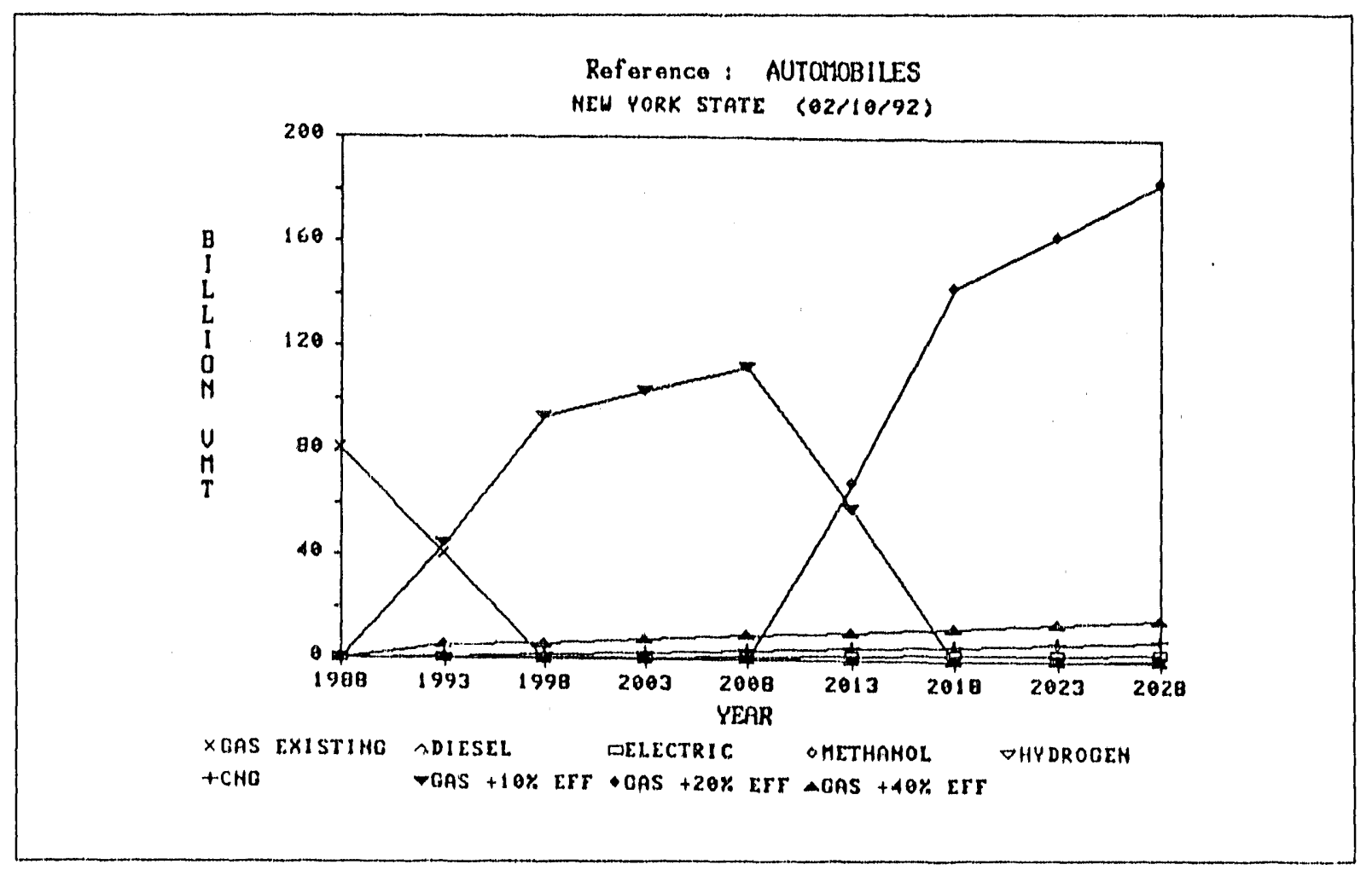

Figure 20. Market shift to more efficient gasoline-fueled cars for reference case. Use of other cars is also show. 


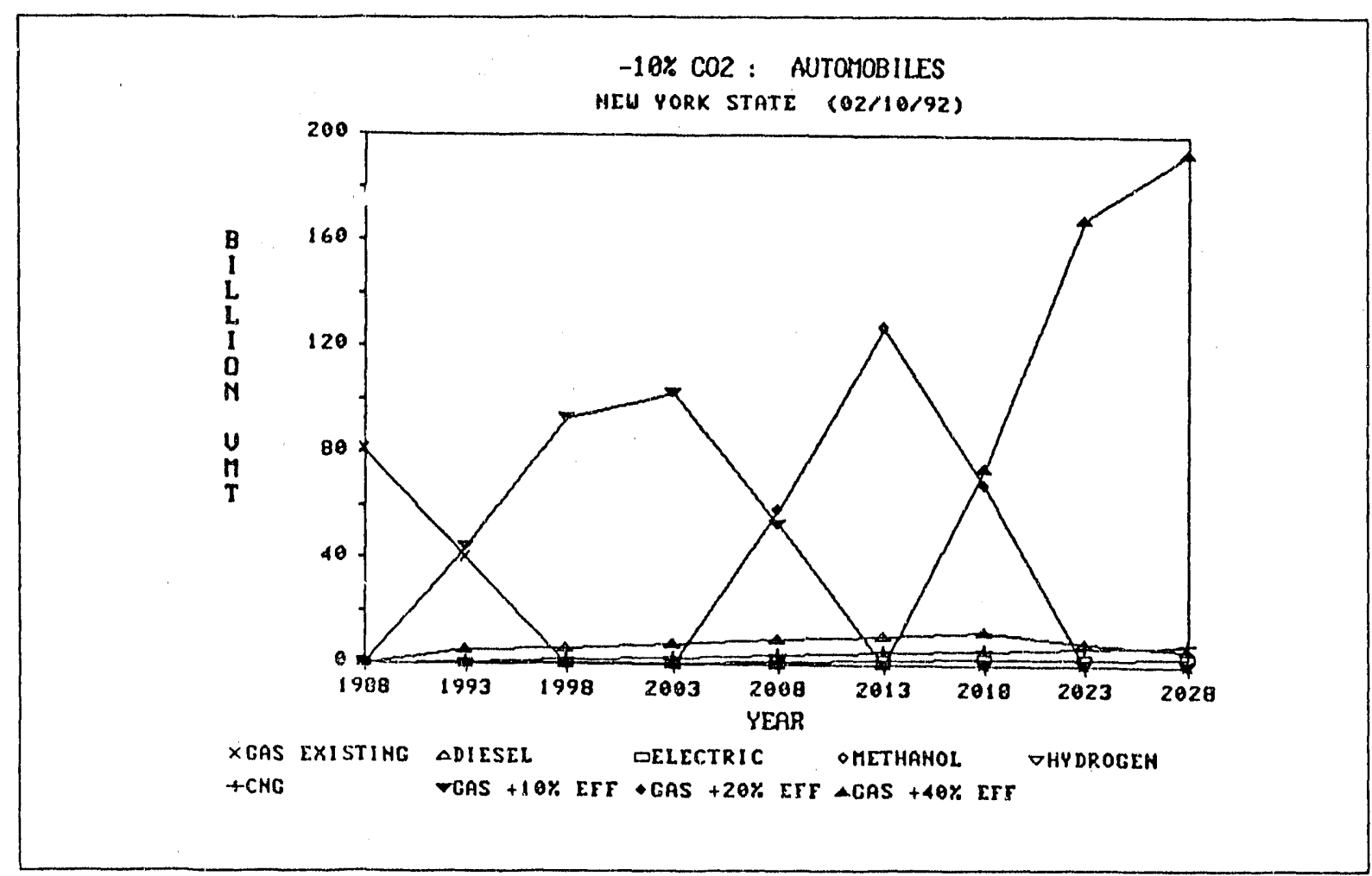

Figure 21. Market shift to more efficient gasoline-fueled cars for $10 \% \mathrm{CO}_{2}$ reduction case, Conventional Technology Scenario. Use of other cars is also shown.

Trucks. Gasoline also continues to dominate the light truck market. Diesel fuel disappears as the existing fleet completes its useful life. Compressed natural gas comes in slowly in all cases and only achieves about 3\% market share by 2028 . There is a shift to more efficient trucks in all cases, occurring earlier when $\mathrm{CO}_{2}$ constraints are imposed (Figures 22 and 23). Diesel remains the only fuel for heavy trucks. There is a shift to a higher efficiency truck in the reference case, but only under $\mathrm{CO}_{2}$ constraint is there a further shift to an even higher efficiency model (Figures 24 and 25). 


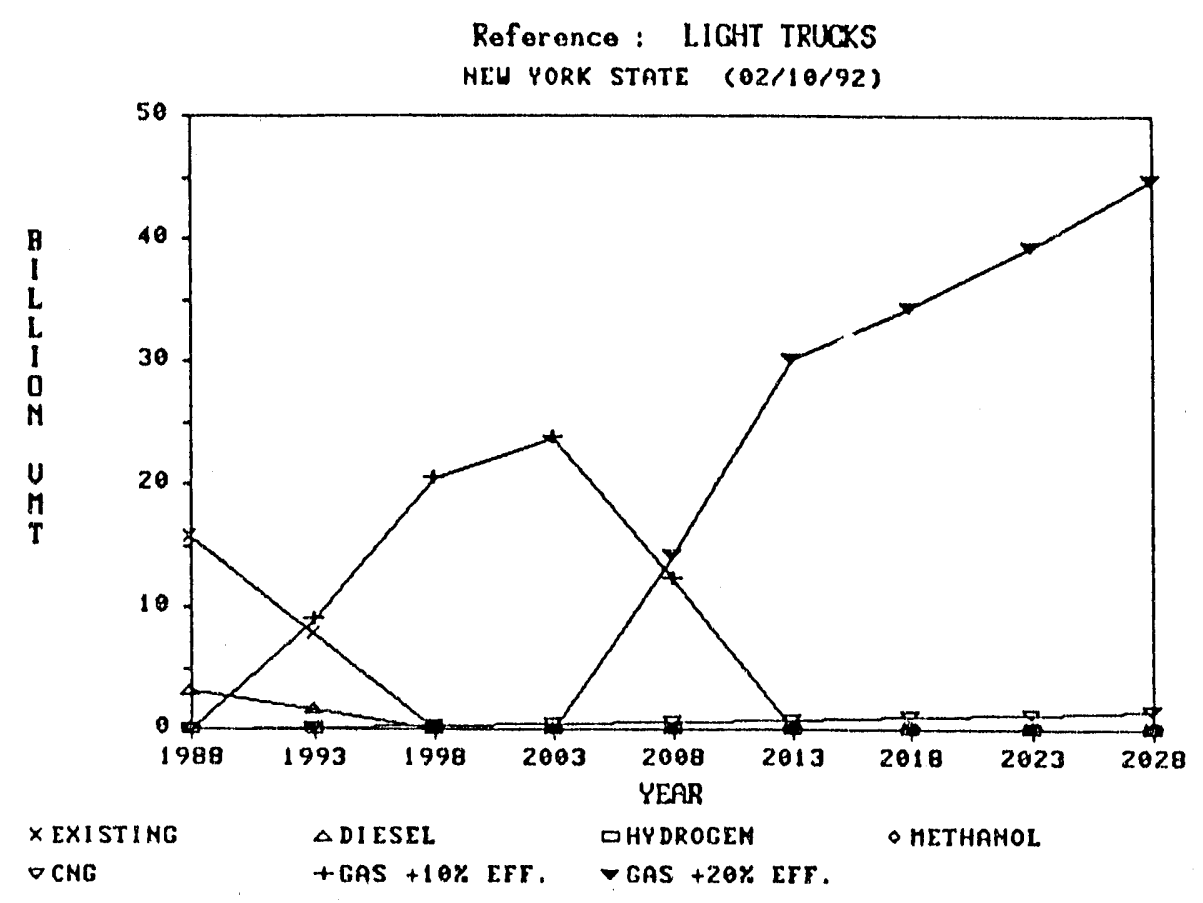

Figure 22. Light trucks, showing shift to more efficient gasoline powered types in reference case.

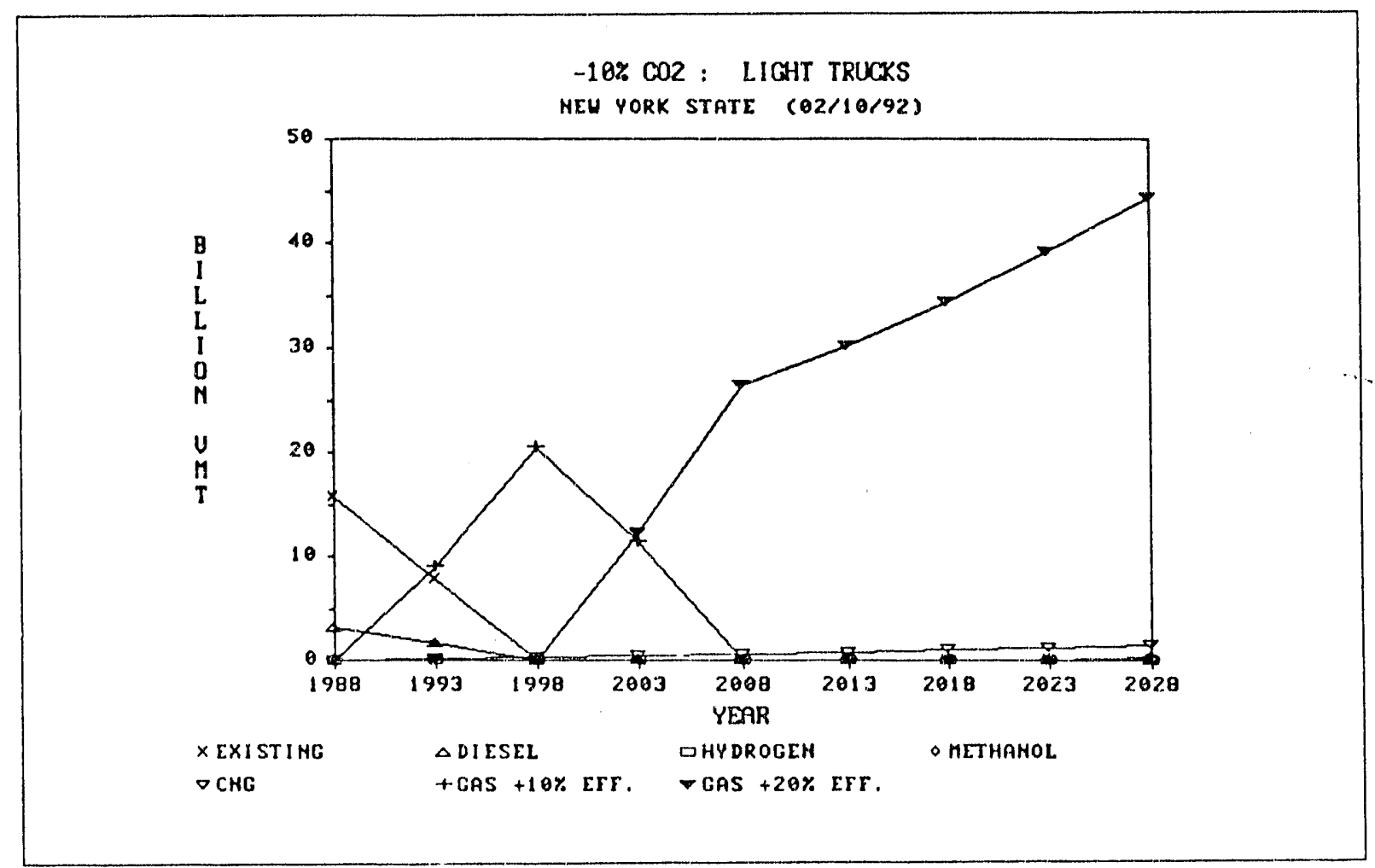

Figure 23. Light trucks, showing faster shift to more efficient gasoline powered typed in $10 \% \mathrm{CO}_{2}$ reduction case, Conventional Technology Scenario. 


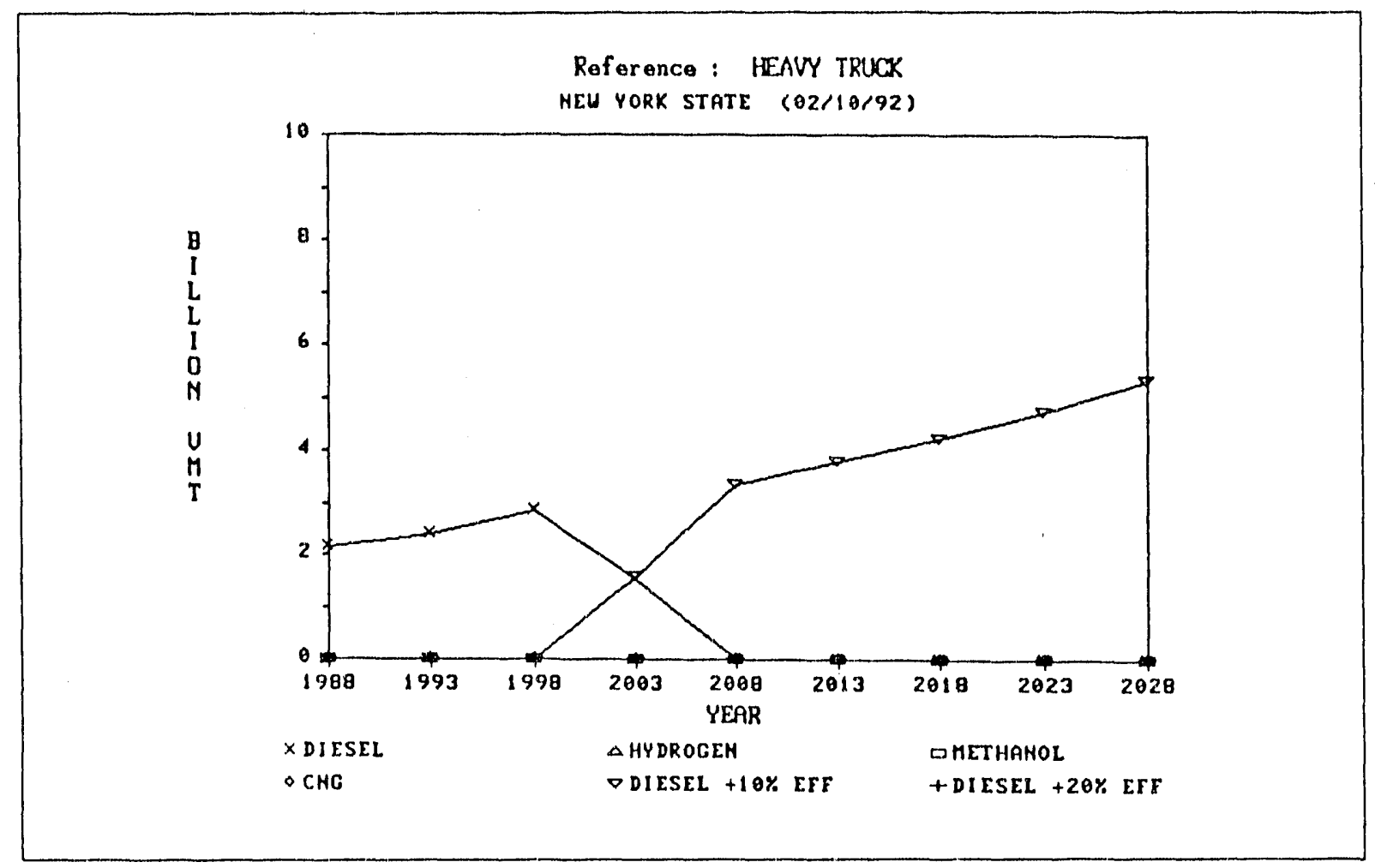

Figure 24. Heavy trucks. Reference case.

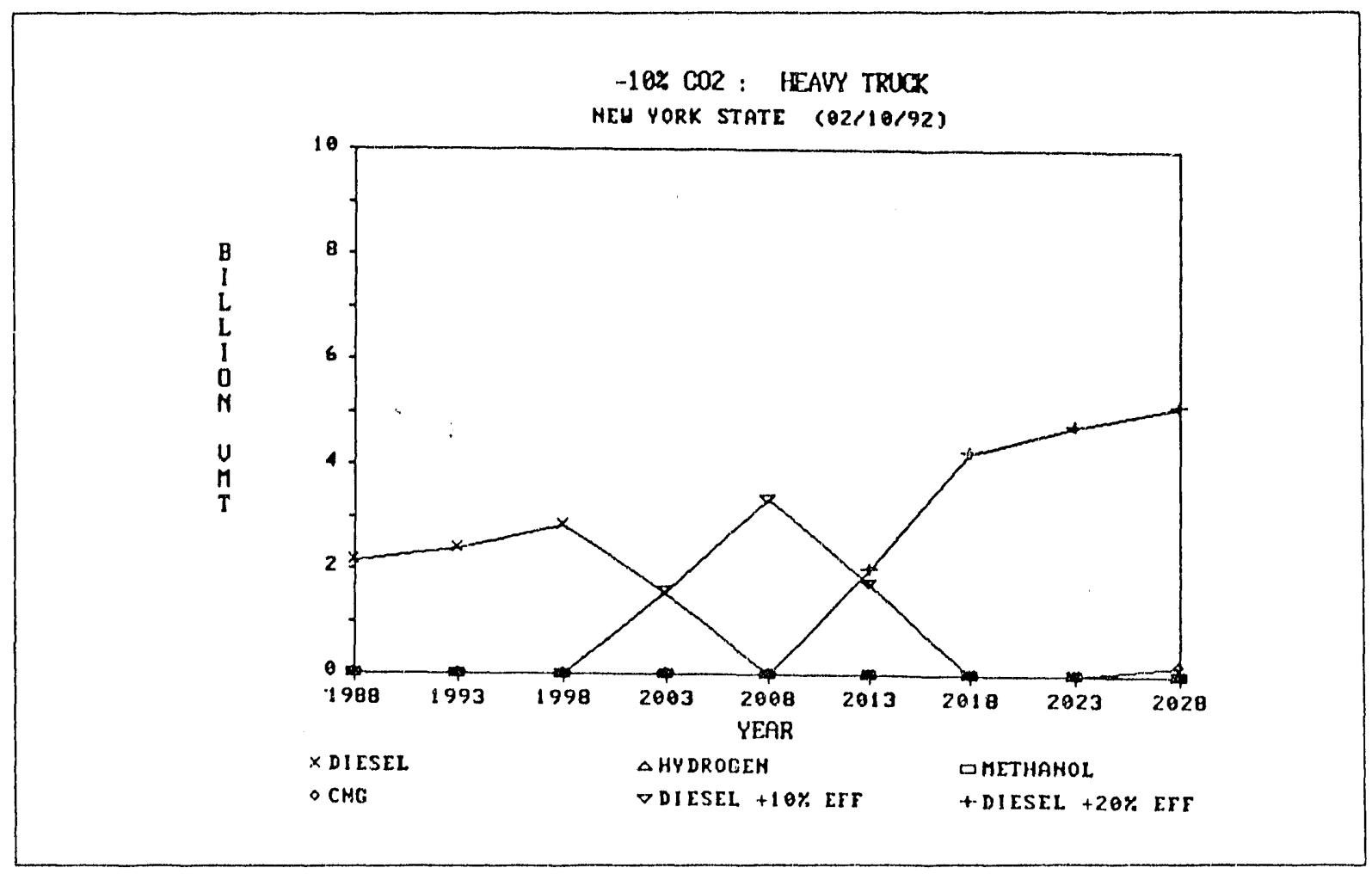

Figure 25. Heavy trucks. $10 \% \mathrm{CO}_{2}$ reduction case in Conventional Technology Scenario. 
Public Transportation. Public transportation modes are not as fully developed in the model as they could be, but still indicate some trends. Buses exhibit no change among cases; there is an early shift to gasoline to diesel followed by a shift to the most efficient diesel buses available. Both suburban and intercity rail exhibit a shift toward electrification. Energy use by aircraft and vessels are not treated in sufficient detail to yield useful information on these modes.

\section{Electricity Generation}

Figure 26 summarizes the mix of electrical generation technologies in terms of electricity produced. The reference case shows coal-fired electric growing rapidly after 2008 , giving a $4.5 \% /$ year average growth rate over the full study period and moving from $23 \%$ to $71 \%$ of electrical production. The rapid growth is primarily in the introduction of new coal technologies that enter the market at a $11 \% /$ year growth rate between 2003 and 2028. The new coal technologies are coal combined cycle, atmospheric fluidized bed, and molten carbonate fuel cells integrated with coal gasification. The latter is a high efficiency decentralized technology that becomes available in 2013. Unlike other coal technologies, this technology becomes more attractive under $\mathrm{CO}_{2}$ constraint, as can be seen by the reduced costs shown in Figure 27. Coal cogeneration units are a relatively small contributor to new coal technologies. These units are only attractive in the reference case (Figure 28). Recall that, although there is some constraint on $\mathrm{SO}_{2}$ emissions, the base scenario does not consider other environmental restrictions that may work against such an increase in coal use.

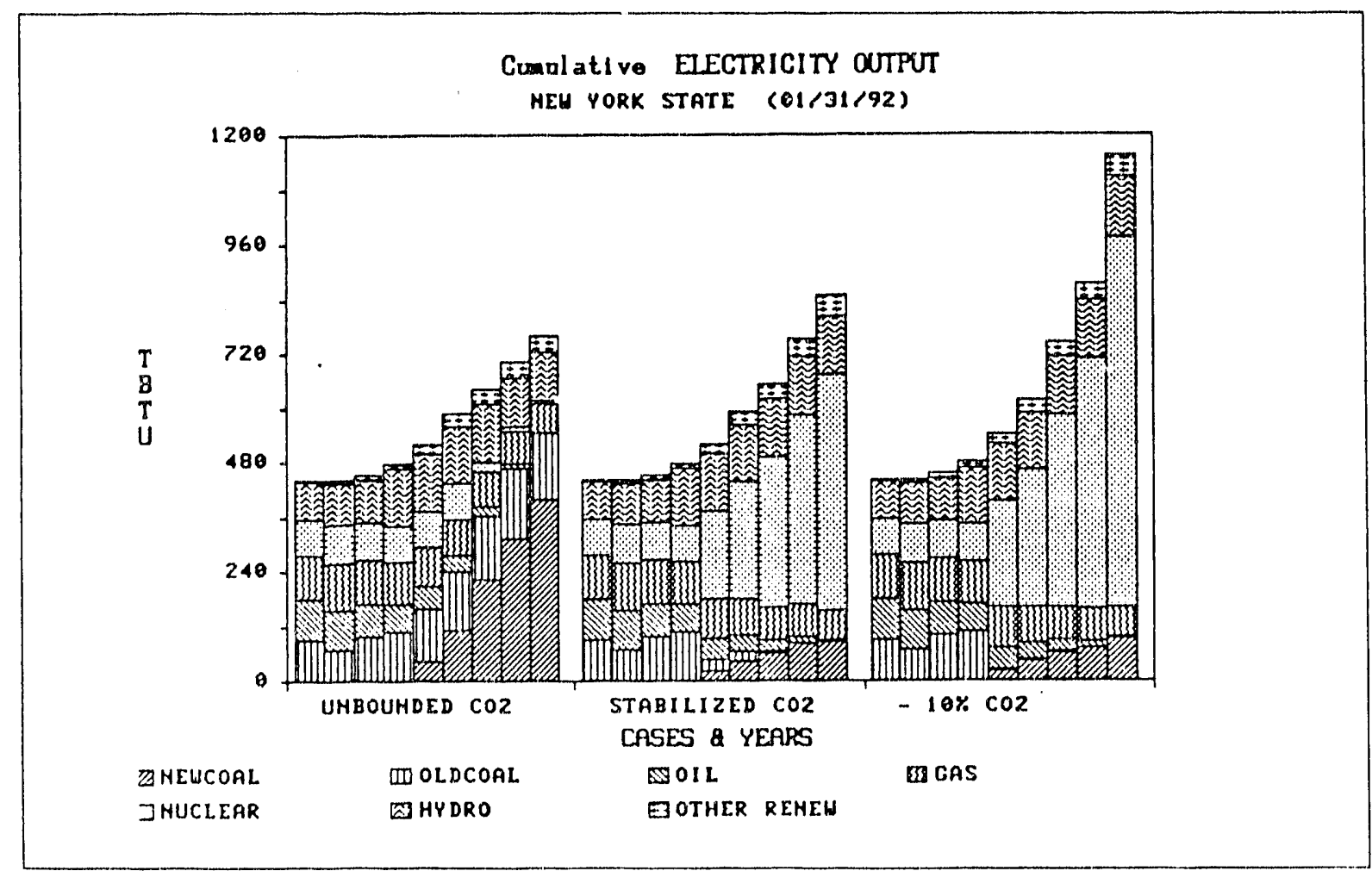

Figure 26. Electricity output by period by fuel type in Conventional Technology Scenario. 
The system builds no new nuclear power plants in the reference case; in the last period it uses only about half of the remaining nuclear capacity, leading to the virtual disappearance of nuclear. Oil and gas exhibit the same pattern in all cases. Gas declines to about $70 \%$ of its 1988 production and oil virtually disappears.

As $\mathrm{CO}_{2}$ constraints are imposed, however, conventional coal plants disappear rapidly. New coal technologies experience a much lower growth rate $(7.2 \% /$ year $)$. At the same time, growth in electrical output increases from $1.35 \% / y$ in the reference case to $1.6 \%$ year in the stability case, then to $2.4 \%$ /year in the $10 \%$ reduction case. The shortfall is made up primarily by nuclear $(5.5 \%$ /year growth rate in the $10 \%$ reduction case, producing $70 \%$ of the electrical output in 2028). The system makes full use of existing nuclear plants and invests in new advanced reactors. Domestic hydroelectric power averages $0.5 \% /$ year growth in all cases, going from 81.8 TBtu domestic production in 1988 to $102 \mathrm{TBtu} /$ year domestic production in 2028. The existing $800 \mathrm{MW}$ contract with HydroQuebec is assumed to exist in all cases and an additional $1000 \mathrm{MW}$ contract is assumed to be available after 1993 in all cases. The activity of the latter decreases in the last two periods in the reference case, but not in the $\mathrm{CO}_{2}$ constrained case (Figures 29 and $30)$. Other renewables experience a similar growth rate $(5.1 \% /$ year $)$, but ultimately produce only $4.4 \%$ of electrical output in 2028 .

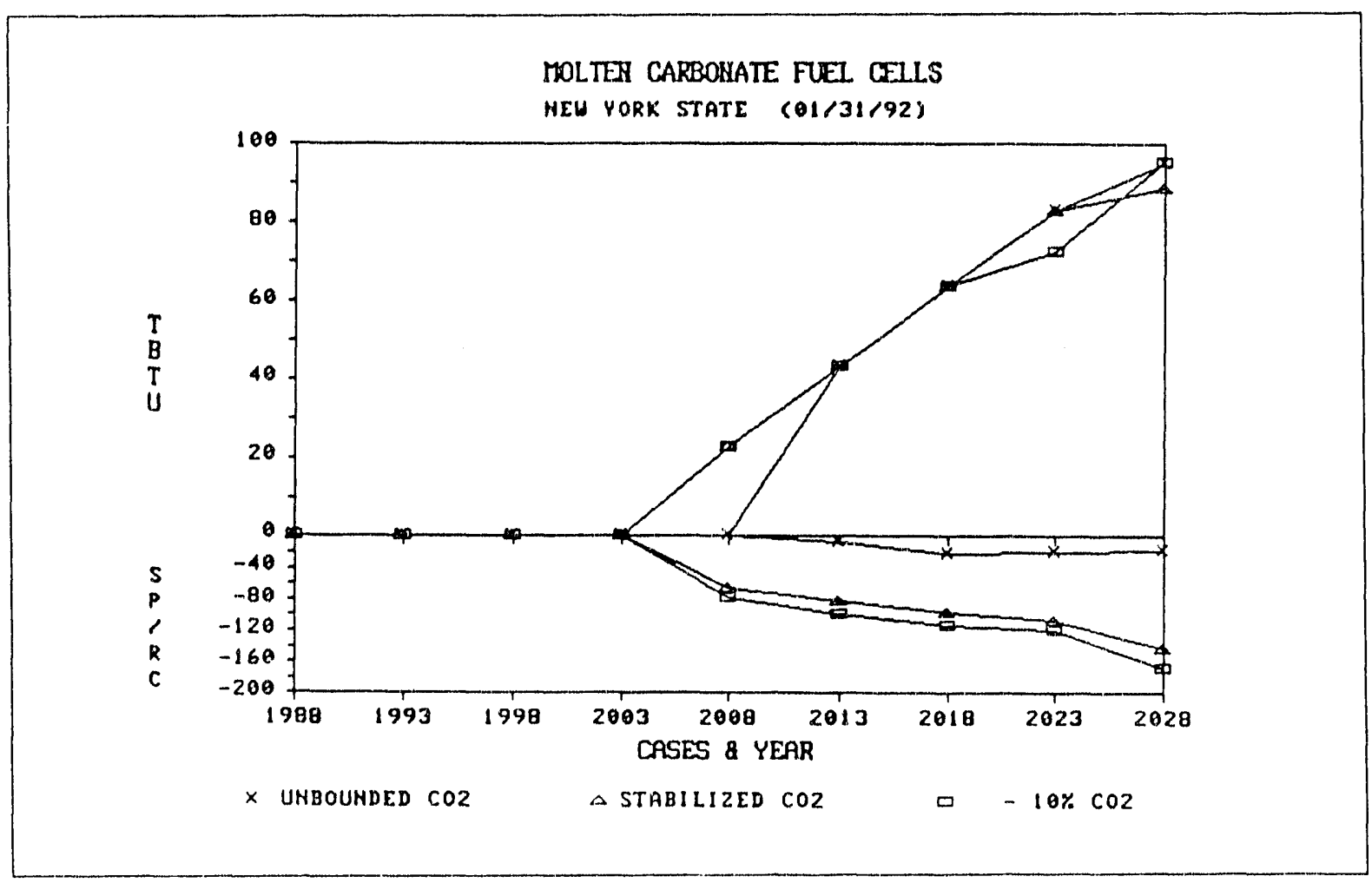

Figure 27. Molten carbonate fuel cell: activity and reduced costs in Conventional Technology Scenario. 


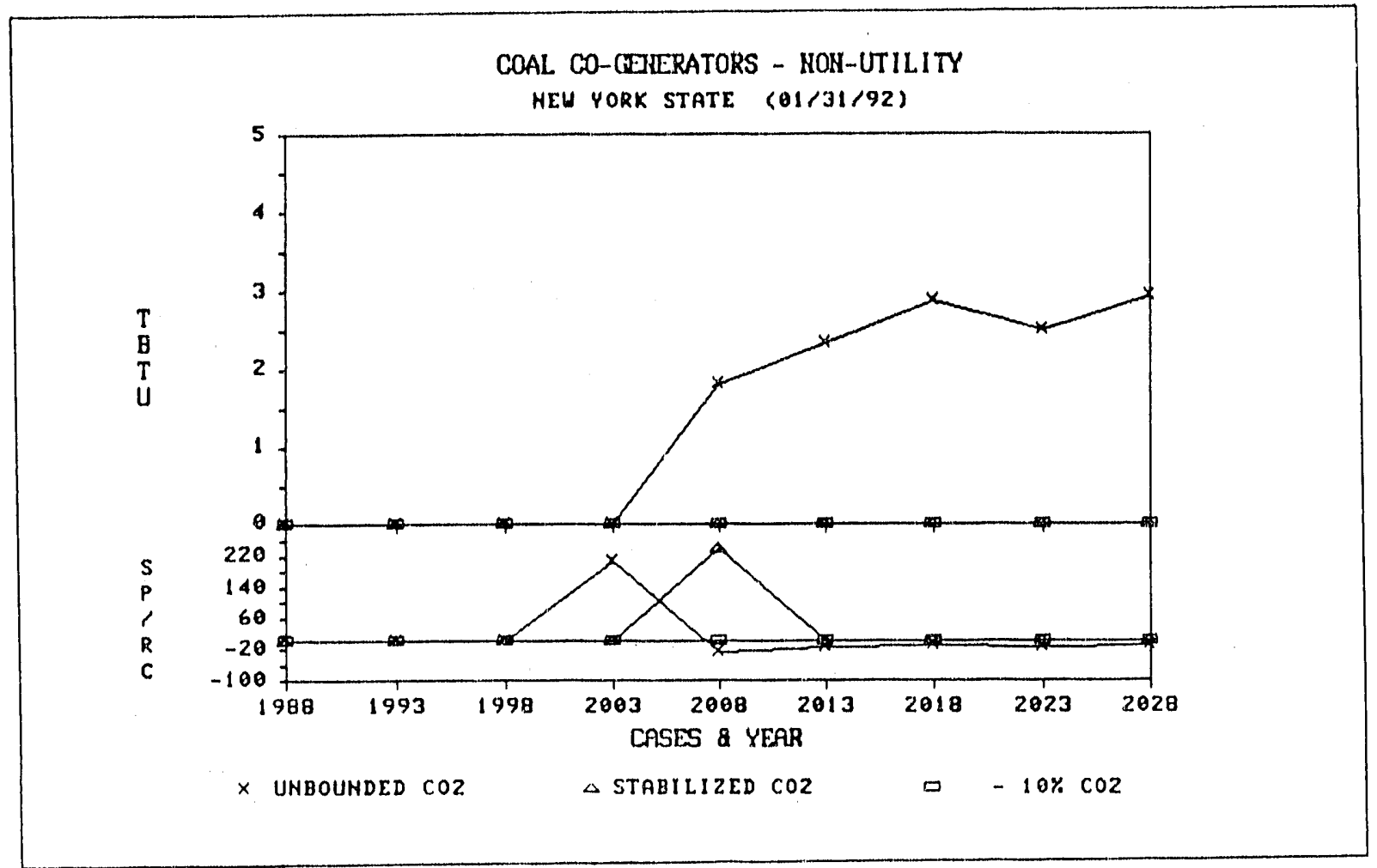

Figure 28. Coal cogeneration: activity and reduced costs in Conventional Technology Scenario. 


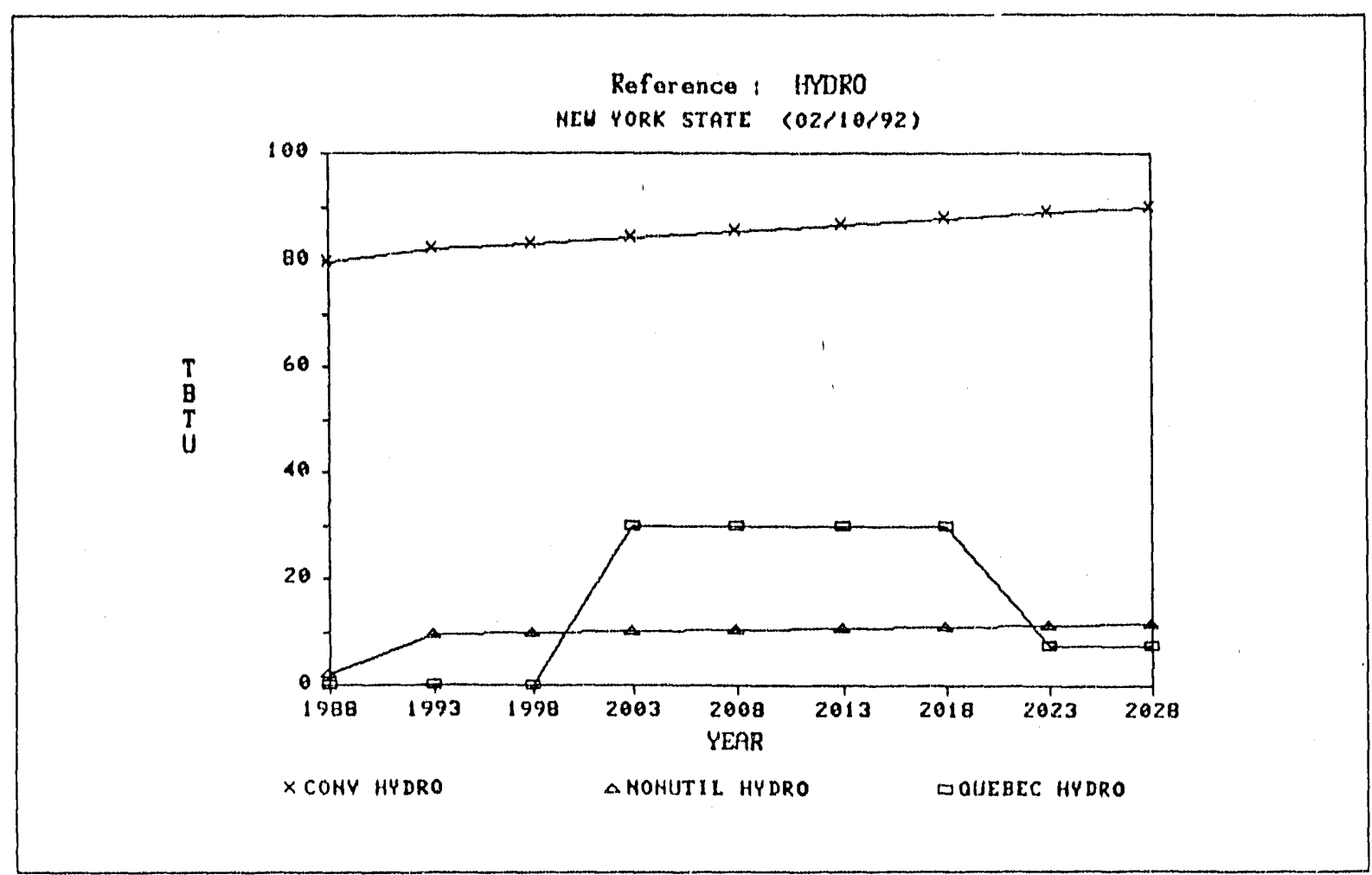

Figure 29. Activity in Reference Case of conventional hydropower and non-utility hydropower in New York State, and of new Quebec hydropower (existing contract with Hydro-Quebec not shown). 


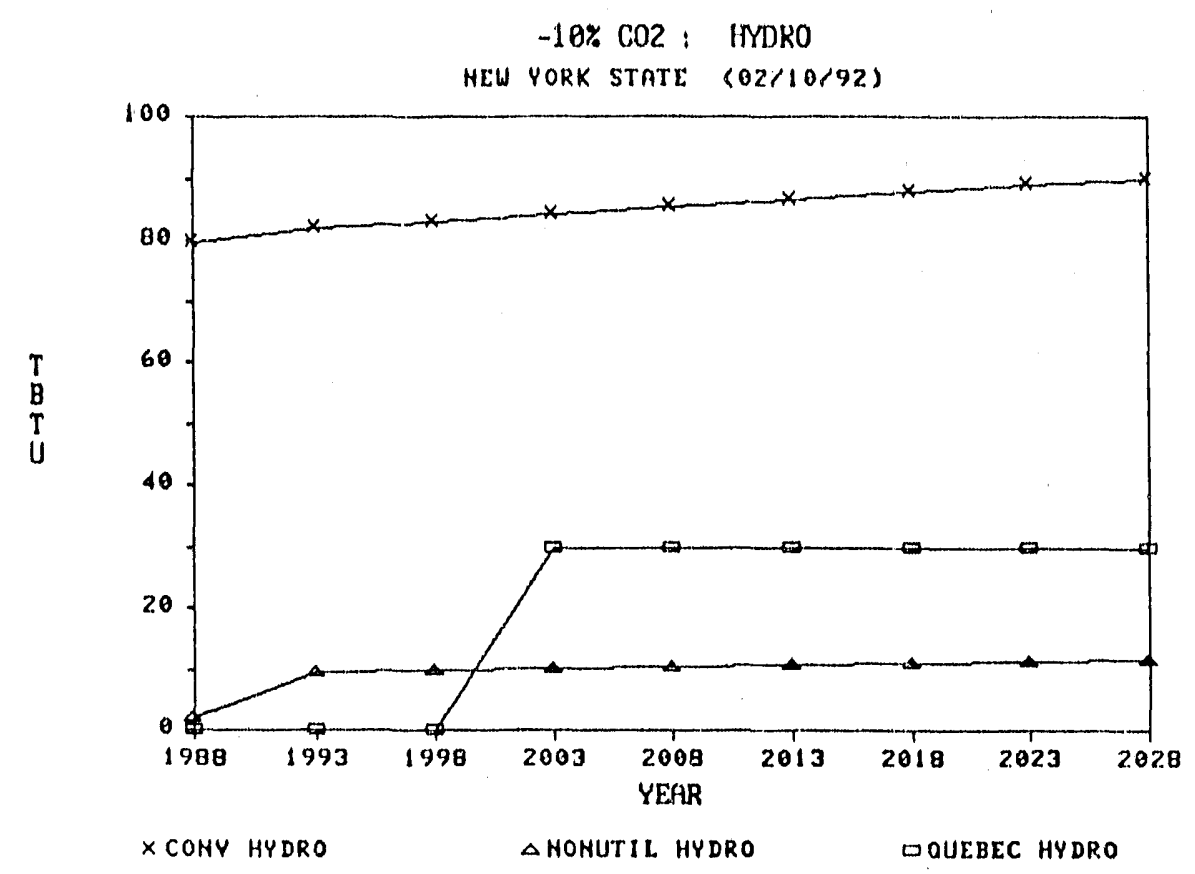

Figure 30. Activity in $10 \% \mathrm{CO}_{2}$ Reduction Case, Conventional Technologis Scenario, of conventional hydropower and non-utility hydropower in New York State, and of new Quebec hydropower (existing contract with Hydro-Quebec not shown).

Figure 31 shows the pattern of renewable electric technologies other than hydroelectric. Hydroelectric is not included on this list since it is so much larger, it would be difficult to focus on differences among biomass, wind, solar thermal and photovoltaics. The pattern is much the same for all cases, although three technologies (biomass, wind, and photovoltaics) achieve greater market penetration under $\mathrm{CO}_{2}$ constraints. Energy producing municipal solid waste incinerators are the largest single renewable technology after hydropower. They increase at a rate of $2.3 \%$ /year. They produce $1.9 \%$ of all electricity in 2028 in the reference case. Their percentage share decreases in the $\mathrm{CO}_{2}$ constrained cases although their absolute production level remains the same. 


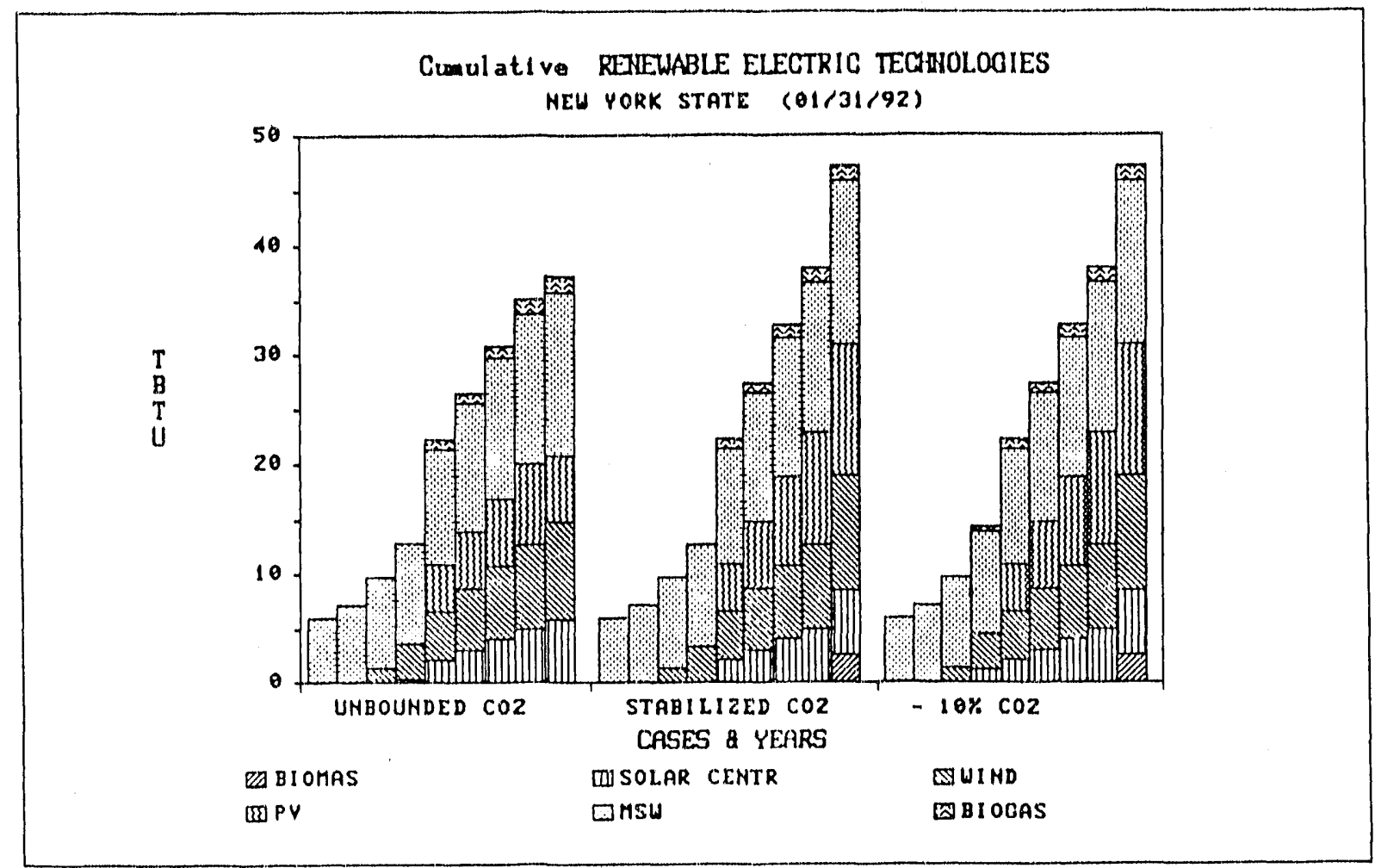

Figure 31. Pattern of renewable electric technologies, Conventional Technology Scenario.

\section{Emissions}

Figure 32 indicates the resulting $\mathrm{CO}_{2}$ emissions, without constraint, increase by $1.3 \%$ /year between 1988 and 2028 despite the substantial increase in conservation, Environmental factors, not fully considered in this scenario, could suppress the projected $\mathrm{CO}_{2}$ growth rate by preventing the increase in coal use for electric power. Comparing the $10 \% \mathrm{CO}_{2}$ reduction case with the reference case, the largest contribution to $\mathrm{CO}_{2}$ reduction is in the electrical generation sector $(65 \%$ of total net reduction in $2008,58 \%$ in 2028). In the near term (2008) the industrial sector is second (21\% of the total net reduction) but in the longer term (2028) the residential (15\%) and transport (11\%) sectors are next in line.

Figures 33-35 show the corresponding emissions of $\mathrm{SO}_{2}, \mathrm{NO}$, and particles. $\mathrm{SO}_{2}$ is constrained as discussed above, but $\mathrm{NO}_{\mathrm{X}}$ and particles are simply tabulated. No attempt was made here to reflect the effect of regulations imposing additional controls on these pollutants, e.g., the potential of implementation of the Clean Air Act Amendments of 1990. The result is that, in the reference case, nitrogen oxides and particles increase as demand for energy services increases. Of interest here is the dramatic, automatic decreases in the emissions of these pollutants as $\mathrm{CO}_{2}$ constraints are imposed. These decreases reflect the fuel shifts and conservation measures introduced to meet $\mathrm{CO}_{2}$ constraints. The dramatic effect on other pollutants, especially particles and sulfur dioxide, illustrates the massive changes wrought in the energy system by $\mathrm{CO}_{2}$ constraints. On the positive side, however, they illustrate the potential colateral environmental benefits of $\mathrm{CO}_{2}$ constraints. 


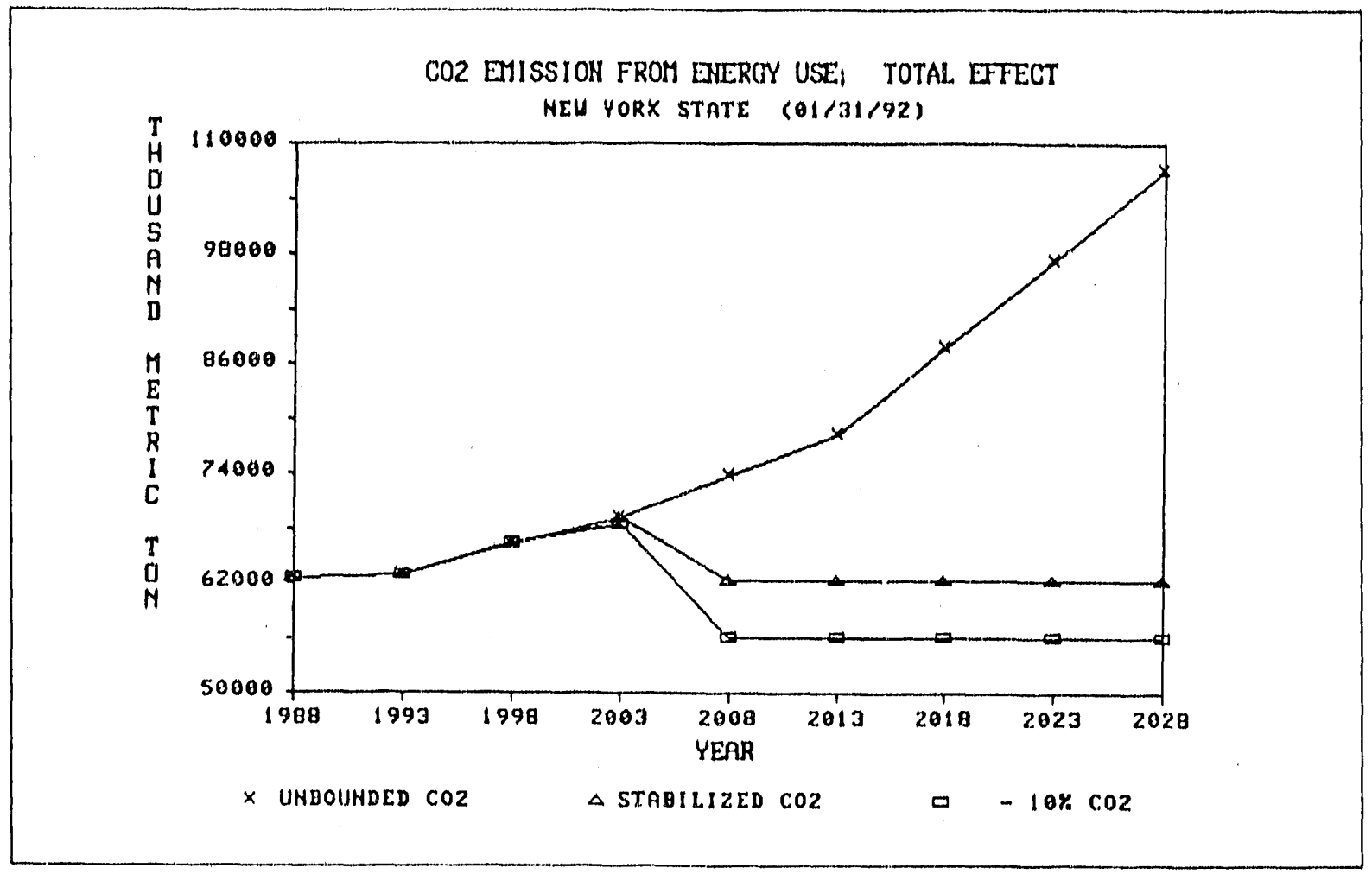

Figure 32. $\mathrm{CO}_{2}$ emissions in Conventional Technology Scenario.

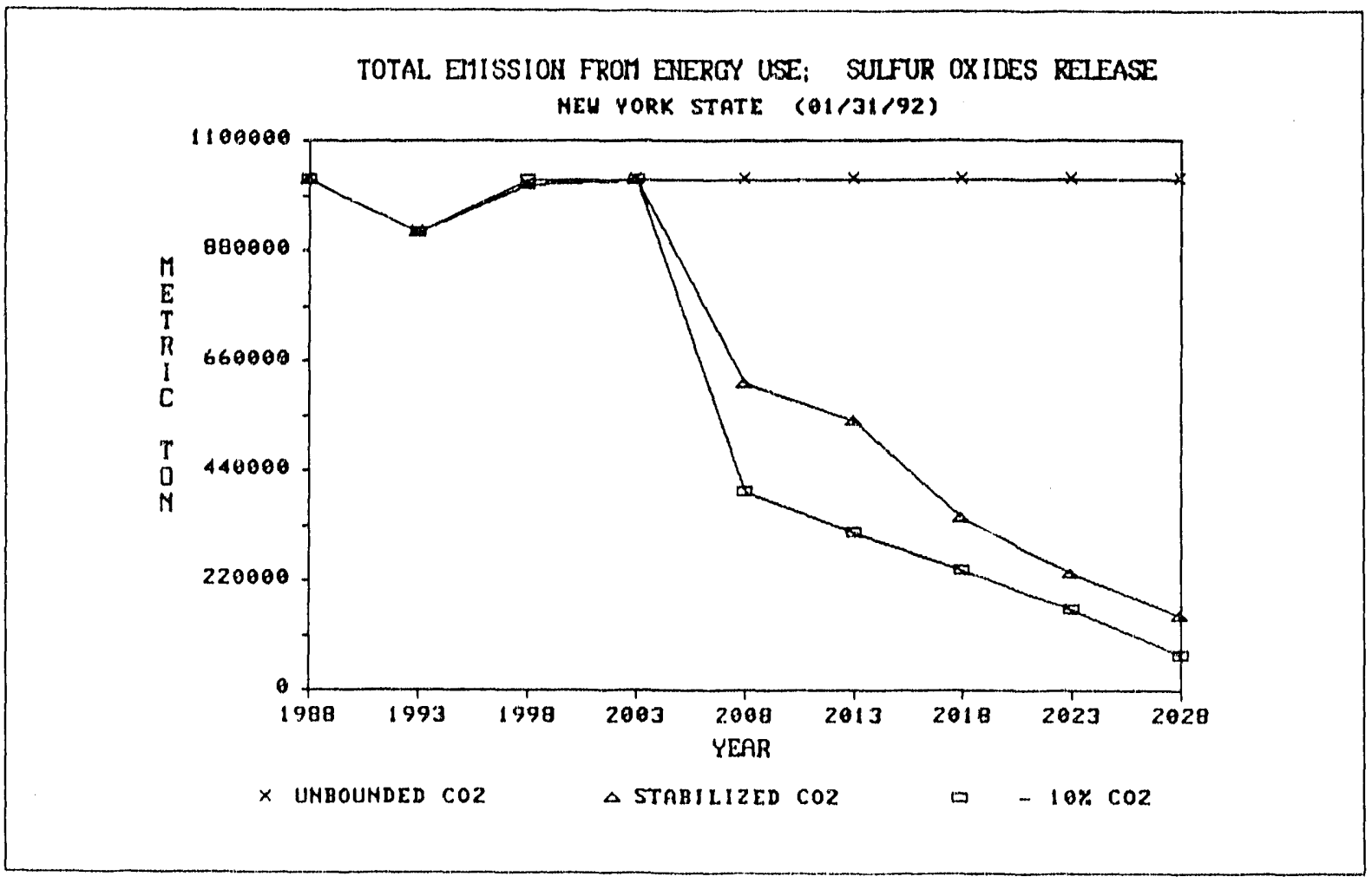

Figure 33. $\mathrm{SO}_{2}$ emissions in Conventional Technology Scenario. 
TOTAL EMISSION FROM EIEROY USE; HITROCEN OXIDES RELEASE NEW YORK STATE (01/31/92)

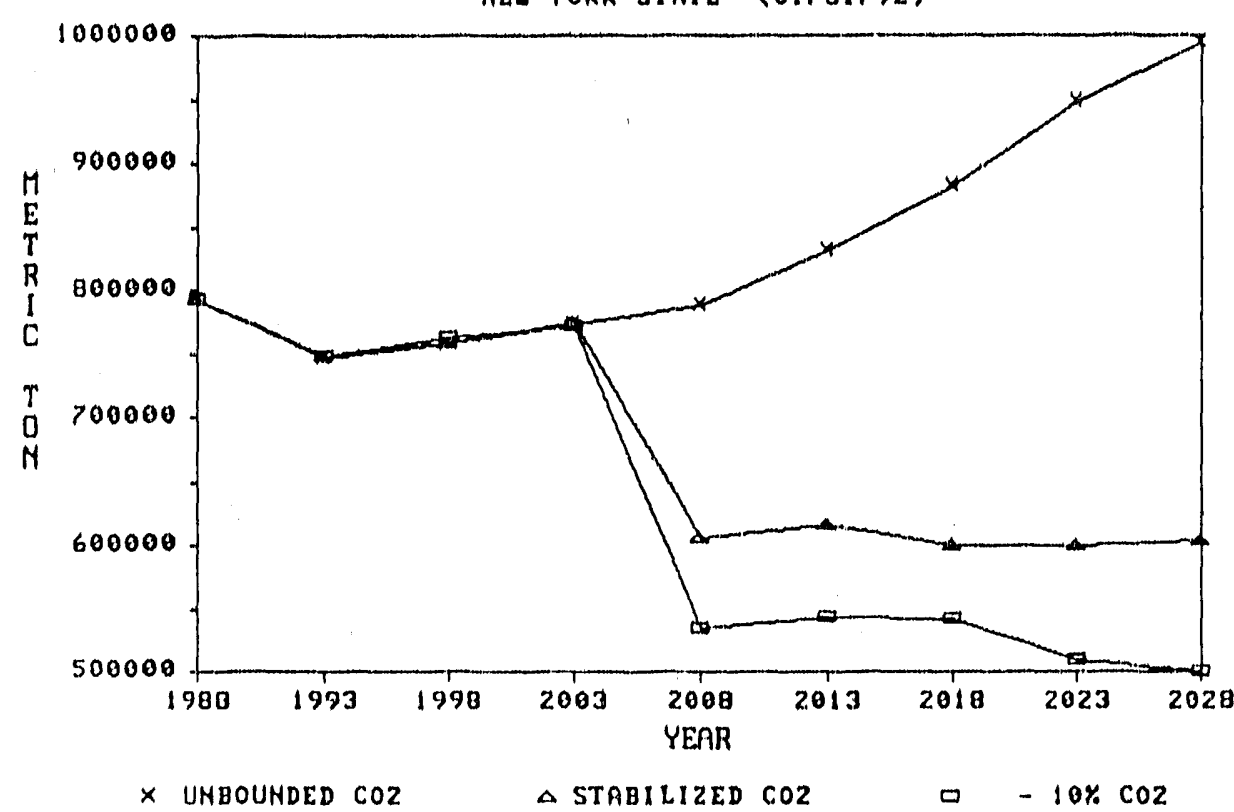

Figure 33. NOx emissions in Conventional Technology Scenario.

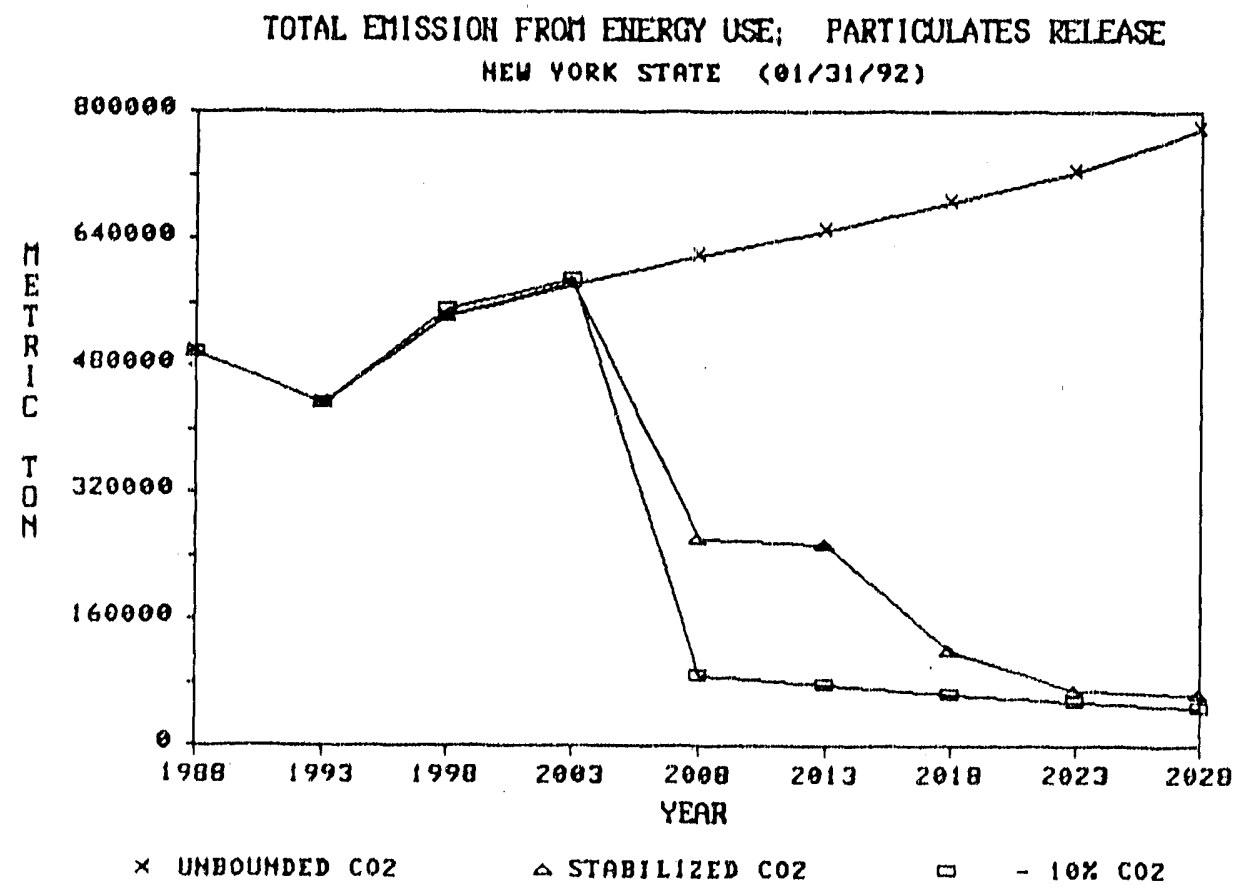

Figure 35. Particulate emissions in Conventional Technology Scenario. 


\section{Comparison of Reference Case with State Encrgy Plan}

MARKAL begins with the same economic forecast as the state energy plan and the same initial conditions. The energy plan forecasts of fuel and technology trends, however, are based on projection of current trends, modified by existing constraints associated with environmental laws and regulations. These take into account many behavioral factors.

MARKAL results are based more rigidly on least-cost decision making. History shows that many currently assumed constraints change over periods of three or four decades. By lifting some of the assumptions about behavior and current societal trends, MARKAL is freed to seek potentially better futures. This makes MARKAL a powerful model for evaluating the potential of alternative strategies and new technologies. MARKAL can be made to match current trends projections, but doing that would decrease its real power. Some of the important lessons from a MARKAL analysis can be gained by comparing MARKAL scenarios with current trends projections.

\begin{tabular}{|lcc|}
$\begin{array}{l}\text { Table 6. Total fuel consumption, 2010. Comparison of SEO current trend } \\
\text { and NYMARKAL reference case. }\end{array}$ \\
\hline \multicolumn{2}{|c|}{ Fuel } & SEO \\
& Current Trend & $\begin{array}{c}\text { NYMARKAL } \\
\text { (\% Change from } \\
\text { Trend) }\end{array}$ \\
\hline Petroleum products & 1797 & $2383(+33 \%)$ \\
Natural gas & 1143 & $752(-34 \%)$ \\
Coal & 335 & $645(+98 \%)$ \\
\hline
\end{tabular}

Current trend data from Draft New York State Energy Plan, Vol. II, Impact Assessment, p. 8, July 1991.

Table 6 compares total fossil fuel consumption in SEO current trends estimates for 2010 with MARKAL reference case results. MARKAL estimates are interpolated between 2008 and 2013. MARKAL uses more coal and oil and less natural gas than the current trends projection.

Table 7 compares the SEO current trend with NYMARKAL reference case for different types of electric power plants. Capacity assignments of Hydro Quebec plants are not included in the table. The correspondence is surprisingly good. MARKAL's lower estimate for oil steam plants but higher estimate for gas steam plants largely reflects differences in the use of multifuel steam plants. Since many renewable technologies are included under "other" in Table 7, the capacity of all renewable electric technologies (not just "other") in the NYMARKAL reference case are detailed in Table 8. 
Table 7. Electric capacity (GWe) by type, 2008. Comparison of SEO current trend and NYMARKAL reference case.

\begin{tabular}{|l|c|c|}
\hline \multicolumn{1}{c}{ Plant type } & Current Trend & NYMARKAL \\
\hline Oil steam & 12.8 & $7.4^{* *}$ \\
\hline Other & 6.0 & 1.2 \\
\hline Utility hydro & 4.4 & 4.3 \\
\hline Coal steam & 4.2 & $5.7^{*}$ \\
\hline Nuclear & 3.9 & 3.8 \\
\hline Combustion turbines & 3.8 & 4.8 \\
\hline Pumped storage & 1.0 & 1.0 \\
\hline Gas steam & 0.5 & $5.2^{* *}$ \\
\hline Total installed capacity & 36.6 & 33.4 \\
\hline
\end{tabular}

*Includes coal combined cycle plants.

**Includes multifuel steam plants in proportion to fuel use $(24 \%$ oil, $75 \%$ gas).

Current trends from SEO Draft New York State Energy Plan, Vol. II, Electricity Supply Assessment, July 1991, p. 58.

Table 8. Capacity of renewable electric technologies in NYMARKAL, reference case, 2008.

\begin{tabular}{|l|c|}
\hline \multicolumn{1}{|c|}{ Technology } & Capacity (MW) \\
\hline Utility Hydro & 4,271 \\
\hline Quebec Hydro & 1,000 \\
\hline Nonutility hydro & 360 \\
\hline Municipal Solid Waste & 352. \\
\hline Wind, local & 100 \\
\hline Solar steam electric & 73. \\
\hline Photovoltaic, central & 73. \\
\hline Photovoltaic, local & 73. \\
\hline Biogas & 55 \\
\hline Wind, local & 49. \\
\hline
\end{tabular}

\section{REFORESTATION SCENARIO}

This scenario examines the implications of $\mathrm{CO}_{2}$ offsets created by sequestering $\mathrm{CO}_{2}$ in trees through reforestation. Reforestation is not strictly an energy technology, but it nonetheless can be implemented in MARKAL. One policy approach that has been 
suggested is to require new large sources of $\mathrm{CO}_{2}$ to of fset their emissions by planting sufficient trees to sequester the lifetime emissions of the facility. This could be easily implemented in MARKAL by simply increasing the capital cost of new fossil power plants to include the appropriate cost of land acquisition, site preparation, seedlings, and planting. Another approach is to treat reforestation as an independent initiative, not tied to any specific energy facility. This approach provides the most information about reforestation as a $\mathrm{CO}_{2}$ sequestering technology and allows the model to decide the most cost--effective place to take credit for the off-set. This latter approach was implemented. The model will invest in reforestation to allow higher emissions from the energy system. This approach allows MARKAL to find the most cost-effective way to take advantage of the allowable emissions rather than coupling them to a specific technology.

The reforestation resource availability and cost were taken from the State Energy Ofince analysis of carbon reduction in New York State (NYSEO, 199lb; Sanghi and Micnael, 1991). Four resources were considered: (1) tropical forests; (2) forest upgrading, increasing the speed of reforestation and the growth of marketable species on under stocked acreage of mixed hardwoods in New York; (3) reforestation on public lands; and (4) reforestation on private lands. All costs were assumed to be initial costs and to include necessary site preparation, seedlings, labor, and, in the case of private land, land acquisition costs. Best estimates of costs were used and were treated as capital cost. The data used are shown in Table 9.

Reforestation was implemented in MARKAL by creating dummy processes representing each of the forest resources. These processes are characterized with a capital cost, a life of 40 years, and a negative carbon emission coefficient. They do not enter into any energy flows, but the model may choose them as a means of reducing $\mathrm{CO}_{2}$. MARKAL requires that process technologies have an input and an output energy carrier. The input is a dummy energy carrier to prevent an artificia! energy flow from being included in energy accounts. The process is assigned an efficiency of zero, so there is no output, although an output energy carrier must be assigned. The output can be any energy carrier since it will have zero flow. The current MARKAL is thus able to handle nonenergy processes that have environmental emissions implications through what is essentially a modeling trick. The new version of MARKAL that will be available in 1992 will provide for materials flows independent of energy flow and so will be able to treat non-energy flows, e.g., material and financial flows, in a more straight-forward manner.

MARKAL invests in all four types of reforestation as soon as $\mathrm{CO}_{2}$ constraints are imposed. The result is that a $20 \%$ reduction in $\mathrm{CO}_{2}$ emissions becomes possible. Since the underlying technologies and limitations from the Conventional Technologies Scenario remain in place, the basic structure of the energy system is much like in that Scenario: coal decreases (Figure 36), nuclear (Figure 37) and renewables (Figure 38) increase sharply as $\mathrm{CO}_{2}$ constraints increase. The overall mix of electrical technologies is shown in Figure 39. In the intermediate period (2008-2013), natural gas plays a larger role in the 20\% reduction case (Figure 40). The pattern of switching from gas to electric space heating in single family residential, seen in the Conventional Technology Scenario, is accentuated in the $20 \%$ reduction case here, indicating the pressure was not an end-period phenomena (Figure 41). 
Table 9. Reforestation Data (from NYSEO, 1991b).

\begin{tabular}{|l|c|c|c|}
\hline \multicolumn{1}{|c|}{ Resource } & $\begin{array}{c}\text { Cost/acre } \\
\text { Dollars }\end{array}$ & $\begin{array}{c}\mathrm{CO}_{2} \text { Uptake } \\
\text { Tons/acre/year }\end{array}$ & $\begin{array}{c}\text { Available } \\
\text { acres. }\end{array}$ \\
\hline Forest Upgrade & 120. & 0.49 & $500,000$. \\
\hline Public Land & 275. & 0.95 & $500,000$. \\
\hline Private Land & 775. & 0.95 & $500,000$. \\
\hline Tropical Forest & 160. & 1.72 & $500,000$. \\
\hline
\end{tabular}

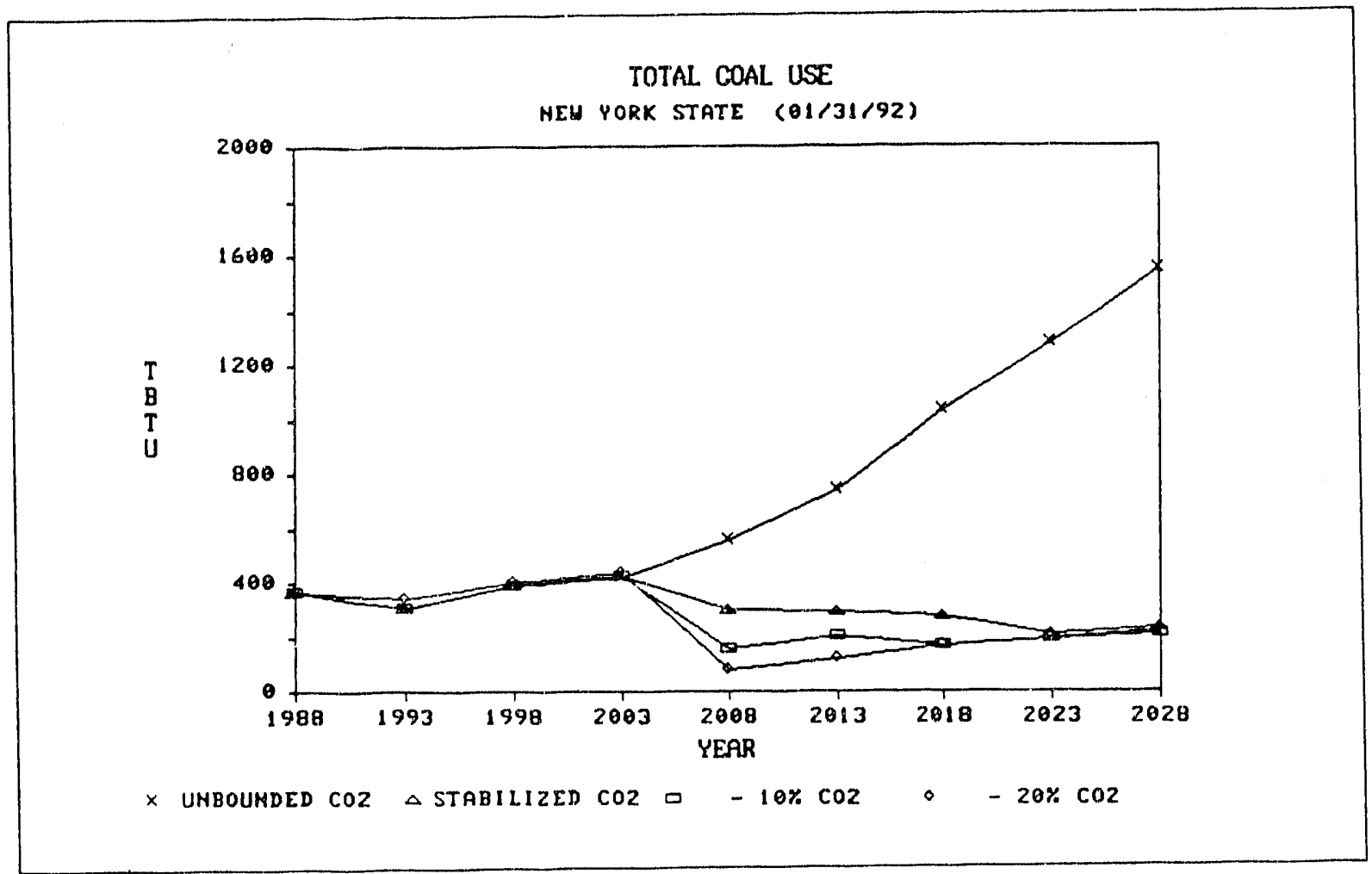

Figure 36. Total coal use in Reforestation Scenario. 


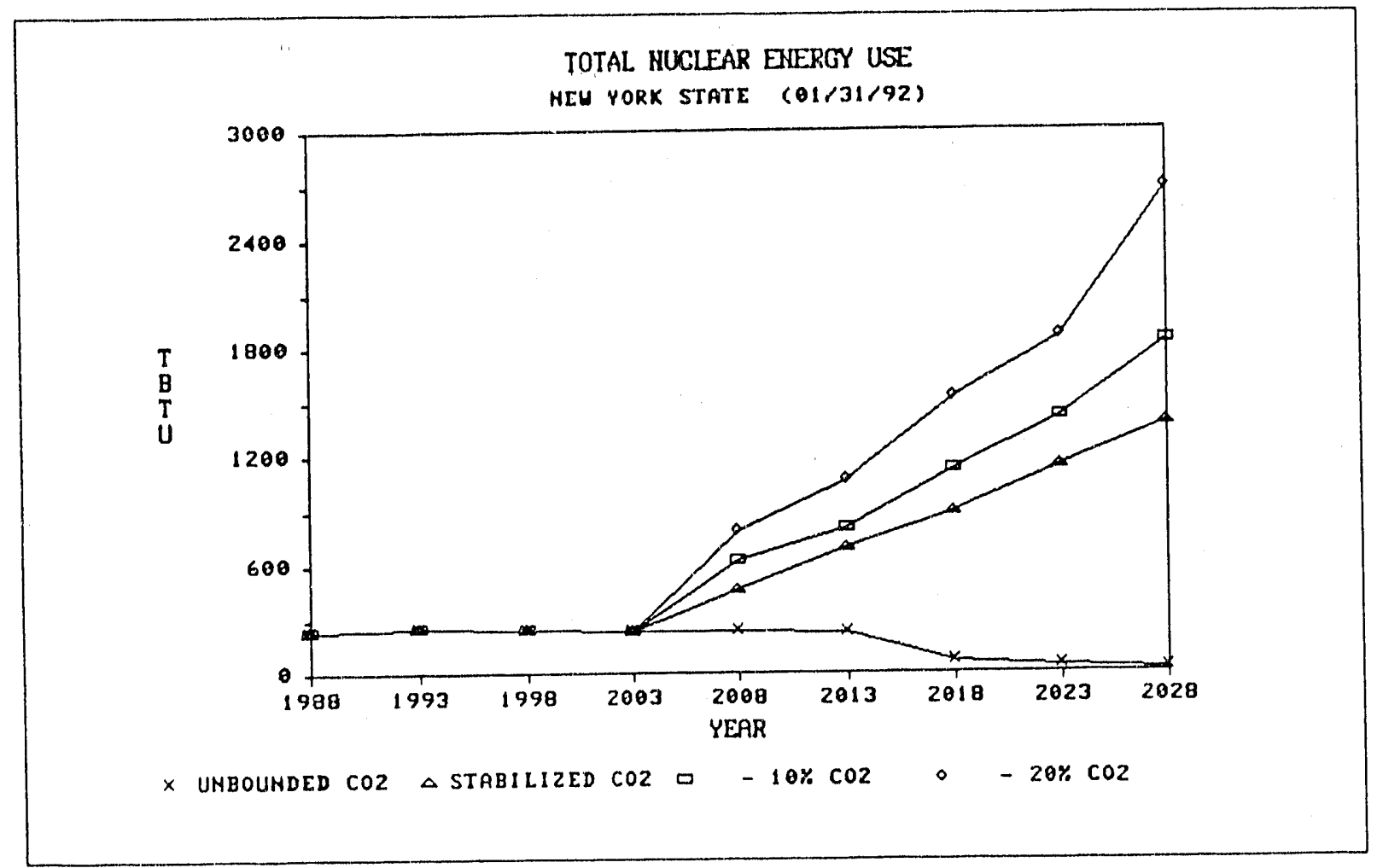

Figure 37. Total nuclear use in Reforestation Scenario.

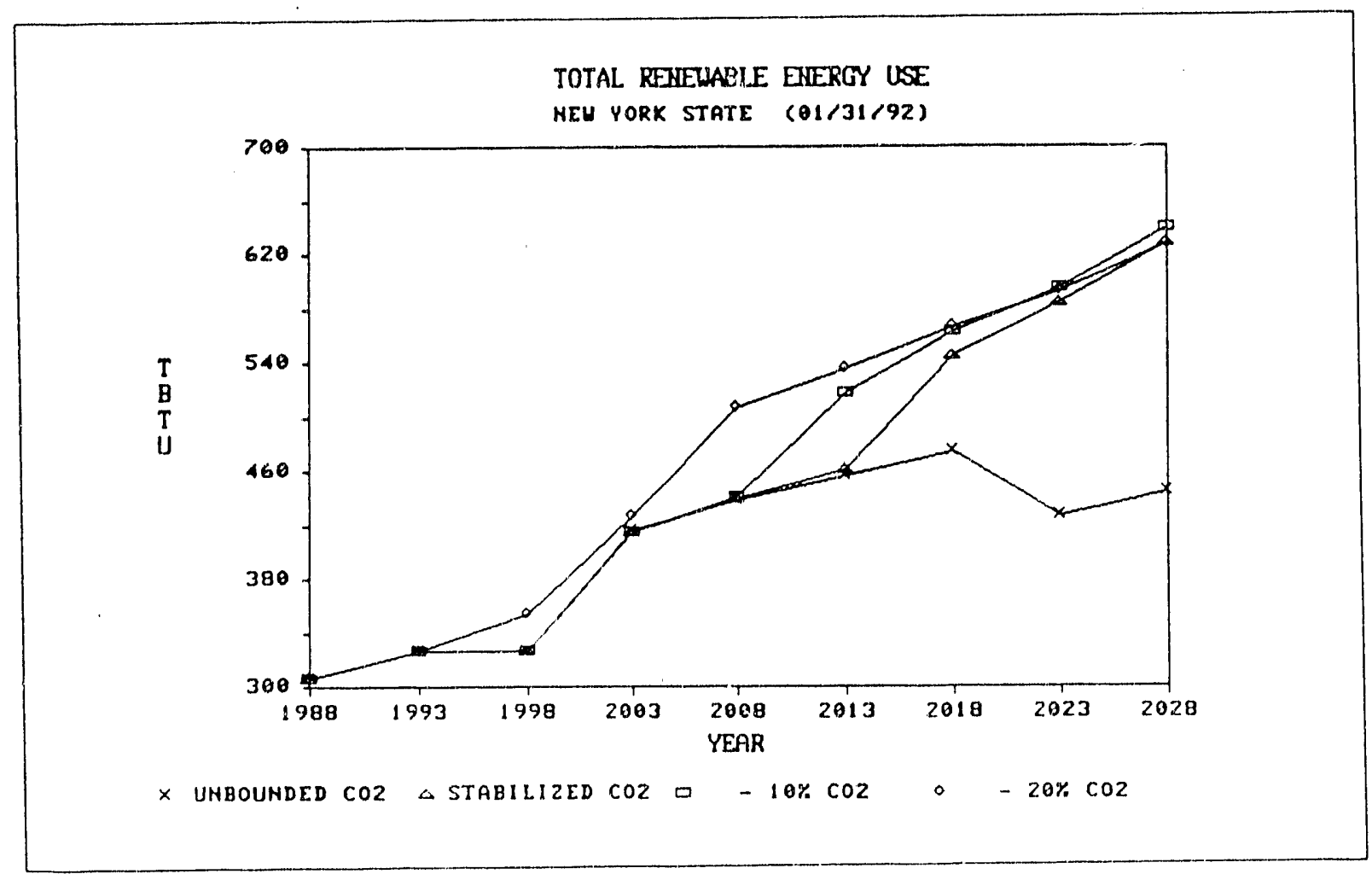

Figure 38. Total use of renewables in Reforestation Scenario. 


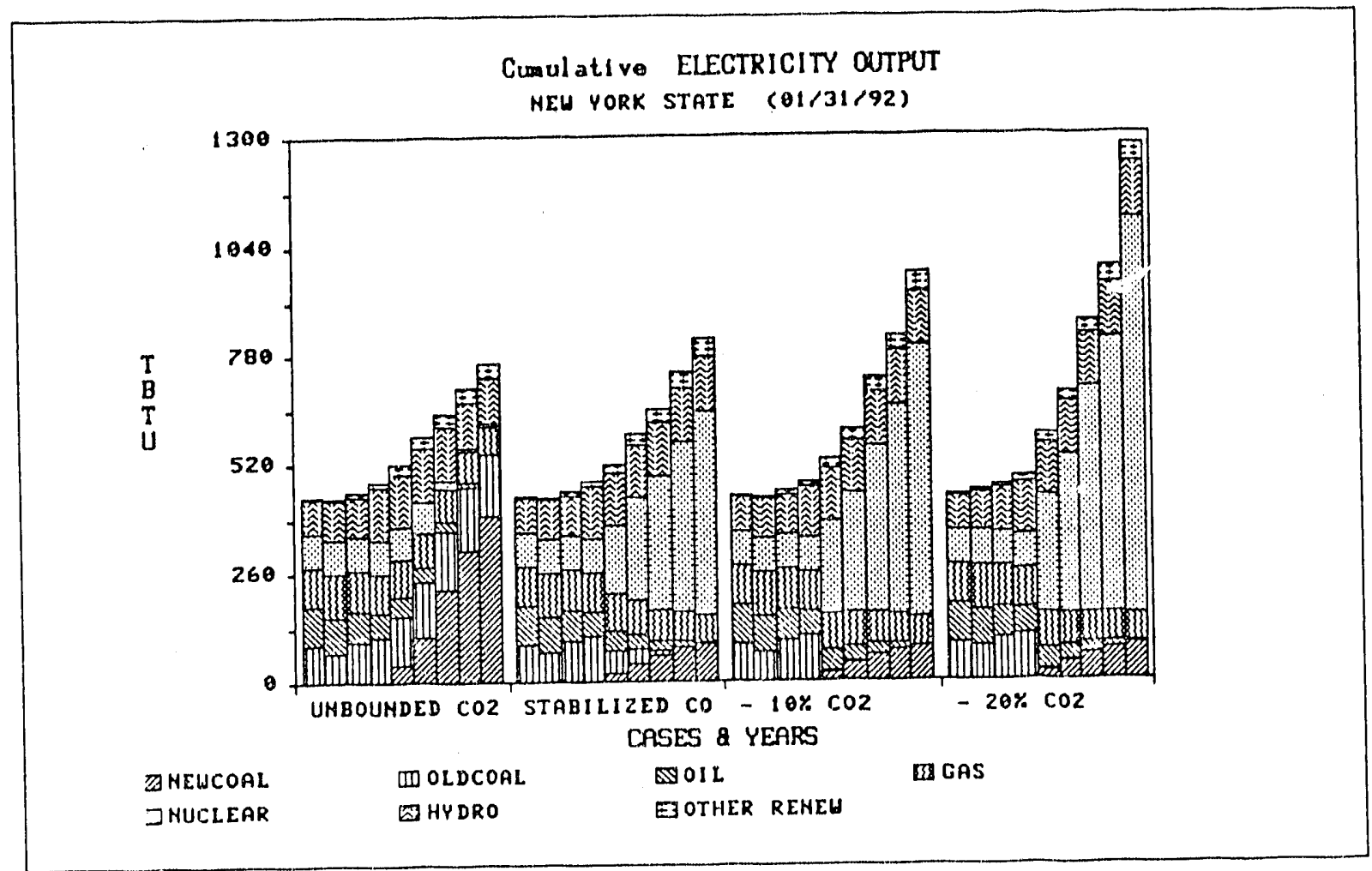

Figure 39. Electric output by energy source type in Reforestaion Scenario.

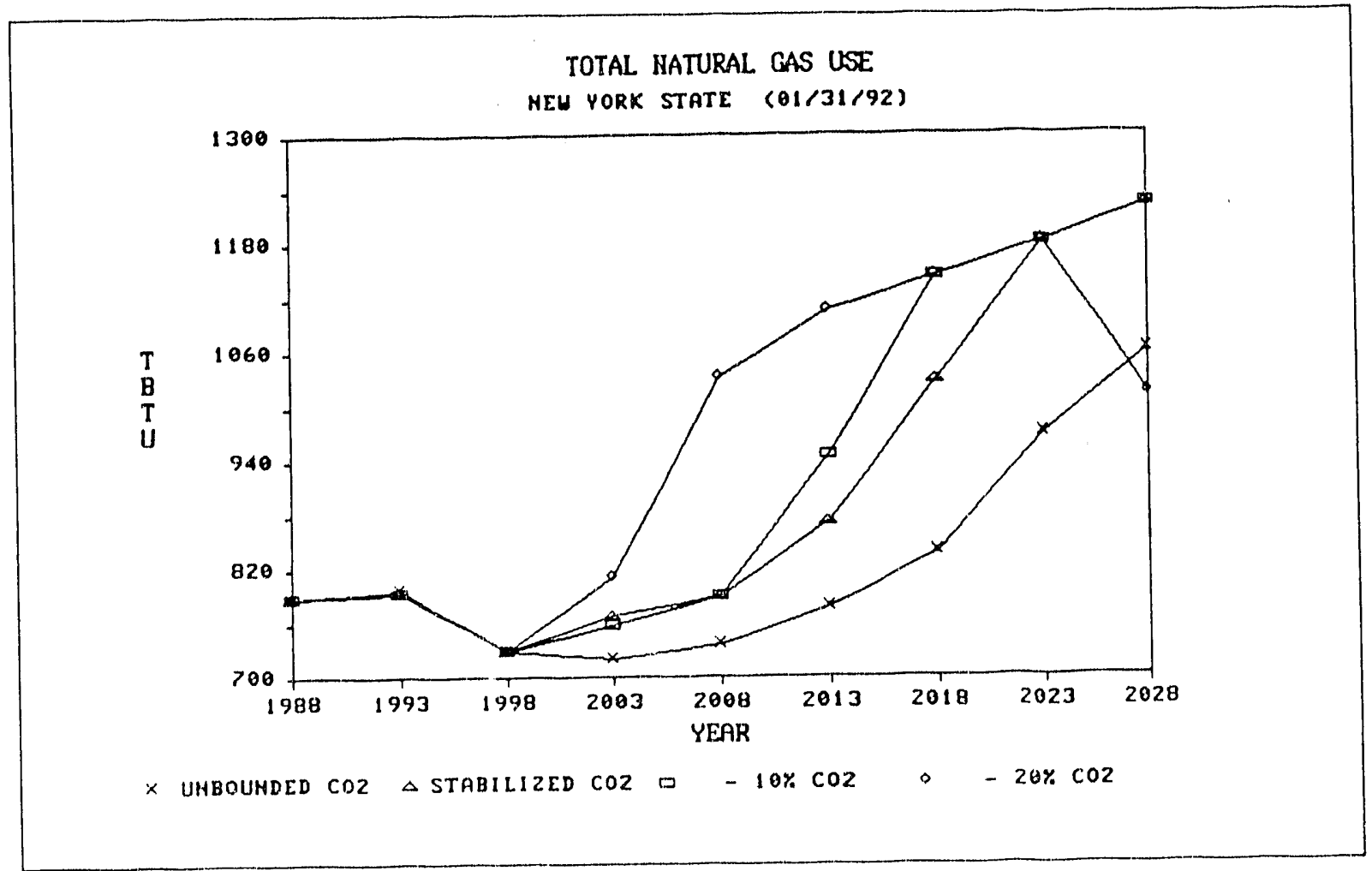

Figure 40. Total natural gas use in Reforestation Scenario. 


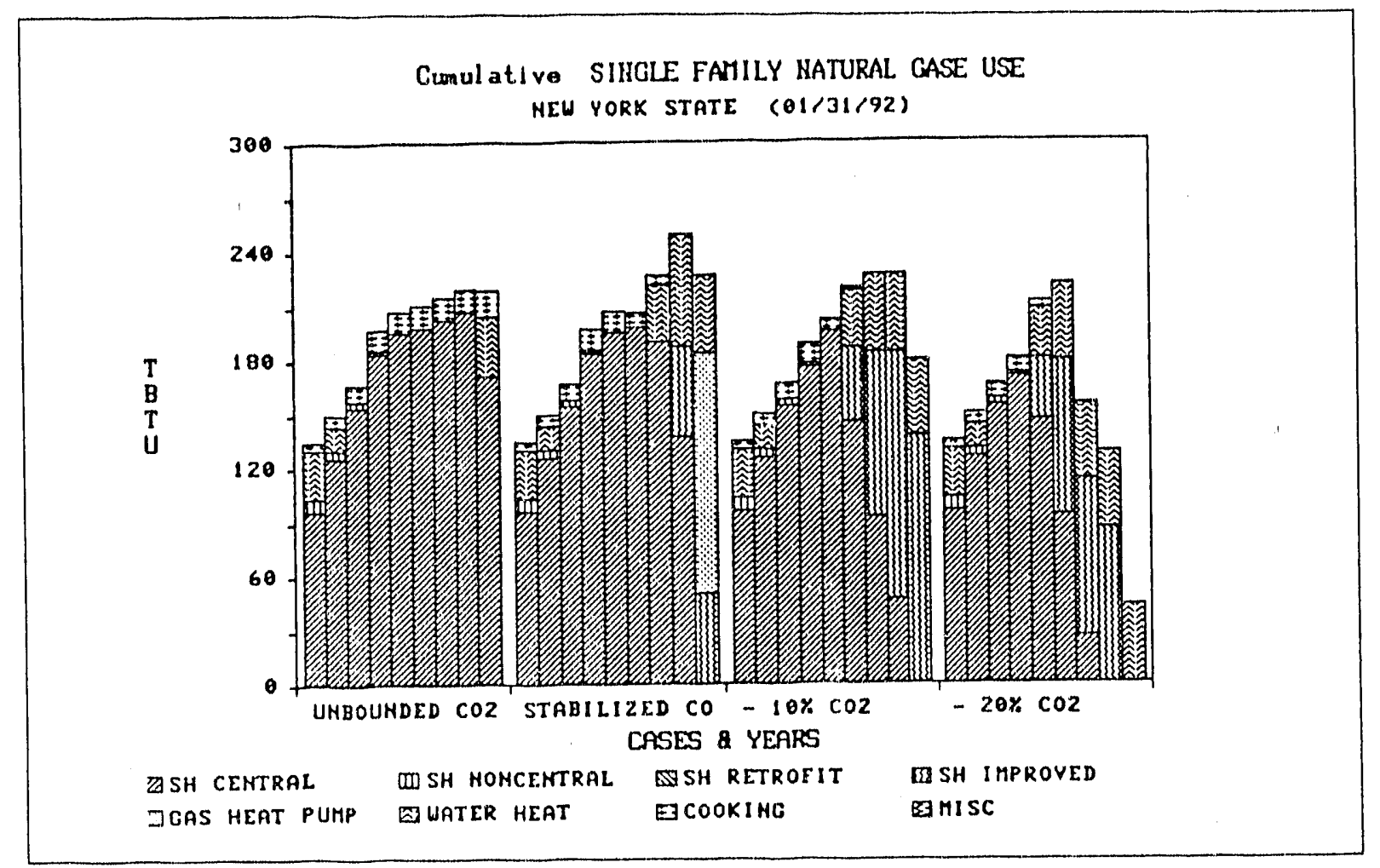

Figure 41. Natural gas use in single family residential buildings, Reforestation Scenario.

\section{INCREASED HYDROELECTRIC IMPORTS SCENARIO}

Hydroelectric provides an essentially pollution-free energy resource. New York State now imports hydroelectric power from Quebec and there is the potential for greatly increased imports. Increased hydroelectric imports could fulfill the same role played by nuclear power in the Conventional Technologies Scenario. This scenario allows a competition between nuclear and hydruelectric. The next scenario (NNQB) explores an energy system with an abundance of hydro but no nuclear.

Like nuclear, hydroelectric power is not without impact or controversy. Issues surrounding import of Quebec hydropower are currently under debate. These involve flooding large land areas and displacing the people who live in those areas. In the case of Quebec hydropower, this is especially troublesome since the effect goes beyond displacing people to disrupting the culture of a native American people. In addition to the social and cultural effects, the proposed system of reservoirs would alter substantially the environment of northern Quebec, especially the character and quality of its water resources. A relatively minor environmental consideration, but pertinent to this study, is that decaying organic matter in the areas flooded yields an increased $\mathrm{CO}_{2}$ emissions. As mentioned above, a $\mathrm{CO}_{2}$ emissions factor was associated with this technology based on Thérien (1990).

A scenario was developed for New York State that examines the implications of large imports of hydroelectric power, eventually equivalent to $10 \mathrm{GW}$ of electrical capacity. This is a sufficiently large amount of power that questions of reliability and capacity 
reserves are important. Projected potential hydroelectric development in Quebec goes up to about $15 \mathrm{MW}$ electrical capacity about 2010. This scenario allows imports from Quebec to grow linearly from the 1993 assumed level of $1800 \mathrm{MW}$ to $10,800 \mathrm{MW}$ electrical in 2028 (these include the current $800 \mathrm{MW}$ import level). MARKAL associates no capacity with electrical imports, yet in reality imports essentially involve contracts for capacity allocation as well as kilowatt-hours. To take this into account, these imports were internalized into the New York State system by defining a technology called Quebec Hydro. What these imports would cost is a matter for future negotiation. This scenario begins in 1998 with 1 GW at a capacity cost of $\$ 250$ per year per $\mathrm{Kw}$ and an energy cost of $\$ 0.02$ per kwh. These costs are similar to those previously negotiated between Hydro Quebec and the New York Power Authority. The capacity cost remains constant, but the energy cost is increased overtime with increasing capacity availability in a manner similar to expected costs disclosed by Hydro-Quebec as new capacity is brought on line (Drouin, 1990).

The addition of $10 \mathrm{GW}$ Quebec hydropower was insufficient to extend $\mathrm{CO}_{2}$ reductions to $20 \% \mathrm{CO}_{2}$. The $20 \% \mathrm{CO}_{2}$ emissions reduction proved infeasible in 2028, although the infeasibility occurred only in the last period. The entire $10 \mathrm{GW}$ of Quebec hydro was put in place during the last period of the $10 \%$ reduction case, so Quebec hydro could not contribute to the supply of additional low- $\mathrm{CO}_{2}$ electricity to meet a further $\mathrm{CO}_{2}$ reduction. Furthermore, it would appear that the reason for the infeasibility was the saturation of all available ways in which low- $\mathrm{CO}_{2}$ electricity could substitute for direct use fossil fuels. This seems evident since nuclear power was not bounded. Future work should explore the implications of adding additional opportunities for electrification, e.g., expanding the upper bounds on electric automobiles.

The principal purpose of this scenario was to compare nuclear and hydro in "headto-head" competition. The results are not entirely conclusive. Capacities by year are shown for each technology in Table 10. Annual output of conventional nuclear (LWR), advanced nuclear (HTR) and Quebec hydropower are shown for each case in Figure 42. In the unconstrained case, as in the reference case, no new nuclear plants are built and existing nuclear plants live out their useful life. Also as in the reference case, Quebec hydropower is similar, it never goes beyond the minimum $1 \mathrm{GW}$ electrical capacity required, although additional power is available from Quebec. This is because the assumed cost of Quebec hydropower is more expensive than coal or nuclear options. At the $\mathrm{CO}_{2}$ stability level, advanced reactors begin to rapidly enter the arena after 2003, but level off after 2018 as Quebec hydro begins to climb. As $\mathrm{CO}_{2}$ constraints become more stringent, advanced reactors enter more rapidly, leveling off at a higher level after 2023 as Quebec hydro again enters. This time Quebec hydro enters later but reaches a higher level, its maximum allowed. One way to look at these results is that in the last period, nuclear fills a gap that Quebec hydroelectric power is unable to provide, even at the high level assumed here.. How large that gap is in earlier years depends on how rapidly Quebec hydropower could be brought into the system. Further sensitivity analysis is necessary to better understand this behavior. The nuclear technologies are unbounded and so do not have reduced costs; Quebec hydro activities and reduced costs are shown in Figure 43. 
Table 10. New Quebec Hydro and Nuclear capacity under $10 \% \mathrm{CO}_{2}$ emissions reduction in Conventional Technology and Additional Hydro Imports, scenarios. New capacity includes all entering the energy system after 1988.

\begin{tabular}{|l|l|l|l|l|l|l|}
\hline \multirow{2}{*}{ Scenario } & \multicolumn{3}{|c|}{ New Nuclear } & \multicolumn{3}{c|}{ New Quebec Hydro } \\
\cline { 2 - 7 } & 2018 & 2023 & 2028 & 2018 & 2023 & 2028 \\
\hline Conventional Tech & 16.7 & 21.5 & 21.5 & $1.0^{*}$ & $1.0^{*}$ & $1.0^{*}$ \\
\hline Add'1 QH Imports & 16.7 & 21.5 & 21.5 & 1.0 & 1.1 & $10.0^{*}$ \\
\hline *Upper bound of available Quebec Hydro. & & & & \\
\hline
\end{tabular}

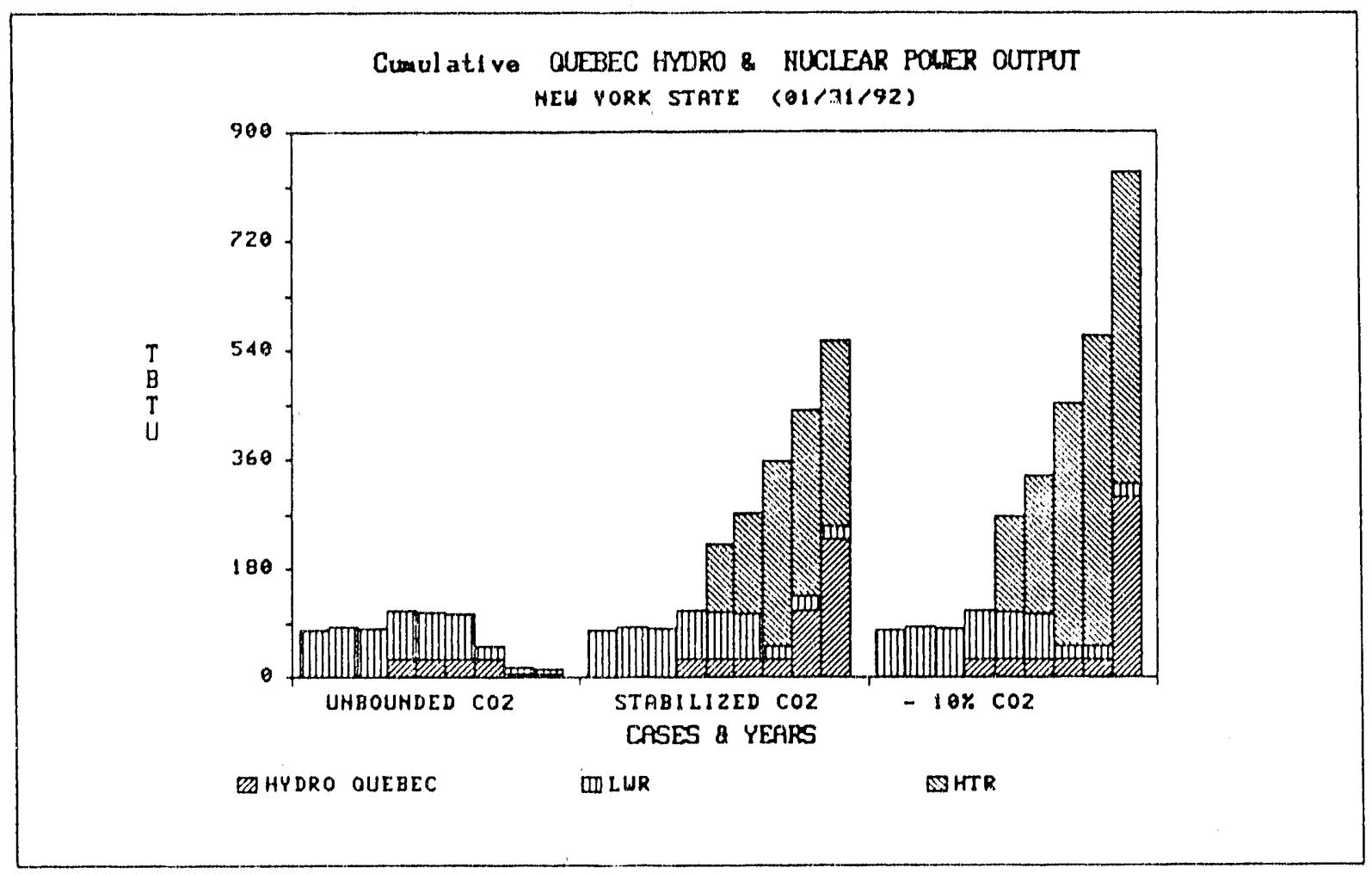

Figure 42. Activity of Quebec hydropower and existing nuclear in unconstrained case of Additional Quebec Hydro Scenario. 


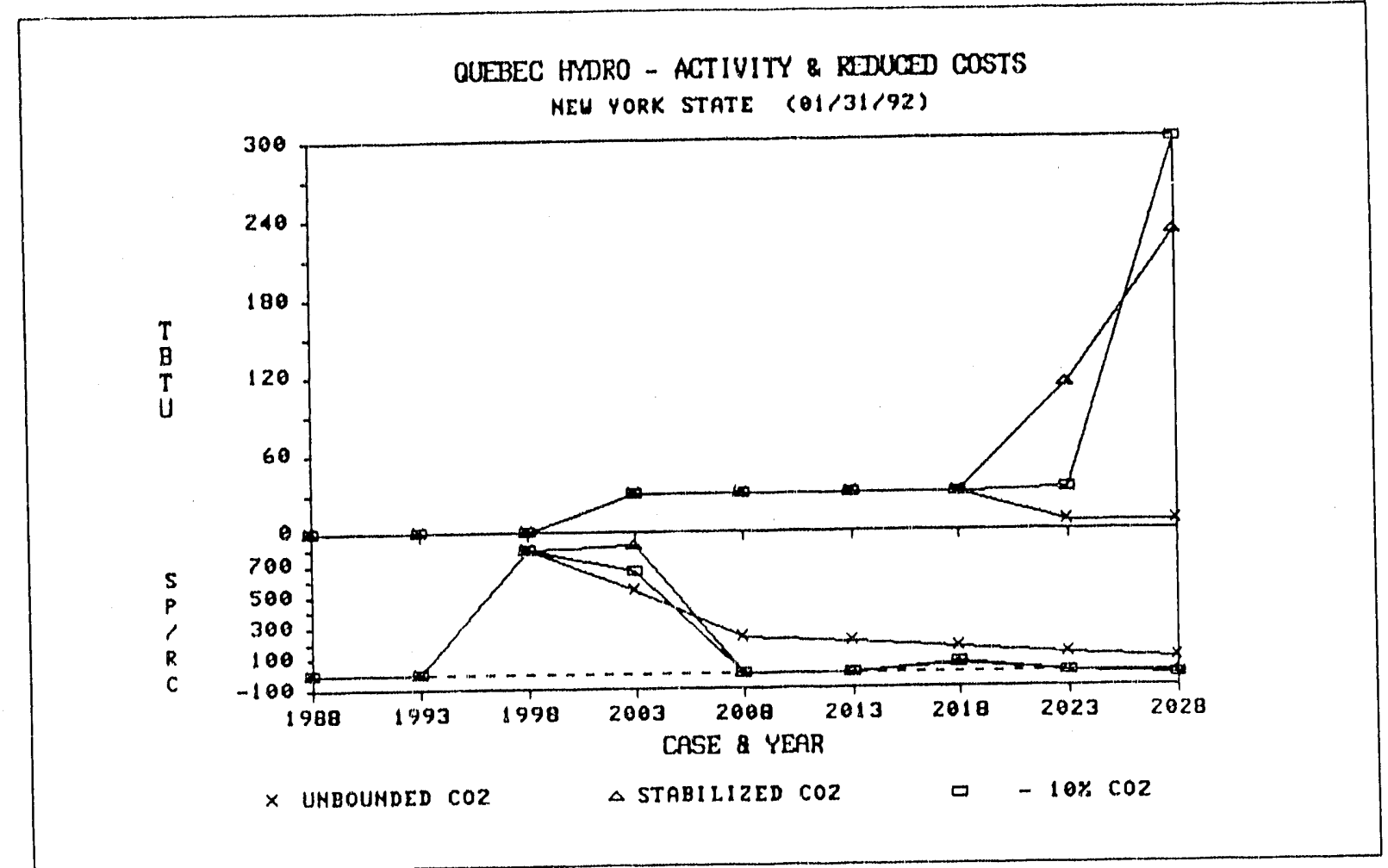

Figure 43. Activity and reduced costs of Quebec hydropower, Additional Quebec Hydro Scenario.

\section{ADDITIONAL HYDRO BUT NO NEW NUCLEAR SCENARIO}

The Conventional Technologies Scenario includes a nuclear power option. This scenario examines the implications of an energy future with no new nuclear plants. It was initially run with Quebec hydropower available at the same level as in the Increased Hydroelectric Imports Scenario (1.8 GW in 1993 increasing linearly to $10.8 \mathrm{GW}$ in 2028). Even the $\mathrm{CO}_{2}$ Stability Case, however, was infeasible in that scenario. Note that the finding of infeasibility is, in itself, useful information. We then increased the availability of Quebec hydropower to $15 \mathrm{GW}$ electrical capacity in 2028. This approximates the expected total availability of Quebec hydropower (although it becomes available at a slower rate then planned). While New York State cannot expect to import this much hydropower from Quebec, one can think of it as an indication of the size of an energy gap that will exist.

Since no new nuclear plants are brought into the unconstrained $\mathrm{CO}_{2}$ case of the More Hydroelectric Imports Scenario, this scenario is exactly the same as the previous one in the absence of $\mathrm{CO}_{2}$ constraints. When $\mathrm{CO}_{2}$ constraints are imposed, huwever, differences appear. The $\mathrm{CO}_{2}$ Stability Case was the only feasible constrained case. Nuclear power use declines as existing plants reach the end of their useful lives. Most of the difference is made up with increased renewable energy sources, up $54 \%$ over the parallel case, QUEB10 in 2028 (growth rate of $4.5 \%$ /year compared with $3.4 \%$ /year in QUEB10). Essentially all of the increase in renewables consisted of increased use of Quebec 
hydropower. As might be expected, under $\mathrm{CO}_{2}$ constrait, Quebec hydropower becomes a more desired energy source when the nuclear alternative is not available; its activity and reduced costs are compared in Figure 45. Activity of end-use conservation is largely unchanged with or without nuclear power, although it was slightly higher in the latter for the last period. It filled in a gap between 2013 and 2028 in QUEB110, a target that could not be reached with Quebec hydro alone and did not seem to be necessary in the $\mathrm{CO}_{2}$ stability case for either scenario. Figure 46 compares the reduced costs of Quebec hydropower and nuclear (LWRs) for the scenario with no new nuclear. This provides a direct comparison of the value of each technology to the system by period for a case when both are constrained (although the constraint on nuclear is more severe than that on Quebec hydropower). Oil products were up $3 \%$ by 2028 . Electricity use was down $10 \%$ compared to QUEB 10 , down $37 \%$ in single family residential, and $21 \%$ in multi--family residential. Growth rate for electricity was $1.1 \%$ /year compared to $1.7 \%$ /year in QUEB10.

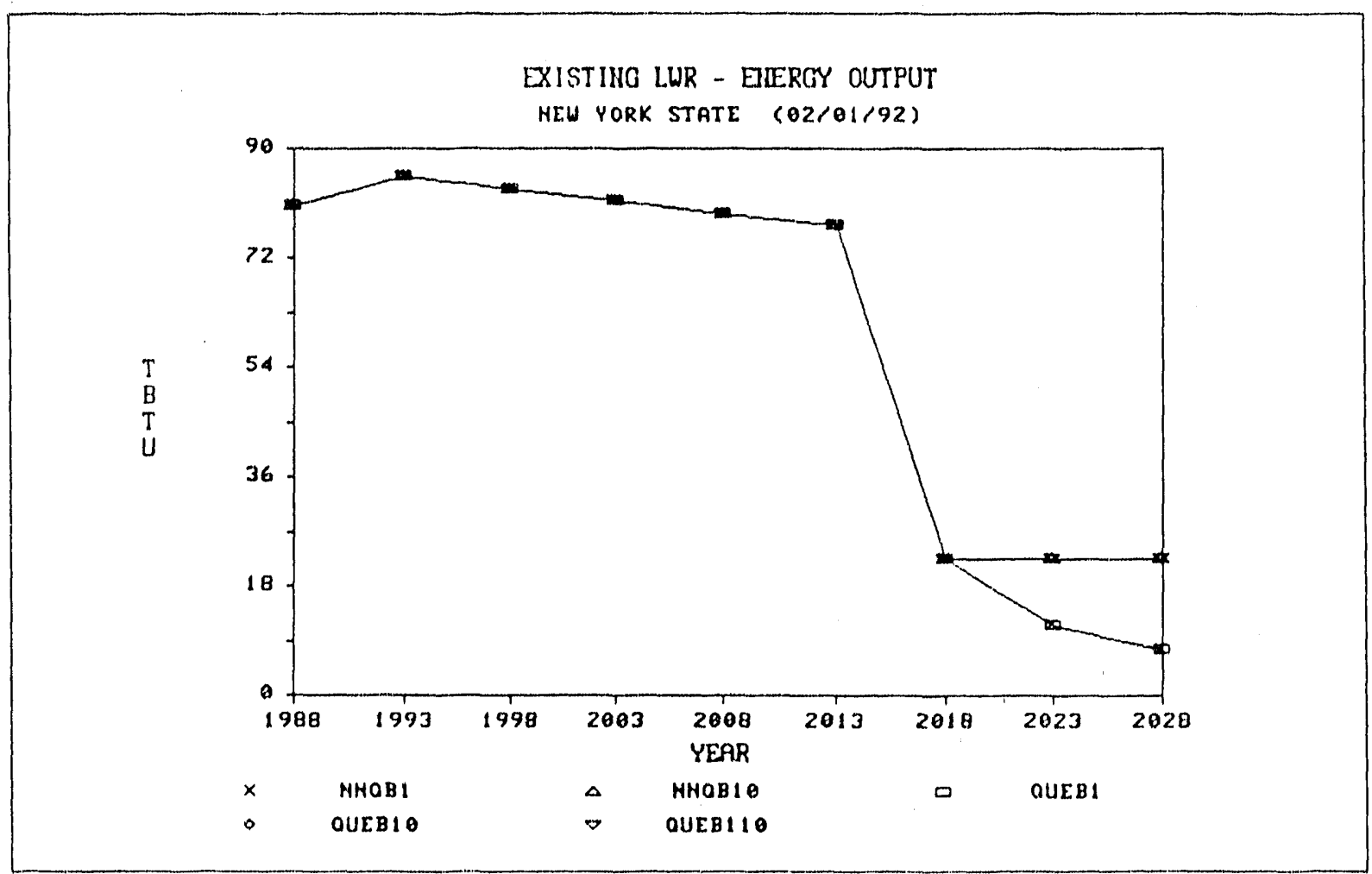

Figure 44. Comparison of nuclear power (LWR) use in Additional Quebec Hydro Scenarios with and without new nuclear power. 


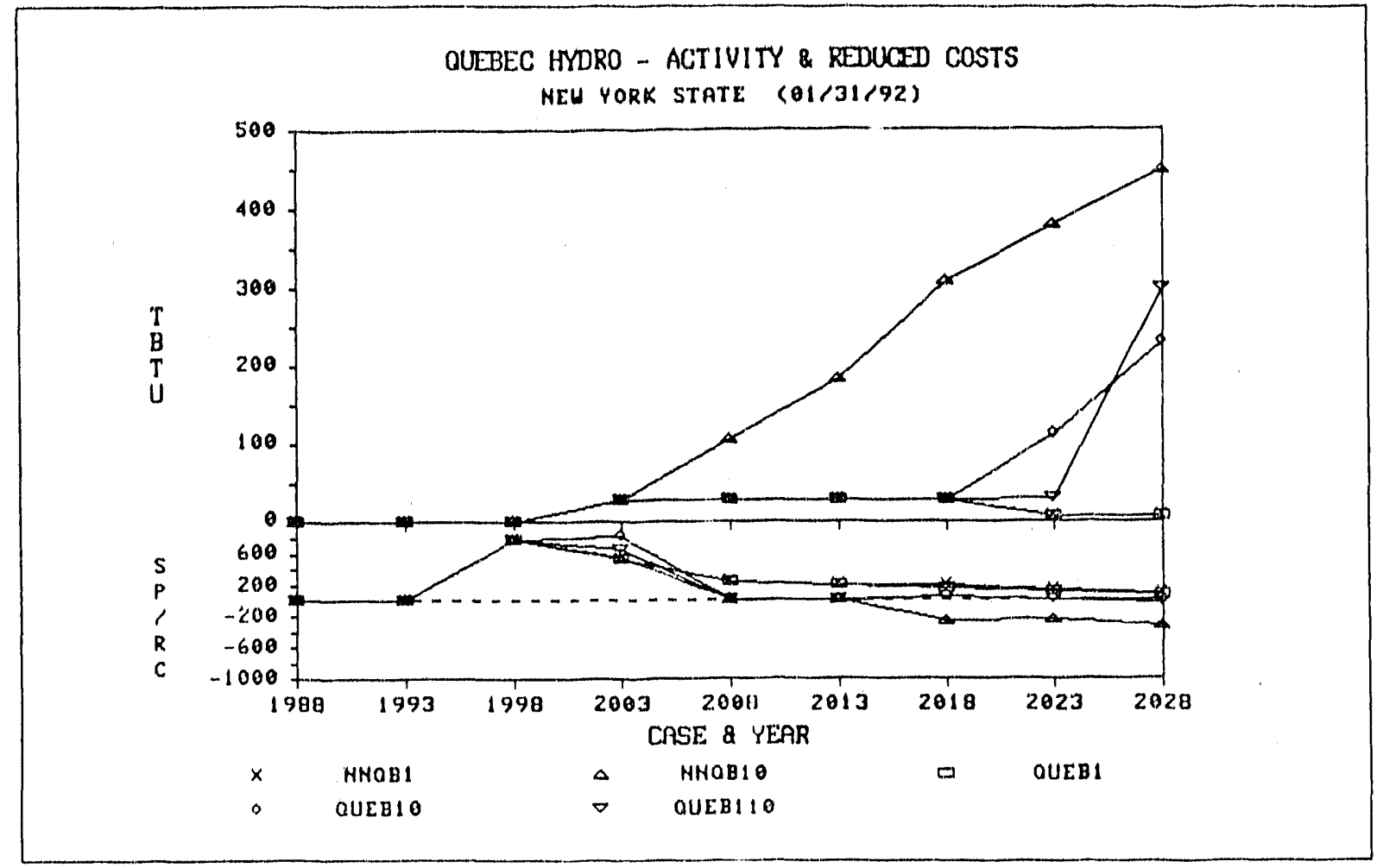

Figure 45. Comparison of activity and reduced cost of Quebec hydroelectric power in Additional Quebec Hydropower Scenarios with and without new nuclear power.

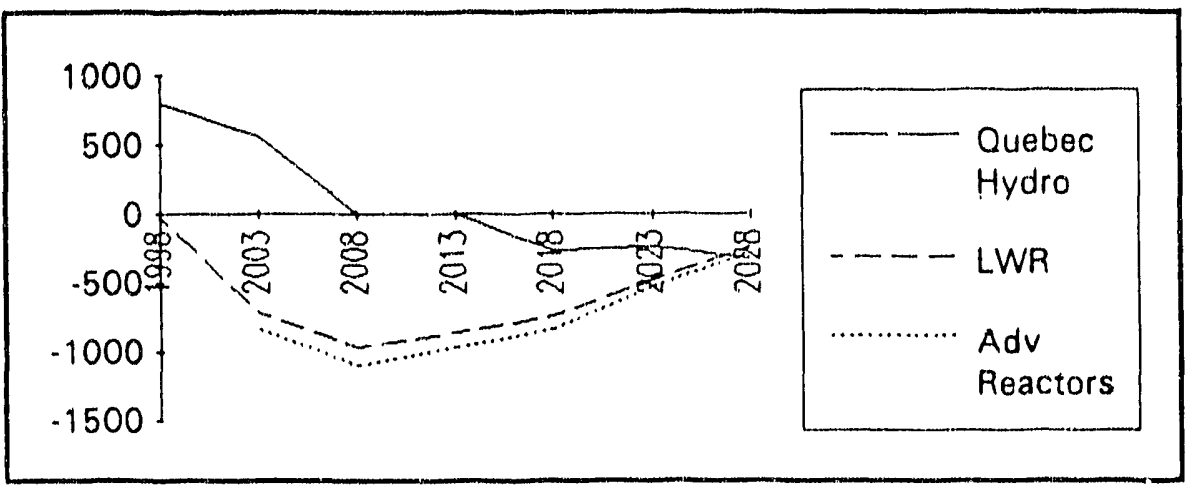

Figure 46. Comparision of reduced costs (change in total system cost in millions of dollars per additional $\mathrm{GW}_{\mathrm{e}}$ ) of Quebec hydroelectric and nuclear power (LWR) in Additional Quebec Hydropower with No Nuclear Power.. 


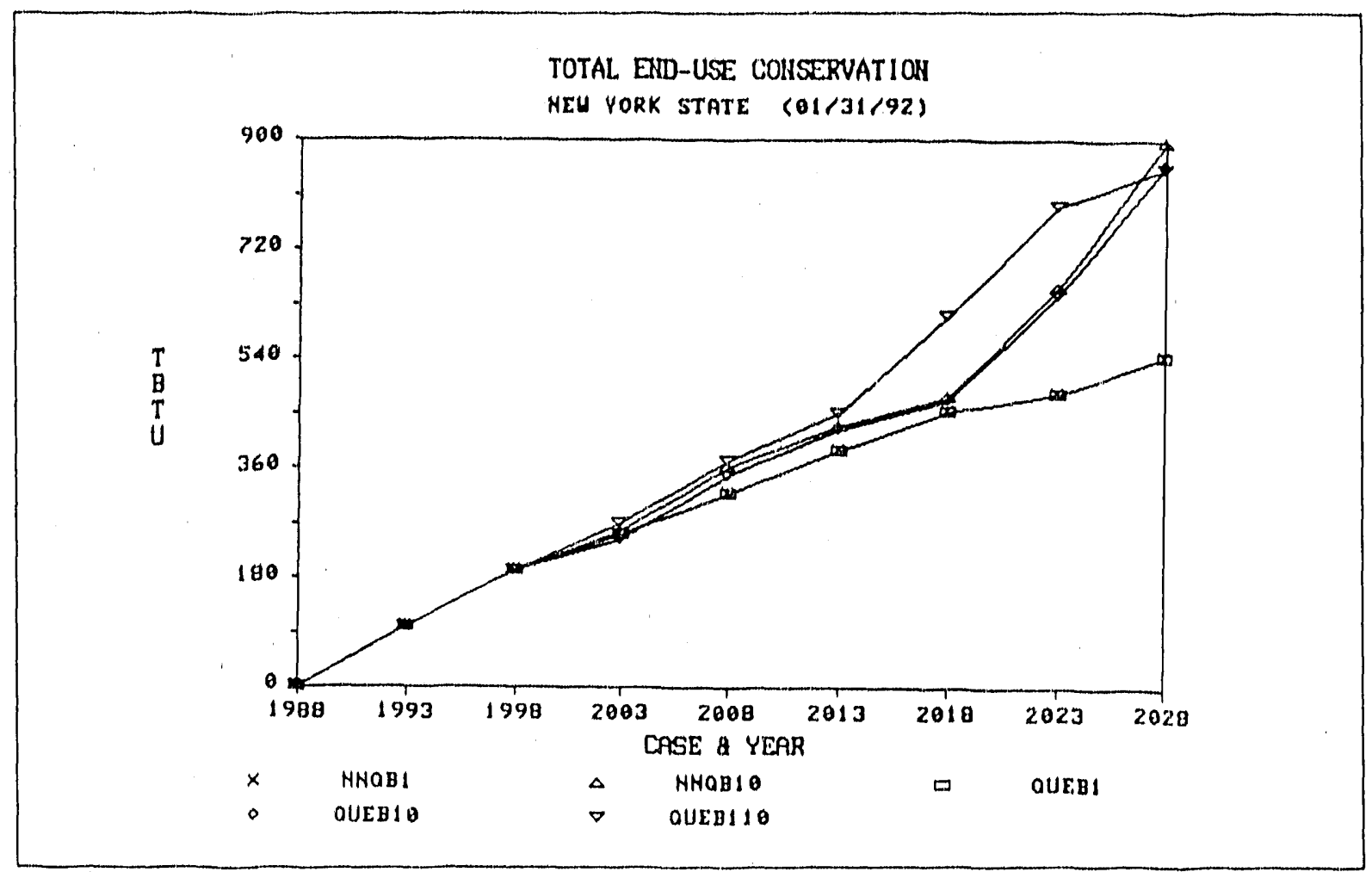

Figure 47. Total end-use conservation in Additional Quebec Hydropower Scenarios with and without nuclear power.

\section{ENHANCED BUILDING CONSERVATION SCENARIO}

In the reference case, three levels of residential building conservation were included in the database, but only one was implemented; we believe that represented a reasonable characterization of building conservation technologies that are beginning to be implemented. Here the second level is implemented as a sensitivity run. We arbitrarily made this equal to the first level in the amount of energy savings allowed, i.e., another $15 \%$ of the residential heating demand, at a capital cost double the first $15 \%$. We also delayed initial implementation until the third period (1998). Parallel technologies were applied to single family and multiple family space heating demands. In the commercial sector, two levels of building conservation were implemented in the reference case. Here we expanded this to three levels. These third level technologies were characterized by the same formula as in residential heating: they were limited to the same contribution to the heating demand as the second level conservation technologies at twice the cost, and were delayed in their initial implementation by one period. These were applied only to office and service buildings, the part of the commercial sector with the greatest opportunities for building conservation. Additional ratio equations were added to link the commercial building conservation to the air conditioning as well as the heating demand. Enhanced building conservation was not applied to the industrial sector since the primary source of end-use conservation there is seen to be improved efficiency rather than building conservation. 
The Enhanced Bullding Conservation Scenario achieved a feasible result for $20 \%$ $\mathrm{CO}_{2}$ reduction case, but not the $30 \% \mathrm{CO}_{2}$ reduction case. The model selected the full potential of the enhanced conservation even in the $10 \% \mathrm{CO}_{2}$ constraint case, indicating that conservation is the most cost effective approach in $\mathrm{CO}_{2}$ reduction among the conventional technologles. Figure 48 shows the distribution and use of building conservation technologies in the Conventional Technologies Scenario and the Enhanced Conservation Scenario for the $10 \% \mathrm{CO}_{2}$ reduction case.

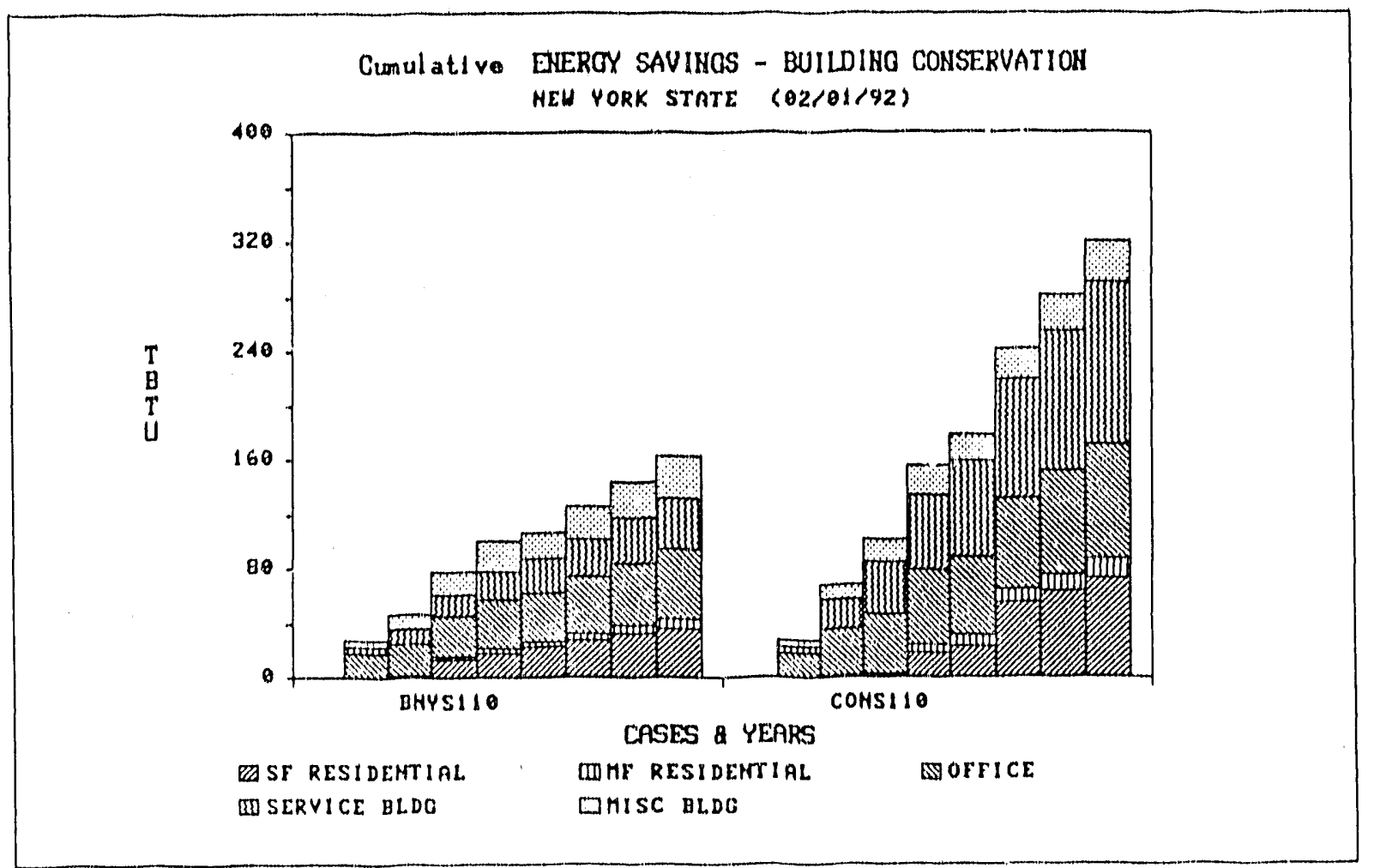

Figure 48. Building conservation contribution to useful energy demand in the $10 \%$ $\mathrm{CO}_{2}$ reduction case for the Conventional Technologies and Enhanced Conservation Scenarios.

\section{CARBON TAX SCENARIO}

Carbon taxes are a policy instrument for reducing $\mathrm{CO}_{2}$ emissions that have received much attention. Fuels are taxed in proportion to their carbon content (and thus their potential $\mathrm{CO}_{2}$ emissions) effectively increasing their price and providing a disincentive for the use of high-carbon fuels. In NYMARKAL, a pollution emissions tax is implemented by inserting a cost line in the environmental emissions factor table (in this case table ENVCO2). The tax imposed was $\$ 15$ per ton of carbon beginning in 1993 and increasing $10 \%$ per year thereafter. 
Tax effects are behavioral effects. Under perfect "rationality" people will implement conservation, switch fuels, or adopt other means to readjust their behavior to reflect the higher costs of fossil fuels. In reality, there is a great deal of inertia associated with such change. Higher carbon taxes then would be predicted by MARKAL are likely to be needed to induce change in a reasonable time. Once the system readjusts, only a tax rate sufficient to produce price differentials needed under "rationality" will be needed to maintain the new status quo, It is these long-term carbon tax rates that MARKAL provides. Econometric models are more focused on behavioral effects and can ald in estimating the short-term, transitional shock taxes needed to induce change in the short-run.

The effect of this tax is seen in Figure 49 . The $\$ 15$ per ton ratcheted tax yields a substantial reduction in emissions, but only approaches a $\mathrm{CO}_{2}$ emissions stability level. Figure 50 shows the effect of the same tax on the US as a whole. The greater effectiveness of the tax in the U.S. illustrates that $\mathrm{CO}_{2}$ reductions are harder to achieve and more expensive to achieve in New York State than in other parts of the U.S.

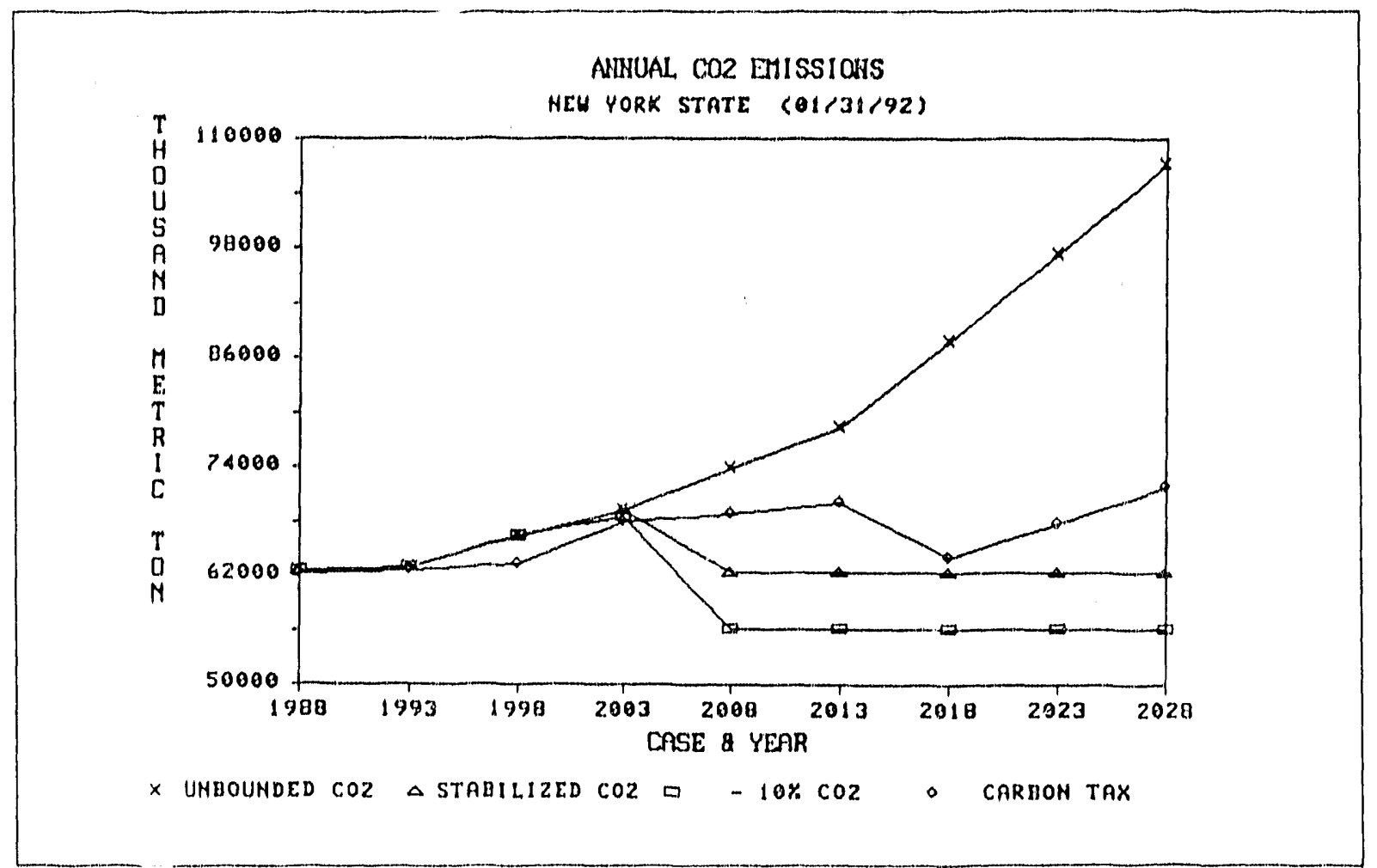

Figure 49. Total New York State energy system $\mathrm{CO}_{2}$ emissions from $\$ 15$ per ton carbon tax, escalating at $10 \%$ per year, compared to emissions from unbounded reference case and constrained cases of the Conventional Technology Scenario. 


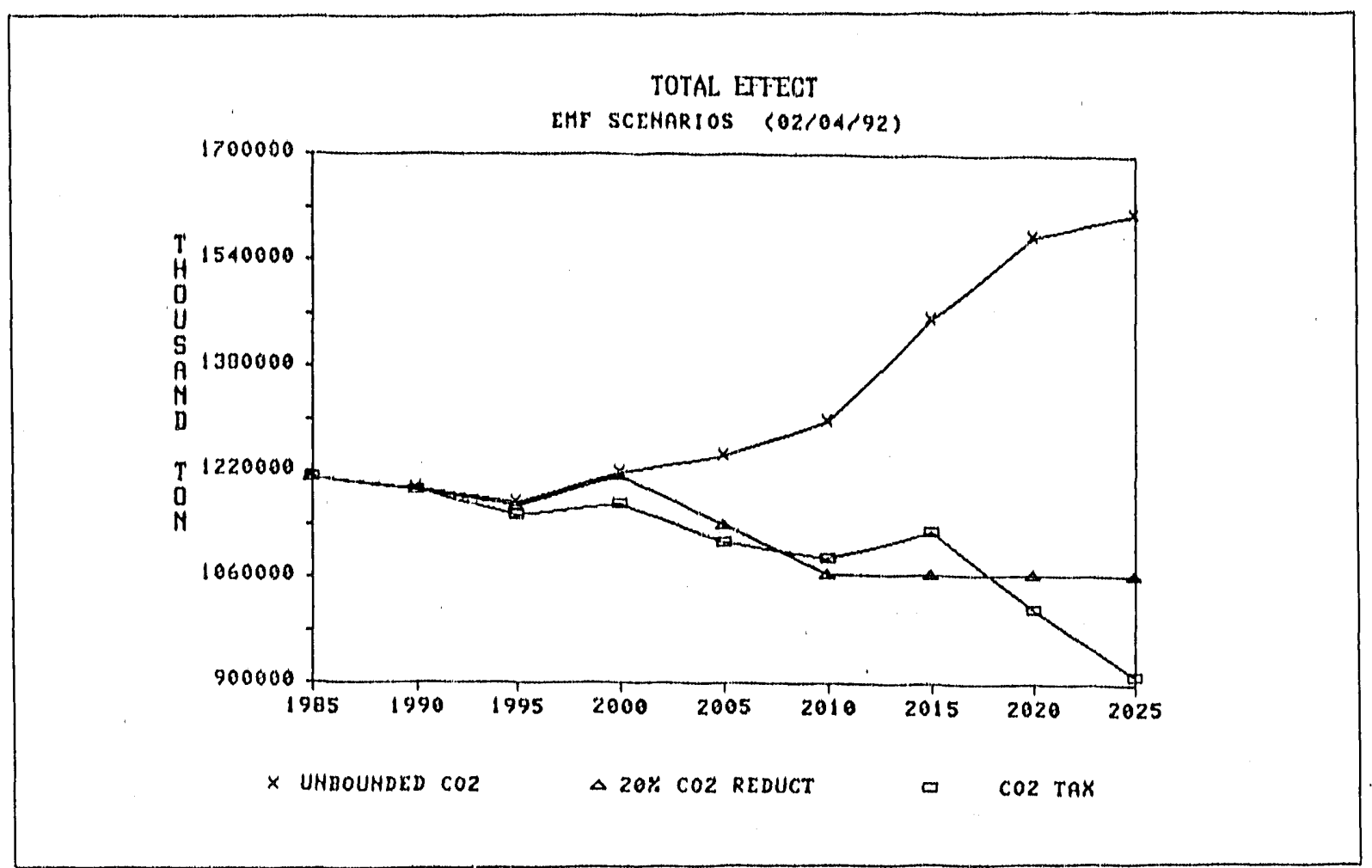

Figure 50. Total United States energy system $\mathrm{CO}_{2}$ emissions from $\$ 15$ per ton carbon tax, escalating at $10 \%$ per year, compared to emissions from unbounded and constrained cases.

\section{DISCUSSION AND CONCLUSIONS}

NYMARKAL is a model of the New York State energy system. It includes numerous options for fuel switching, improved efficiency of supply-side and demand-side technologies, end-use conservaiton, increased use of renewable energy, reforestation, and pollution taxes such as a carbon tax. NYMARKAL represents the New York State energy system as a set of typical technologies for generating, converting, and using energy as it evolves over a 45-year period. In a variety of scenarios, the model chooses from a menu of several hundred candidate technologies to select the set that meets projected energy demands, environmental restrictions, and other constraints at least cost. NYMARKAL was applied here in demonstration analyses to explore strategies to reduce $\mathrm{CO}_{2}$ emissions. The analyses begin with the same economic forecast as used in the State Energy Plan and the same initial conditions. However, it takes a different approach to analysis. The energy plan forecasts of fuel and technology trends are based on projections of current trends, modified by environmental regulations and behavioral factors. MARKAL results are based more rigidly on least-cost decision-making. By lifting some of the assumptions about behavior and current societal trends, MARKAL is freed to seek potentially better futures. This is especially appropriate when looking 20 to 40 years into the future, an important time-frame for considerations of greenhouse gas emissions. MARKAL can be made to match projections of current trends, but doing that would decrease its real power. Some of the important lessons from a MARKAL analysis can be gained by comparing MARKAL scenarios with trend projections. 
Climate change is a global issue. II is being addressed in international, national, and state forums. New York may, on lis own, decide to take action to reduce $\mathrm{CO}_{2}$ emissions. New York may also be required to lake action based on national legislation or international agreements entered into by the United States. It is important to understand the costs and other implications for the State and how New York compares with the rest of the U.S. We have constructed and run a MARKAL model of the U,S, and use it to provide a comparison. It is more difficult and more expenslve to reduce carbon emissions in New York State than in the United States as a whole. This can be IIlustrated by three different comparisons between the two studies:

- Greater emission reductions were feasible in the US than in New York. The maximum $\mathrm{CO}_{2}$ emissions reduction target achleved (and sustained) in the constrained analyses presented here was $20 \%$ below 1988 levels. That larget was achleved only by making available a wide range of technological options including reforestation, end-use conservation, nuclear, and imported hydropower. Our MARKAL analyses of the U.S. achieved $20 \% \mathrm{CO}_{2}$ reduction in 2010 , increasing toward $50 \%$ reduction in 2050 without adding reforestation or other means of carbon sequestration.

- The average cost of achieving stated emissions reduction targets was lower in the U.S. than in New York. The estimated average cost of carbon removal in New York State in this analysis from the unconstraince case to the stability case ranges from $\$ 14 /$ ton carbon to $\$ 22 /$ ton carbon, depending on the scenario. The average cost of further carbon removal to the $10 \%$ level ranged from $\$ 48 /$ ton carbon to $\$ 72 /$ ton carbon. In the two scenarios in which $20 \% \mathrm{CO}_{2}$ reductions could be achieved, the average cost of the additional increment ranged from $\$ 94 /$ ton carbon to $\$ 150 /$ ton carbon. In contrast, our analysis of the U.S. as a whole indicated that $\mathrm{CO}_{2}$ emissions stability could be achleved at an average cost of $\$ 3.50 /$ ton carbon and the additional increment from stability to $20 \% \mathrm{CO}_{2}$ emissions reduction was only $\$ 11 /$ ton carbon.

- $\mathrm{CO}_{2}$ reductions resulting from the same level carbon tax were greater in the U.S. than in New York. The same carbon tax level $(\$ 15 /$ ton carbon increasing at $10 \%$ /year) that results in a $20 \%$ reduction in $\mathrm{CO}_{2}$ emissions nation-wide falls short of stabilizing $\mathrm{CO}_{2}$ emissions in New York State.

The implication is that, were a common carbon tax instituted, it would have less effect in New York and most carbon emissions reduction would take place elsewhere in the country where it is more cost-effective. Alternatively, were all states required to reduce $\mathrm{CO}_{2}$ emission an equal percentage (say by $20 \%$ ), the cost per unit emissions reduction to New York would be much greater than in the rest of the country. If as a nation we wish to reduce carbon emissions, the most cost-effective approach would be to aim at greater emissions reduction outside of New York.

What makes reducing $\mathrm{CO}_{2}$ emissions in New York more difficult and more expensive? Studies around the world have found that reducing $\mathrm{CO}_{2}$ emissions invariably translates into reducing coal use. Coal provides a substantial fraction of primary energy in the United States and therefore the country as a whole has the capability of significant reductions in $\mathrm{CO}_{2}$ emissions with the impact largely confined to this single sector. The US also has a bigger and more diverse arsenal of alternative technologies and resources than 
does New York. For example, geothermal and solar energy are more abundant in other parts of the country.

What do the MARKAL results so far say about how $\mathrm{CO}_{2}$ emissions can be reduced in New York State? What must go, what new technologies or resources should come to the fore? We examined end-use conservation, increased efficiency in use of fossil fuels, fuel switching among, fossil fucls (e.g., oil or coal to natural gas), nuclear power, hydroelectric power, other non-carbon energy sources, and sequestering carbon in trees. These are each discussed below.

Advocates of conservation and renewables often argue that these are "no regret" options, that is, even if $\mathrm{CO}_{2}$ reductions were to prove unnecessary, investment in conservation and renewables will have been money well spent. MARKAL analyses examine this issue in the following way: technologies that are indeed "no regret" will be selected in the cases with no $\mathrm{CO}_{2}$ constraints. Our NYMARKAL and USMARKAL models eliminate the institutional barriers that impede introduction of these technologies in the real world. Our findings are that conservation indeed enters the energy system rapidly even in the absence of $\mathrm{CO}_{2}$ constraints. Use of renewable energy also increases, but in New York, its growth rate is not outstanding. Without $\mathrm{CO}_{2}$ constraints it grows at about the same rate as oil or natural gas. Much of the renewable energy is hydroclectric. Under $\mathrm{CO}_{2}$ constraint, MARKAL invests in pore conservation and renewables. From an economic viewpoint, this additional investment is not "no regret" but is cost-effective only under $\mathrm{CO}_{2}$ constraints.

In the Conventional Technology Scenario, NYMARKAL increases conservation at $4.9 \% /$ year without constraint, increasing to $6.2 \%$ /year with $\mathrm{CO}_{2}$ constraints. In the Enhanced Conservation Scenario, annual average increases in conservation in unconstrained and constrained cases are $5.4 \% /$ year and $6.6 \%$ year respectively. The additional conservation technologies available in the Enhanced Conservation Scenario are sufficient to allow MARKAL to achieve the $20 \% \mathrm{CO}_{2}$ reduction target. The rate of increase of conservation in New York is higher in both cases than in the US as a whole, although the relative change due to $\mathrm{CO}_{2}$ constraint is lower (see Table 11).

The reverse is true for renewables, for which the rate of increase is lower in New York than in the US, although the change upon introducing $\mathrm{CO}_{2}$ constraints is greater. In the New York Additional Quebec Hydropower Scenario, the unconstrained case includes only slightly higher growth in renewables, but with $\mathrm{CO}_{2}$ constraint, the annual average increase in renewables increases to $3.8 \% /$ year. 
Table 11. Comparison of average annual growth rate for conservation and renewables between U.S. and New York State (Conventional Technologies Scenario) for unconstrained and constrained $\mathrm{CO}_{2}$ emissions.

\begin{tabular}{|c|c|c|}
\hline & Unconstrained & Constrained \\
\hline New York & & \\
\hline Conservation & 4.9 & 6.2 \\
\hline Renewables & 0.8 & 1.4 \\
\hline United States & & \\
\hline Conservation & 3.0 & 4.7 \\
\hline Renewables & 3.4 & 4.0 \\
\hline
\end{tabular}

One conservation technology of especial note is improved lighting systems in commercial buildings. This has bcen targeted by utilitics as a prime candidate for refucing electrical load. NYMARKAL, however, selects this technology only when the system is highly stressed, i.e., in the $20 \%$ $\mathrm{CO}_{2}$ removal case for conservation and the stability case for the No New Nuclear Scenario. The reduced costs shown in Figure 51 tell the story. Reduced costs are slightly higher for service buildings and miscellaneous

buildings, where the technology was never selected. In the later periods, reduced costs of lighting technologies in all three types of buildings are close; a small difference in the cost estimates of this technology, well within the range of uncertainty expected when projecting costs 20 years in the future, would be sufficient to alter the decision to use this technology and the amount it is used. Perhaps more important, it is surprising that commercial lighting technologies did not come out more favorably in the results. Because of the importance of this technology to demand-side management plans, analysis of a more detailed breakdown of lighting technologies is warranted before drawing any conclusions.

Increased efficiency in fossil fuel use is available to the model on the supply and the demand side. The model includes several new, higher efficiency coal-fired power plants and new, higher efficiency, residential, commercial, and industrial furnaces for gas, oil, and coal. Without $\mathrm{CO}_{2}$ constraints, a variety of more efficient coal electric power devices are brought into the system. As $\mathrm{CO}_{2}$ emission constraints increase, only the most efficient technologies are included. 


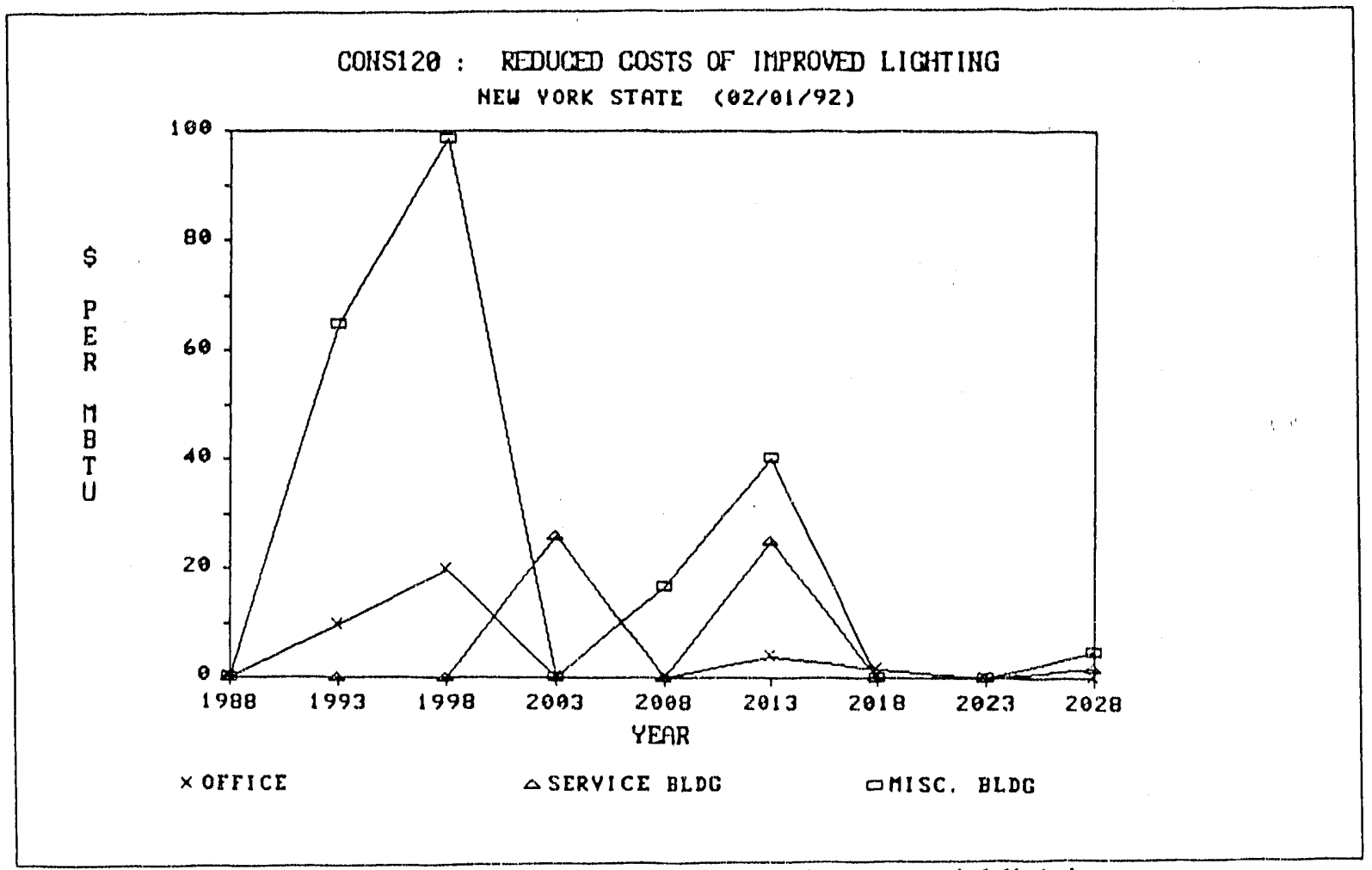

Figure 51. Reduced costs of improved commercial lighting.

As expected, $\mathrm{CO}_{2}$ constraints result in substantial decreases in the use of coal $(85 \%$ in the Conventional Technology Scenario). Oil use also decreases, with the size of the decrease growing over time. In some sectors (e.g., single family space heating), oil disappears entirely. Use of gas as a fuel for electric power generation does not change, but some of the decreases in oil and coal use for direct combustion by end-users is displaced by gas. Overall, gas use increases. The increase bulges to $35-40 \%$ over the unconstrained case in the mid-years after the $\mathrm{CO}_{2}$ reduction target date (2013-2018) and then narrows (8\% in 2028). Total fuel switching among fossil fuels is the same as the increase in gas use. In the Conventional Technology Scenario during the peak period (2013), this is 316 TBtu/year, about $10 \%$ of all fossil energy and $6 \%$ of total primary energy.

Nuclear and Quebec hydropower were the two primary non-carbon fuels that could fill the gap left by reductions in coal and oil to meet $\mathrm{CO}_{2}$ emissions constraints. Substantial reductions in $\mathrm{CO}_{2}$ emissions could not be sustained without nuclear or large future imports of Quebec hydropower. In no scenario were we able to achieve and sustain even $10 \%$ reduction in $\mathrm{CO}_{2}$ emissions without additional nuclear power. Even with $15 \mathrm{GW}$ electrical capacity available from Quebec in the No New Nuclear - Hydro Quebec Scenario, only a stable $\mathrm{CO}_{2}$ target could be achieved. If the Siate wants or needs to do more than stabilize $\mathrm{CO}_{2}$ emissions, and wants to avoid adding new nuclear capacity, other options must be explored.

Renewable technologies, other than hydroelectricity generated in New York State and Quebec, are municipal solid waste, wind turbines, solar thermal power, photovoltaics,

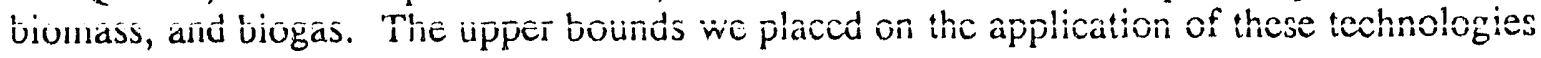


in New York total ??. This is only [fraction] of hydroelectric potential, so the the potential contribution of technologies is limited. Nonctheless, under $\mathrm{CO}_{2}$ emissions constraints, all of these other renewable energy sources reach their upper bounds. Figures 50 and 51 show the reduced costs of centralized and local renewable technologies for the highest $\mathrm{CO}_{2}$ constraint in each scenario. These suggest that, among these non-hydropower renewable technologies, local and central wind, photovoltaics and solar steam electric have the most consistent and sustained growth, coupled with consistently high reduced costs (indicating a high marginal value to the model). Considering the potential value of these technologies, future analyses should investigate opportunities to raise those upper bounds, allowing more renewable energy into the system. Their maximum use, however, is limited.

Simply keeping track of emissions of other pollutants in NYMARKAL provides the opportunity to assess the effect of $\mathrm{CO}_{2}$ constraints on sulfur dioxide, nitrogen oxides, and particulate pollution emissions (e.g., Figures 33-35). The dramatic reductions, especially in $\mathrm{SO}_{2}$ and particles, illustrate the massive effect that $\mathrm{CO}_{2}$ constraints can have on the energy system. A $10 \%$ reduction in the level of $\mathrm{CO}_{2}$ emissions can result in a reduction of other pollutants beyond what has been possible through existing clean air legislation. There are two sides to this result. First, $\mathrm{CO}_{2}$ constraints can yield substantial collateral benefits in reducing emissions of other pollutants. As with energy conservation conservation, $\mathrm{CO}_{2}$ constraints tend to push in the direction of more general environmental quality

improvement. On the other side, however, it must be remembered that greater air quality improvements have not been made to date largely because of the large costs involved. The fact that they occur automatically as the result of meeting $\mathrm{CO}_{2}$ emission reduction targets does not not make these costs any less burdensome to society.

How much of a reduction in New York State $\mathrm{CO}_{2}$ emissions is technologically feasible? The demand for energy services in New York State is projected to grow. Without an unlimited supply of energy, at some point this increasing demand must exceed supply, resulting in a technically infeasible situation. When $\mathrm{CO}_{2}$ emissions restrictions are added, the system becomes further constrained and the point of infeasibility comes closer in time to the present. The question of technological feasibility then is not it a reduction is infeasible, but at what point in the future will a given level of $\mathrm{CO}_{2}$ emissions reduction become infeasible? The State Energy Office's usual planning horizon is about 20 years. That puts the point at which carbon emission controls are imposed in this study near the edge of the planning horizon, yet it appears that maintaining $\mathrm{CO}_{2}$ emission goals beyond initial target dates may be harder than meeting initial targets. Therefore, this study looked two decades further into the future, to 2028. Beyond the third or fourth decade of the next century, social and technological changes beyond our vision can be expected to intervene. New technologies or resources may emerge, technologies may advance beyond expectation, or population shifts, lifestyles or technological changes may result in lower demands for energy services. Global climate change is a problem that requires us to consider consequences much further into future, at least to 2100 , but we cannot expect to make detailed projections that far ahead. We can and do need to consider detailed technological options over a 40-50 year future, however, and that is the task on which NYMARKAL focuses.

NYMARKAL helps to provide insight. Sometimes this confirms conventional wisdom but other times it points out overlooked possibilities and fills knowledge gaps. One can gain insight by reading about the results of model runs, but the model can be used to 

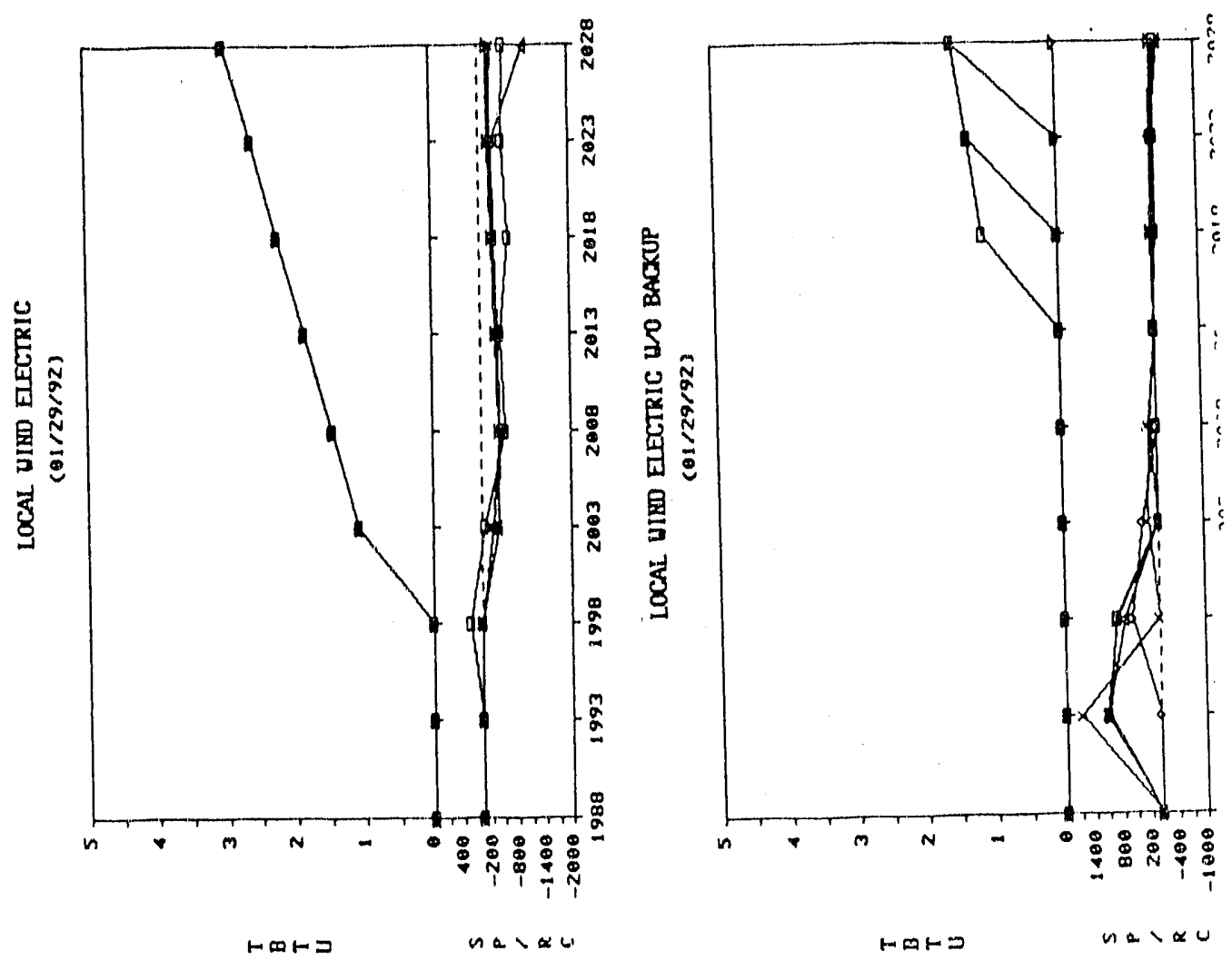

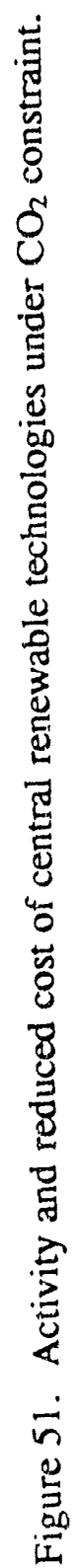

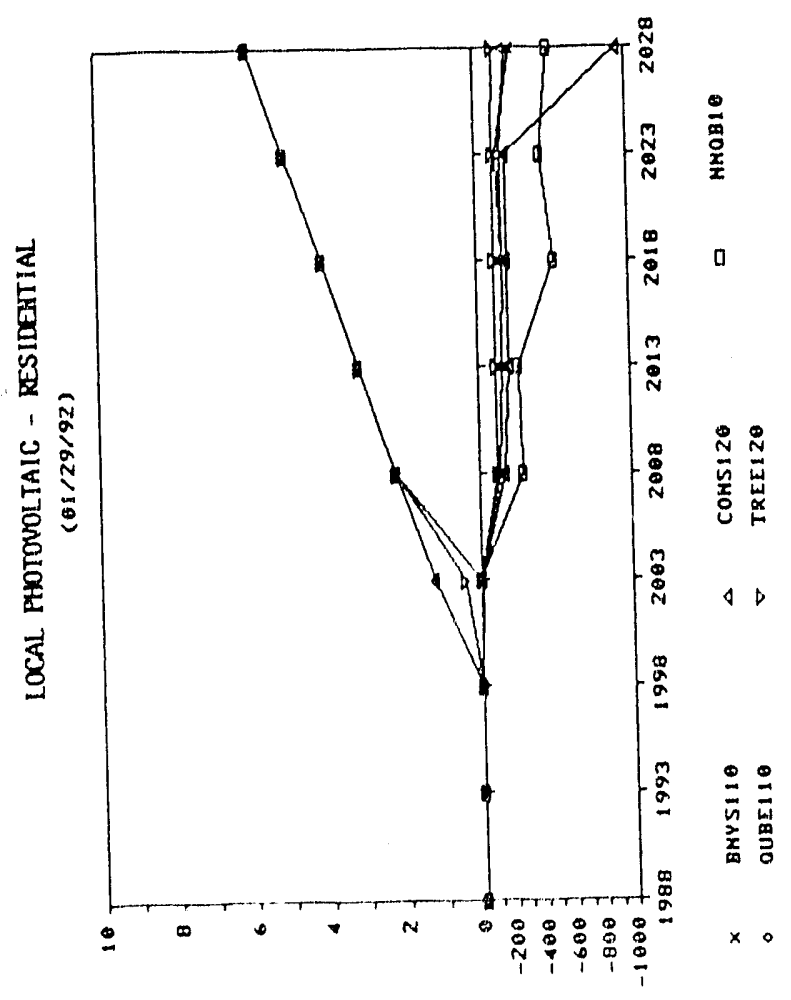

ルロトコ

$-60 A-$ 

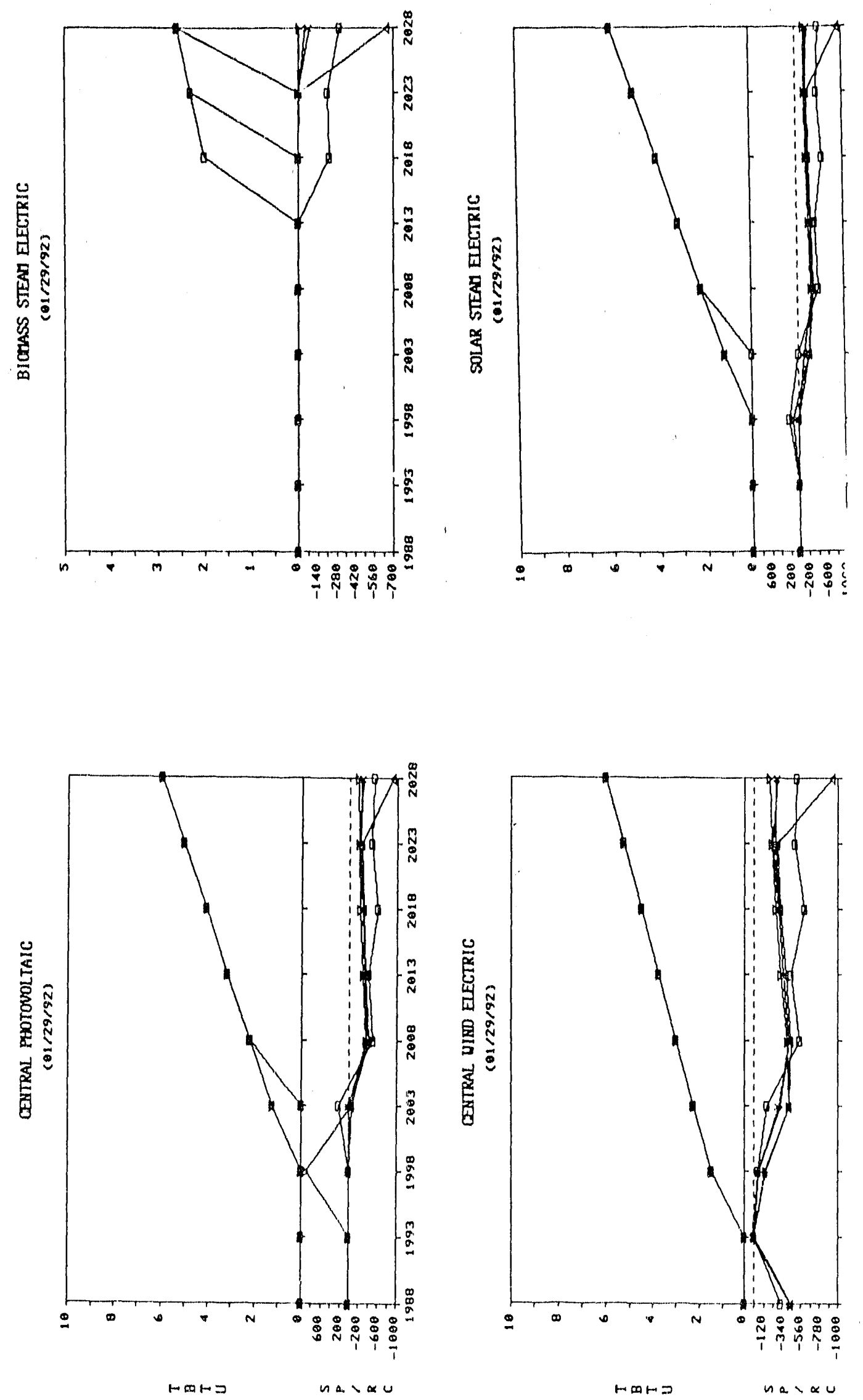

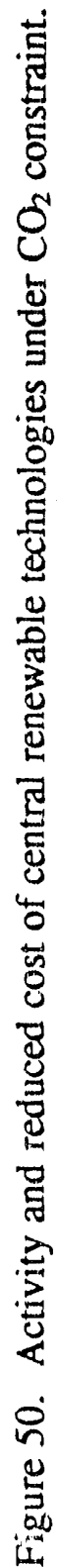


greater advantage. Energy system planning involves an interaction among complex technological, economic, environmental, social, and political considerations. It is through interaction among people from those areas that real advances can be made. NYMARKAL can provide a common framework of discussion for such interaction.

\section{REFERENCES}

Beller, M. (ed). 1975. Sourcebook for Energy Analysis (BNL 50843), Brookhaven National Laboratory, Upton, NY 11973.

Butcher, S.S. and M.J. Ellenbecker. 1982. Particulate emission factors for small wood and coal stoves, JAPCA $32:$ 380-384.

DeLuchi, M.A., D. Sperling and R.A. Johnston. 1987. A Comparative Analysis of Future Transportation Fuels (UCB-ITS-RR-87-13). Institute of Transportation Studies, University of Califomia, Berkeley, CA.

DOE. 1980a. Technology Characterizations Environmental Information Handbook (DOE/EV-0072). U.S. Department of Energy, Washington, D.C.

DOE. 1980b. Environmental Data, Energy Technology Characteristics, Coal (DOE/EV0061/3). U.S. Department of Energy, Washington, D.C.

DOE. 1981. Energy Technologies and the Environment (DOE/EP-0026). U.S. Department of Energy, Washington, D.C.

DOE. 1983. Energy Technology Characterizations Handbook: Environmental Pollution and Control Factors (DOE/EP-0093). U.S. Department of Energy, Washington, D.C.

DOE. 1988. Energy Technologies \& the Environment (DOE/EH-0077). U.S. Department of Energy, Washington, D.C.

Drouin, R. 1990. Notes pour l'allocution devant le Club d'Electricit du Quebec.

Giesen, G., D. Wilde, G. Wolfrum. 1989. MARKAL Report writer, Version 2.11, Documentation for Users. Forschnungszentrum Julich GmbH (KFA), Julich, Germany.

Fishbone, L.G. and Abilock, H. 1981. MARKAL, a linear-programming model for energy systems analysis: technical description of the BNL version, Energy Research 5: 353-375.

Fishbone, L.G., Giesen, G., Goldstein, G., Hymmen, H.A., Stocks, K.J., Vos, H., Wilde, D., Zolcher, R., Balzer, C. and Abilock, H. 1983. User's guide for MARKAL (BNL/KFA version 2.0), A multi-period, linear-programming model for energy systems analysis (BNL 51701), Brookhaven National Laboratory, Upton, N.Y. 
Giesen, G., Wilde, D. and Wolfrum, G. 1989. MARKAL, a linear-programming model for energy systems analysis, report writer, version 2.11 , documentation for users, Forschnungszentrum Julich GmbH, Julich, Germany.

Goldstein, G. 1991. PC-MARKAL and the MARKAL Users Support System (MUSS) (BNL 46319), Brookhaven National Laboratory, Upton, N.Y.

Jorgenson, D.W. and Wilcoxen, P.J. 1989. Environmental regulation and U.S. economic growth (Discussion paper 1458), Harvard Institute of Economic Research, Cambridge, MA.

Manne, A.S., Condap, R., and Preckel, P. 1981. ETA-MACRO: a user's guide, (EPRI EA-1724), Electric Power Research Institute, Palo Alto, CA.

Manne, A.S., Beltramo, M.A., Rutherford, F.F., Svoronos, A.N., and T.F. Wilson. 1983. ETA-MACRO: A progress report (EPRI EA-3170), Electric Power Research Institute, Palo Alto, CA.

Mortimer, N. 1991. Nuclear power and global warming, Energy Policy 19:76.

Moskowitz, P.D. and L.D. Hamilton. 1988. Energy and complex industrial systems, environmental emissions data reporting and acquisition, Annex III in Emissions, Environmental Transport, and Dose-Response Models: Guidelines for Case Studies (WHO/PEP/88.13), World Health Organization, Geneva.

NYSEO. 1991a. Draft New York State Energy Plan. Prepared jointly by New York State Energy Office, Department of Public Service, Department of Environmental Conservation, Albany, NY.

NYSEO. 1991b. Analysis of Carbon Reduction in New York State. New York State Energy Office, Albany, NY.

Perry, A.M., R.M. Rotty and D.B. Reister. 1977. Net energy from nuclear power, in Nuclear Power and its Fuel Cycle, Vol I. International Atomic Energy Agency, Vienna, pp. 709-721.

Sanghi, A.K. and K.S. Michael. 1991. Carbon sequestering through reforestation: cost and potential for New York. Presented at the 84th Annual Meeting, Air \& Waste Management Association, Vancouver, British Columbia.

Thérien, N. 1990. Impacts cumulatifs-enjeu "Qualite de l'air", Etude des enjeux environnementaux associes a l'effet de serre suite a la creation de reservoirs hydroelectriques. Rapport final presente a la Vice-presidence Environnement d'HydroQuebec.

University of Oklahoma. 1975. Energy Alternatives: A Comparative Analysis. Science and Public Policy Program, University of Oklahoma, Norman, OK. 


\section{APPENIIX I, LISTING AND DESCRIPTION OF NYMARKAL OUTPUT FILES.}

The convention we adopted for output files was a four digit alphanumeric code identifying the scenario (e.g., TREE for the reforestation scenario), followed by a fifth digit to identify different versions of the scenario, if any. Finally, the level of $\mathrm{CO}_{2}$ reduction associated with the case was designated as "0" for stability, "10" for a $10 \%$ reduction from 1988 levels by 2008, "20" for a $20 \%$ reduction from 1988 levels by 2008, etc. File listings follow:

BNYS1 Reference case; Conventional Technology Scenario

BNYS10 Conventional Technology Scenario, $\mathrm{CO}_{2}$ stability

BNYS110 Conventional Technology Scenario, $10 \%$ reduction in $\mathrm{CO}_{2}$

TREE1 Reforestation Scenario, $\mathrm{CO}_{2}$ unbounded

TREE10 Reforestation Scenario, $\mathrm{CO}_{2}$ stability

TREE110 Reforestation Scenario, $10 \%$ reduction in $\mathrm{CO}_{2}$

TREE120 Reforestation Scenario, 20\% reduction in $\mathrm{CO}_{2}$

CONS1 Enhanced Building Conservation Scenario, $\mathrm{CO}_{2}$ unbounded

CONS10 Enhanced Building Conservation Scenario,, $\mathrm{CO}_{2}$ stability

CONS110 Enhanced Building Conservation Scenario, $10 \%$ reduction in $\mathrm{CO}_{2}$

CONS120 Enhanced Building Conservation Scenario, 20\% reduction in $\mathrm{CO}_{2}$

QUEB1 Increased Hydroelectric Imports Scenario, $\mathrm{CO}_{2}$ unbounded

QUEB10 Increased Hydroelectric Imports Scenario, $\mathrm{CO}_{2}$ stability

QUEB110 Increased Hydroelectric Imports Scenario, $10 \%$ reduction in $\mathrm{CO}_{2}$

NNQB1 Increased Hydroelectric Imports and No New Nuclear Power Scenario,, no $\mathrm{CO}_{2}$ constraint.

NNQB10 Increased Hydroelectric Imports and No New Nuclear Power Scenario, $\mathrm{CO}_{2}$ stability.

TAXC1 Carbon Tax Case. No direct constraints on $\mathrm{CO}_{2}$ used with this scenario 


\section{APPENDIX II. EMISSIONS OF OTHLR GRENNHOUSE GASES}

Other grecnhouse gases include methane $\left(\mathrm{CH}_{4}\right)$, nitrous oxide $\left(\mathrm{N}_{2} \mathrm{O}\right)$, tropospheric ozone $\left(\mathrm{O}_{3}\right)$, and chlorofluorocarbons (CFCs). In addition, carbon monoxide (CO), non-methane hydrocarbons, and nitrogen dioxide $\left(\mathrm{NO}_{2}\right)$, while not grecnhouse gases themselves, contribute to atmospheric chemistry reactions that increase the amount of methane and ozone in the atmosphere. Non-methane hydrocarbons and nitrogen dioxide are the key ozone precursors, while carbon monoxide competes with methane for oxygen; as the amount of $\mathrm{CO}$ in the atmosphere increases, the amount of methane removed from the atmosphere through oxidation declines (Ciborowski, 1989).

Here we deal only with direct emissions of greenhouse gases, thus focusing on methane, nitrous oxide and CFCs. It now appears that CFCs have both warming and cooling effects, so role as important greenhouse gases is in question. Moreover, efforts are underway to increase the specd of elimination of the use of CFCs. The contribution of new emissions of CFCs to global warming in comparison to $\mathrm{CO}_{2}$ and methane emissions produced over the 45 year study period of NYMARKAL will probably be small. Emissions and equivalent greenhouse gas effect of these gases are given in Table II-1.

Table II-1. Emissions of greenhouse gases in New York State.

\begin{tabular}{|l|c|c|c|}
\hline Greenhouse Gas & $\begin{array}{c}\mathrm{CO}_{2} \\
\text { Equivalence }\end{array}$ & $\begin{array}{c}\text { Emission } \\
\text { Ktons/y }\end{array}$ & $\begin{array}{c}\mathrm{CO}_{2} \text { Equiv. } \\
\text { Emission }\end{array}$ \\
\hline Carbon Dioxide & 1 & $232,000$. & $232,000$. \\
\hline Methane & 21 & $2,081$. & $47,701$. \\
\hline $\mathrm{N}_{2} \mathrm{O}$ & 290 & 74.3 & $21,547$. \\
\hline $\mathrm{CFCs}$ & $1500-7300$ & 31. & $?$ \\
\hline Others & & & $47,647 . *$ \\
\hline *Based on NY share of US GHG emissions. \\
Table adopted from NY State Energy Office (1991).
\end{tabular}

The emission estimates of methane and nitrous oxides in Table II-1 are subject to considerable uncertainty. Based on $\mathrm{CO}_{2}$ equivalence of these estimates, however, $\mathrm{CO}_{2}$ contributes $64 \%$ of the warming potential of greenhouse gas emissions in New York State. This assumes CFCs make no contribution. Were CFCs included, the $\mathrm{CO}_{2}$ contribution would be $48 \%$.

Emissions of greenhouse gases other then $\mathrm{CO}_{2}$ are important for two reasons: First, they provide a perspective on the extent of the greenhouse problem that is addressed by the current analysis of $\mathrm{CO}_{2}$ emissions (50-64\%). Second, they assist in decisions on what new emission sources are important to include in NYMARKAL. Emission rates 
of methane and $\mathrm{N}_{2} \mathrm{O}$ are more variable and more uncertain than emisston rates of $\mathrm{CO}_{2}$. None-the-less, it is useful to include current estimates of these emissions to allow the analysis to address a larger share of the problem.

Sources of methane in New York State include criterle fermentation, wetlands, biomass burning, termites, landfills, oceans, freshwater bodies, saltwater bodies, and the natural gas transmission and distribution system. The latter is the key domestic energy source of methane for consideration for inclusion in NYMARKAL. Emissions from landfills are also of possible interest, since NYMARKAL now includes methane from landfills as an energy resource. The more that resource is used, the lower the direct emission of methane to the atmosphere.

Coal mines are another source of methane. Adding methane emissions to coal imports and imports of coal-fired electricity is a high priority, as is adding methane emissions associated with production and transport of imported natural gas.

Sources of $\mathrm{N}_{2} \mathrm{O}$ in New York State include fossil fuel combustion, biomass burning, soil emissions, and lightning. All but the latter are energy systems emissions that can be added to NYMARKAL.

\section{Reference}

Ciborowski, P. 1989. Sources, sinks, trends, and opportunities, Chapter 14 in D.E. Abrahamson (ed), The Challenge of Global Warming, Island Press, Washington, D.C., pp. 213-230. 


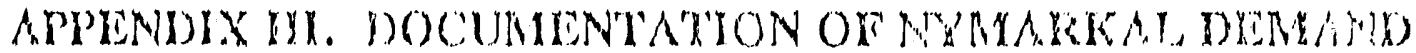 CATEGORZES AND PROJECWIONDATA}

\section{Demand Categories}

The demand calegories in MARKAL, are energy dernands associaled will a spific economic activity or entity. 'Table III-1 lists the demand categories defined in NY MARKAL.

Industrial The classilication of industrial demand calcegories for NY MARKAL posed some difficultics because most of the existing consumplion data iate reported in icrms of Standard Industrial Classification (SIC) group, not by sprefific ondense based on which linkage can be established with the sperefie demand lechnolugies that matisfy these demands. In this study, we have deflired "process heat" to be the dimand calcgory that uses all the fossil fuels consumed in the industrial ector. The. electricity demand was broken down into two demand categories: "motor driving" and "lighting de other uses". In addition, a fourth demand callegory was created to include industrial use of energy resources as feerstocks and non-encrgy applications, although there is no demand datla available in these activities.

Residential. The demand categories defined in NY MARKAL were aggregated from the enduse demands by housing type reported in the NY REEPS morel. "Multiple family" in MARKAL was formed by combining three housing types ciefinud in RELIPS: Two to four units, five plus units, and mobile homes.

In addition, dishwashers, refrigerators, freezers, and other appliances listed in REEPS were aggregated into a single catcgory: "Miscellancous appliances". Thesc aggregations were made in order to keep the size of NY MARKAL and the computer run time to achieve the optimal solution at a manageable level. The values of the energy and economic parameters associated with theșe newly defined demand categories in MARKAL were calculated as the weighted averages of the corresponding values of their components defined in REEPS. Other major demand categories brought into MARKAL from the residential model include space heating, water heating, and air conditioning. 
Table III-1, NYMARKAL Demand Categories.

\begin{tabular}{|l|l|}
\hline I1 & Industrial Process Heat \\
I2 & Electric Motor Drive \\
I3 & Lighting \& Misc Electric \\
N1 & Petrochemical Feedstocks \& Nonenergy \\
R0 & Single Family Space Heating \\
R1 & Single Family Water Heating \\
R2 & Single Family Air Conditioning \\
R3 & Single Family Cooking \\
R4 & Single Family Miscellancous Appliances \\
R5 & Multiple Family Space Heating \\
R6 & Multiple Family Water Heating \\
R7 & Multiple Family Air Conditioning \\
R8 & Multiple Family Cooking \\
R9 & Multiple Family Miscellancous Appliances \\
RA & Office Building Space Heating \\
RB & Office Building Water Heating \\
RC & Office Bldg Air Conditioning \& Ventilation \\
RD & Office Building Lighting \& Appliances \\
RE & Service Building Space Heating \\
RF & Service Building Water Heating \\
RG & Service Building Air Conditioning \& Ventilation \\
RH & Service Building Lighting \& Appliances \\
RI & Miscellaneous Space Heating \\
RJ & Miscellaneous Buildings Water Heating \\
RK & Miscellaneous Buildings Air Conditioning \& Ventilation \\
RL & Miscellaneous Buildings Lighting \& Appliances \\
RX & Commercial Buildings Miscellaneous Use \\
T1 & Automobile \\
T2 & Light Truck \\
T3 & Bus \\
T4 & Subway \& Urban Rail \\
T5 & Intercity Rail - Freight \\
T7 & Air \\
T8 & Vessel \\
T9 & Misc Transport \\
TH & Heavy Truck \\
\hline
\end{tabular}


Commercial. In defining the demand categories in the commercial sector, the ten building types classified in the NY CEDMS model were aggregated into three groups as shown in Table III-2.

\begin{tabular}{|l|l|}
\hline \multicolumn{2}{|l|}{$\begin{array}{l}\text { Table III-2, Mapping from } \\
\text { CEDMS to NYMARKAL } \\
\text { Building Types. }\end{array}$} \\
\hline MARKAL. & NY CEDMS \\
\hline Office & Office \\
\hline Service & Restaurant \\
\hline & Retail \\
\cline { 2 - 2 } & Grocery \\
\cline { 2 - 2 } & Health \\
\cline { 2 - 2 } & Hotel \\
\hline Miscellaneous & Warehouse \\
\hline & School \\
\cline { 2 - 2 } & College \\
\cline { 2 - 2 } & Miscellaneous \\
\hline
\end{tabular}

The enduse demands in CEDMS were also aggregated into four categories: Space heat, water heat, air conditloning \& ventilation, and lighting $\&$ miscellaneous appliances. This was achieved by combining lighting, refrigeration, cooking, and miscellaneous equipment defined in CEDMS into a single enduse dernand: "Lighting and miscellaneous appliances". Similar to the residential sector, the values of the energy and economic parameters for the newly defined demand categories were calculated as the weighted averages of the corresponding values of their components listed I CEDMS.

Transportation. The transportation demand categories defined in NY MARKAL were based on the modal classification of the NYSDOT Energy Demand Model. One adjustment made was the aggregation of "light"," medium", and "light-heavy" trucks classified in the latter into a single mode of "light truck" in MARKAL.

\section{Demand Projections}

The projections of future end-use demands in MARKAL were made in the End-use Demand (EUD) Tables developed for the demand categories. An EUD table contains the following parameters:

- Basis, $B(T)$ : The underlying projection (economic, demographic, or energy) based on which future energy enduse demands are determined. $\mathrm{T}$ stands for the time periods (1 to 9) in the planning horizon..

- Saturation, $S(T)$ : The fraction of the potential demand for a particular demand category actually being fulfilled at a given time period.

- Base Year Energy Consumption, DE(1): The energy consumption (by demand technologies) in a specific demand category in the base year. 
- Enduse Demand, EUD(T): The amount of useful energy that would be required in a specific demand category exclusive of the efficiencies of individual demand technologies.

- Unit Enduse Demand, EUD: Enduse demand divided by the basis.

In projecting future enduse demands, the enduse demand in the base year $(T=1$, or 1988) was first calculated as the sum of the products of the base year energy consumption of each demand technology and its efficiency. This total was then divided by the product of the basis and saturation $(B(1) \times S(1))$ in the base year to obtain the unit enduse demand. Future enduse demands are projected by multiplying the unit enduse demand to the basis in each future time period $t$, taking into account changes in the saturation rates if assumed (EUD X $B(t) \times S(t)$ ). It should be emphasized here that the enduse demand represents the useful energy (i.e. after device efficiency) required to maintain the activity in a demand category. Actual fuel demands (including electricity and cinservaticin? to satisfy these enduse demands are determined by the activity level of the demand devices obtained in MARKAL's optimal solution.

In this study, a single projection for each demand category was made on various growth assumptions reported in the 1989 SEO Energy Demand Forecast Assessment. They are shown in Tables A6 (the "DM" tables of the NY MARKAL input files). The projected enduse demands (in BBtu) are displayed in the "DEMAND" row under each demand category. It should be emphasized that these projections are not intended to predict what will occur in each sector in the future but to provide a reference point based on which energy system impacts under various energy and environmental policies can be evaluated. The specific assumptions made and the basis for projections in each demand category are described in the sections which follow.

Industrial. The base year industrial consumption pattern, $\mathrm{DE}(1)$, was established by allocating all current fossil fuel consumption to process heat. Electricity consumption was broken down by motor driving, lighting and other uses according to NYSERDA distribution. The bases for projection used in the EUD tabies are individual energy growth indexes projected in the 1989 SEO Reference II Scenario. The allocation of all fossil fuels to process heat is certainly open to refutation as these fuels are also being used for other purposes (e.g. diesel fuel for mechanical drive). Clearly, a more comprehensive and desegregated (by enduse) demand pattern of industries within New York State will have to be established for studies in which the primary focus is on industrial energy impact. This effort, however, is not within the scope of this study.

Residential. The base year energy consumption by trouseholds was established based on data compiled in the NY REEPS. The bases for projecting enduse demands by demand category are household forecasts (single family, two to four units, five plius units, and mobile homes) reported in the 1989 SEO Reference II Scenario. As
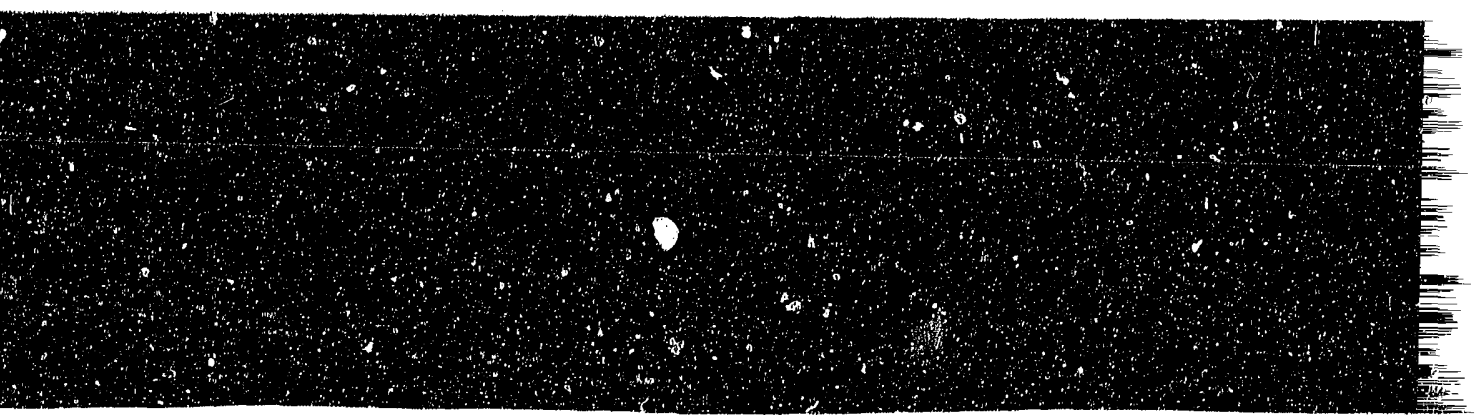
described earlier, the multiple units and mobile homes defined in REEPS were combined into a single category of "multiple family" in MARKAL.

Commercial. The commercial energy consumption pattern in the base year was established from data compiled in the NY CEDMS Model. The base year commercial floorspace by building type were projected into the future based on the annual growth rates assumed in the 1989 SEO Reference II Scenario. These projected floorspace (by the ten building types defined in CEDMS) were aggregated into three categories, providing the bases for commercial enduse demand projections in office, service establishments, and miscellaneous buildings.

Transportation. The base year transportation energy consumption by mode were based on data published by NYSDOT. The bases for projecting enduse demands by passenger modes are the projected modal activities in terms of vehicle miles traveled (VMT). For freight modes, these bases are measured in terms of ton miles (TM). 


\section{APPENDIX IV. ENVIRONMENTAL EMISSIONS COEFFICIENTS}

The following tables provide the environmental emissions by technology for $\mathrm{NO}_{x}$, total particles (TP), $\mathrm{SO}_{2}(\mathrm{SOx})$, as well as carbon monoxide $(\mathrm{CO})$ and volatile organic carbon (VC), which were not included in NYMARKAL. Coefficients are given in the units used in the original source (ieferenced in the assumptions column) and in $\mathrm{kg} / \mathrm{mmBtu}$, the form they were entered in NYMARKAL. Source references are given below. Following the general emissions coefficient tables is a table showing the method of estimating emissions from the current automobile fleet.

\section{Referencers}

AFSEF. 1990. AIRS Facility Subsystem Emission Factors, US Environmental Prntection Agency, National Air Data Branch. Electronic database.

Butcher, S.S. and M.J. Ellenbecker. 1982. Particulate emission factors for small wood and coal stoves, J. Air Pollution Control Assoc. 32: 380-384.

Beller, M. (ed) 1975. Sourcebook for Energy Assessment (BNL 50483). Brookhaven National Laboratory, Upton, NY 11973.

Deluchi, M.A., D. Sperling, and R.A. Johnston. 1987. A Comparative Analysis of Future Transportation Fuels (UCB ITS-RR-87-13. Institute of Transportation Studies, University of California, Berkeley.

DOE/EH-0077. 1988. Energy Technologies and the Environment. US Department of Energy.

DOE/EV-0061/3. 1980. Environmential Data, Energy Technology Characterizations: Coal. U.S. Department of Energy, Washington, D.C.

DOE/EV-0072. 1980. Technology Characterizations, Environmental Information Handbook. U.S. Department of Energy, Washington, D.C.

DOE/EP-0026. 1981. Energy Technoiogies and the Environment. U.S. Department of Energy, Washington, D.C.

DOE/EP-0093. 1983. Energy Technology Characterizations Handbook: Environmental Pollution and Control Factors. U.S. Department of Energy, Washington, D.C.

Energy Alternatives: A Comparative Analysis. 1975. Science and Public Policy Program, Univ of Oklahoma, Norman. 


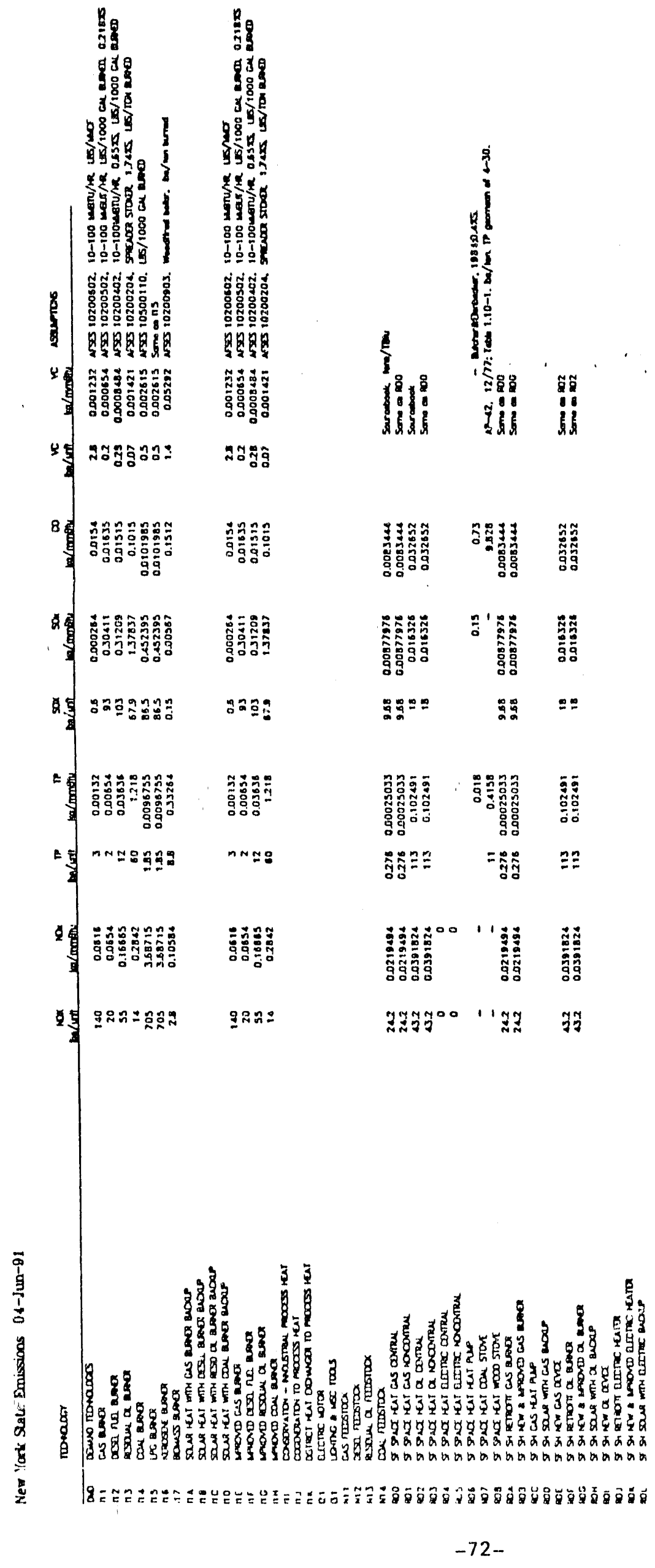




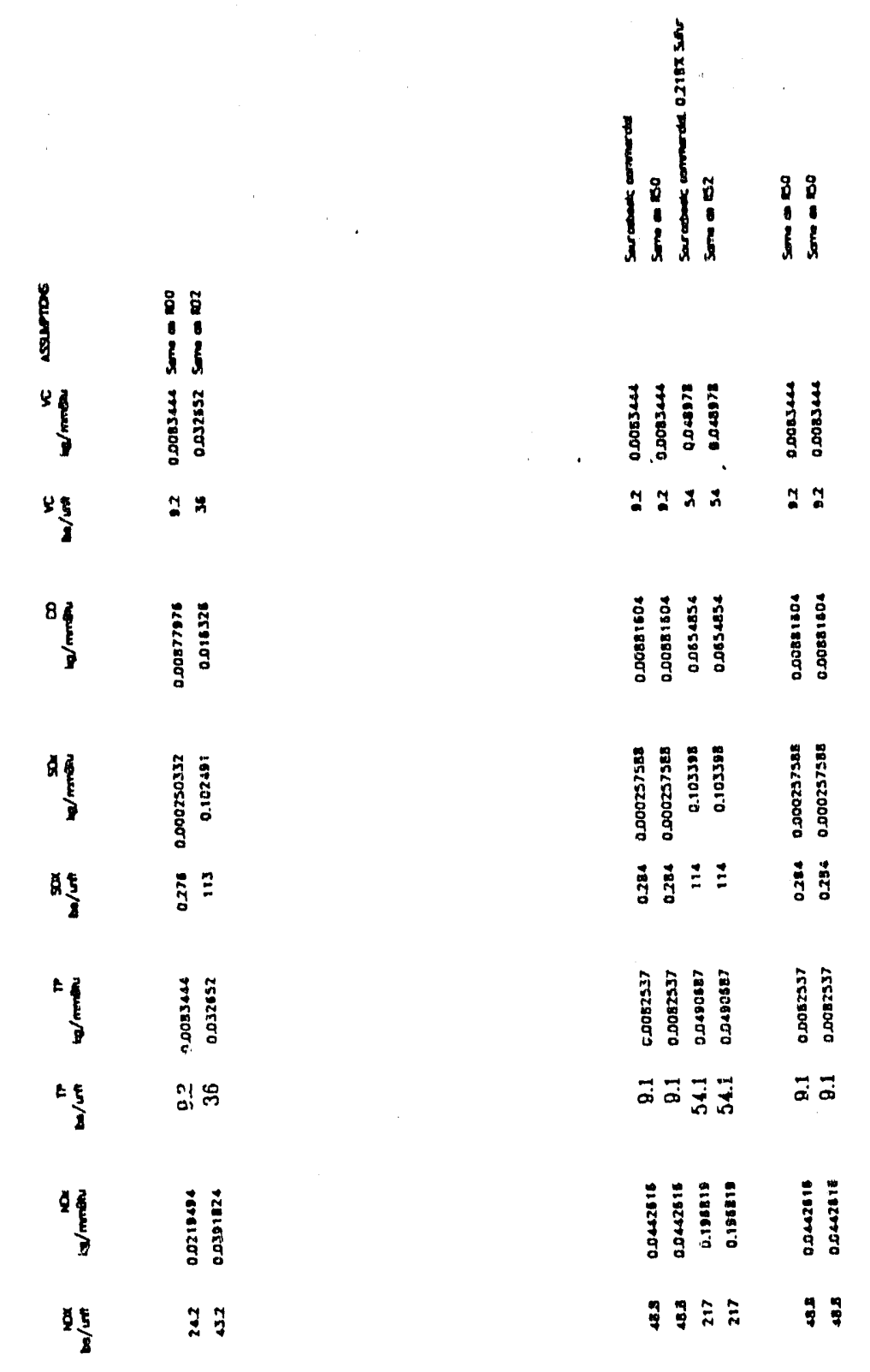

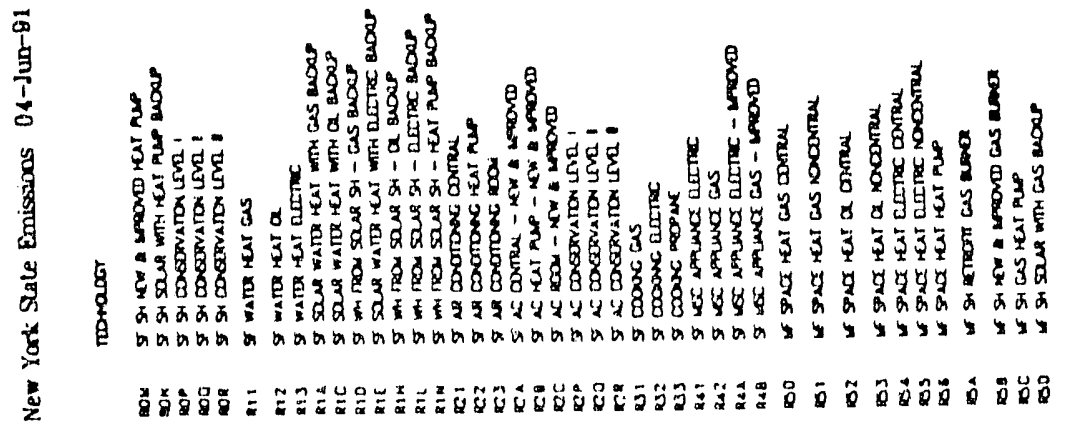




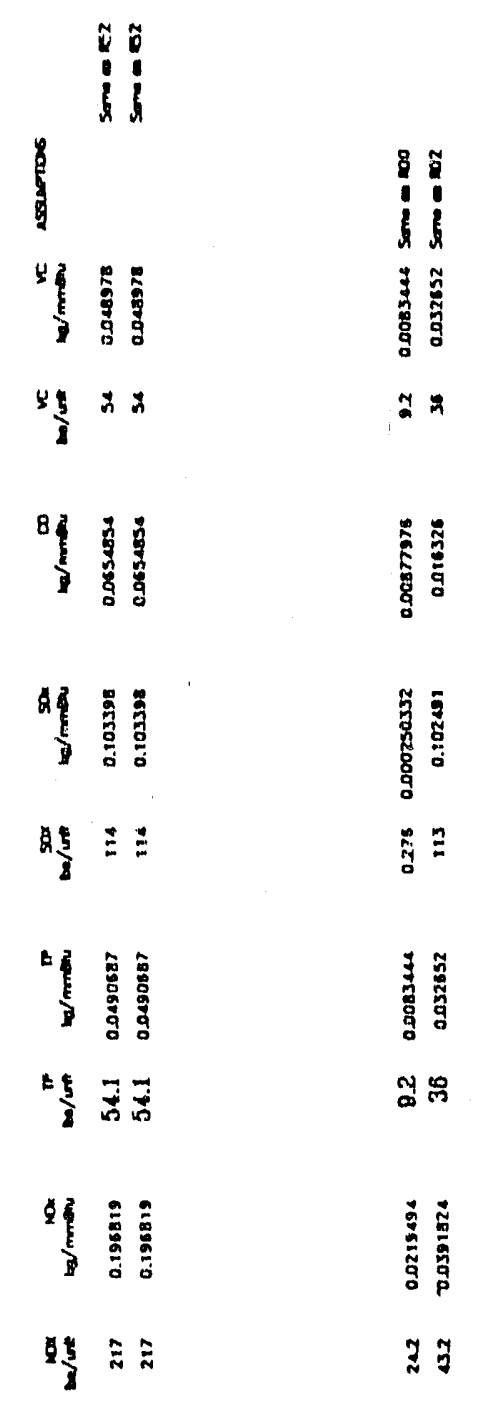

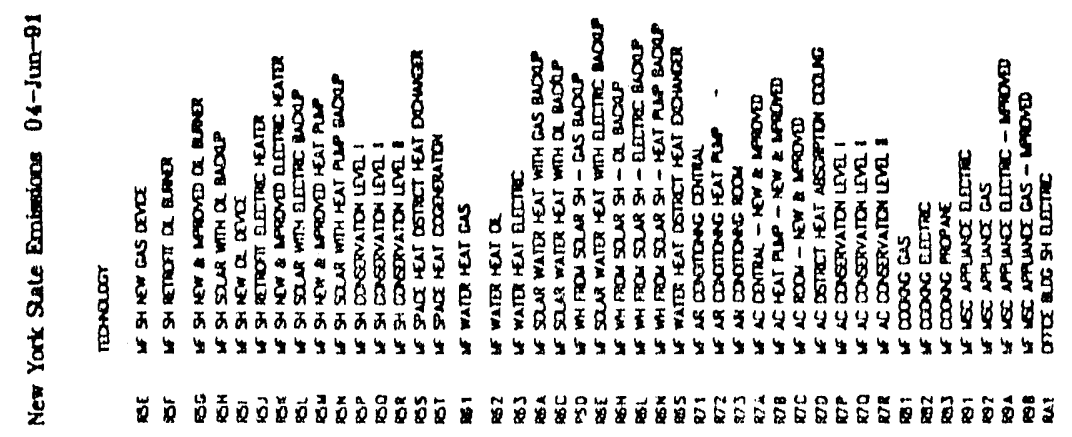




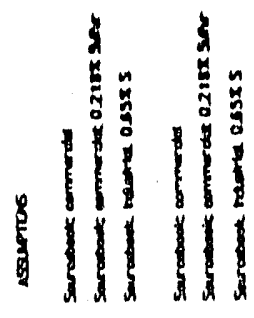

प)

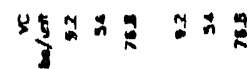

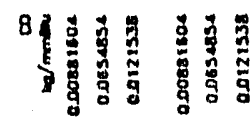

ชรุํำำลำ

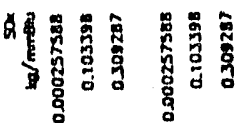

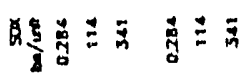

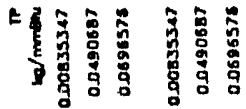

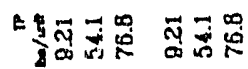

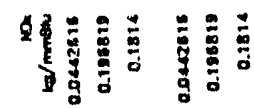

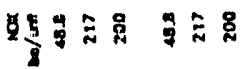

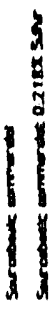

高

도

ㅎํㅇํำ

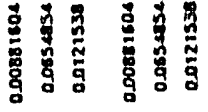

ำำ

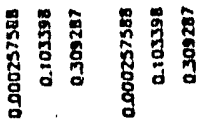

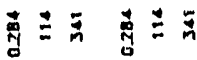

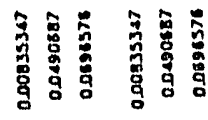

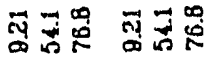

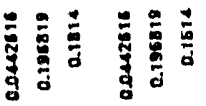

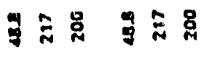

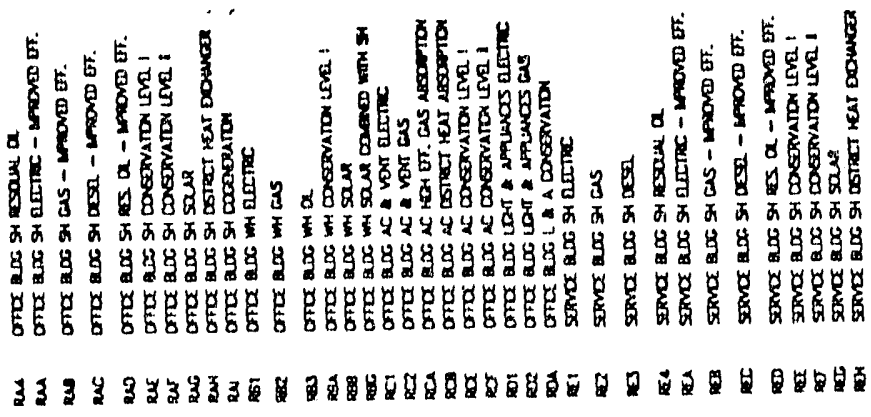




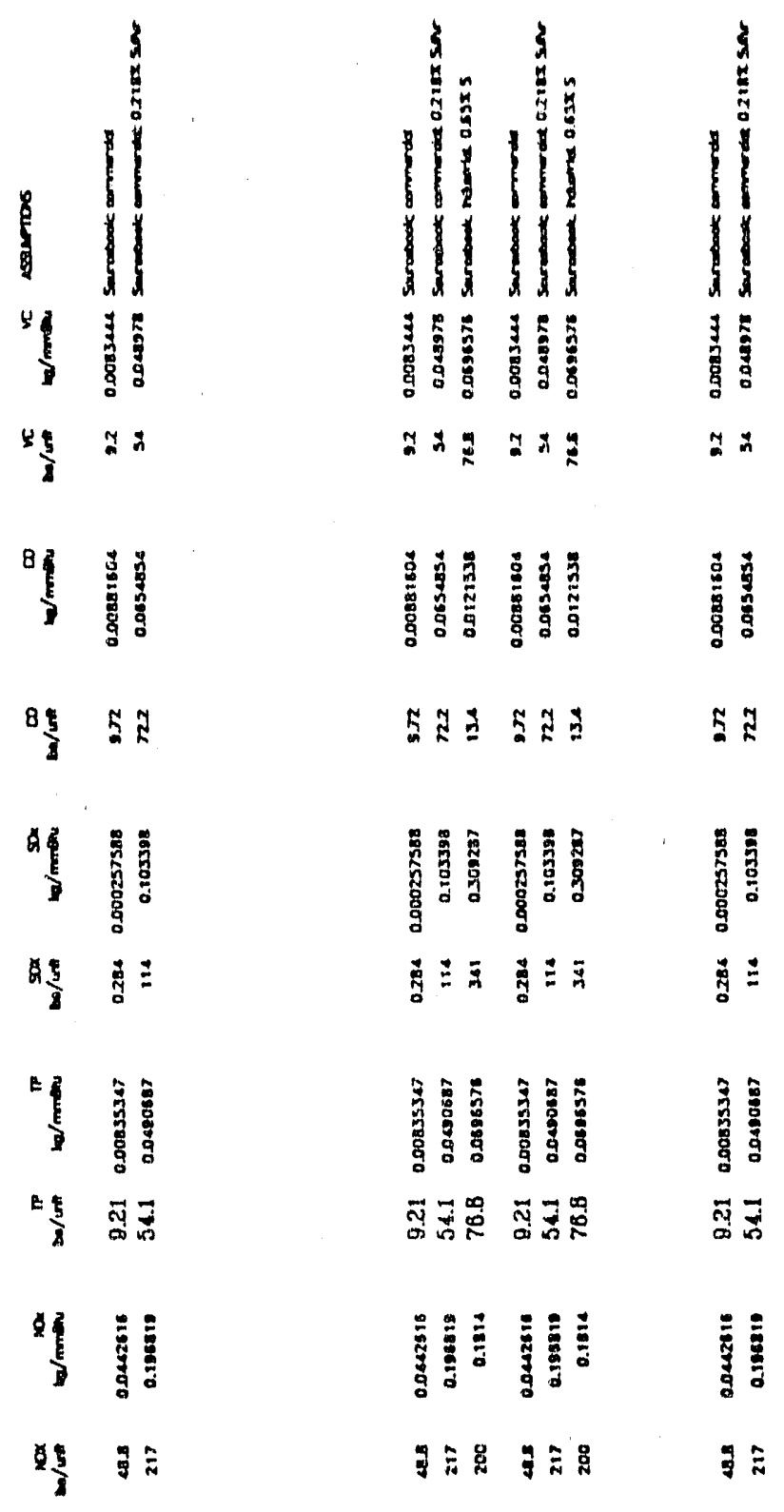

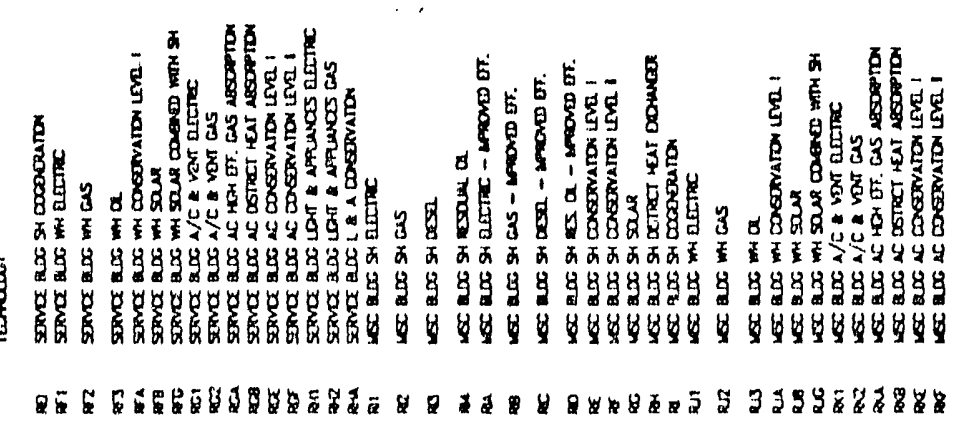




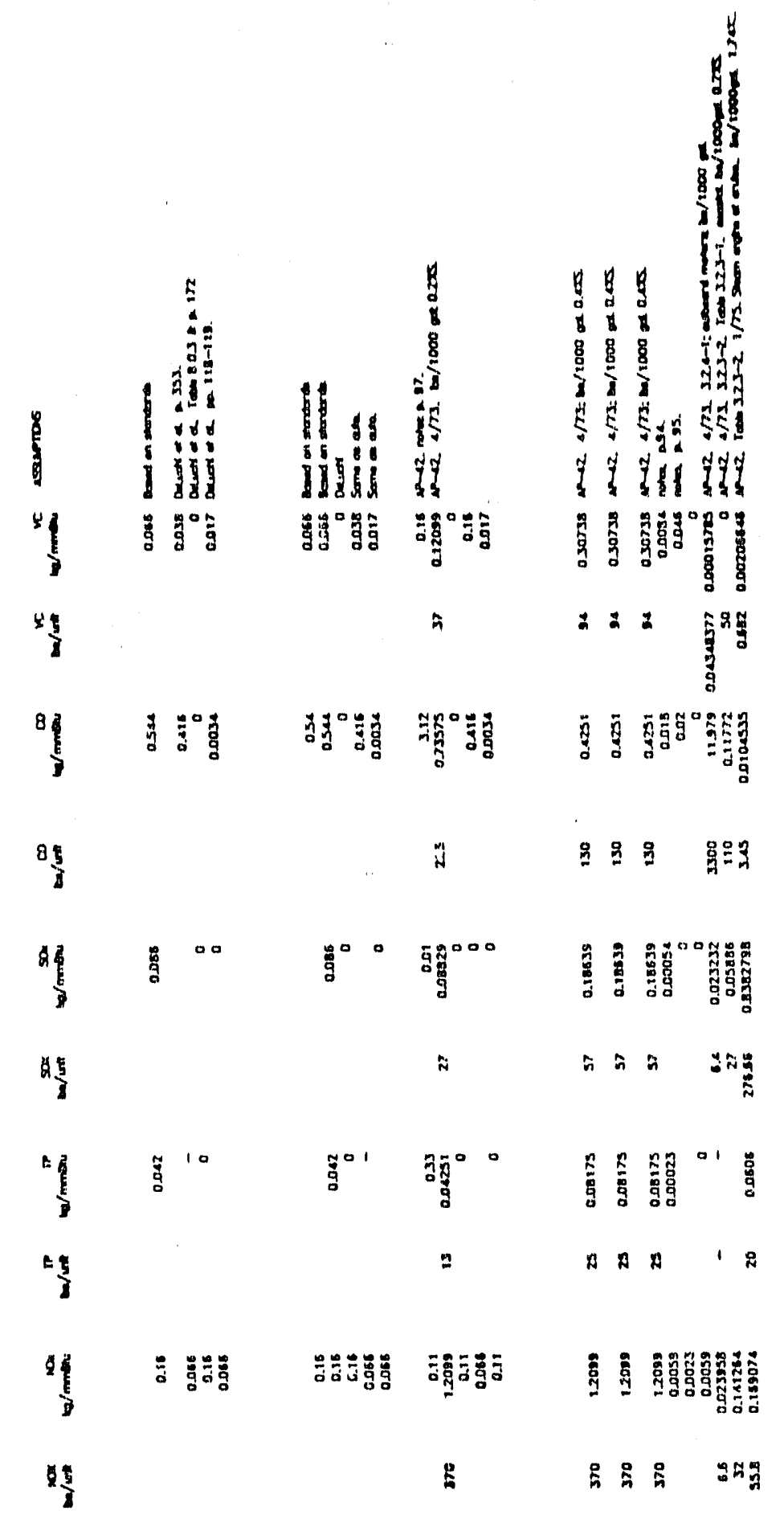

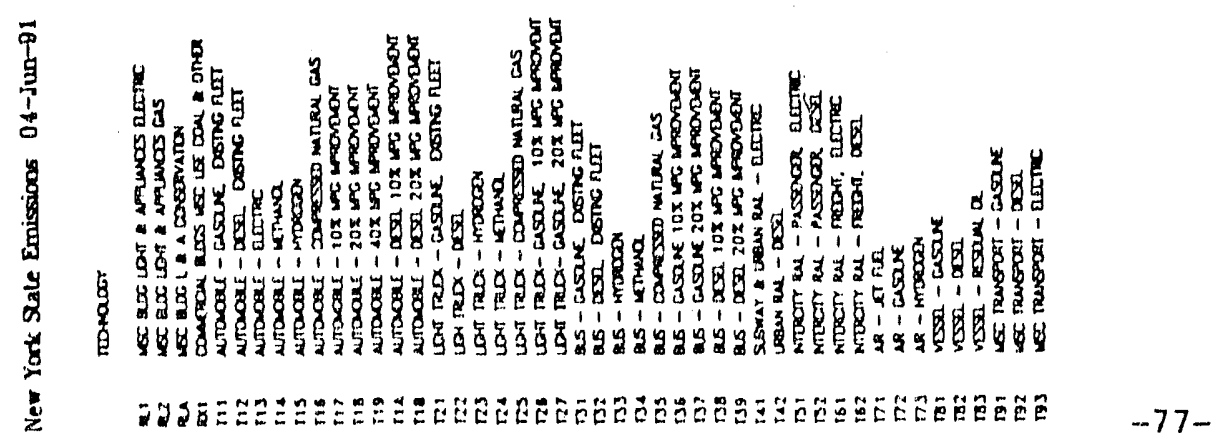



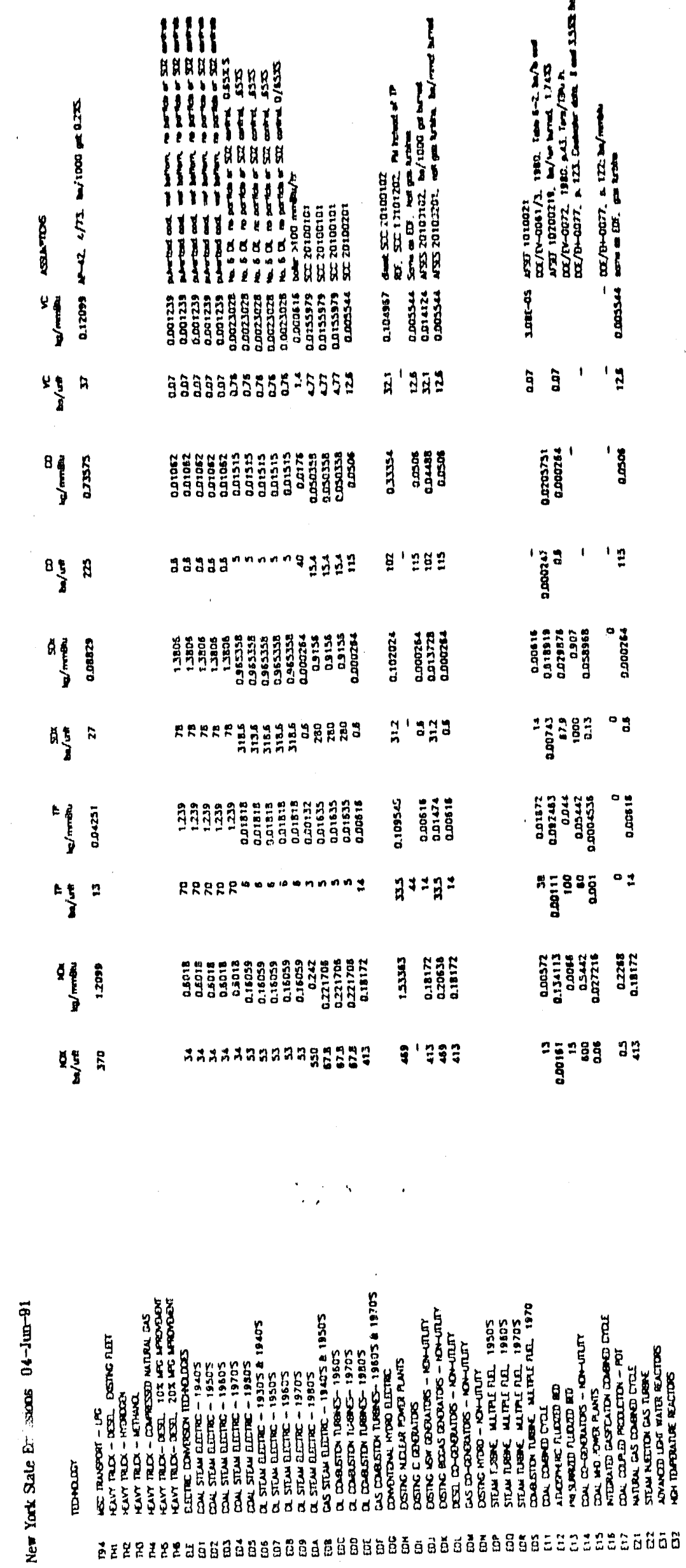

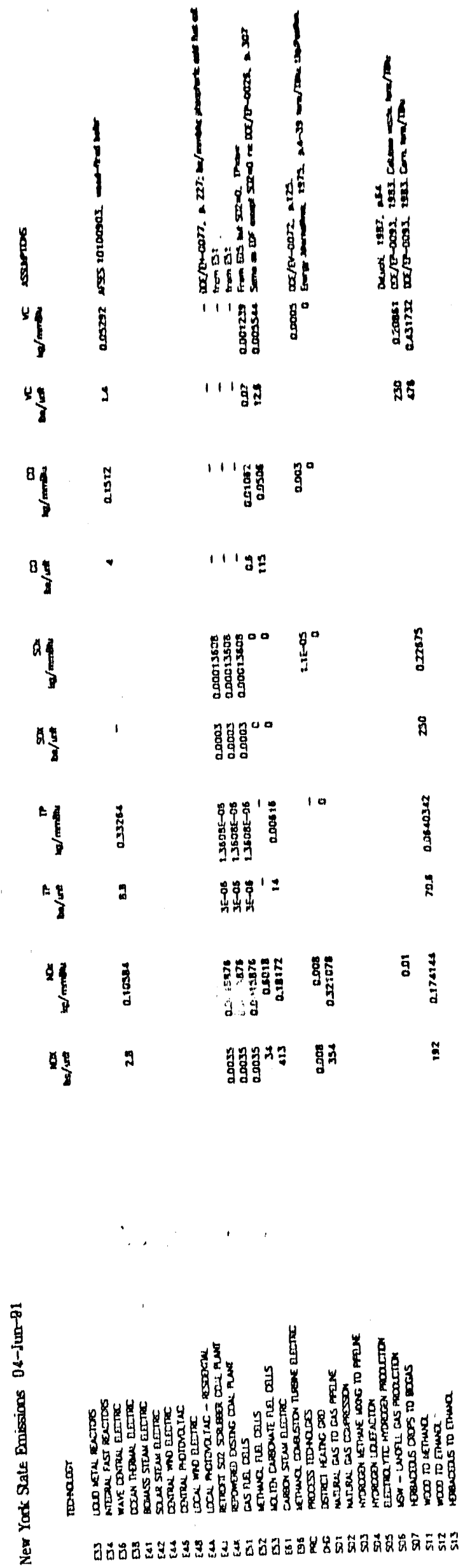


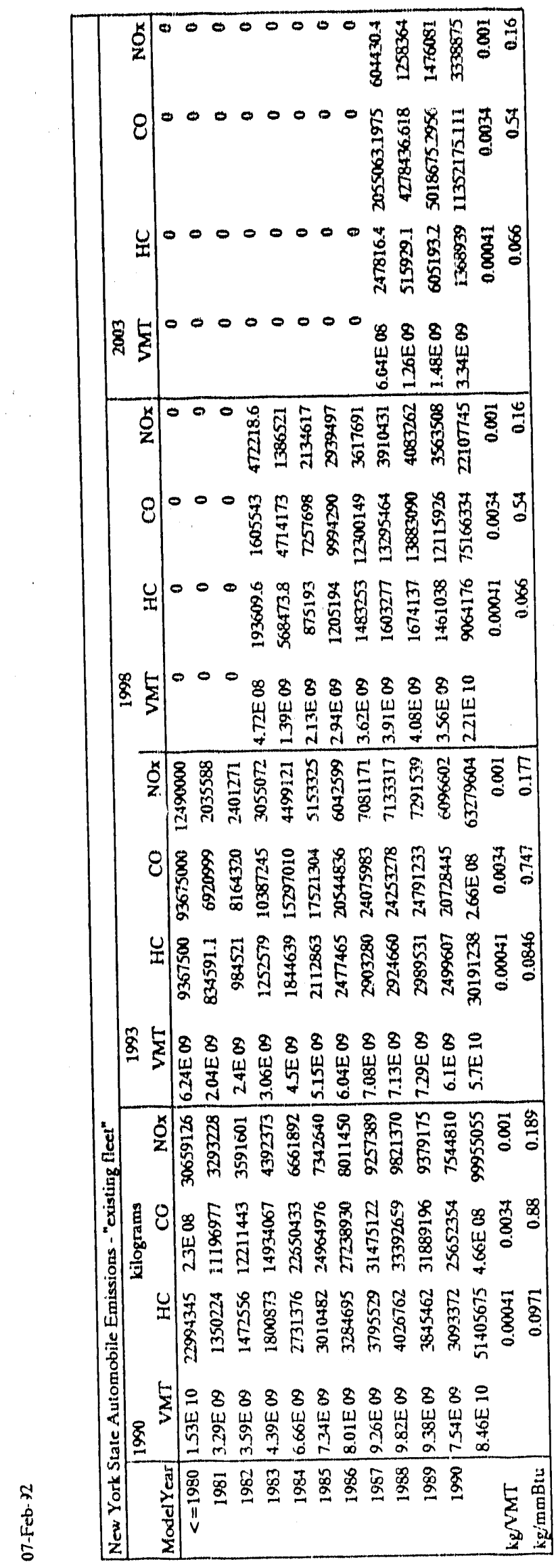




\section{APPENDIX V. DOCUMENTATION OF TECHINOLOGY DATABASE}

\section{Data Structure And Sources}

The structure of NY MARKAL data simulates the flow of energy in various forms (energy carriers) from their sources of supply through intermediate steps of transformation, transportation, and transmission, to the demand devices which satisfy the enduse demand in each demand category. The enduse demands which drive the system are calculated based on current energy consumption pattern, utilization efficiencies, current and projected economic bases associated with the enduses. The intermediate steps include electricity generation (centralized and decentralized), resource and fuel processing, energy storage, and various energy transportation and transmission networks. The sources of supply include imports, in-state mining, and renewable energy resources. Parallel to the energy flow, a set of environmental emission coefficients accounting the amount of carbon dioxide, sulfur oxides, nitrogen oxides, and particles released per unit flow of energy is also defined for each technology in the database.

In addition to the references cited earlier in this report, other primary sources used completing the NY MARKAL database are Draft New York State Energy Plan (NYSEO, 1989), New York State Energy Office Residential End-Use Energy Planning System (REEPS), New York State Energy Office Commercial Energy Demand Modeling Service (CEDMS), New York State Econometric Industrial Energy Demand Model (EIEDM), Annual Energy Review published by the New York State Energy Office (NYSEO, 1990), the New York State Department of Transportation Demand Model (NYSDOT, 1988 ) capacity planning and operating statistics from the New York Power Pool (NYPP 1990a, 1990b, 1990c), Technical Assessment Guide of Electric Power Research Institute (EPRI, 1987), technolngy assessments by the U.S. Department of Energy (DOE 1991c), the New York State Energy Advisory Service to Industry Program (EASI, 1989), The New York State Energy Research and Development Authority Electricity Conservation Study (NYSERDA, 1986), the U.S. MARKAL Database (U.S. MARKAL, 1991).

Despite the vast amount of information provided in these sources, arbitrary assumptions had to be made in cases in which the required data or projections were not readily available. This is particularly true during the development of NY MARKAL input data for the time periods beyond the terminal year (2010) in the current State Energy Plan. For the purpose of demonstrating the capability and use of MARKAL, however, the base rase and the few scenarios established in this study were shown to be responsive for analyzing the impact of energy and environmental policies and issues of interest within the State, notwithstanding the inherent uncertainties in long run projections and the dubious quality of a small fraction of the input data. 
In the following sections, a brief discussion on the data characterization, data sources, and key assumptions made in completing the input data files for each MARKAL classes is presented. Because of the exceedingly large volume of Information involved, however, specific values contained in these files are not included in this report, for which the users may conveniently inquire from NY MARKAL input tables through MUSS.

\section{Energy Resource}

In NY MARKAL, the energy resources cover all fossil fuel imports from out of state, the natural gas produced within the state, and net electricity imports from Pennsylvania and Quebec, Canada. Table V-1 (Class SRCENCP in NY MARKAL) lists the base case supply sources which contribute or have the potential to contribute to the New York State energy system. For natural gas, total potential supply includes projected supply (pipeline and non-pipeline sources) to local distribution companies, new gas supplies from proposed projects, from indigenous mining, and purchases of enduse customers. For periods beyond 2010, this total and its price components were linearly extrapolated to 2023 (the terminal year in NY' MARKAL) using their average growth rates between 1990 and 2010 projected in the 1989 SEO forecast.

For refined oll products, coal, and nuclear fuel, their future supplies to the State were assumed to be unlimited within the NY MARKAL planning horizon. The Import costs of refined oil products were extrapolated from the reference forecast of the 1989 SEO. The import prices of coal were based on its projected costs to electric utilities. The prices of nuclear fuel reflect the cost increases in fuel processing and distribution in the national market. Future wood supplies and costs in the State were kept at their current consumption and price levels.

Electricity imports from Quebec, Canada were projected based on the renewal of the current diversity contract $(800 \mathrm{MW})$ and the approval of the $1000 \mathrm{MW}$ firm capacity contract. Future imports from Pennsylvania were kept at the current level.

\section{Conversion Technologies}

In MARKAL, conversion technologies are defined as those which produce electricity or district heat or both. Table V-2 (Class ELE in NY MARKAL) lists existing and new electric generation technologies defined in the base case. Each technology is characterized by a set of technical parameters which include fuel type(s), availability factor, heat rate, and the useful life time. The key financial factors associated with each technology are investment cost per unit capacity, operating and maintenance cost (fixed and variable). For existing power plants and conversion facilities, data on these parameters were obtained from actual operating statistics compiled by New York Power Pool and the Energy Information Administration of 
evaluations. Conservation supply schedules for various commercial buildings by enduse were constructed based on NYSERDA study and data collected under EASI Program.

In the transportation sector, the base year energy consumption patterns and the characteristics of the current fleet in each mode were derived base on NY DOT historical data. The new demand devices include more efficient vehicles and vehicles using alternative fuels that have potential to satisfy future New York State transportation needs. The technical and economic data for these options were derived from DOE transportation studies and policies.

\section{Energy Conservation Data from EASI}

We obtained data from NYSEO that was collected in the Energy Advisory Service to Industry (EASI) program between June 1987 and April 1990 on potential energy savings from conservation measures.

Preparation Of EASI Data For NYMARKAL. The EASI data were segregated into industry (SIC 2,3) and commerce (SIC 5, 6, 7, 8). Within these two sectors, the data were separated into those energy conservation measures (ECM) that save electricity and those that save other fuels. Within electricity-saving ECMs, those that affect electric motor use were separated from those that do not. All cogeneration ECMs were removed from this database since MARKAL treats cogeneration separately.

Five or six percent of the data had a zero entry in either the investment cost or energy savings category. All these were eliminated from the database. In some cases, the cost may indeed have been zero (for example, turning down thermostats). In other cases, a cost may be estimated from other applications of the same ECM. The database may therefore be further fine-tuned by screening these other ECMs that were omitted here. No estimate is included of the effect of these ECMs on operations or maintenance costs.

Scaling up to New York State. EASI was a sample of a subset of the New York industrial and commercial sectors. It was important to understand to what fraction of the commercial and industrial energy demands the EASI data were applicable. Review of the latest Census of Manufactures showed that establishments with over 500 employees accounted for only $1 \%$ of manufacturing establishments in New York State. Categories in the Census of Manufacturers did not have a 400 employee cutoff to match the EASI criteria. Since the percentage of large establishments was very low, even though their percentage share of the total industrial energy use would be higher by an unknown amount, it was decided to scale up the EASI data to the entire state. In part this can be justified on the basis that at least some of the conservation measures in the EASI data are applicable to large as well as small industries. Table V-4 shows the scaling factor to be used in the column, "Factor, Total/EASI."

Results. The energy conservation supply curves for the EASI sample are shown in Figures $V-1$ through $V-8$, as indicated in Table $V-4$. In all cases, the $X$-axis shows energy savings in $10^{9} \mathrm{Btu}$. The $\mathrm{Y}$-axis shows initial investment in thousands of dollars. 
The precise coordinates of the end-point can be read from Table V-4 in the columns labeled Energy Savings and \$ Investment. Figures 1 and 5, "Except Electricity," were scaled up by the total fuel use outside the electrical sector estimated for 1988 in the New York State Annual Energy Review, 1970-1988, pp. 22 and 24, shown as Total Purchased Fuels in Table V-5. Table V-5 also compares the data from three sources. For total electricity, Figures V-2 and V-6, the coordinates were scaled up according to total industrial or commercial electricity consumption in the seven private NYS utilities, averaged for 1988 and 1989. This calculation is shown in Table V-6. (New York Power Authority electricity, delivered principally to large industrial and municipal customers, is not included in these figures.) With the electrical sector separated into segments with and without electric motors, total electrical use must be similarly divided. In Table V-4, "Total Sample Energy" shows the energy use by establishments in which the individual ECMs were recommended. Inasmuch as the same establishment may have an electric motor ECM and one that does not affect electric motors, the sum of Total Sample Energy for Electricity (except motors) and Electric Motors is greater than Total Sample Energy for Electricity alone.

\section{Reference:}

US Department of Commerce, Bureau of the Census. 1990. 1987 Census of Manufacturers, Geographic Area Series, New York. U.S. Government Printing Office, Washington, D.C.

US Department of Commerce, Bureau of the Census. 1983.1982 Census of Manufacturers, Fuels and Electric Energy Consumed, MC82-S-4 (part 2). U.S. Government Printing Office, Washington, D.C.

US Department of Energy, Energy Information Agency. State Energy Data Report, Consumption Estimates, 1960-1988, EIA 0214(88). 


\begin{tabular}{ll}
\hline Table V-1. Energy ResOUICE In Markal (MARKAL CLASS \\
SRCENCP) & \\
IMPDSH1 & RESIDUAL OIL IMPORTS \\
IMPDSL1 & DIESEL FUEL IMPORTS \\
IMPELC1 & ELECTRICITY IMPORTS FROM PA \\
IMPELC2 & ELECTRICITY IMPORTS FROM QUEBEC \\
IMPGSL1 & GASOLINE IMPORTS \\
IMPHCO1 & LOW SULFUR COAL (.5\%) IMPORTS \\
IMPHCO2 & MEDIUM SULFUR COAL (1.5\%) IMPORTS \\
IMPHCO3 & HIGH SULFUR COAL (2.5\%) IMPORTS \\
IMPJTF1 & JET FUEL IMPORTS \\
IMPKER1 & KEROSENE IMPORTS \\
IMPLPG1 & LPG IMPORTS \\
IMPLWR1 & LWR STANDARD FUEL IMPORTS \\
IMPNGA1 & GAS SUPPLY TO BROOKLYN UNION \\
IMPNGA2 & GAS SUPPLY TO CENTRAL HUDSON \\
IMPNGA3 & GAS SUPPLY TO COLUMBIA \\
IMPNGA4 & GAS SUPPLY TO CON EDISON \\
IMPNGA5 & GAS SUPPLY TO CORNING \\
IMPNGA6 & GAS SUPPLY TO NATIONAL FUEL \\
IMPNGA7 & GAS SUPPLY TO LILCO \\
IMPNGA8 & GAS SUPPLY TO NYSE\&G \\
IMPNGA9 & GAS SUPPLY TO NIAGARA MOHAWK \\
IMPNGAA & GAS SUPPLY TO ROCHESTER G\&E \\
IMPNGAB & GAS SUPPLY TO ORANGE \& ROCKLAND \\
IMPNGAD & NEW GAS SUPPLIES - PROPOSED PROJECTS \\
IMPNGAE & MISC GAS SUPPLIES \\
IMPPAP1 & PROPANE IMPORTS \\
MINNGA1 & NEW YORK INDIGENOUS GAS SUPPLY \\
RNWBIT1 & NEW YORK INDIGEOUS WOOD SOURCES \\
RNWBIT2 & INDUSTRIAL WOODFUEL-WASTES ETC. \\
RNWHBC1 & HERBACEOUS ENERGY CROPS \\
PNWMCA1 & MICROALGAE DIESEL EQUIVALENT \\
RNWMSW1 & MUNICIPAL SOLID WASTE \\
& \\
&
\end{tabular}

\begin{tabular}{|l|l|}
\hline \multicolumn{2}{|c|}{ Table V-2. Electrical Technologies (MARKAL CLASS ELE) } \\
\hline E01 & COAL STEAM ELECTRIC - $1940^{\prime} \mathrm{S}$ \\
\hline E02 & COAL STEAM ELECTRIC - $1950^{\prime} \mathrm{S}$ \\
\hline E03 & COAL STEAM ELECTRIC - $1960^{\prime} \mathrm{S}$ \\
\hline E04 & COAL STEAM ELECTRIC - 1970 'S \\
\hline
\end{tabular}




\begin{tabular}{|c|c|}
\hline E05 & COAL STEAM ELECTRIC - $1980^{\prime} \mathrm{S}$ \\
\hline E06 & OIL STEAM ELECTRIC - $1930^{\prime}$ S \& $1940^{\circ} S$ \\
\hline E07 & OIL STEAM ELECTRIC - 1950 'S \\
\hline E08 & OIL STEAM ELECTRIC - 1960 'S \\
\hline EO9 & OIL STEAM ELECTRIC $-1970^{\prime} \mathrm{S}$ \\
\hline EOA & OIL STEAM ELECTRIC - 1980 'S \\
\hline EOB & GAS STEAM ELECTRIC - 1940'S \& 1950'S \\
\hline EOC & OIL COMBUSTION TURBINES- $1960^{\prime} \mathrm{S}$ \\
\hline EOD & OIL COMBUSTION TURBINES- 1970 'S \\
\hline EOE & OIL COMBUSTION TURBINES- 1980 'S \\
\hline EOF & GAS COMBUSTION TURBINES- 1960 'S \& 1970'S \\
\hline EOG & CONVENTIONAL HYDRO ELECTRIC \\
\hline $\mathrm{EOH}$ & EXISTING NUCLEAR POWER PLANTS \\
\hline EOI & EXISTING IC GENERATORS \\
\hline EOJ & EXISTING MSW GENERATORS - NON-UTILITY \\
\hline EOK & EXISTING BIOGAS GENERATORS - NON-UTILITY \\
\hline EOL & DIESEL CO-GENERATORS - NON-UTILITY \\
\hline EOM & GAS CO-GENERATORS - NON-UTILITY \\
\hline EON & EXISTING HYDRO - NON-UTILITY \\
\hline EOP & STEAM TURBINE, MULTIPLE FUEL, 1950 'S \\
\hline EOQ & STEAM TURBINE, MULTIPLE FUEL, 1960 'S \\
\hline EOR & STEAM TURBINE, MULTIPLE FUEL, 1970'S \\
\hline EOS & COMBUSTION TURBINE, MULTIPLE FUEL, 1970 \\
\hline E11 & COAL COMBINED CYCLE \\
\hline E12 & ATMOSPHERIC FLUIDIZED BED \\
\hline E13 & PRESSURIZED FLUIDIZED BED \\
\hline E14 & COAL CO-GENERATORS - NON-UTILITY \\
\hline E16 & INTEGRATED GASIFICATION COMBINED CYCLE \\
\hline E21 & NATURAL GAS COMBINED CYCLE \\
\hline E22 & STEAM INJECTION GAS TURBINE \\
\hline E31 & ADVANCED LIGHT WATER REACTORS \\
\hline E32 & HIGH TEMPERATURE REACTORS \\
\hline E33 & LIQUID METAL REACTORS \\
\hline E34 & INTEGRAL FAST REACTORS \\
\hline E41 & BIOMASS STEAM ELECTRIC \\
\hline E42 & SOLAR STEAM ELECTRIC \\
\hline E44 & CENTRAL WIND ELECTRIC \\
\hline E45 & LOCAL WIND ELE W/OUT BACKUP \\
\hline E46 & CENTRAL PHOTOVOLTAIC \\
\hline E48 & LOCAL WIND ELECTRIC \\
\hline & IC - RESIDEN IIAL \\
\hline
\end{tabular}


Table V-2. Continued

EAJ RETROFIT SO2 SCRUBBER COAL PLANT

E4K REPOWERED EXISTING COAL PLANT

E51 GAS FUEL CELLS

ES2 METHANOL FUEL CELLS

ES3 MOLTEN CARBONATE FUEL CELLS

E61 CARBON STEAM ELECTRIC

E96 METHANOL COMBUSTION TURBINE ELECTRIC

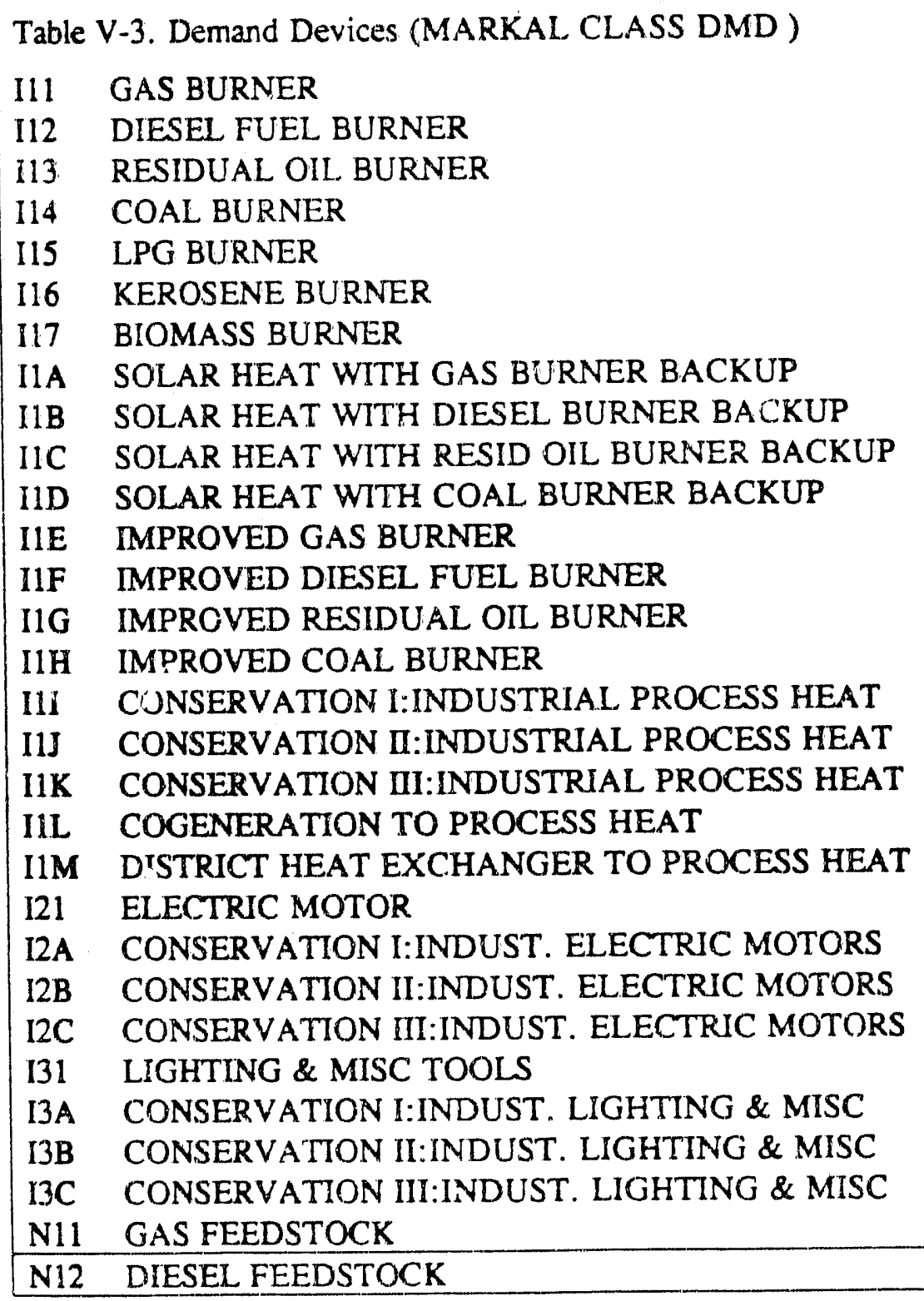

Table V-3. Demand Devices (MARKAL CLASS DMD)

III GAS BURNER

I12 DIESEL FUEL BURNER

113. RESIDUAL OIL. BURNER

114 COAL BURNER

I15 LPG BURNER

I16 KEROSENE BURNER

117 BIOMASS BURNER

IIA SOLAR HEAT WITH GAS BURNER BACKUP

IIB SOLAR HEAT WITH DIESEL BURNER BACKUP

IIC SOLAR HEAT WITH RESID OIL BURNER BACKUP

IID SOLAR HEAT WITH COAL BURNER BACKUP

IIE IMPROVED GAS BURNER

IIF IMPROVED DIESEL FUEL BURNER

IIG IMPRCVED RESIDUAL OIL BURNER

IIH IMPROVED COAL BURNER

III CONSERVATION I:INDUSTRIAL PROCESS HEAT

I1J CONSERVATION II:INDUSTRIAL PROCESS HEAT

IIK CONSERVATION III:INDUSTRIAL PROCESS HEAT

IIL COGENERATION TO PROCESS HEAT

IIM DISTRICT HEAT EXCHANGER TO PROCESS HEAT

I21 ELECTRIC MOTOR

I2A CONSERVATION I:INDUST. ELECTRIC MOTORS

I2B CONSERVATION II:INDUST. ELECTRIC MOTORS

I2C CONSERVATION III:INDUST. ELECTRIC MOTORS

I31 LIGHTING \& MISC TOOLS

I3A CONSERVATION I:INDUST. LIGHTING \& MISC

I3B CONSERVATTON II:INDUST. LIGHTING \& MISC

I3C CONSERVATION III:INDUST. LIGHTING \& MISC

N11 GAS FEEDSTOCK

N12 DIESEL FEEDSTOCK 
Table V-3, Continued.

NI3 RESIDUAL OIL FEEDSTOCK

N14 COAL FEEDSTOCK

ROO SF SPACE HEAT GAS CENTRAL

RO1 SF SPACE HEAT GAS NONCENTRAL

RO2 SF SPACE HEAT OIL CENTRAL

R03 SF SPACE HEAT OIL NONCENTRAL

R04 SF SPACE HEAT ELECTRIC CENTRAL

R05 SF SPACE HEAT ELECTRIC NONCENTRAL

R06 SF SPACE HEAT HEAT PUMP

R07 SF SPACE HEAT COAL STOVE

R08 SF SPACE HEAT WOOD STOVE

R09 SF SPACE HEAT LPG BURNER

ROA SF SH RETROFTT GAS BURNER

ROB SF SH NEW \& IMPROVED GAS BURNER

ROD SF SH SOLAR WITH GAS BACKUP

ROE SF SH NEW GAS DEVICE

ROF SF SH RETROFIT OIL BURNER

ROG SF SH NEW \& IMPROVED OIL BURNER

ROH SI SH SOLAR WITH OIL BACKUP

ROL SF SH SOLAR WITH ELECTRIC BACKUP

ROM SF SH NEW \& IMPROVED HEAT PUMP

ROP SF SH CONSERVATION LEVEL I

ROQ SF SH CONSERVATION LEVEL II

ROR SF SH CONSERVATION LFVEL III

R11 SF WATER HEAT GAS

R12 SF WATER HEAT OIL

R13 SF WATER HEAT ELECTRIC

RIA SF SOLAR WATER HEAT WITH GAS BACKUP

RIC SF SOLAR WATER HEAT WTTH OIL BACKUP

RID SF WH FROM SOLAR SH - GAS BACKUP

RIE SF SOLAR WATER HEAT WITH ELECTRIC BACKUP

RIH SF WH FROM SOLAR SH - OIL BACKUP

R1L SF WH FROM SOLAR SH - ELECTRIC BACKUP

R21 SF AIR CONDITIONING CENTRAL

R22 SF AIR CONDITIONING HEAT PUMP

R23 SF AIR CONDITIONING ROOM

R2A SF AC CENTRAL - NEW \& IMPROVED

R2B SF AC HEAT PUMP - NEW \& IMPROVED

R2C SF AC ROOM - NEW \& IMPROVED

R2P SF AC CONSERVATION LEVEL I

R2Q SF AC CONSERVATION LEVEL II 


\begin{tabular}{|ll|}
\hline Table & V-3. COntinUE. \\
\hline R2R & SF AC CONSERVATION LEVEL III \\
R31 & SF COOKINNG ELECTRIC \\
R33 & SF COOKING PROPANE \\
R41 & SF MISC APPLIANCE ELECTRIC \\
R42 & SF MISC APPLIANCE GAS \\
R4A & SF MISC APPLIANCE ELECTRIC - IMPROVED \\
R50 & MF SPACE HEAT GAS CENTRAL \\
R51 & MF SPACE HEAT GAS NONCENTRAL \\
R52 & MF SPACE HEAT OIL CENTRAL \\
R53 & MF SPACE HEAT OIL NONCENTRAL \\
R54 & MF SPACE HEAT ELECTRIC CENTRAL \\
R55 & MF SPACE HEAT ELECTRIC NONCENTRAL \\
R56 & MF SPACE HEAT HEAT PUMP \\
R57 & MF SPACE HEAT LPG BURNER \\
R58 & MF SPACE HEAT KEROSENE BURNER \\
R5A & MF SH RETROFIT GAS BURNER \\
R5B & MF SH NEW \& IMPROVED GAS BURNER \\
R5D & MF SH SOLAR WITH GAS BACKUP \\
R5E & MF SH NEW GAS DEVICE \\
R5F & MF SH RETROFIT OIL BURNER \\
R5G & MF SH NEW \& IMPROVED OIL BURINER \\
R5H & MF SH SOLAR WITH OIL BACKUP \\
R5L & MF SH SOLAR WITH ELECTRIC BACKUP \\
R5M & MF SH NEW \& IMPROVED HEAT PUMP \\
R5P & MF SH CONSERVATION LEVEL I \\
R5Q & MF SH CONSERVATION LEVEL II \\
R5R & MF SH CONSERVATION LEVEL III \\
R5S & MF SPACE HEAT DISTRICT HEAT EXCHANGER \\
R5T & MF SPACE HEAT COGENERATION \\
R61 & MF WATER HEAT GAS \\
R62 & MF WATER HEAT OIL \\
R63 & MF WATER HEAT ELECTRIC \\
R6A & MF SOLAR WATER HEAT WITH GAS BACKUP \\
R6C & MF SOLAR WATER HEAT WITH OIL BACKUP \\
R6D & MF WH FROM SOLAR SH - GAS BACKUP \\
R6E & MF SOLAR WATER HEAT WITH ELECTRIC BACKUP \\
R6H & MF WH FROM SOLAR SH - OIL BACKUP \\
R6L & MF WH FROM SOLAR SH - ELECTRIC BACKUP \\
R6S & MF WATER HEAT DISTRICT HEAT EXCHANGER \\
R71 & MF AIR CONDITIONING CENTRAL \\
\hline R72 & MF AIR CONDITIONING HEAT PUMP \\
\hline
\end{tabular}


Table V-3. Continued.

R73 MF AIR CONDITIONING ROOM

R7A MF AC CENTRAL - NEW \& IMPROVED

R7B MF AC HEAT PUMP - NEW \& IMPROVED

R7C MF AC ROOM - NEW \& IMPROVED

R7P MF AC CONSERVATION LEVEL I

R7Q MF AC CONSERVATION LEVEL II

R7R MF AC CONSERVATION LEVEL III

R81 MF COOKING GAS

R82 MF COOKING ELECTRIC

R83 MF COOKING PROPANE

R91 MF MISC APPLIANCE ELECTRIC

R92 MF MISC APPLIANCE GAS

R9A MF MISC APPLIANCE ELECTRIC - IMPROVED

RA1 OFFICE BLDG SH ELECTRIC

RA2 OFFICE BLDG SH GAS

RA3 OFFICE BLDG SH DIESEL

RA4 OFFICE BLDG SH RESIDUAL OIL

RAB OFFICE BLDG SH GAS - IMPROVED EFF.

RAC OFFICE BLDG SH DIESEL - IMPROVED EFF.

RA OFFICE BLDG SH RES. OIL - IMPROVED EFF.

D

RAE OFFICE BLDG SH CONSERVATION LEVEL I

RAF OFFICE BLDG SH CONSERVATION LEVEL II

RAG OFFICE BLDG SH SOLAR

RA OFFICE BLDG SH DISTRIC'T HEAT EXCHANGER

H

RAI OFFICE BLDG SH COGENERATION

RB1 OFFICE BLDG WH ELECTRIC

RB2 OFFICE BLDG WH GAS

RB3 OFFICE BLDG WH OIL

RBA OFFICE BLDG WH CONSERVATION LEVEL I

RBB OFFICE BLDG WH SOLAR

RBG OFFICE BLDG WH SOLAR COMBINED WITH SH

RC1 OFFICE BLDG AC \& VENT ELECTRIC

RC2 OFFICE BLDG AC \& VENT GAS

RCA OFFICE BLDG AC HIGH EFF. GAS ABSORPTION

RCB OFFICE BLDG AC DISTRICT HEAT ABSORPTION

RCE OFFICE BLDG AC CONSERVATION LEVEL I

RCF OFFICE BLDG AC CONSERVATION LEVEL II

RD1 OFFICE BLDG LIGHT \& APPLIANCES ELECTRIC

RD2 OFFICE BLDG LIGHT \& APPLIANCES GAS 
Table V-3. Continued.

RD OFFICE BLDG L \& A CONSERVATION

A

RDB OFFICE BLDG IMPROVED LIGHTING SYSTEM

RE1. SERVICE BLDG SH ELECTRIC

RE2 SERVICE BLDG SH GAS

RE3 SERVICE BLDG SH DIESEL

RE4 SERVICE BLDG SH RESIDUAL OIL

REB SERVICE BLDG SH GAS - IMPROVED EFF.

REC SERVICE BLDG SH DIESEL - IMPROVED EFF.

RED SERVICE BLDG SH RES. OIL - IMPROVED EFF.

REE SERVICE BLDG SH CONSERVATION LEVEL I

REF SERVICE BLDG SH CONSERVATION LEVEL $\|$

REG SERVICE BLDG SH SOLAR

REH SERVICE BLDG SH DISTRICT HEAT EXCHANGER

REI SERVICE BLDG SH COGENERATION

RF1 SERVICE BLDG WH ELECTRIC

RF2 SERVICE BLDG WH GAS

RF3 SERVICE BLDG WH OIL

RFA SERVICE BLDG WH CONSERVATION LEVEL I

RFB SERVICE BLDG WH SOLAR

RFG SERVICE BLDG WH SOLAR COMBINED WITH SH

RG1 SERVICE BLDG A/C \& VENT ELECTRIC

RG2 SERVICE BLDG A/C \& VENT GAS

RGA SERVICE BLDG AC HIGH EFF. GAS ABSORPTION

RGB SERVICE BLDG AC DISTRICT HEAT ABSORPTION

RGE SERVICE BLDG AC CONSERVATION LEVEL I

RGF SERVICE BLDG AC CONSERVATION LEVEL II

RHI SERVICE BLDG LIGHT \& APPLIANCES ELECTRIC

RH2 SERVICE BLDG LIGHT \& APPLIANCES GAS

RH SERVICE BLDG L \& A CONSERVATION

A

RHB SERVICE BLDG IMPROVED LIGHTING SYSTEM

RI1 MISC BLDG SH ELECTRIC

RI2 MISC BLDG SH GAS

RI3 MISC BLDG SH DIESEL

RI4 MISC BLDG SH RESIDUAL OIL

RIB MISC BLDG SH GAS - IMPROVED EFF.

RIC MISC BLDG SH DIESEL - IMPROVED EFF.

RID MISC BLDG SH RES. OIL - IMPROVED EFF.

RIE MISC BLDG SH CONSERVATION LEVEL I

RIF NISC BLDG SH CONSERVATION LEVEL II 
Table V-3. Continued.

\begin{tabular}{ll} 
RIG & MISC BLDG SH SOLAR \\
RIH & MISC BLDG SH DISTRICT HEAT EXCHANGER \\
RII & MISC BLDG SH COGENERATION \\
RI1 & MISC BLDG WH ELECTRIC \\
RI2 & MISC BLDG WH GAS \\
RJ3 & MISC BLDG WH OIL \\
RJA & MISC BLDG WH CONSERVATION LEVEL I \\
RIB & MISC BLDG WH SOLAR \\
RJG & MISC BLDG WH SOLAR COMBINED WITH SH \\
RK1 & MISC BLDG A/C \& VENT ELECTRIC \\
RK2 & MISC BLDG A/C \& VENT GAS \\
RKA & MISC BLDG AC HIGH EFF. GAS ABSORPTION \\
RKB & MISC BLDG AC DISTRICT HEAT ABSORPTION \\
RKE & MISC BLDG AC CONSERVATION LEVEL I \\
RKF & MISC BLDG AC CONSERVATION LEVEL II \\
RL1 & MISC BLDG LIGHT \& APPLIANCES ELECTRIC \\
RL2 & MISC BLDG LIGHT \& APPLIANCES GAS \\
RLA & MISC BLDG L \& A CONSERVATION \\
RLB & MISC BLDG IMPROVED LIGHTING SYSTEM \\
RX1 & COMMERCIAL BLDGS MISC USE COAL \& OTHER \\
T11 & AUTOMOBILE - GASOLINE, EXISTING FLEET \\
T12 & AUTOMOBILE - DIESEL, EXISTING FLEET \\
T13 & AUTOMOBILE - ELECTRIC \\
T14 & AUTOMOBILE - METHANOL \\
T15 & AUTOMOBILE - HYDROGEN \\
T16 & AUTOMOBILE - COMPRESSED NATURAL GAS \\
T17 & AUTOMOBILE - 10\% MPG IMPROVEMENT \\
T18 & AUTOMOBILE - 20\% MPG IMPROVEMENT \\
T19 & AUTOMOBILE - 40\% MPG IMPROVEMENT \\
T1A & AUTOMOBILE - DIESEL 10\% MPG IMPROVEMENT \\
T1B & AUTOMOBILE - DIESEL 20\% MPG IMPROVEMENT \\
T21 & LIGHT TRUCK - GASOLINE, EXISTING FLEET \\
T22 & LIGH TRUCK - DIESEL \\
T23 & LIGHT TRUCK - HYDROGEN \\
T24 & LIGHT TRUCK - METHANOL \\
T25 & LIGHT TRUCK - COMPRESSED NATURAL GAS \\
T26 & LIGHT TRUCK - GASOLINE, 10\% MPG IMPROVEMT \\
T27 & LIGHT TRUCK - GASOLINE, 20\% MPG IMPROVEMT \\
T31 & BUS - GASOLINE, EXISTING FLEET \\
T32 & BUS - DIESEL, EXISTING FLEET \\
\hline T33 & BUS - HYDROGEN \\
\hline &
\end{tabular}




\begin{tabular}{|ll|}
\hline Table V-3. Continued. \\
\hline T34 & BUS - METHAN DL \\
T35 & BUS - COMPRESSED NATURAL GAS \\
T36 & BUS - GASOLINE 10\% MPG IMPROVEMENT \\
T37 & BUS - GASOLINE 20\% MPG IMPROVEMENT \\
T38 & BUS - DIESEL 10\% MPG IMPROVEMENT \\
T39 & BUS - DIESEL 20\% MPG IMPROVEMENT \\
T41 & SUBWAY \& URBAN RAIL - ELECTRIC \\
T42 & URBAN RAIL - DIESEL \\
T51 & INTERCITY RAIL - PASSENGER, ELECTRIC \\
T52 & INTERCITY RAIL - PASSENGER, DIESEL \\
T61 & INTERCITY RAIL - FREIGHT, ELECTRIC \\
T62 & INTERCITY RAIL - FREIGHT, DIESEL \\
T71 & AIR - JET FUEL \\
T72 & AIR - GASOLINE \\
T73 & AIR - HYDROGEN \\
T81 & VESSEL - GASOLINE \\
T82 & VESSEL - DIESEL \\
T83 & VESSEL - RESIDUAL OIL \\
T91 & MISC TRANSPORT - GASOLINE \\
T92 & MISC TRANSPORT - DIESEL \\
T93 & MISC TRANSPORT - ELECTRIC \\
T94 & MISC TRANSPORT - LPG \\
TH1 & HEAVY TRUCK - DIESEL, EXISTING FLEET \\
TH2 & HEAVY TRUCK - HYDROGEN \\
TH3 & HEAVY TRUCK - METHANOL \\
TH4 & HEAVY TRUCK - COMPRESSED NATURAL GAS \\
TH5 & HEAVY TRUCK- DIESEL, 10\% MPG IMPROVEMENT \\
TH6 & HEAVY TRUCK - DIESEL, 20\% MPG IMPROVEMENT \\
\hline
\end{tabular}


Table V-4. Summary of EASI Sample.

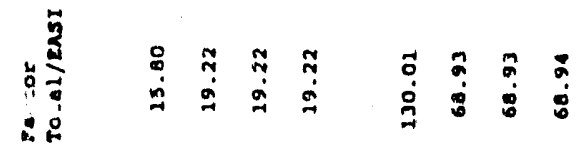
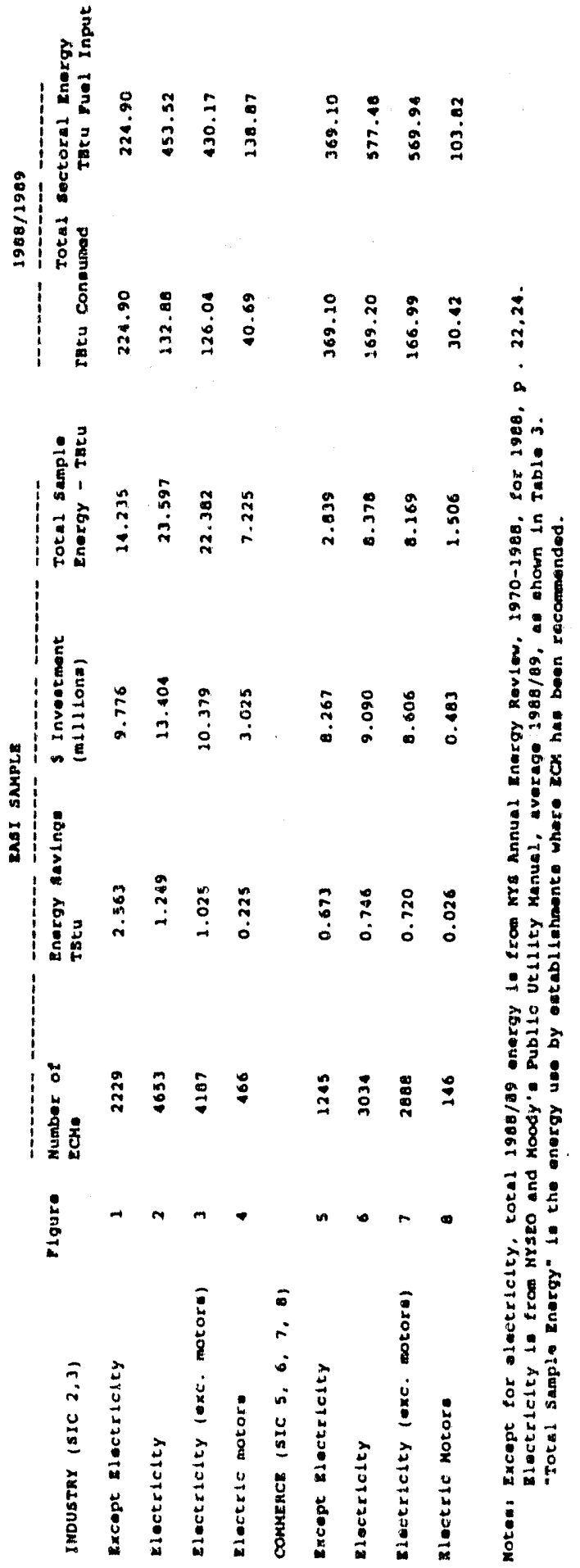

-95 . 
Table V-5. Industrial Energy Consumption, New York State, 1981 and 1988.

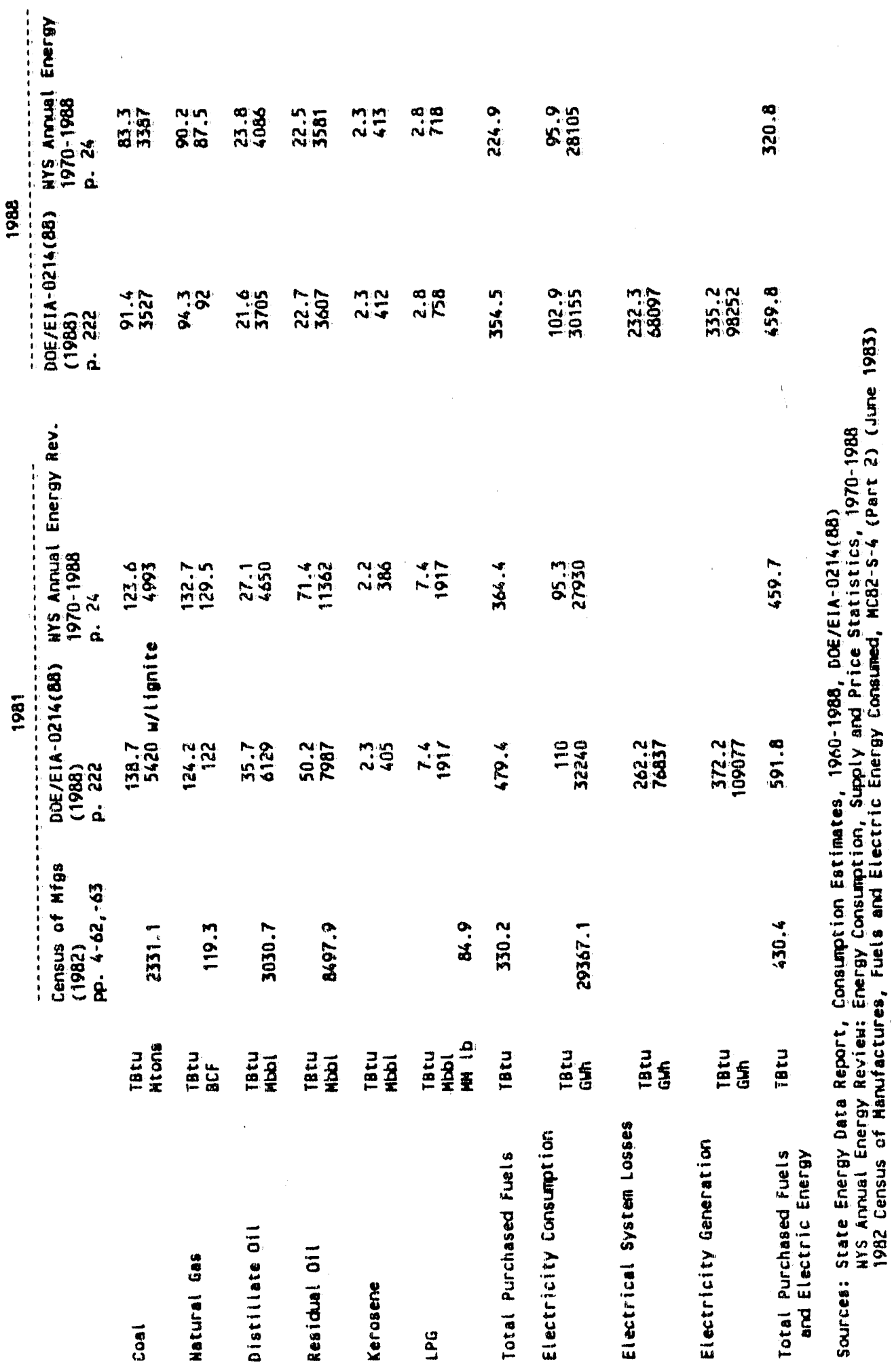


Table V-6. New York State Industrial and Commercial Electricity Use.
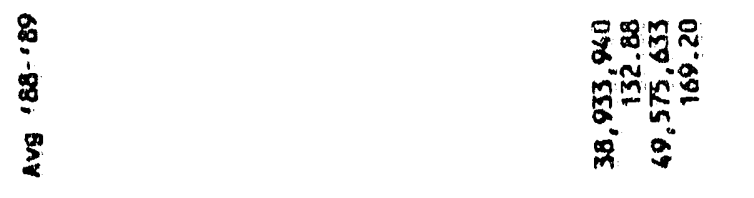

吾

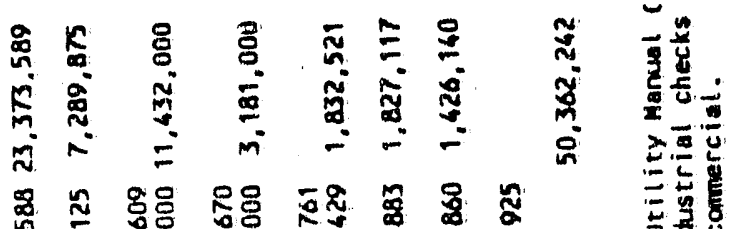

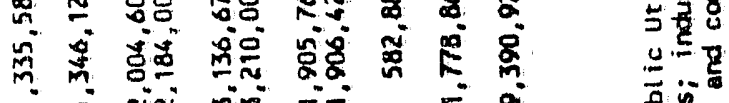

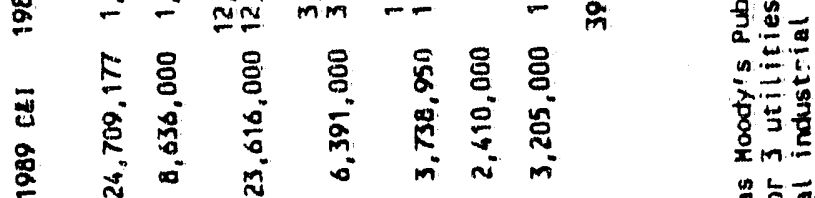

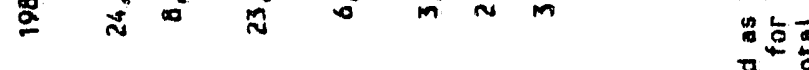

क

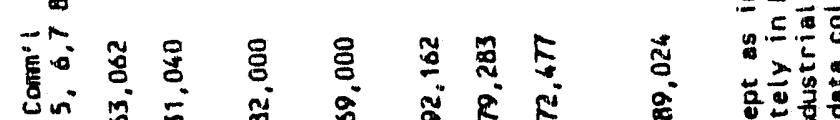

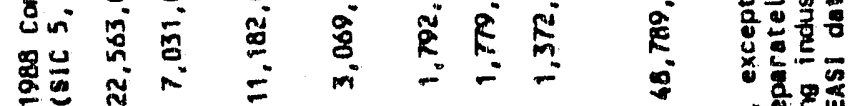

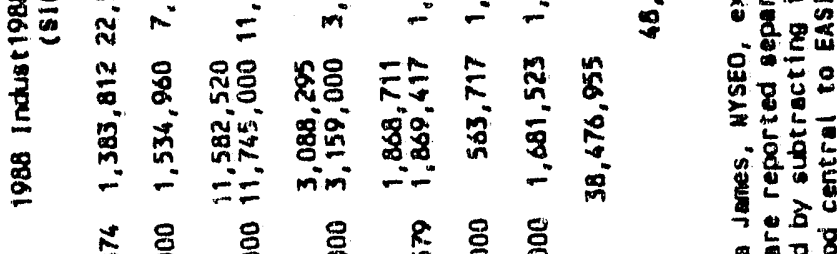

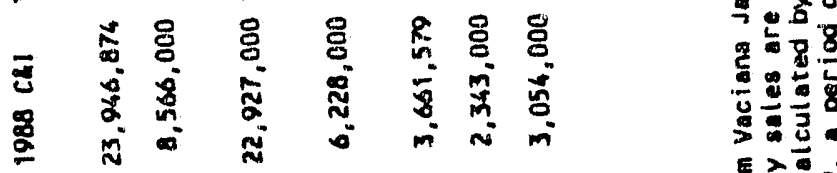

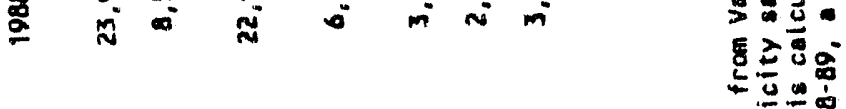

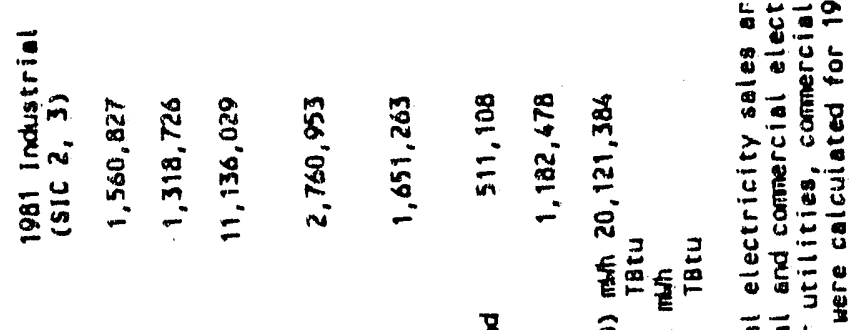

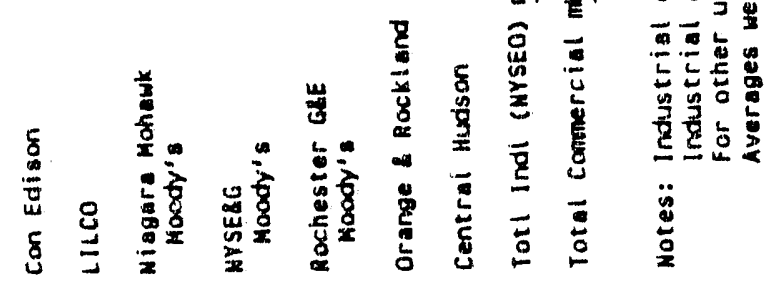


Figure V-1

Cumulatlve Energy Conservation Supply Curve SIC 2,3 Excepl Elactitelty (od t tod)

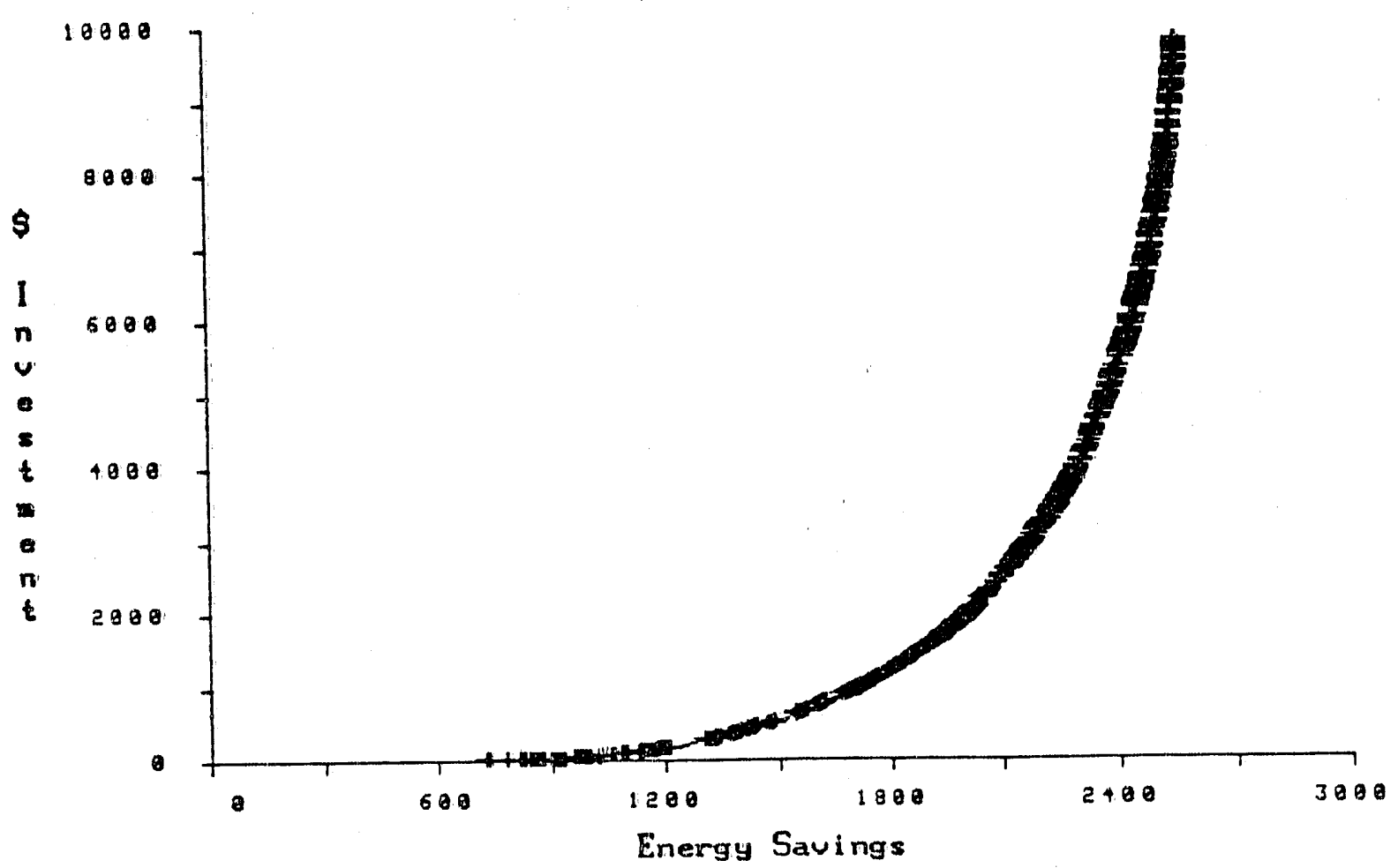

Figure V-2

Cumulative Energy Conservati un Supply Curvo indusiry (sIC 2.3 ) All E.etrle (no coo)

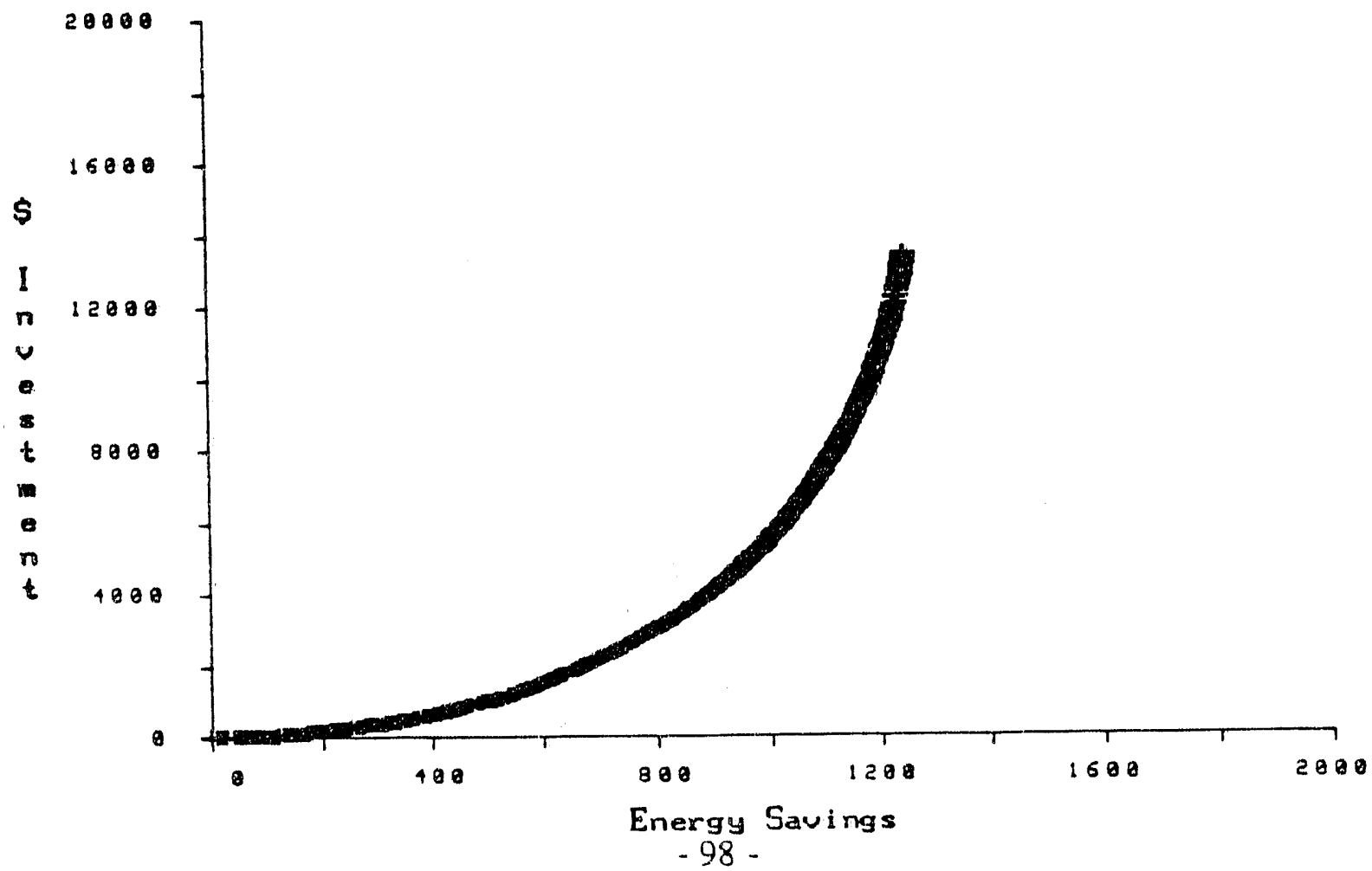


Figure $\mathrm{V}-3$

Cumulativo SIC 2 \& 3 , Eloctriclty Only

Ho motors or cogeneralion (adiod)

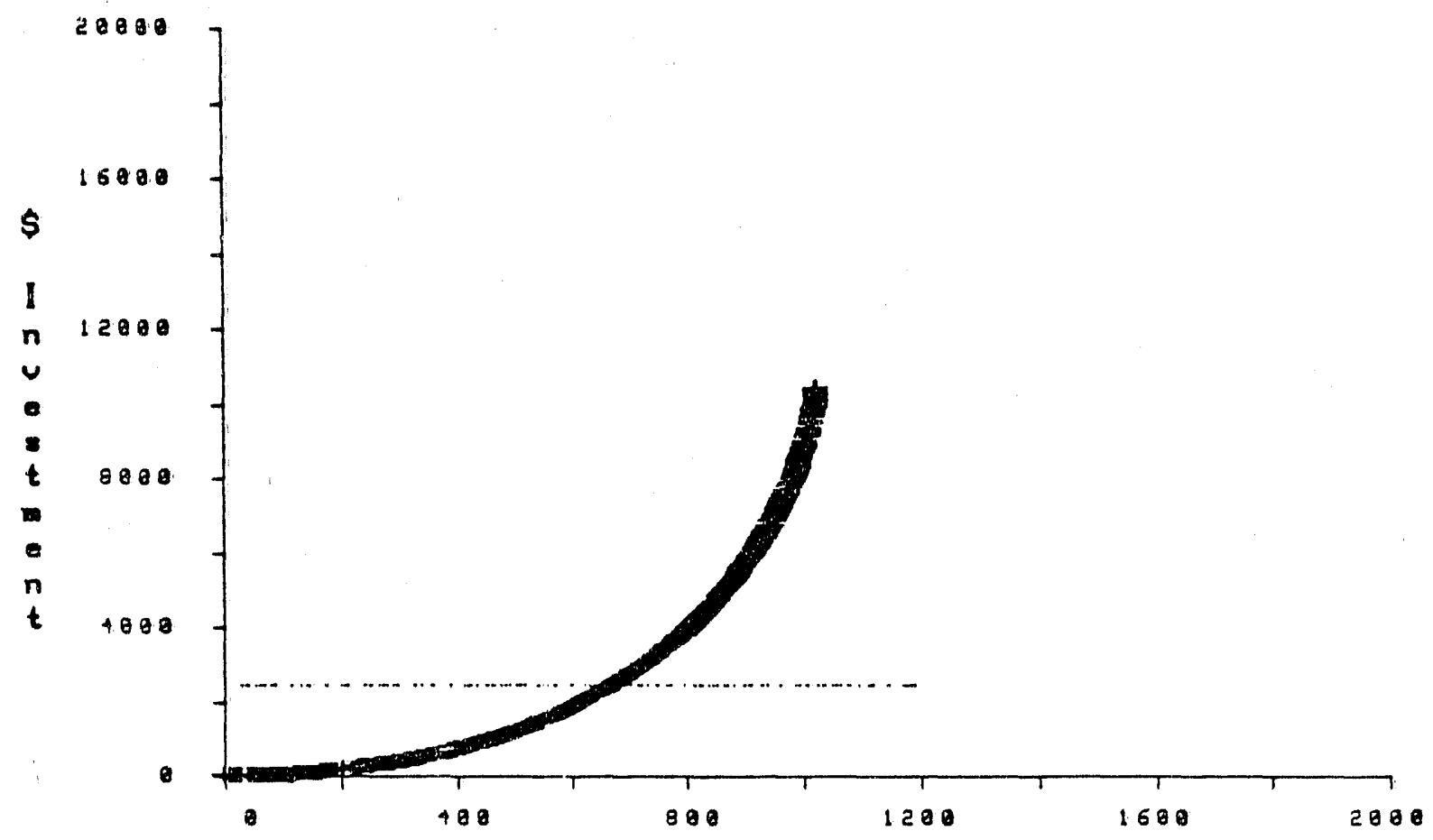

Energy Jawings

Figure $V-4$

Cumulative SIC 2 \& 3, Electriclty Dnly

Electrie Molors Dniy (odllod)

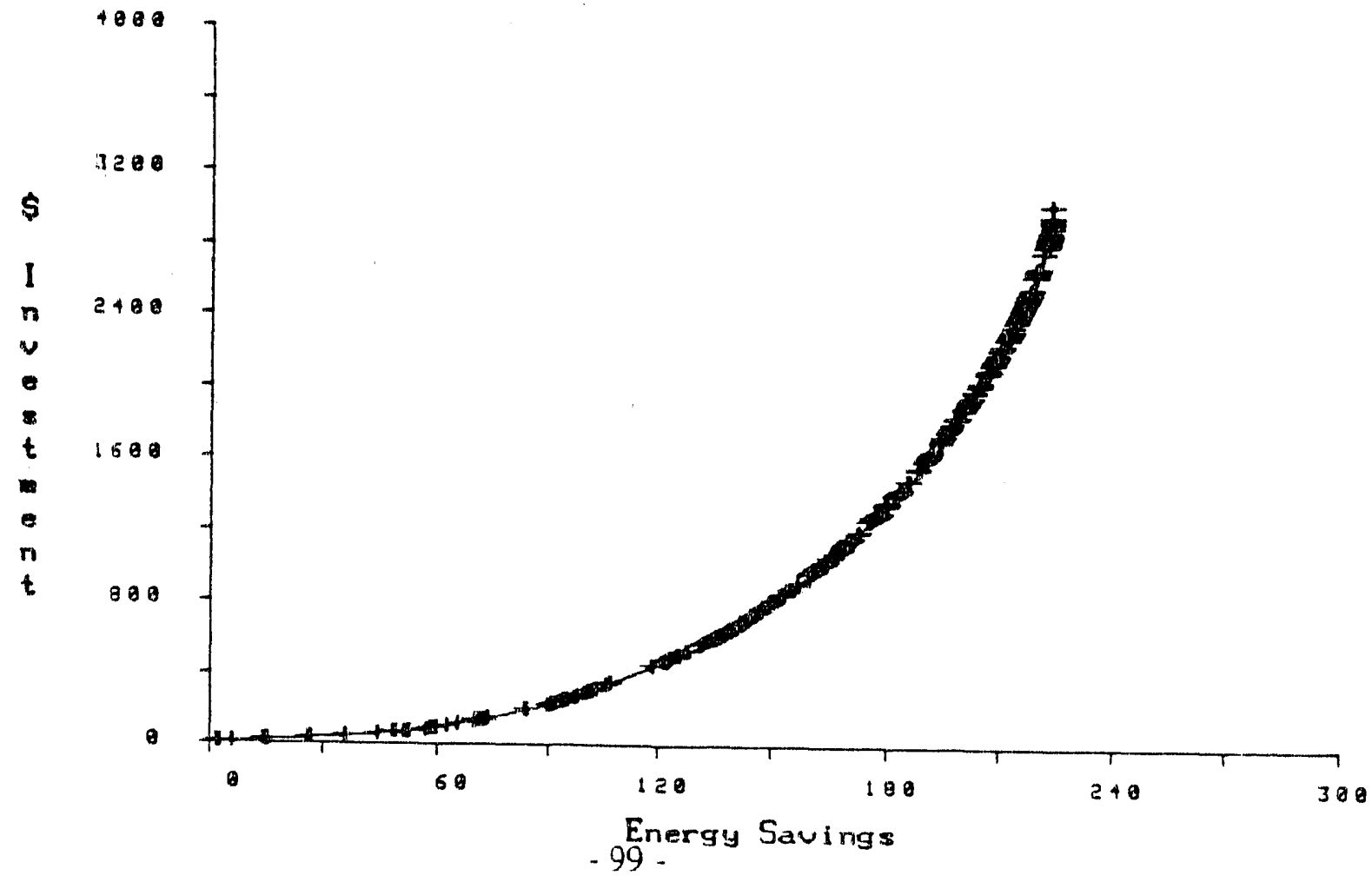


Figure V-5

Cumulatlve Wholesale \& Rotall Trado, FIRE, Serulce SIC 5,6, t, a cOMMERCSAL (except electric)

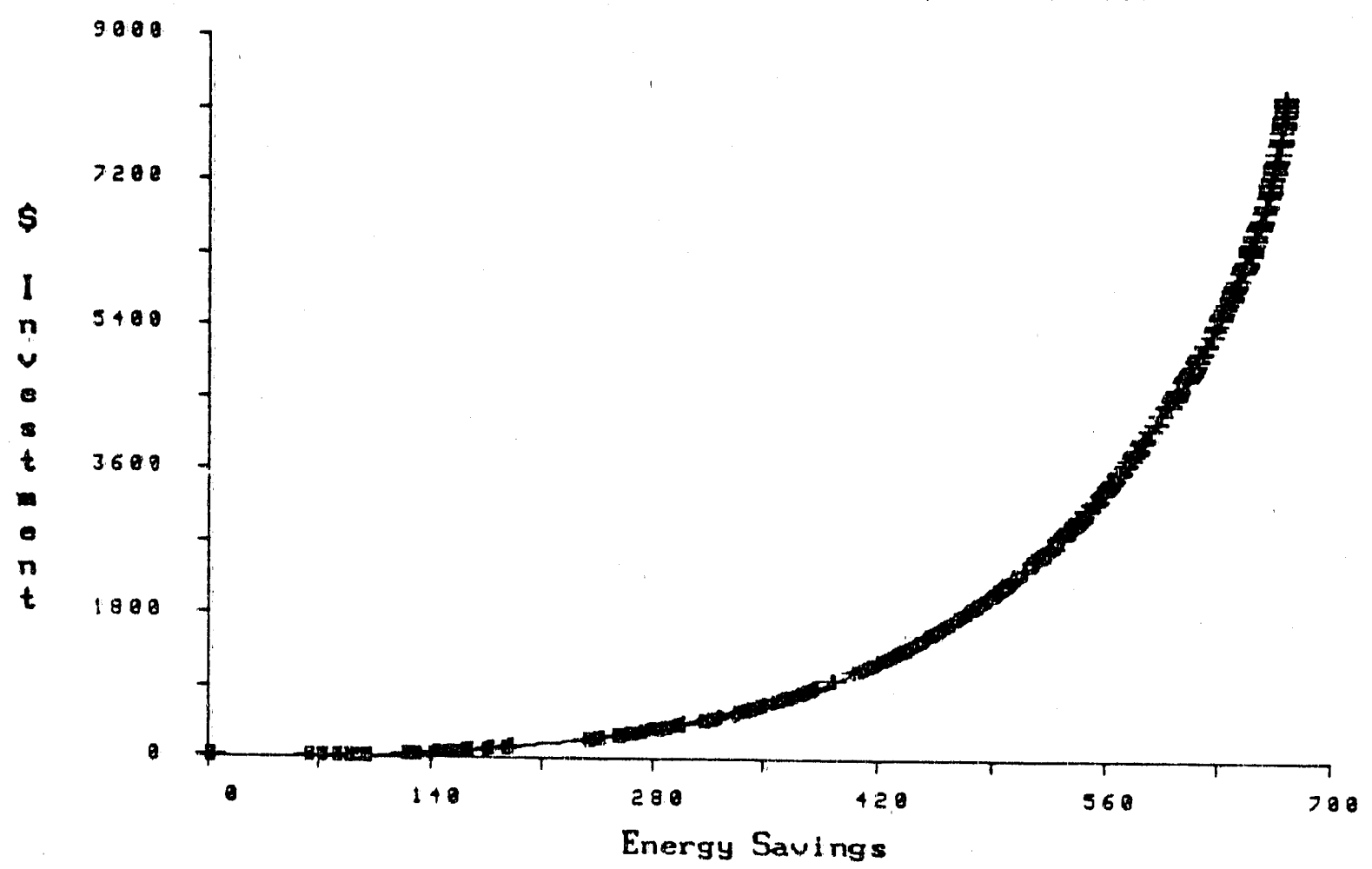

Figure V-6

Cumulative Wholesalo \& Retall Trado, FIRE, Servico SIC 5,6,7,8 COMMERCIAL (electrielty only

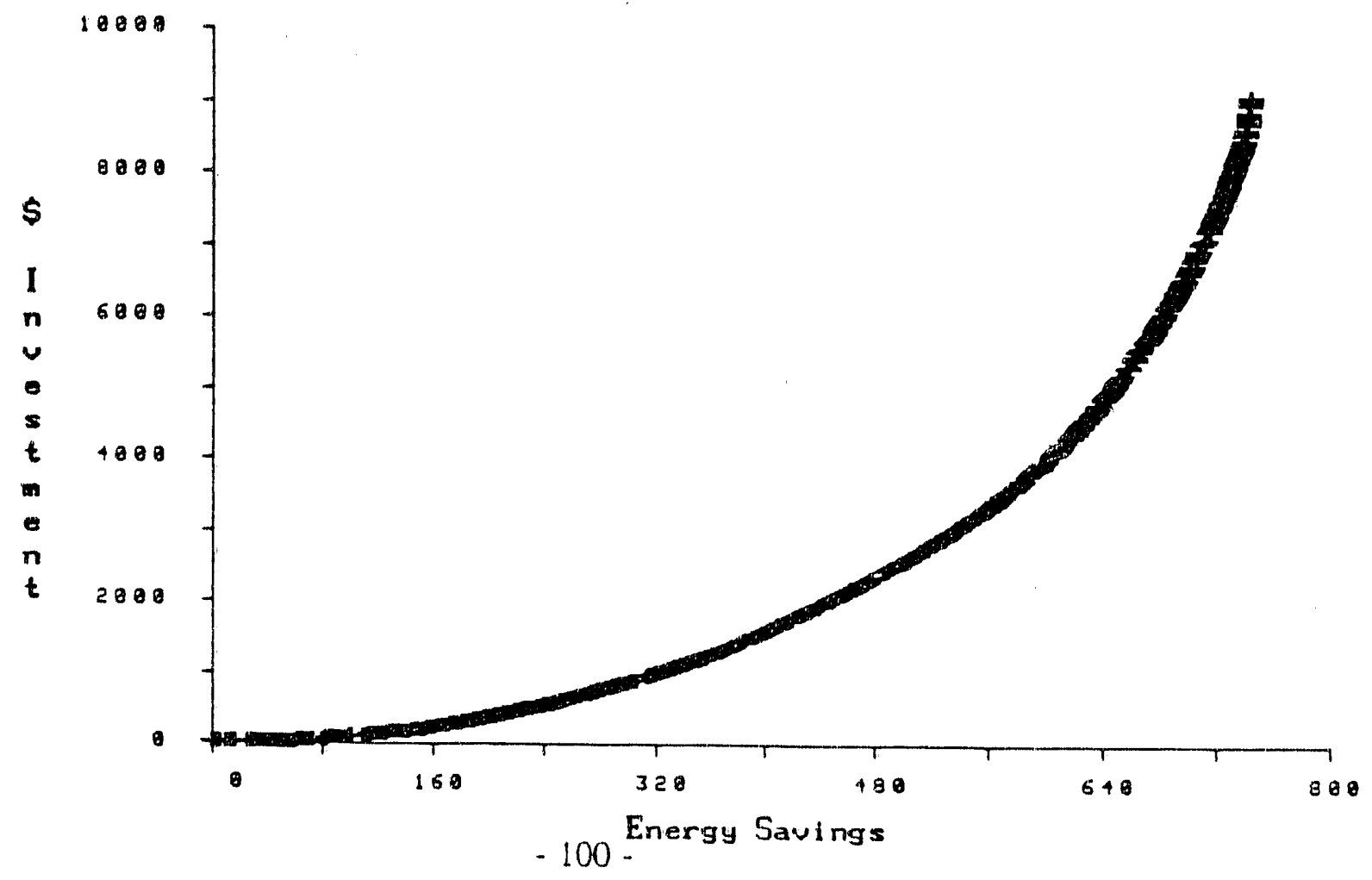


Figure V-7

Cumulativo Eloctricity Conservation Supply Curvo

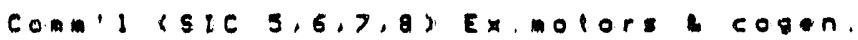

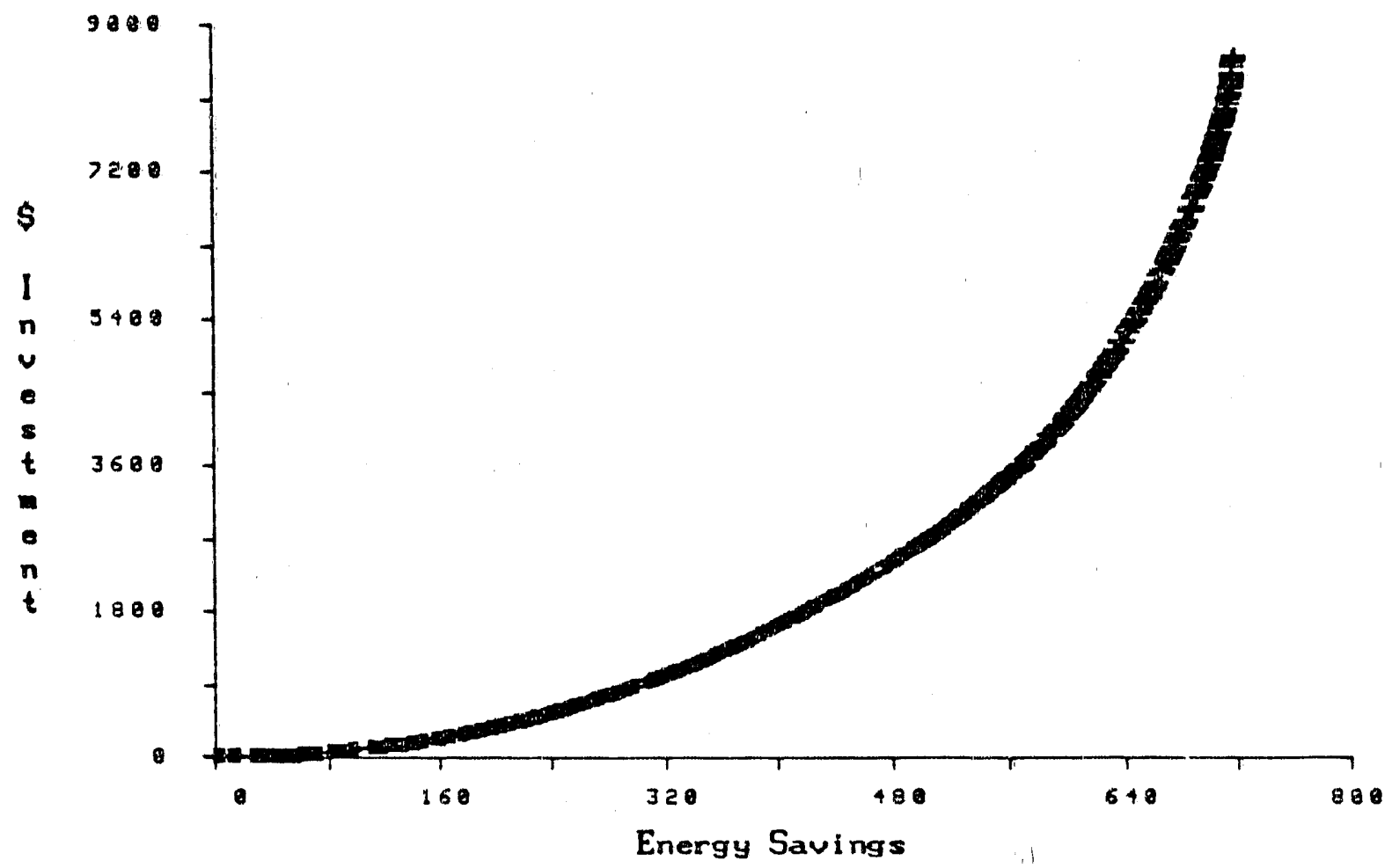

Figure $V-8$

Cumulativo Electriclty Conservation Supply Curvo condi (SIC 3,6,7,8) Elec. Molars onty

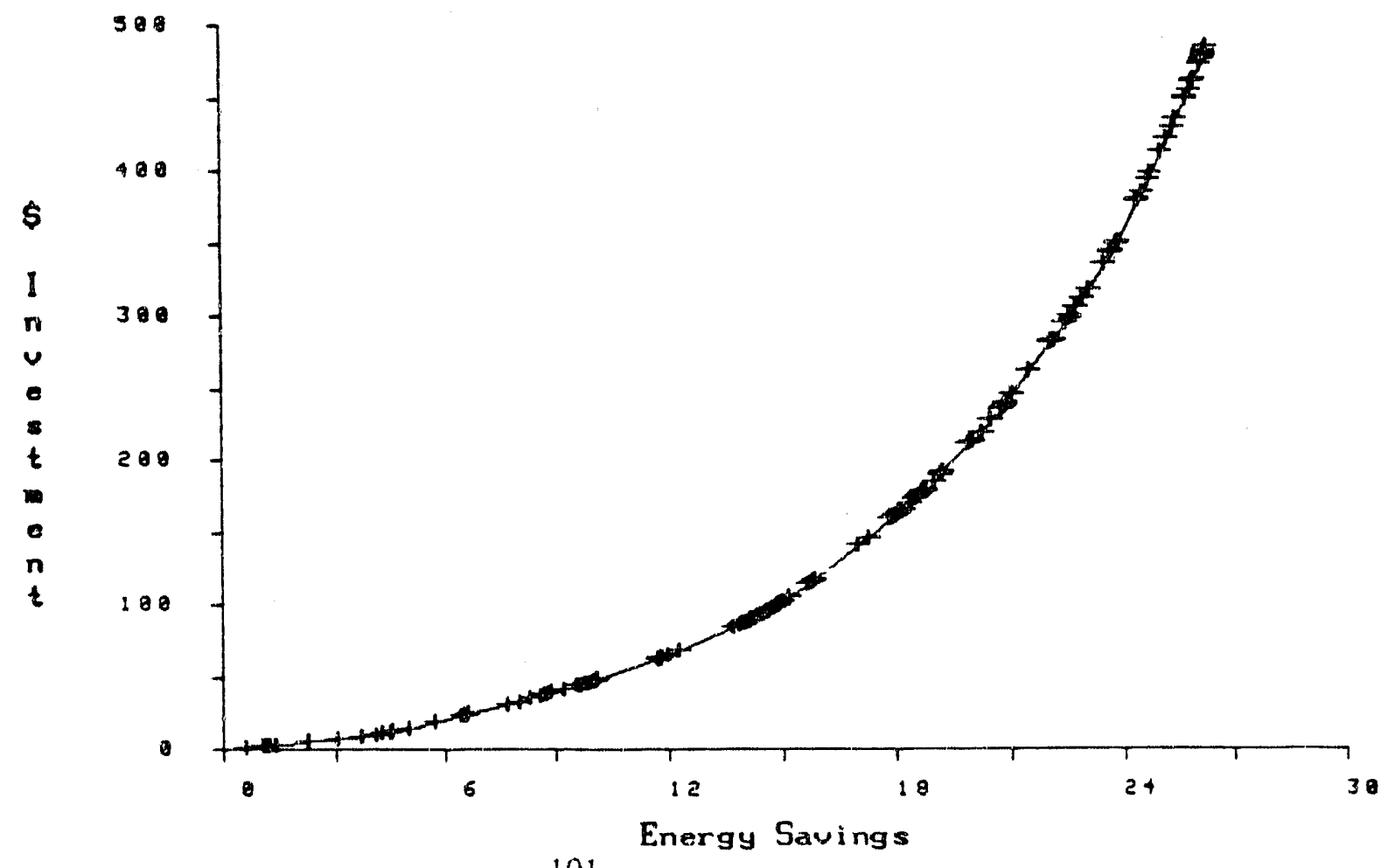



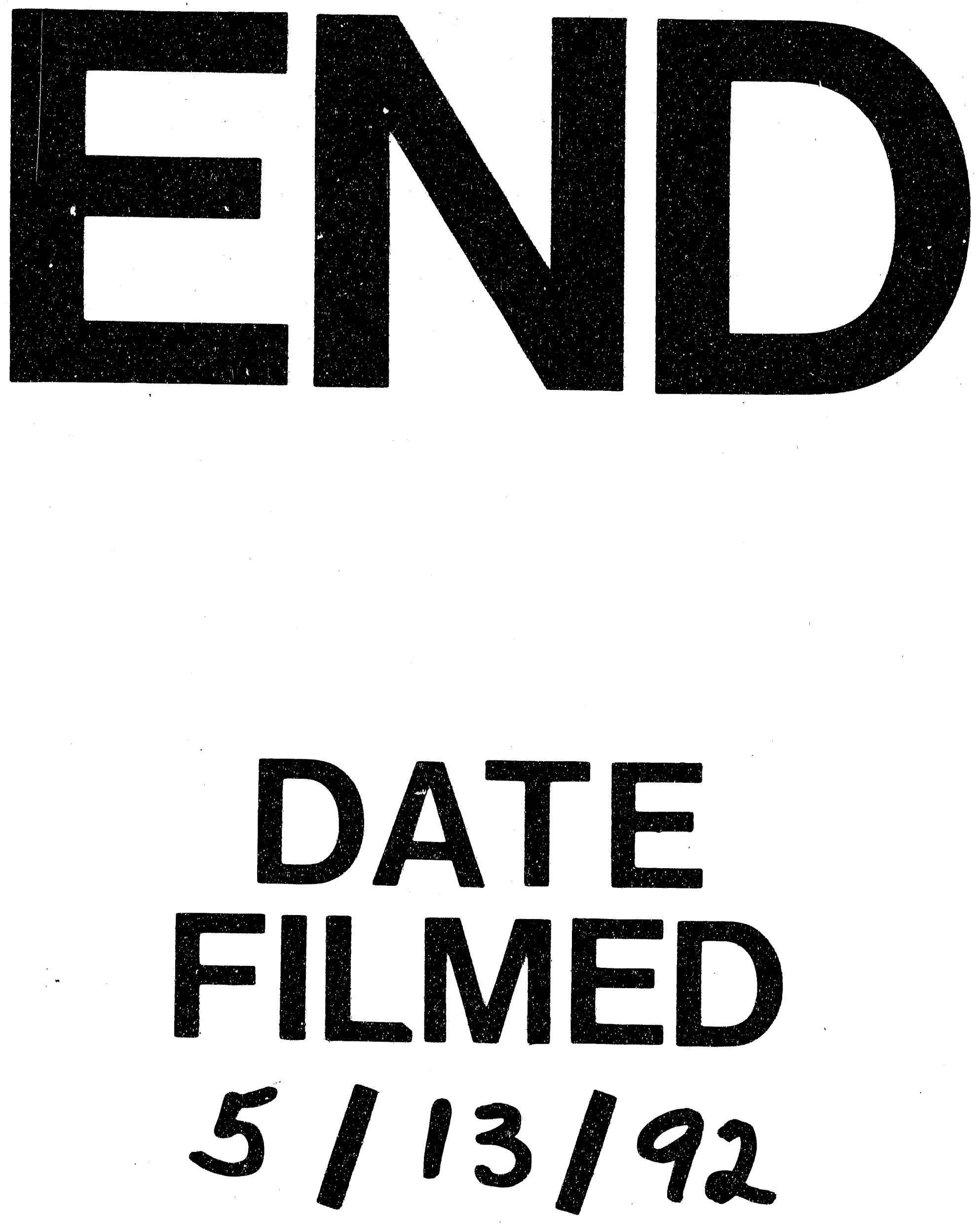
